\title{
Global governance in the management of natural resources : the case of the Extractive Industries Transparency Initiative (EITI)
}

Citation for published version (APA):

Slobozhan, O. (2014). Global governance in the management of natural resources : the case of the Extractive Industries Transparency Initiative (EITI). [Doctoral Thesis, Maastricht University]. Boekenplan. https://doi.org/10.26481/dis.20141104os

Document status and date:

Published: 01/01/2014

DOI:

10.26481/dis.20141104os

Document Version:

Publisher's PDF, also known as Version of record

Please check the document version of this publication:

- A submitted manuscript is the version of the article upon submission and before peer-review. There can be important differences between the submitted version and the official published version of record.

People interested in the research are advised to contact the author for the final version of the publication, or visit the DOI to the publisher's website.

- The final author version and the galley proof are versions of the publication after peer review.

- The final published version features the final layout of the paper including the volume, issue and page numbers.

Link to publication

\footnotetext{
General rights rights.

- You may freely distribute the URL identifying the publication in the public portal. please follow below link for the End User Agreement:

www.umlib.nl/taverne-license

Take down policy

If you believe that this document breaches copyright please contact us at:

repository@maastrichtuniversity.nl

providing details and we will investigate your claim.
}

Copyright and moral rights for the publications made accessible in the public portal are retained by the authors and/or other copyright owners and it is a condition of accessing publications that users recognise and abide by the legal requirements associated with these

- Users may download and print one copy of any publication from the public portal for the purpose of private study or research.

- You may not further distribute the material or use it for any profit-making activity or commercial gain

If the publication is distributed under the terms of Article $25 \mathrm{fa}$ of the Dutch Copyright Act, indicated by the "Taverne" license above, 
Global Governance in the

Management of Natural Resources

The Case of the Extractive Industries

Transparency Initiative (EITI) 


\section{(C) 2014 Oxana Slobozhan}

All rights reserved. No part of this publication may be reproduced, stored in a retrieval system, or transmitted in any form, or by any means, electronic, mechanical, photocopying, recording or otherwise, without the prior permission in writing, from the author.

ISBN 9789086663484

Published by Boekenplan, Maastricht 


\title{
Global Governance in the
}

\section{Management of Natural Resources}

\section{The Case of the Extractive Industries}

\section{Transparency Initiative (EITI)}

\author{
Dissertation \\ to obtain the degree of Doctor at the Maastricht University, \\ on the authority of the Rector Magnificus, Prof. dr. L.L.G. Soete \\ in accordance with the decision of the Board of Deans, \\ to be defended in public on Tuesday 4 November 2014, at 16:00 hours \\ by
}

Oxana Slobozhan 


\section{Supervisors:}

Prof. dr. L.L.G. Soete

Prof. dr. T. Conzelmann

\section{Assessment Committee:}

Prof. dr. J. Ritzen (Chairman)

Prof. J.G. Frynas, Middlesex University, UK

Dr. L. Krebs

Dr. P. Pattberg, VU University Amsterdam

Dr. A. Spendzharova 


\section{Acknowledgments}

First and foremost, I would like to express my deepest gratitude to Prof. Thomas Conzelmann and Prof. Luc Soete who supervised me during the PhD process. I am particularly indebted to Thomas Conzelmann for the time he has put in guiding this dissertation project, and I owe a great deal of what I learned during my $\mathrm{PhD}$ studies to the many meetings and discussions we had about the different chapters of the thesis. I am grateful to Luc Soete for the joint team meetings we had and the discussions which helped me to strengthen the arguments in different parts of the dissertation. In particular, the idea to compare extensive disaggregation practices in all EITI countries was inspired by one of the joint meetings we had. I thank the members of the reading committee of this dissertation, Prof. Jo Ritzen, Prof. Jedrzej George Frynas, Dr. Lutz Krebs, Dr. Philipp Pattberg and Dr. Aneta Spendzharova, for their insightful comments which helped me to improve the final version of the dissertation.

Part of the fieldwork for this $\mathrm{PhD}$ project was conducted in Oslo, and I thank the Research Council of Norway which funded my visiting fellowship at PRIO for this purpose. I am grateful to Prof. Halvard Buhaug who hosted my research project and to the staff of PRIO who facilitated my visit and were very supportive. I also thank the staff of the EITI Secretariat who provided very useful insights about the EITI process for my exploratory fieldwork.

Chapter 5 of this thesis would not have been possible without the help of the EITI stakeholders in Azerbaijan and Kazakhstan who shared their insights about the EITI implementation in their home countries and showed me how difficult the reform process can be. I am particularly grateful for their honesty and some of the personal experiences they shared which deeply touched me.

At MGSoG/UNU-MERIT, I thank Dr. Mindel van de Laar, Dr. Franziska Gassmann, Susan Roggen, Eveline in de Braek and Wilma Coenegrachts who provided academic and administrative support for many of my concerns and 
questions during the $\mathrm{PhD}$ studies. I would like to extend my gratitude to colleagues at FASOS and the Faculty of Law whom I had the pleasure to work with and learn from during my teaching activities. I am also grateful to the students in my tutorials for being a joy to work with and not letting me stagnate intellectually focusing only on the EITI during the process of working on the dissertation. Friends and colleagues whom I met in Maastricht, thank you for your companionship and for sharing many special memories during the years of my $\mathrm{PhD}$ studies.

Finally and most importantly, I am grateful to my family for patiently enduring the $\mathrm{PhD}$ process together with me and providing never ceasing support in all my academic aspirations. This thesis would not have existed without you. 


\section{Table of Contents}

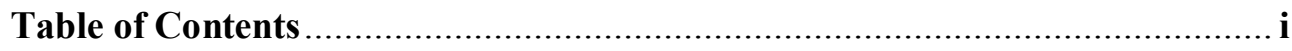

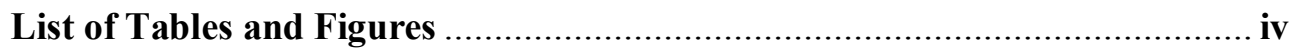

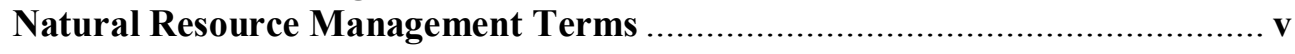

Introduction: Structure and the Main Findings of the Dissertation ................ 1

Chapter 1: The Potential of Transparency-focused Transnational Initiatives in Overcoming the Resource Curse .................................................................. 7

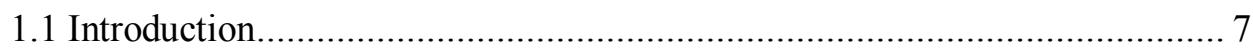

1.2 Negative Impacts of Resource Abundance ............................................... 9

1.3 Is the Resource Curse Unavoidable? .......................................................... 14

1.4 Which Causal Pathways of the Resource Curse Does Transparency

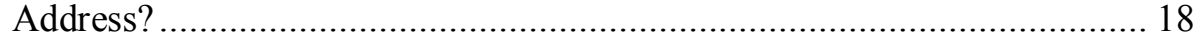

1.5 Tracing Potential Impact of Transparency-focused Transnational Initiatives in Natural Resource Management: KP, PWYP, NRC, and EITI ................. 26

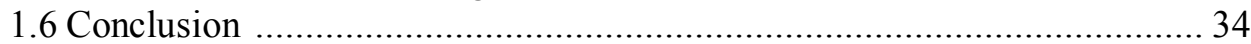

Chapter 2: Theoretical Framework ………................................................. 37

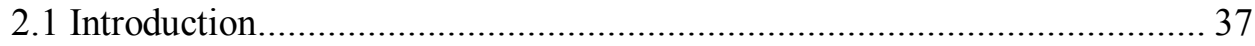

2.2 Review of the Literature on the EITI: Motivating This Project's Research

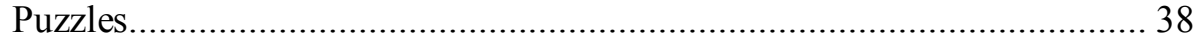

2.3 Conceptualizing the Dependent Variables.................................................. 46

2.4 Rational Actor Framework Applied to the Empirical Questions of the

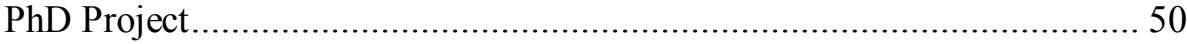

2.4.1 Why countries adopt new policies.................................................. 53

2.4.2 How do implementation activities differ between the EITIimplementing countries, and why?................................................. 54

2.4.3 How does the configuration of stakeholder positions at the MSGs impact the implementation activities? ............................................ 55

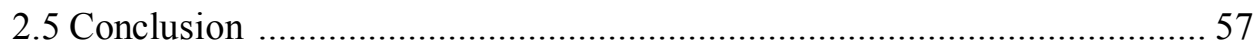

\section{Chapter 3: Why Adopt? Determinants of Country Decisions to Initiate}

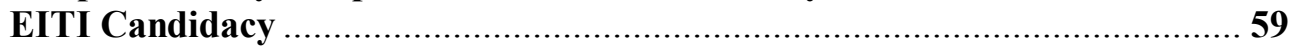

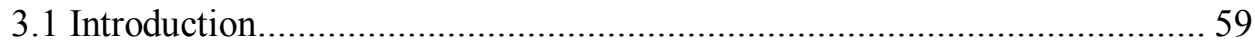

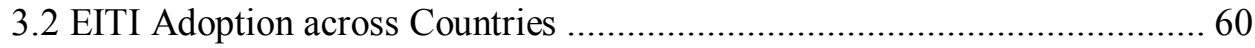

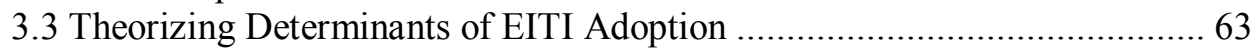

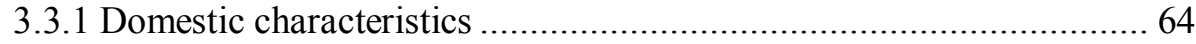




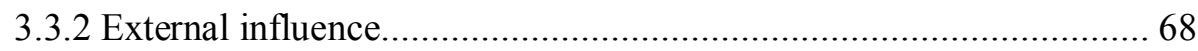

3.4 Research Model, Methodology, and Data ............................................ 69

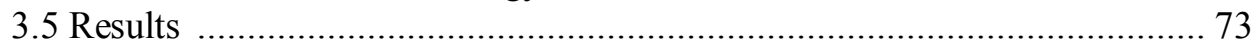

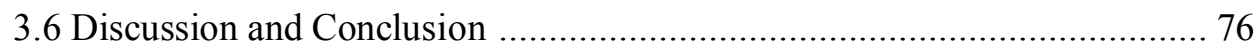

Chapter 4: Opening up the Black Box of EITI Compliance: Cross-country Differences in the Implementation Activities ............................................ 78

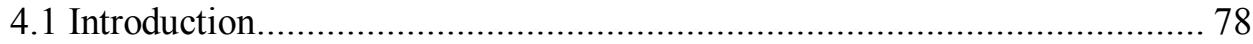

4.2 Conceptualizing Implementation, Compliance, and Effectiveness ............. 79

4.3 Cross-country Differences in the EITI Implementation ........................... 83

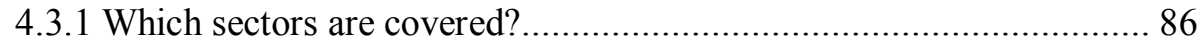

4.3.2 How is materiality of revenue streams defined? .............................. 87

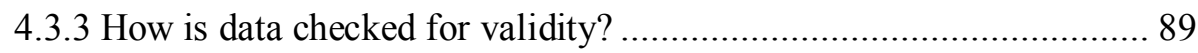

4.3.4 What is the extent of disaggregation?........................................... 90

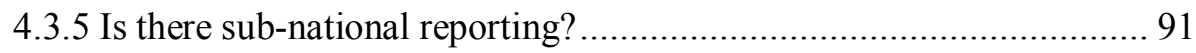

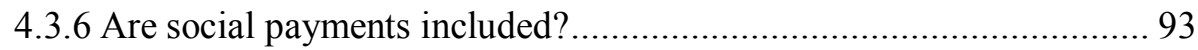

4.3.7 Are additional phases of the resource management cycle included?... 93

4.3.8 In the years prior to official EITI guidelines, was there a multistakeholder group established? ................................................... 94

4.4 Who Does More and Why? Disaggregation Practices among the

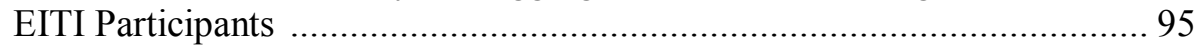

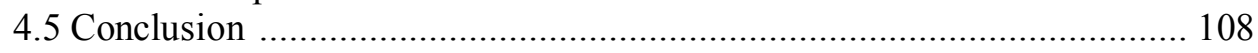

\section{Chapter 5: The Influence of Stakeholder Arrangements on the EITI} Implementation in Azerbaijan and Kazakhstan ....................................... 111

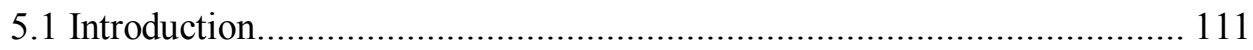

5.2 Similarities in Socio-economic Structures of Azerbaijan and Kazakhstan 115

5.3 MSG Stakeholder Positions: Expectations from the Literature ............... 121

5.4 EITI Implementation Activities in Azerbaijan and Kazakhstan ............... 127

5.4.1 Summary of Implementation History in Azerbaijan and Kazakhstan 127

5.4.2 Which sectors are covered?.................................................... 130

5.4.3 How is "materiality" of revenue streams defined?.......................... 130

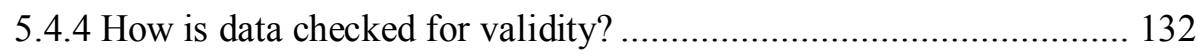

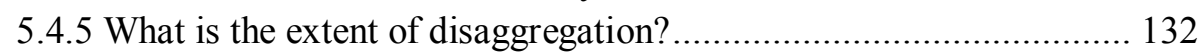

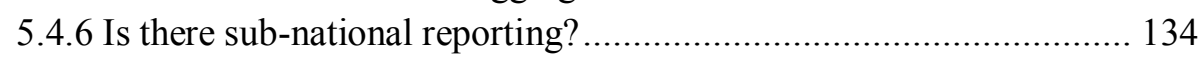

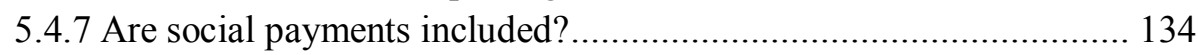

5.4.8 Are additional phases of resource management cycle included? ...... 134

5.4.9 In the years prior to official EITI guidelines, was there a MSG

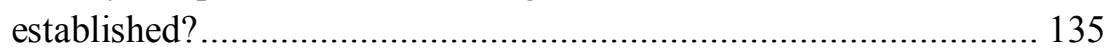


5.4.10 Comparative summary of implementation activities in Azerbaijan and Kazakhstan.

5.5 Analyzing the Influence of Stakeholders on the Implementation Activities

5.6 Conclusion

Chapter 6: Lessons from Implementation: Reforming the EITI?................ 153

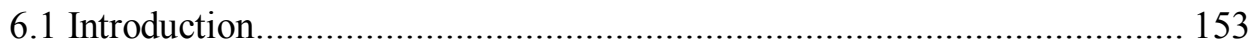

6.2 Challenges of Non-adoption and Absence of Extensive Implementation . 154

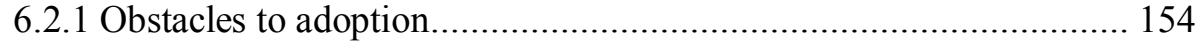

6.2.2 Obstacles to extensive implementation.......................................... 156

6.3 New Instruments Improving Transparency in Natural Resource Management

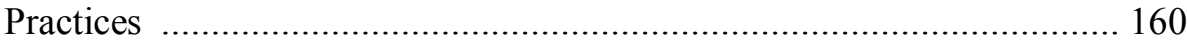

6.3.1 Mandatory EITI extensive requirements .................................... 162

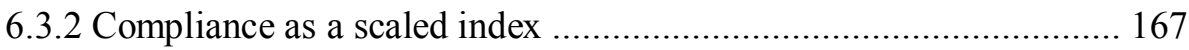

6.3.3 Mandatory company reporting: US and EU law developments........ 169

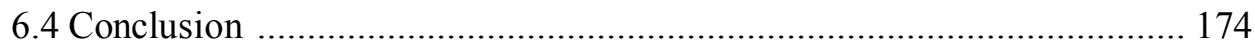

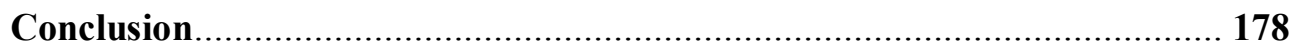

Annex I. The EITI Principles and Criteria ............................................. 184

Annex II. Resource-Rich Countries and EITI Implementation Status ....... 186

Annex III. EITI Dataset Codebook .......................................................... 189

Annex IV. List of the Conducted Interviews........................................... 210

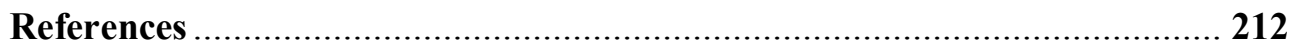

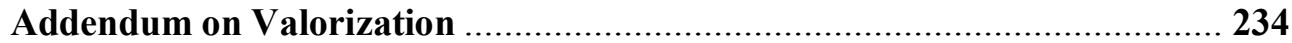

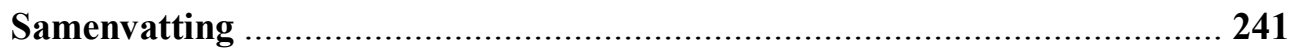

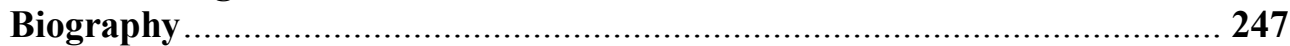

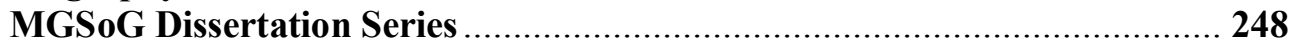




\section{List of Tables and Figures}

Table 1.1: Causal Pathways to the "Resource Curse"........................................ 13

Table 1.2: Causes of the Resource Curse and Transparency in the Resource

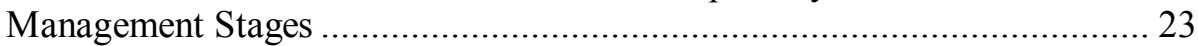

Table 1.3: Transparency-focused Regulatory Instruments: Conceptualizing the

Differences of Potential Impact ................................................................. 29

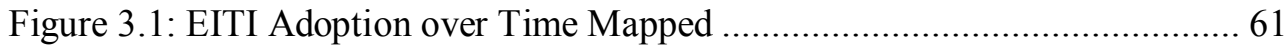

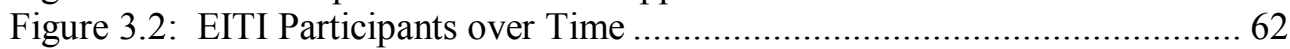

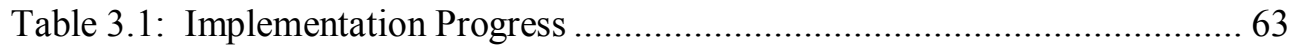

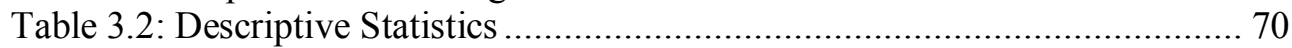

Table 3.3: Description of Variables ………........................................................ 71

Table 3.4: Determinants of EITI Adoption ........................................................ 74

Table 4.1: Conceptualizing EITI Implementation Activities …........................... 85

Table 4.2: Type of Reporting in the EITI Implementers over Time: Reports

Published from the Beginning of Implementation until June 2011 ............. 98

Table 4.3: Overview: Regime Type, Reporting Sector and Disaggregation

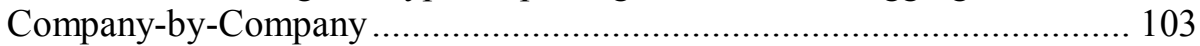

Table 4.4: Considering Only the Cases with Disaggregation by Companies....... 105

Table 4.5: Considering Only the Cases of EITI Countries with a Polity Score Equal

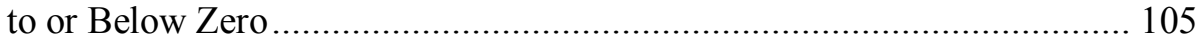

Table 4.6: Considering Only the Cases with Absence of Disaggregation by

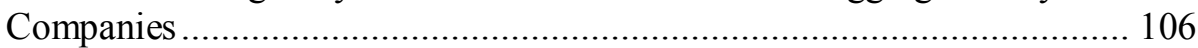

Table 4.7: Considering Only the Cases of EITI Countries Carrying out Reporting in

the Non-oil Mining Sector................................................................... 107

Table 5.1: Oil and Natural Gas Reserves in Azerbaijan and Kazakhstan ............ 116

Figure 5.1: Exports of Fuels and Mining Products by Azerbaijan and Kazakhstan

Figure 5.2: Exports of Fuels by Azerbaijan and Kazakhstan ............................... 117

Figure 5.3: Oil Production in Azerbaijan and Kazakhstan................................. 118

Figure 5.4: Polity Trends in Kazakhstan and Azerbaijan: 1991-2010 ................. 120 


\section{Natural Resource Management Terms ${ }^{1}$}

Benefit Stream - a potential source of economic benefit to the government from the extractive industry.

Concessionary System - under this system the extractive company is granted the right to explore for, develop, produce, transport, and market hydrocarbons or minerals within a fixed area for a specific amount of time. The production and sale of the products from the concession is then subject to rentals, royalties, bonuses, and taxes. The company holds title to the resources produced.

Contractual System - under this system the government retains ownership of the mineral reserves. Contractual systems are divided into service contracts (contractor receives compensation in cash) and production sharing agreements (compensation in kind).

Downstream - activities involving refining of crude oil, and selling and distribution of natural gas, mineral products, and products derived from crude oil.

EITI Suggested Benefit Streams for Reporting ${ }^{2}$

- Host government's production entitlement - host government's share of the total production (in kind and/or in cash), which can be transferred directly to the host government, or to the national state-owned company.

- National State-Owned Company production entitlement -national state-owned company's share of the total production (in kind and/or in

\footnotetext{
${ }^{1}$ Based on EITI Source Book (2005).

${ }^{2}$ EITI Source Book, 2005, pp. 27-28.
} 
cash), which is derived from the national state-owned company's equity interest.

- Profits taxes - taxes levied on the profits of a company's upstream activities.

- Royalties - royalty arrangements can include a company's obligation to dispose of all production and pay over a proportion of the sales proceeds. Sometimes the host government makes sales arrangements independently of the concession holder, in which case the royalty arrangements are similar to a host government's production entitlement.

- Dividends - dividends paid to the host government as shareholder of the national state-owned company.

- Bonuses (such as signature, discovery, production) - payments related to various bonuses, such as for discovery of additional reserves, or achievement of the set targets.

- License fees, rental fees, entry fees and other considerations for licenses and/or concessions - payments to the host government and/or national state-owned company for various licensed activities.

- Other significant benefits to host governments - include tax levied on the income, production, or profits of companies, but exclude tax levied on consumption (such as value-added taxes, personal income taxes, or sales taxes). 
Equity Share - the percentage of economic interest in/benefit derived from a concession, license, operation, or company.

Materiality criterion - a benefit stream is material if its omission or misstatement could influence the decisions of a user taken on the basis of the information included in the EITI report. Materiality provides a threshold on which information has to be relevant.

Upstream - all activities related to exploration, development, and production of mineral assets up to the point where the minerals extracted are in a marketable state without further processing activities involving. Phases of upstream activities include prospecting, acquisition of rights, exploration, appraisal or evaluation, development and construction, recovery and production, closure and decommissioning. 


\section{Introduction: Structure and the Main Findings of the Dissertation}

It is a well-known phenomenon that countries rich in natural resources are often unable to convert their resource potential into economic growth. Instead, resourceabundant countries are paradoxically prone to suffer from underdevelopment. The literature on negative impacts of natural resources has steadily grown since the 1950 s, and two main strands of explanations for the resource curse have emerged.

Traditionally, most scholars have focused on the economic mechanisms explaining the resource curse, but more recently, political mechanisms behind the phenomenon have been taken into consideration. Research has shown that whether natural resources turn out to be a curse or a blessing is to a large extent determined by the institutions and policies of the government. This insight seems to imply that the solution to the resource curse simply lies in the right set-up of natural resource management. The situation is much more complicated, however. Because the presence of natural resources is often linked to corruption, the very institutions that are needed for proper governance of natural resources get eroded (or not formalized at all). Politicians who stand to profit in corrupt environments are deterred from investing in strong institutions. As a result, countries where natural resources led to the "political resource curse" have found themselves in a resource trap situation: high budget revenues from extractives are misused through corruption channels, and, vice versa, institutions weakened by corruption are unable to effectively use revenues from the extractive sector.

Until recently, the domestic management of resources has received considerable attention in studies on natural resource governance. As this research has established, abundance in natural resources, with the right management, may well contribute to a country's economic growth and development. Yet many resource-rich countries continue to experience problems associated with the 
resource curse, which means that existing best practices of natural resource management are not converted into sound policy on the ground. Part of the explanation for this phenomenon has to do with the political channels of the resource curse, which erode the institutions involved, thus creating incentive structures where the political will to implement the necessary reforms is lacking.

As a response to this conundrum, and despite the traditional association of natural resource management with governmental discretion, the past decade has seen a rise in transnational voluntary regulation focusing on transparent governance of the extractive sectors. The practices that have come forward in the last ten to fifteen years are not binding obligations, and for this reason the potential of the new initiatives remains to be assessed. Against this background, the aim of this dissertation is to examine whether transnational regulation of natural resource governance through voluntary and non-binding instruments can contribute to solving the resource curse in countries that are locked in weak institutions and are unable to manage their resource revenues effectively. In particular, I focus on the Extractive Industries Transparency Initiative (EITI), a voluntary regulatory instrument which aims to both increase transparency in the management of natural resource revenues and mitigate the potential negative impacts of natural resources. More specifically, and owing to the voluntary nature of this instrument, I probe the conditions under which we see the adoption of the EITI by specific countries, and after its adoption, an ambitious or "extensive" implementation of this instrument. By exploring the EITI adoption and implementation processes, the project is able to disentangle the mechanisms of the EITI's functioning.

The dissertation is structured as follows. The resource curse is discussed in more detail in Chapter 1, where I devote particular attention to the identification of the mechanisms contributing to the resource curse and the assessment of how, and by what means, these mechanisms are targeted by different transparency-focused transnational initiatives. Analysis of the potential impact of the Kimberley Process (KP), the Publish What You Pay (PWYP) Campaign, the Natural Resource Charter 
(NRC), and the EITI reveals that transparency-focused initiatives mostly address the political mechanisms (less so the economic ones) leading to the resource curse. Among the instruments assessed, the EITI is the only initiative that both involves multiple actors (companies, civil society, and government) and that, in principle, allows the inclusion of all natural resource management stages in the reporting process. Because of these two properties of the EITI's programmatic design, the instrument is capable of targeting all relevant actors involved, as well as most of the mechanisms leading to the resource curse. This is why I choose to focus on the EITI as one of various potentially interesting transnational and global initiatives targeting transparency in natural resource governance.

Having established in Chapter 1 the need to study the EITI and the mechanisms by which it can address the governance of natural resources, Chapter 2 moves to building the theoretical framework for the specific questions of the project. So far, global governance literature has largely concentrated on the questions related to the emergence of transnational and global frameworks of governance. If questions relating to the functioning of these mechanisms have been less prominent in the past, they are increasingly addressed in current scholarship. Within the discipline of political science alone, it is possible to observe a divide already, resulting in a situation where similar questions are studied by different strands of research. Chapter 2 draws insights from these different bodies of literature and outlines the research questions for each of the empirical chapters that follow. Next, it proceeds to specifying the dependent variables of interest, while also explaining the particular theoretical and conceptual choices in the study of the specific questions addressed in this dissertation.

The central concern of Chapter 3 is under what conditions governments choose to adopt the EITI, given that EITI membership may not only yield benefits, but also generate policy constraints and costs of implementation. Given the sensitivity of natural resource governance associated with the political mechanisms of the resource curse, the question of adoption is highly relevant indeed. From the 
literature on the political impediments to effective management of resources, we know that disrupting the status quo by introducing self-imposed transparencyfocused regulation may be highly costly for the elites who have been benefiting from the non-openness of the system. By addressing the question of what determines the likelihood of adopting the EITI, the aim is to establish the structural conditions - country characteristics and external influence factors - that impact the decision to adopt the standard. The decision to adopt the EITI is operationalized as a binary variable (yes or no), while the chapter uses binary logistic regression as a statistical tool. The dataset for the analysis is compiled from a variety of sources. The results show that the likelihood of EITI adoption increases for resource-rich countries. I also find support for the hypotheses predicting an effect of low income and ethnic fractionalization on EITI adoption. The analysis shows no significant effect of regime level on EITI adoption, but countries that recently saw a change of polity with a trend toward democratization are more likely to adopt the EITI.

Depending on the model specification, there is some evidence of the relevance of external influences, such as the presence of international donors. For the EITI as a regulatory instrument, the findings mean that the critical country cases - those that can potentially benefit from the initiative, yet are not adopting it - are resource-rich high-income countries marked by a sustained history of stable regime, be it democratic or authoritarian.

After having established the country characteristics that increase likelihood of adoption, there are still questions related to the differences in EITI implementation patterns. Study of adoption does not allow for making inferences about further stages of the policy process, as the design of the EITI permits countries to decide on the particularities of their implementation process. Accordingly, it is possible to observe different types of implementation activities among the group of adopting countries. The central question discussed in Chapter 4 is therefore formulated as follows: how do implementation activities differ in practice, and what determines the extensiveness of implementation in a given 
country? To gain insight into this issue, this chapter's argument presents a typology of implementation activities along different procedural and content-related dimensions. Possible reasons for more extensive implementation choices are theorized, followed by a comparison of the differences in the implementation of, arguably, one of the critical dimensions - extensive disaggregation practice across EITI participants. I conclude that both the regime type and the sector in which EITI reporting is done are crucial for the extensiveness of the implementation activities. Carrying out the EITI in the non-oil mining sector turns out to be a sufficient condition for extensive disaggregation. For the countries implementing the EITI in the oil and gas sector, a positive polity score is a necessary (but not sufficient) condition for the inclusion of extensive disaggregation. For the EITI as a global standard, these findings imply that authoritarian countries implementing the EITI in the oil and gas sector are the most difficult cases as regards disaggregated reporting. At the same time, these cases are critical for the success of the initiative.

Against this background, Chapter 5 takes a closer look at the implementation of the EITI in the critical case countries by developing a comparative case study of two authoritarian countries with similar socio-economic characteristics that are implementing the EITI in the oil and natural gas sector (Azerbaijan and Kazakhstan). The comparability of contextual factors allows me to investigate in detail the implementation activities in these critical contexts. In particular, I am interested in the influence of the multi-stakeholder groups (MSGs) where the three stakeholder constituencies representing the government, companies, and civil society decide on the type of the EITI implementation activities. This search direction is motivated by theoretical expectations derived from the literature on the likely nature of stakeholder positions. By process tracing of the implementation activities, supported by interviews with the stakeholders, the findings reveal that the ideological distance between the stakeholders leads to policy stability and only incremental change in the implementation process. 
Finally, Chapter 6 provides a synthesis of the findings. I take up the two key themes of this research project: under what conditions do adoption and extensive implementation occur, and under what conditions do we see the emergence of difficulties in adoption and implementation. After summarizing the study's empirical findings on the contexts in which EITI adoption and, subsequently, extensive implementation are particularly difficult, I proceed to assess the extent to which different, currently discussed reform scenarios for the EITI might provide solutions to these challenges. These reform scenarios pertain to three themes: the increase in EITI mandatory requirements, interpretation of compliance as a scaled index rather than a binary pass/fail outcome, and mandatory extensive reporting for the extractive companies, as required by recent US and EU law making.

In the conclusion of this thesis, I reconsider two more abstract discussions. The first one of these highlights the implications of the findings on theorizing adoption and implementation of voluntary regulation instruments falling within the scope of global governance arrangements. The second one returns to the issue of the potential effectiveness of such instruments in increasing the transparency of natural resource management and combating the resource curse. 


\section{Chapter 1: The Potential of Transparency-focused Transnational Initiatives in Overcoming the Resource}

\section{Curse}

Summary: Central to the study of resource-rich countries is the paradox of the resource curse: many resource-abundant countries are unable to convert their wealth potential into development outcomes. In the past decades, there has been an increase in voluntary regulatory instruments that focus on transparency as a solution to problems associated with the resource curse. Some of such initiatives include the Extractive Industries Transparency Initiative (EITI), the Kimberley Process Certification Scheme (KPCS), the Publish What You Pay (PWYP) Campaign, and, more recently, the Natural Resource Charter (NRC). The literature evaluating the impact of these transnational efforts has been largely skeptical, often focusing on the shortcomings of voluntary regulation, rather than its potential in overcoming resource curse-related symptoms. This chapter assesses which of the mechanisms contributing to the resource curse are addressed by the voluntary transnational initiatives with a focus on transparency in one or more phases of natural resource management. It does so by theorizing the channels of transparency effect, thus making a conceptual contribution to the literature on natural resource governance, and, in particular, the potential impact of global transnational efforts targeting natural resource management. The findings reveal that when it comes to the resource curse, transparency-focused initiatives are mostly geared to political mechanisms (and less so to economic ones). Furthermore, each of the initiatives under investigation differs with respect to not only how many phases of the resource management cycle they are designed to target, but also the type of actors they focus on.

\subsection{Introduction}

It is well-known that countries rich in natural resources are often unable to convert their wealth potential into economic development. The literature on impacts of natural resource abundance comprises a multiplicity of studies, some of which look into the impacts of resource abundance on economic development, while others are interested in the impacts on political institutions. A separate line of research within conflict studies investigates the impacts of natural resources on conflict incidence, conflict duration, and the intensity of conflicts. Each one of these research 
programs identifies different channels via which resources can have a negative influence on various aspects of development, implying that different mechanisms of governance are required to prevent or target the interrelated problems. The past decades have seen an increase in different voluntary transnational initiatives focusing on transparency as a strategy to prevent or overcome the negative impacts of resource abundance. Prominent transnational initiatives with a focus on transparency in one or more phases of natural resource management are the Extractive Industries Transparency Initiative (EITI), the Kimberley Process Certification Scheme (KPCS), the Publish What You Pay (PWYP) Campaign, and, more recently, the Natural Resource Charter (NRC). The aim of this chapter is to assess the potential of these transnational efforts for overcoming the symptoms of the resource curse by focusing on the mechanisms via which each of the abovementioned initiatives is capable of targeting the problems associated with the resource curse.

To develop the argument of this chapter, section 1.2 introduces the literature on the resource curse, primarily with the purpose of identifying different channels via which natural resources can have negative impacts. Next, the literature on the institutional set-up required for effective governance of natural resources is discussed (in section 1.3). As the literature on domestic management of natural resources underscores, not all resource-rich countries are destined for the resource curse, and with the right policies in place, natural resources can actually be managed effectively. In section, 1.4, particular attention is devoted to the importance of transparency throughout the cycle of natural resource management and the potential of transparency policies in addressing each of the different (economic, as well as political) mechanisms contributing to the resource curse. In section 1.5, I address the paradox that governments of the resource-rich countries are not always able (or willing) to implement the policies needed for sound resource management, thus creating a policy void which voluntary regulatory instruments are trying to fill at the global level. I also analyze the differences 
between the four transnational initiatives mentioned above by considering the following four questions: 1) which actors are targeted by the instrument, 2) which actors are designed to lead the initiative nationally, 3) which phases of the resource management cycle are targeted, and 4) what mode of governance is used. After explaining the decision to focus on the EITI, among other potentially interesting governance initiatives in the sector, I conclude with a summary in section 1.6.

\subsection{Negative Impacts of Resource Abundance}

For understanding through which particular channels transparency-focused regulatory instruments may overcome some of the grim prospects connected to natural resources, it is vital to recognize all the mechanisms through which the presence of natural resources in a country can contribute to negative political and economic outcomes. One of the early observations in the literature is the connection between resource abundance and economic underdevelopment. Countries that have large amounts of natural resources are often poor economic performers and experience what has been labeled the resource curse (Auty, 1993) or the Paradox of Plenty (Karl, 1997). ${ }^{3}$ The term "resource curse" was first used by Richard Auty in 1993 to describe how resource-rich countries are often unable to convert their resource wealth into positive development outcomes and how, counter-intuitively, these countries show worse economic performance than those without an abundant natural resource base (Auty, 1993; Hausmann \& Rigobón, 2003; Sachs \& Warner, 1995, 2000, 2001).

One of the economic explanations behind this paradox is known as the Dutch Disease (Corden, 1984; Corden \& Neary, 1982), a situation where an increase in the country's natural resource revenues leads to the increase in the

\footnotetext{
${ }^{3}$ The terms 'resource curse' or 'Paradox of Plenty' should not be confused with the 'Dutch Disease'. The latter term refers only to one of the mechanisms contributing to the phenomenon of the resource curse, yet is often incorrectly used as synonymous to the resource curse.
} 
value of the national currency relative to other currencies, thereby making the manufacturing sector less competitive in the international market. The appreciation of the exchange rate results in rising prices of the country's exports in sectors other than the extractive sector, thus making manufacturing less competitive globally and limiting possibilities of export-led growth.

Another economic explanation for slower growth of countries specializing in the exports of primary products is the Singer-Prebisch hypothesis on the declining terms of trade (Prebisch, 1950), according to which the prices of exports in primary commodities ${ }^{4}$ decrease over time as compared with the prices of imports in manufacturing. As a result, the export revenue of countries specializing in natural resources allows one to buy increasingly fewer manufactured goods, thus inhibiting opportunities for development investments. The Singer-Prebisch thesis inspired the import-substitution policies of the 1960s and 1970s as a strategy to increase competitiveness of the manufacturing sector.

Other scholars focused on price volatility of natural resource products that may increase difficulties in the fiscal management of export earnings and, thus, limit the opportunities for growth. Still others have argued that growth opportunities are inhibited by the enclave structure of natural resource production, which can take place without involvement of other industrial sectors. Furthermore, concerns have been raised regarding international firms' investments in the extraction of resources primarily benefiting the companies and their countries of origin rather than the host countries (Humphreys, Sachs \& Stiglitz, 2007, pp.4-5; Singer, 1950). Finally, some have shown that the economic outcomes in the resource-rich countries may be conditional on human capital endowments (Gylfason, 2001; Kurtz \& Brooks, 2011).

In addition to possible adverse effects on economic growth, there is evidence that resource abundance leads to negative impacts on political

\footnotetext{
${ }^{4}$ These include not only mineral commodities, but also other primary products (e.g. in agriculture, forestry, or fishing).
} 
institutions, such as corruption and low state capacity (Gelb, 1988; McFerson, 2009; Ross, 1999; Sala-i-Martin \& Subramanian, 2003). What may appear as policy mistakes regarding revenue mismanagement can in fact be rational decisionmaking, resulting from the fact that large resource revenues provide more incentives to loot or inefficiently redistribute resource rents (Collier \& Hoeffler, 2005; Robinson, Torvik, \& Verdier, 2006). Research has found that politicians may loot resource revenues rather than invest them when they expect not to stay in power for a longer time period (Collier \& Hoeffler, 2005; Robinson et al., 2006), when the ruling elite is based on a small, easily identifiable group, i.e. ethnicity (Collier, 2000c; Collier \& Hoeffler, 2005; Hodler, 2006; Morrison, 2011), or when patronage politics becomes the main mechanism of ensuring electoral or military support (Collier \& Hoeffler, 2005; Robinson et al., 2006).

Besides direct incentives for looting that natural resources may provide for politicians in power, the link between resource abundance and weak institutions can be an indirect one. On theoretical grounds, it can be expected that countries strongly relying on income from resource revenues have a reduced need for taxation. On the one hand, citizens who are not taxed may demand less of the government. On the other hand, governments for which tax revenues are not the main source of budget have fewer incentives to engage with their citizens. Thus, the system of checks and balances gets eroded or does not become formalized at all. These theoretical arguments on the links between resource wealth and obstacles to democratization are supported by empirical evidence. Ross (2001), using timeseries cross-national data for 113 countries, finds that wealth from natural resources indeed impedes democratization, particularly in poor countries. Controlling for other possible effects, he shows that oil, as well as non-fuel mineral wealth (both measured by export value as fractions of GDP), increase antidemocratic effects. He finds support for three main mechanisms through which natural resources weaken democratic freedoms. The first mechanism operates via the rentier state effect, where the large resource revenues coming into the budget 
allow the state to use low tax rates and high spending, thus eroding the incentives for citizens to participate in democratization processes. The second mechanism forcefully prevents democratization by forms of repression. Finally, the third mechanism is that of modernization, meaning that the population of the state fails to move into industrial and service sector jobs, making civil society movements for democratization less likely. According to the findings, all three effects are visible in the oil-rich exporters, whereas non-fuel mineral exporters suffer from the rentier state effect, but not from the repression effect, and only to a limited extent from the modernization effect.

Moreover, richness in natural resources may lead to social unrest and even civil war in a country. The debate on resource abundance and civil war is an arena of scholarship in its own right, with a multiplicity of studies (Ballentine \& Sherman, 2003; Berdal \& Malone, 2000; Collier, 2000a, 2000b; Collier \& Hoeffler, 2004; Collier et al., 2003; Fearon, 2005; Fearon \& Laitin, 2003; Herbst, 2000; Humphreys, 2003; Klare, 2001; Ross, 2003; Ross, 2004; Snyder, 2002). Depending on the type of natural resource (minerals or hydrocarbons ${ }^{5}$ ), the relationship between natural resources and conflict may differ. For instance, de Soysa \& Neumayer (2007) confirm the well-documented findings on energy resources increasing the risk of a civil war onset; however, they also find that mineral resources are not a risk factor for civil war. When focusing on hydrocarbons, we can differentiate between direct and indirect mechanisms through which energy resources may lead to the outbreak of war. Hydrocarbons can provide direct incentives for rebels through various opportunities, such as looting from pipelines or extorting oil companies, as well as prospects of large future revenues after a successful secession. The indirect mechanisms of influence operate via the negative impact on the economic growth (either through economic or political channels). Grievances increase, which in turn may lead to a rebellion (Lujala, Rød, \& Thieme, 2007, p.240). Collier and Hoeffler (2005) highlight the

\footnotetext{
${ }^{5}$ These include oil and natural gas.
} 
results of Weinstein (2005), according to which even in the conditions of "political disease" when one would expect a "grievance" rebellion against bad government, such a rebellion gets crowded out by "opportunistic" rebellion, more attractive for groups seeking political power in the context of resource-rich countries. The increased likelihood of war and the increased duration of conflicts associated with resource abundance are other indirect links connecting natural resources and low state of development in many resource-rich countries.

Table 1.1 Causal Pathways to the Resource Curse

\begin{tabular}{lc}
\hline Economic Mechanisms & Political Mechanisms \\
\hline & Looting and inefficient redistribution \\
Dutch Disease & due to \\
Declining terms of trade & Short time horizons \\
Price volatility & Political power based on ethnic group \\
Enclave structure of resource production & Patronage politics for electoral or \\
International firms profit more than governments & military support \\
Low stock of human capital & Erosion of checks and balances \\
& Wars $\quad$ Direct mechanisms of looting \\
& Indirect mechanisms via low state \\
& capacity
\end{tabular}

Source: based on the literature reviewed in section 1.2.

As seen from the literature reviewed above, the explanations of the resource curse vary and may run via multiple causal pathways. Economic and political mechanisms both contribute to difficulties associated with converting the potential of the resource wealth into a positive development outcome. The complexity of the issue at hand has direct implications for policymaking: different causal pathways to the resource curse need to be addressed by different types of policies, possibly targeting very different sectors of the country's economy or polity. 


\subsection{Is the Resource Curse Unavoidable?}

Despite the grim prospects of resource abundance outlined in the previous section, there is also a consensus among scholars that with the right policies and prudent management of the resources it is possible to prevent or even completely avoid the resource curse. Some studies have argued that we have plenty of successful country examples, such as the US, Canada, Norway, Australia, Finland, and Sweden, where industrialization had happened due to initial exports in primary commodities, which later on created linkages to other industries, manufacturing included (Blomström \& Kokko, 2007; Innis, 1956; Watkins, 1963; Wright \& Czelusta, 2004). The importance of government intervention in the development of linkages to other industries (especially backward linkages producing inputs into the commodities sector, rather than forward linkages focusing on processing commodities $^{6}$ ) is also brought up by Kaplinsky (2011). He argues that focusing on backward linkages producing inputs into the commodities sector is a particularly viable option for today's resource-rich countries, given that the manufacturing sector has been much more difficult to enter after the success of newly industrialized economies. Another reason why specialization in commodities may be a good development strategy in today's world pertains to the raised prices of energy and minerals resulting from the rising demand in rapidly growing economies, China in particular (IMF, 2008; Kaplinsky, 2011). This is why resource abundance and specialization in primary commodities do not necessarily lead to negative development outcomes; on the contrary, under certain conditions they can contribute to economic growth.

Aside from theoretical arguments on how natural resources may in fact contribute to economic development, the empirics of the resource curse have been challenged by an increasing number of studies. It turns out that whether or not

\footnotetext{
${ }^{6}$ As an example, backward linkages from mineral extraction can lead to better equipment and more advanced engineering technology, while forward linkages from mining can develop when processing the extracted minerals and manufacturing new products. For detailed discussion, consult Kaplinsky (2011).
} 
natural resources are associated with low economic growth largely depends on how resource abundance is measured. For example, when using the net resource export per worker or the reserves per capita (Lederman \& Maloney, 2007; Maloney, 2002; Stijns, 2005), rather than the ratio of natural resources exports to GDP (Sachs \& Warner 1995, 2000, 2001), as indicators of resource abundance, the negative relationship between resource abundance and growth disappears. Recent literature confirms these results, arguing that natural resources can in fact have a positive effect on economic growth, depending on the operationalization of resource abundance, as well as the specification of the model (Cavalcanti, Mohaddes, \& Raissi, 2011; Kurtz \& Brooks, 2011).

These findings have presented a strong case for the ambivalent impacts of natural resources. As Stijns (2005) argues, both positive and negative links between natural resources and economic growth exist, thus leading to differences in results, depending on how variables are measured and the study is designed. In this context, Kaplinsky (2011, p.9) also puts forward the following argument: "What emerges and is interpreted as a manufacturing sector causally weakened by a commodities specialization is in fact often a commodity specialization in an economy with no or little history of industrial development."

As a logical consequence of these findings, research has moved into studying under what conditions natural resources lead to successful development outcomes. Recent studies have shown that institutions are a key variable determining whether a country will benefit from its natural resources (Bhattacharyya \& Hodler, 2010; Stevens \& Dietsche, 2008; van der Ploeg, 2011). Mehlum, Moene, \& Torvik (2006) find that resource abundance impacts economic growth negatively only if institutional quality is low. Robinson et al. (2006) argue that whether benefits of resource booms are realized largely depends on institutions. Particularly important, it seems, are institutions against patronage, associated with distribution of public jobs or other favors by politicians in exchange for electoral support, and against rent-seeking, which leads to a decrease 
in entrepreneurial activity in industries other than natural resource management. Addressing corruption in general also helps resource-rich countries to prevent the symptoms of the resource curse (Kolstad, Wiig, \& Williams, 2009). Investing in education in order to harness human capital is argued to matter as well (de Ferranti, Perry, Lederman, \& Maloney, 2002), in particular given the possible inverse relationship between natural resource abundance and education (Gylfason, 2001). Lederman and Maloney (2007) argue that when appropriate policies and institutions are in place, resource wealth can significantly contribute to economic growth. The economic institutions encouraging careful macroeconomic management and prudent fiscal policy are extremely important for mitigating the negative effects of the possible Dutch Disease (IMF, 2007), and there is also considerable body of evidence documenting the link between prudent macroeconomic policies and positive economic outcomes in specific country cases (for a more detailed discussion on this literature, see Frynas, 2010).

Current research on governance of the extractive sectors has mostly focused on domestic approaches, i.e. government policies which can ensure effective management of natural resources (Rudra \& Jensen, 2011). First, a number of studies have looked into the options of decentralizing the distribution of resource revenues: taxes levied by sub-national governments directly on the industry, formula-based share transfers from the central government, or indirect transfers through national budget allocations are all variants of this policy. While the first two approaches may be necessary in post-conflict peace building arrangements, they have a number of serious drawbacks and decrease the effectiveness of a central government's macroeconomic planning (Ahmad \& Mottu, 2002; Ross, 2007; Ross, Lujala, \& Rustad, 2011). Second, studies have investigated the implications of different contractual arrangements between governments and companies (Cramton, 2007; Johnston, 2007; Radon, 2007). Third, to deal with the volatility of income from natural resource revenues and to improve the long-term fiscal management of resources, one of the commonly administered strategies is the 
establishment of natural resource funds, often referred to as stabilization or savings funds (IMF, 2007). Humphreys \& Sandbu (2007), however, argue that good expenditure policies can be carried out in the absence of natural resource funds and show that the effectiveness of such funds largely depends on whether their designed structure is able to alter incentives of the political actors involved. Particularly important factors are regulation by strong rules rather than general guidelines, decision-making representing diverse political groups, and transparency of operation. Finally, as the IMF has argued, transparency during all stages of natural resource management is crucial in establishing the necessary preconditions for effective management of resource revenues, as it fosters efficient use of public funds, reduces the risk of unstable macroeconomic policies, and improves public confidence in the budgetary process (IMF, 2007).

The past decade has seen rapid developments in transparency-focused efforts targeting natural resource management via global voluntary initiatives ${ }^{7}$ (Acosta, 2013). A particularly curious feature of these initiatives is their focus on transparency, especially since there is yet little empirical evidence specifying the conditions under which we may expect transparency-focused measures in the extractive sectors to contribute to development outcomes. For instance, Kolstad and Wiig (2008) show that despite positive indirect effects, transparency may be insufficient to overcome political mechanisms of corruption, and can even have certain negative effects. A literature review in Frynas (2010, pp. 168-169) provides evidence of potential positive effects of transparency in revenue spending on development, lower government debt in particular. The benefits of policies focusing on earlier stages of resource management are less evident and operate via indirect channels (Frynas, 2010; Kolstad \& Wiig, 2008). In addition, there is literature documenting - at best - only modest success, and - at worst - failures of transparency-focused single project interventions (Pegg, 2006; Gillies, 2010, pp.109-110; Haufler, 2010a, p.61; Winters \& Gould, 2011).

\footnotetext{
${ }^{7}$ Specific regulatory instruments are discussed in section 1.5 of this chapter.
} 
Despite these concerns regarding ambiguous impacts of transparency and, even more importantly, absence of evidence that transparency should be a priority among the various reforms needed in the resource-rich countries, recent reforms in the U.S. and the EU (COM, 2011, pp. 8-9; Disclosure of Payments by Resource Extraction Issuers, 2012) show a trend toward establishing further transparencyfocused regulation even beyond voluntary initiatives - via laws affecting extractive companies. ${ }^{8}$ For academics and policy makers working on the issues related to natural resource governance, it is becoming increasingly difficult to ignore these developments in soft and hard law regulating natural resource management. Given our limited knowledge about the causal links between transparency-focused policies and the development outcomes, it becomes all the more puzzling that these initiatives are adopted and implemented. In terms of existing knowledge gaps in the literature, there is a need not only to continue advancing our knowledge on the precise effects of transparency in settings with different scope conditions, but also investigate the functioning of the newly established and rapidly developing regulatory instruments. If the empirical evidence on the impacts of transparency is still ambiguous, why are countries adopting these policies, how does the implementation differ, and can we say that the type of implementation affects our ultimate concerns about the positive impacts of transparency?

\subsection{Which Causal Pathways of the Resource Curse Does \\ Transparency Address?}

To theorize potential positive effects of transparency in the extractive sector management, it is important to have a good grasp of the natural resource management stages, and, in particular, to understand at which stages different political and economic causal mechanisms of the resource curse come into play. Depending on the degree of specification used, the stages of the natural resource

\footnotetext{
${ }^{8}$ For a detailed discussion see Chapter 6 of the dissertation.
} 
management process may slightly vary. Yet all classifications specify at least the following main stages: set-up of the legal framework and contracts, revenue collection (including physical transportation, as well as revenue reporting), revenue distribution (between central and regional authorities), and revenue spending (IMF, 2007; NRC, n.d).

Resource management starts with setting up the roles and responsibilities of parties involved, i.e. governments and companies. The legal framework guiding the ownership of the natural resources and the power to grant rights of exploration, production, and trade needs to be specified in the constitution and the national (and sometimes subnational) law. There are two types of fiscal regime arrangements that may govern the extraction of oil and natural gas: 1) tax/royalty systems, in which companies have the right to explore, exploit, and sell the resources and are being taxed on their activities, and 2) production-sharing contracts, in which companies extract and develop the resource, with a share of production going to the host government (IMF, 2007). ${ }^{9}$ Irrespective of the fiscal regime chosen, the negotiation of good contract terms is critical in order to prevent one of the economic mechanisms of the resource curse - the situation when the international companies profit more than the governments by signing unfair or not-the-best-possible deals. To ensure the country is getting a good deal on the revenue entitlements, the terms need to be clear. ${ }^{10}$ On the other hand, the political mechanisms of the resource

\footnotetext{
${ }^{9}$ Corporate income tax, in this case, goes either directly to the state, or to the national stateowned company (NSC); elements of tax/royalty systems could be included.

${ }^{10}$ Besides monetary and in-kind entitlement, such contracts often have additional arrangements on quasi-fiscal activities and/or subnational contributions. Quasi-fiscal activities are arrangements of social, environmental, or subsidy expenditures on the part of companies that are arranged outside of the state budget. Examples of such would be requirements for companies to provide social services or public goods, such as road construction, building a school, etc., or a requirement to provide products at less than market price for domestic consumption. Subnational revenue entitlements concern the arrangements at the regional level, specified in the law. The resource revenues can be controlled centrally, but in a number of countries, such as the US, Canada, and Australia, subnational governments own the resource; in other countries, legislation may require a share of revenue with subnational governments, based on a certain formula (IMF, 2007).
} 
curse may also be affected. The information on the contracts has traditionally been very secretive, and, despite the fact that a number of countries have started disclosing information on some of the contracts, most contractual agreements are still kept confidential. This presents a political risk of corruption already at the very beginning of the resource management cycle, via agreements through which part of the revenues can leak, causing the country involved to miss out on the revenue entitlement.

While both the economic and the political mechanisms of the resource curse are relevant to setting up the legal framework and contracts - the first stage of the resource management process, the stage of revenue collection concerns the political mechanisms, mainly ensuring that the revenues (or resources in-kind) are not looted or misappropriated along the way. The risks at this stage occur in the physical transport of the resource, or in actual collection of the revenues. The direct mechanisms of looting occur during the phase of resource transportation, whereas indirect looting takes place via corruption channels.

The revenue distribution stage of the resource management concerns the decisions regarding planning and allocating the resource revenues. The political risks of revenue looting or inefficient redistribution continue to exist during the stage of revenue distribution, such as in the allocation of revenues to central and regional authorities. Furthermore, depending on the country context and the chosen formula of revenue distribution, there is an economic risk of suboptimal fiscal planning. This can happen due to variations in how the revenues are planned to be distributed: sometimes resource revenues are controlled centrally, but there are a number of countries where the resource is owned at the sub-national level. In addition, formulas of revenue sharing can be applied.

Finally, during the last stage of revenue spending, the main challenge is to realize the potential of the revenues collected. This mainly applies to risks of bad economic decisions, such as suboptimal investment decisions, or weak long-term fiscal planning. However, the risk of inefficient revenue spending due to corruption 
(a political mechanism of the resource curse) still remains, even in the last phase of the resource management cycle, for instance through misuse of natural resource funds, or other corruption schemes in revenue spending.

What we can thus observe is that political mechanisms contributing to the resource curse operate throughout the complete cycle of the resource management process. Economic mechanisms are visible in all phases of the resource management, with the exception of revenue collection stage.

Having discussed the various potential economic and political policy problems of the natural resource management process, I will now assess how transparency-focused policies can help at each stage of the resource management cycle. The common IMF policy recommendation (2007) for the stage of contract arrangements is to make all contracts and terms of agreements public. Apart from getting a good deal on the arrangements with extractive companies, transparency is needed to ensure that the government's earnings are indeed collected. As such, at this stage, transparency is geared to the political mechanisms contributing to the resource curse, as well as to one of the economic mechanisms: ensuring a fair deal between the government and companies. For the second stage of resource collection, policies preventing physical looting of the resource may include securing production sites. To prevent such looting, security in the physical revenue collection and transparency in the reporting phase of revenue collection are needed. At this stage, corruption, as well as direct mechanisms of looting (causing wars), are targeted. To prevent possible corruption during the revenue distribution and revenue spending phase, a transparent process makes public the information on revenue distribution (whether managed centrally or via subnational arrangements) and revenue spending. Transparency in revenue spending may indirectly help to plan fiscal policy as well: open access to the information on resource spending encourages public debate on policies carried out by the government (central and/or subnational). Finally, through increased citizen involvement transparency in all stages of the resource management process helps to target the erosion of checks 
and balances, as well as low state capacity, which, as underscored in the literature review, impede democratization processes in resource-rich countries.

By tracing the various phases of the natural resource management process, we see that transparency - as an obvious strategy to battle corruption mechanisms - is not sufficient to prevent the resource curse when it targets only one, or even a few, of the resource management stages. Targeting only one phase of the cycle may simply move the locus of corruption associated with political mechanisms of the resource curse to one of the other resource management stages. Therefore, in order to target the political mechanisms of the resource curse, transparency is needed in setting up the fiscal regime and contracts, revenue collection, revenue distribution, and revenue spending. ${ }^{11}$

Table 1.2 below serves to illustrate my argument by summarizing the main mechanisms of the resource curse discussed in detail in section 1.2 and listing the institutional policy remedies suggested in section 1.3. The key point here is that most of these policy remedies (particularly for political mechanisms, and less so for the economic ones) need transparency practices to be operational and effective. The table's third column indicates which phases of the natural resource management process are affected by transparency practices associated with the policies listed in the second column.

\footnotetext{
${ }^{11}$ Despite the positive impacts of transparency, negative effects may also exist. An obvious example is securing physical transportation of the resource in the stage of revenue collection; here transparency may increase direct looting. Another, perhaps more ambiguous, example is transparency in the revenue distribution stage, particularly in subnational distribution schemes. Electorate demanding higher revenue shares for their respective constituencies (with regions specializing in extractives) can unwillingly work against the interests of the country as a whole, leading to sub-optimal or inefficient economic planning of the government.
} 
Table 1.2 Causes of the Resource Curse and Transparency in the Resource Management Stages

\begin{tabular}{|c|c|c|}
\hline Causes of the Resource Curse & $\begin{array}{l}\text { Which Policies can target the } \\
\text { problem? }\end{array}$ & $\begin{array}{l}\text { Which stages of resource } \\
\text { management benefit from } \\
\text { transparency policies? }\end{array}$ \\
\hline \multicolumn{3}{|l|}{ Economic mechanisms } \\
\hline Dutch Disease & $\begin{array}{l}\text { Investments in linkages with } \\
\text { other sectors }\end{array}$ & $\begin{array}{l}\text { Possible indirect impact from } \\
\text { transparency in revenue spending } \\
\text { via increased involvement of } \\
\text { activist groups with relevant } \\
\text { expertise }\end{array}$ \\
\hline Declining terms of trade & $\begin{array}{l}\text { Investments in linkages with } \\
\text { other sectors }\end{array}$ & $\begin{array}{l}\text { Possible indirect impact from } \\
\text { transparency in revenue spending } \\
\text { via increased involvement of } \\
\text { activist groups with relevant } \\
\text { expertise }\end{array}$ \\
\hline Price volatility & $\begin{array}{l}\text { Fiscal planning, natural } \\
\text { resource funds }\end{array}$ & $\begin{array}{l}\text { Possible indirect impact from } \\
\text { transparency in revenue spending } \\
\text { via increased involvement of } \\
\text { activist groups with relevant } \\
\text { expertise }\end{array}$ \\
\hline $\begin{array}{l}\text { Enclave structure of resource } \\
\text { production }\end{array}$ & $\begin{array}{l}\text { Investments in linkages with } \\
\text { other sectors }\end{array}$ & $\begin{array}{l}\text { Possible indirect impact from } \\
\text { transparency in revenue spending } \\
\text { via increased involvement of } \\
\text { activist groups with relevant } \\
\text { expertise }\end{array}$ \\
\hline $\begin{array}{l}\text { International firms profit more } \\
\text { than governments }\end{array}$ & $\begin{array}{l}\text { Negotiation of better contract } \\
\text { terms for governments }\end{array}$ & $\begin{array}{l}\text { Setting up the fiscal framework } \\
\text { and contracts, revenue collection }\end{array}$ \\
\hline Low stock of human capital & Investments in education & $\begin{array}{l}\text { Possible indirect impact from } \\
\text { transparency in revenue spending } \\
\text { via increased citizen involvement }\end{array}$ \\
\hline \multicolumn{3}{|l|}{ Political mechanisms } \\
\hline $\begin{array}{l}\text { Looting and inefficient } \\
\text { redistribution }\end{array}$ & $\begin{array}{l}\text { Transparency of revenue } \\
\text { management }\end{array}$ & $\begin{array}{l}\text { Setting up the fiscal framework } \\
\text { and contracts, revenue collection, } \\
\text { revenue distribution, revenue } \\
\text { spending }\end{array}$ \\
\hline Erosion of checks and balances & $\begin{array}{l}\text { Democratization, fiscal rents } \\
\text { from citizen taxation }\end{array}$ & $\begin{array}{l}\text { Indirect impact from transparency } \\
\text { in all stages via increased citizen } \\
\text { involvement }\end{array}$ \\
\hline \multicolumn{3}{|l|}{ Wars } \\
\hline Direct mechanisms of looting & $\begin{array}{l}\text { Securing production sites, } \\
\text { ban on imports of looted } \\
\text { resources }\end{array}$ & $\begin{array}{l}\text { Revenue collection (via tracking } \\
\text { resource trade) }\end{array}$ \\
\hline $\begin{array}{l}\text { Indirect mechanisms via low } \\
\text { state capacity }\end{array}$ & $\begin{array}{l}\text { Transparency of revenue } \\
\text { management }\end{array}$ & $\begin{array}{l}\text { Indirect impact from transparency } \\
\text { in all stages via increased citizen } \\
\text { involvement }\end{array}$ \\
\hline
\end{tabular}

Source: analysis based on review of the literature on causes of the resource curse (section 1.2), policies preventing the resource curse (section 1.3), and the stages of natural resource management (section 1.4). 
As argued above and shown in the table, the transparency remedies to the problems associated with the economic channels of the resource curse lie mostly within the sphere of revenue spending. Moreover, they operate only via indirect linkages, such as possible influence of activist groups with relevant expertise pressuring the government to act on the information available. The mechanisms contributing to the political resource curse benefit from transparency practices in all stages of the natural resource management process: contract (as well as information on licensing procedures and fiscal regime) disclosure, tracking the actual revenue collection through a transparent reporting system, providing information on revenue distribution mechanisms, and revenue spending.

To illustrate the discussion, some of the economic and political mechanisms contributing to the resource curse are discussed in the next step. According to the literature reviewed in section 1.3, most economic mechanisms should be addressed with policies in the revenue spending cycle of the resource management, via strategic investments of the revenue collected and the aim of developing linkages to other sectors. For instance, transparency in revenue collection would not have an impact on the Dutch disease because the issue at stake is not that the revenues fail to end up in the budget, but rather that, once received, they have an adverse impact on other processes in the economy. The solution to the problem, then, lies in prudent spending, with investments in linkages to other sectors. Therefore, if transparency policies can be of help with this mechanism, it would only be to encourage careful planning of revenue spending policies. As Table 1.2 illustrates, most of the economic explanations of the resource curse have to do precisely with the revenue spending issues, and, therefore, transparency policies targeting these mechanisms focus on this particular stage of the revenue management cycle, operating only via possible indirect effects. One notable exception is the channel contributing to the resource curse symptoms tied to unfair sharing of profit between governments and international companies. This economic 
mechanism needs transparency in contract disclosure, as well as revenue collection phases, rather than the revenue spending phase.

When considering political mechanisms contributing to the resource curse symptoms, all of them are related to the failure to include the revenues due in the budget, i.e. the stages preceding the spending phase (though some looting or misappropriation of revenues during the spending phase can also occur). Thus, in order to target the issues tied to looting and corruption in redistribution policies, transparency is needed from the very beginning of the resource revenue cycle from setting up the fiscal regime and contracts, through revenue collection reporting, up to revenue distribution, and finally, revenue spending. When it comes to addressing all types of looting and inefficient redistribution issues, the full cycle of natural resource management would benefit from transparency. The direct mechanisms causing civil war would particularly benefit from policies securing the sites (policies not linked to transparency), or bans on looted resources (policies focused on trade in the resource at hand). Of course, the erosion of checks and balances involves a much broader issue, calling perhaps for policies beyond those focusing on the natural resource management cycle. Yet, indirectly, even this issue can benefit from transparency, provided that open access to information increases citizen activism.

It is natural to expect differences in the stages of resource management targeted by various transparency practices: the economic explanations of the resource curse are mostly related to a government's ineffectiveness in translating fiscal resource rents into development in other sectors; political explanations, on the other hand, are connected to a government's inability or even disincentive to collect good fiscal rents for its national budget. Both aspects of the management cycle are crucial. To develop, one needs to know where to invest and how to spend the resource revenues well (issues tied to the economic mechanisms of the resource curse). At the same time, it is crucial to ensure that the resource revenues end up in the budget, thus breaking the incentives or opportunities for looting and corruption 
of the politicians in power (problems that may present themselves at any stage of the resource management process).

\subsection{Tracing Potential Impact of Transparency-focused Transnational Initiatives in Natural Resource Management: KP, PWYP, NRC, and EITI}

The discussion on the domestic policies that are most effective in addressing particular problems associated with management of natural resources has been highly useful for identifying best practices and strategies of mitigating symptoms of the resource curse, if not for avoiding it altogether. Despite the usefulness of such studies, however, the problems associated with the resource curse have not disappeared. The challenge to transform the potential of national wealth from natural resources into economic growth and improved standards of living remains a critical one for the population in many less developed and developing countries. Part of the explanation why research findings on good practices of domestic resource management are not being translated into policies on the ground may have to do with the lacking willingness of countries to implement such policies, or with a lacking capacity to implement them on account of the poor quality of a country's institutions. In such a case in particular, approaches focusing on the domestic management of resources cannot fully address the resource trap for countries which already suffer from the symptoms of the political resource curse and which, therefore, lack the institutions for effectively establishing and carrying out the necessary policies for development-based usage of natural resource revenues. In most difficult resource-rich country settings, we find a state of society, which North, Wallis, Webb, \& Weingast (2007) label as "limited access order," where political and economic elites have captured control of the state to such extent that any normal functioning of bureaucracies and state structures is bound to break down. In such environments, the ruling elites may not even have an interest in 
developing their country, thus perpetuating instability and low levels of development. The difficulties associated with setting up good natural resource management practices are particularly prominent in countries which are most in need of them and would potentially benefit the most.

Undoubtedly, both the will and the capacity of governments to implement policies of sound resource management will vary from one resource-rich country to the next. Yet, because such sound management continues to be a critical issue in many resource-rich countries, it becomes obvious that governments alone are not always able, or, in certain cases, willing, to tackle the issue. As argued, research has offered many insights on which particular domestic institutions and management practices are needed. However, the problem of the political resource curse - erosion of institutions - makes resource management difficult even in the presence of best practice guides, which have been developed for domestic resource management. While these guides address important issues in different phases of natural resource management, all of them assume the government as being the main actor, thus ignoring the fact that many problems of the resource-rich countries stem from the very fact that the government is unable or unwilling to implement the necessary policies.

Given the rise of non-hierarchical global and transnational forms of governance, which began to develop at the end of the $20^{\text {th }}$ century, it is logical to turn to the prospects of such regulation instruments in tackling the policy problems faced by resource-rich countries, especially since these forms of regulation have recently become more prominent in the field of natural resource governance. The potential of such voluntary forms of regulation in preventing or mitigating possible negative impacts of natural resources is both scientifically interesting and policyrelevant, especially as there still is little knowledge on the effectiveness of these instruments. Among some of the well-known transnational initiatives in natural resource management are the Kimberley Process (KP) to stop trade in "conflict diamonds," the Natural Resource Charter (NRC) with guidelines for governments, 
the Publish What You Pay (PWYP) campaign for revenue transparency in the extractive industries, and the Extractive Industries Transparency Initiative (EITI), partly originating in the efforts of the PWYP campaign. While all of these initiatives have a particular focus on transparency practices, they target different actors and different phases of the natural resource management process, which means that their channels of influence vary, while, as a result, the causal mechanisms of the resource curse they target differ as well.

To assess the potential of the global and transnational initiatives in targeting the causal pathways to the resource curse, I proceed with discussing each instrument in detail. Conceptualizing the similarities and differences between them, I make a case for focusing on the EITI in this $\mathrm{PhD}$ project. In particular, I am interested in the following four questions: 1) which actors are targeted by the instrument, 2) who leads the initiative nationally, 3) which phases of the resource management cycle are being targeted, and 4) what mode of governance is used. The first question is needed in order to understand whose behavior the regulatory instrument is attempting to change. In the issue area of concern, there are at least two obvious actors - the governments and the companies, and targeting either one of them, or both simultaneously, will result in very different outcomes. The second question seeks to understand which actors are designed to run the initiative at the national level. Against the background of the political mechanisms contributing to the resource curse, this is important to consider. After all, if the regulatory instrument leaves implementation of the initiative in the hands of actors who are benefitting from the status quo, the adoption and implementation of transparency measures become unlikely. Thirdly, grounded in the discussion of transparency effects, which were conceptualized in the previous section, I assess which resource management stages are targeted by each of the regulatory instruments. Finally, based on the discussion of the differences between the initiatives, the last question aims to classify the modes of governance of the different transparency-focused efforts. 
Table 1.3 Transparency-focused Regulatory Instruments: Conceptualizing the Differences of Potential Impact

\begin{tabular}{|c|c|c|c|c|}
\hline $\begin{array}{l}\text { Regulatory } \\
\text { Instrument }\end{array}$ & $\begin{array}{l}\text { Behavior of } \\
\text { which actors is } \\
\text { being targeted? }\end{array}$ & $\begin{array}{l}\text { Who leads the } \\
\text { initiative } \\
\text { nationally? }\end{array}$ & $\begin{array}{l}\text { Which phase of the } \\
\text { resource management } \\
\text { cycle is being } \\
\text { targeted? }\end{array}$ & $\begin{array}{l}\text { What is the } \\
\text { type of the } \\
\text { regulatory } \\
\text { instrument? }\end{array}$ \\
\hline $\begin{array}{l}\text { Kimberley } \\
\text { Process (KP) }\end{array}$ & $\begin{array}{l}\text { Governments, } \\
\text { diamond } \\
\text { miners }\end{array}$ & Governments & $\begin{array}{l}\text { Resource (diamond } \\
\text { only) trade; to some } \\
\text { extent, physical } \\
\text { transportation of the } \\
\text { resource }\end{array}$ & $\begin{array}{l}\text { Global } \\
\text { governance } \\
\text { arrangement }\end{array}$ \\
\hline $\begin{array}{l}\text { Natural Resource } \\
\text { Charter (NRC) }\end{array}$ & Governments & Governments & $\begin{array}{l}\text { Contract disclosure, } \\
\text { revenue collection, } \\
\text { revenue distribution, } \\
\text { revenue spending }\end{array}$ & $\begin{array}{l}\text { Transnational } \\
\text { network }\end{array}$ \\
\hline $\begin{array}{l}\text { Publish What } \\
\text { You Pay } \\
\text { (PWYP) }\end{array}$ & $\begin{array}{l}\text { Companies; } \\
\text { governments } \\
\text { added later }\end{array}$ & NGOs & $\begin{array}{l}\text { Revenue collection; } \\
\text { contract disclosure } \\
\text { and revenue spending } \\
\text { added later }\end{array}$ & $\begin{array}{l}\text { Global NGO } \\
\text { campaign }\end{array}$ \\
\hline $\begin{array}{l}\text { Extractive } \\
\text { Transparency } \\
\text { Initiative (EITI) }\end{array}$ & $\begin{array}{l}\text { Governments, } \\
\text { companies, } \\
\text { civil society }\end{array}$ & $\begin{array}{l}\text { Multi-stakeholder } \\
\text { groups } \\
\text { (representing } \\
\text { constituencies of } \\
\text { government, } \\
\text { companies, and } \\
\text { civil society) }\end{array}$ & $\begin{array}{l}\text { Revenue collection in } \\
\text { the minimum } \\
\text { requirements; } \\
\text { contract disclosure, } \\
\text { revenue distribution, } \\
\text { revenue spending in } \\
\text { extensive forms }\end{array}$ & $\begin{array}{l}\text { Global } \\
\text { governance } \\
\text { arrangement }\end{array}$ \\
\hline
\end{tabular}

Source: own analysis.

The KP positions itself as a conflict-prevention instrument, which ensures that trade in diamonds does not fuel wars and rebel activity. Started out as a campaign against "blood diamonds" (for a historical overview of events leading to the KP's establishment, see Grant \& Taylor, 2004; Wright, 2004), by 2003 the movement was institutionalized as a formal certification scheme, the requirements of which prevent conflict diamonds from being traded in the legitimate markets. Each export or import of rough diamonds must be accompanied by the KP certificate; KP participants agree to trade in diamonds only among KP members. Furthermore, participating governments pledge to ensure that domestic trading is not contaminated by illicit sales (Fishman, 2004-2005, p.226; Wright, 2004, p.699). Participation in the initiative is voluntary; as of November $2012 \mathrm{KP}$ members account for $99.8 \%$ of the global production of the rough diamonds (KP, 
n.d-a). The participants of the KP include states and regional economic integration organizations (currently, the EU); the observers include the diamond industry and civil society groups (KP, n.d-b). Once a country adopts the initiative, implementation is carried out by national administrations, which means that legislation regulating the KP varies among participant countries. The enforcement mechanism has been argued to be weak, as monitoring of the process is done via voluntary peer reviews, and incentives for governments to cheat still remain (Fishman, 2004-2005, pp. 234-235, p. 239). For example, Haufler (2010b, pp.411412) points out that fraudulent certificates or certified diamonds from suspicious sources continue to be a problem, especially in the contexts of weak governments with high corruption levels. This weakness of the KP largely stems from the fact that the instrument gives strong responsibilities to governments, which creates an inherent difficulty of implementation in contexts with low state capacity. As indicated, these are the countries where political mechanisms of the resource curse are likely. In the case of voluntary regulation, there are the risks of a country's adoption of the instrument with empty promises and a lack of enforced national implementation. Even in cases where a political will of governments implementing the initiative can be reasonably assumed, the KP addresses only one particular issue of resource trade. The political mechanism contributing to the resource curse targeted by the KP is the direct mechanism of looting. Furthermore, the KP addresses only illicit trade in diamonds and does not focus on other resources. Also, the issues of resource smuggling (belonging to the physical transportation stage preceding trade) are addressed by participants with varying degree of effectiveness, again depending on the way the initiative is implemented nationally. In this respect, Fishman (2004-2005, p. 237) argues that control at the mines in many countries continues to be weak.

The NRC was designed as a tool to guide governments on the practices of sound natural resource management and was originally developed by a group of independent experts under the leadership of Paul Collier. Currently, the NRC is 
governed by the Oversight Board, which is supported by an International Secretariat and Technical Advisory Group composed of experts. While the Charter does not exclude the possibility of future formalization in the form of a voluntary international compact (NRC, n.d), at present the NRC is not more than a set of voluntary recommendations. Although the Charter's principles (NRC, 2010) target all phases of the natural resource management process, in contexts already suffering from the mechanisms contributing to the political resource curse, the extent of the NRC's impact is questionable. Because the Charter is designed as a tool for governments, its effects strongly depend on the political will to implement the guidelines. In contexts of resource-rich countries where such will is likely to be absent, the NRC has limited influence, if any. In this sense, the Charter is similar to the KP: the locus of implementation decisions still remains with the governments, and this presents a challenge in domestic settings of low institutional quality or absence of the willingness to implement the extensive practices suggested voluntarily. The difference with the KP lies in the Charter's overarching focus, which concerns the full cycle of the resource management process.

The PWYP started out in 2002 as a transparency campaign to encourage extractive companies to publish their payments to the governments of countries in which they operate. The PWYP originally targeted company activity only, but over time its agenda was extended to targeting the governments to publish what they receive, as well as disclose information about further stages of natural resource management, such as contract disclosure and revenue spending. In addition, the PWYP campaign aims to increase the scope and depth of transparency in natural resource governance by encouraging stakeholders to adopt and implement the Extractive Industries Transparency Initiative (EITI) and a number of other emerging practices, which are discussed in more detail in Chapter 6. As a global network of civil society organizations, the PWYP does not involve companies or government in the decision-making structures; rather it targets these actors via campaigning. The PWYP was the first transnational governance movement 
attempting to target the political mechanisms contributing to the resource curse by encouraging companies to disclose the information on their payments in the extractive sectors. The PWYP campaign puts pressure on governments to disengage from corrupt practices and openly reveal the information on the revenues coming into the country - so as to target the looting mechanisms of the resource curse. Furthermore, by coordinating the civil sector movements in resource-rich countries, the PWYP creates pressure on the government, thus possibly contributing to democratization processes in the resource-rich settings. At the same time, the focus on the civil society groups as the main actor leading the campaign may be a weakness regarding countries troubled by political mechanisms tied to the resource curse. Governments in such countries may suppress PWYP campaigning at the national level, while such campaigning at the grassroots level may be weak or non-existent, notably in settings where the political mechanisms of the resource curse have impeded democratization processes.

The EITI was formally announced by then British Prime Minister Tony Blair at the 2002 World Summit for Sustainable Development in Johannesburg, and it was officially launched at the First EITI Plenary Conference held in London in June 2003. Unlike the above-discussed instruments, the EITI combines two elements in its design. The first of these is a multi-stakeholder element: the EITI involves government, companies, and civil society as constituencies at the national level. The second is the EITI's scope: while primarily focusing on upstream activities in the natural resource management, it leaves possibilities for voluntary inclusion of all natural resource management stages. Thus, in principle the EITI design allows one to target most of the resource curse mechanisms, as well as all of the stakeholders involved. Whether and how precisely these possibilities for extensions are realized during the implementation process is an important question to explore.

The EITI quickly became one of the pioneering approaches targeting the governance of natural resources. Through improving transparency in resource 
management, the initiative aims to mitigate potential negative impacts of natural resources. The EITI Secretariat has defined the EITI's mission as follows:

Countries rich in natural resources such as oil, gas, and mining have tended to under-perform economically, have a higher incidence of conflict, and suffer from poor governance. These effects are not inevitable and it is hoped that by encouraging greater transparency in countries rich in these resources, some of the potential negative impacts can be mitigated. (EITI International Secretariat, 2009)

The EITI's minimum requirement is transparency in the revenue reporting process. Beyond that, however, the voluntary aspect of the EITI allows for differences in the ways joining countries implement the standard. This option of extending the implementation process in various ways - which is an integral element of the EITI's design - leaves the potential of targeting the full scope of natural resource management. Crucially, these more extensive activities are encouraged in the EITI design, and as the new EITI guidelines (launched in May 2013) have shown, many initially voluntary practices have now become mandatory EITI activities.

The adoption of the EITI standard starts with a government's voluntary decision to join, and this is similar to the voluntary set-up of the KP, also set up as a global governance arrangement. Yet, once the implementation starts, the EITI significantly differs from the KP in terms of domestic implementation. Once the EITI is initiated nationally, the participating country has to organize a multistakeholder group (MSG), which determines the particularities of implementation in each participating country. Crucially, the EITI requires participation in the MSG of the company, civil society, as well as government constituencies. ${ }^{12}$ The EITI process, then, is neither privately-led, as is true of the PWYP, nor is it fully stateled, as is true of the NRC or the KP activities. ${ }^{13}$ The inclusion of state, private, and

\footnotetext{
${ }^{12}$ In the case of the KP, civil society and companies also participate, but only as observers at the global KP structures. Nationally, the KP is led by the governments. There are no MSG-like bodies of implementation.

${ }^{13}$ Though both the NRC and the KP activities are state-led nationally, as Table 1.3 and the discussion above reveals, they differ with respect to the type of regulatory initiative. The
} 
non-state actors in the implementation process without giving one group a dominant role is a particularly interesting facet of the EITI. Moreover, the option of various extensions in the way the EITI is implemented leaves this instrument with the capacity of targeting the full resource revenue management cycle. Such capacity, in theory, also characterizes the design of the PWYP and the NRC. Yet, as evident from the discussion above, by focusing on NGOs (in the case of the PWYP) and governments (in the case of the NRC) as the actors targeted, these regulatory instruments fail to include all relevant stakeholders in the natural resource management process. Against this challenge, the EITI designs the national implementation process to be led by a consensus-based tripartite body - including the stakeholders of companies and civil society, as well as the government. Such design intends to drive the implementation process toward the extensions, on the assumption that extensive implementation is always in the interest of at least one of the stakeholders, civil society. As such, this dissertation focuses on the EITI among other potentially interesting transparency-focused initiatives - as a regulatory instrument that warrants further study.

\subsection{Conclusion}

By reviewing the literature on the causal mechanisms of the resource curse, this chapter has identified the economic and political mechanisms contributing to this phenomenon. Further review of the literature focusing on the domestic management of natural resources has shown that in the presence of appropriate policies, it is possible to overcome, or even prevent, the symptoms of the resource curse. Particular attention was devoted to the role of transparency in different phases of the resource management: argued to be important throughout the full cycle of resource management, transparency was shown to target mostly political

$\mathrm{NRC}$ is a transnational network of experts with global governing structures, whereas the decision-making in KP is designed as a global governance arrangement, involving states as participants and diamond trading associations and civil society groups as observers. 
mechanisms of the resource curse and less so the economic ones. Yet the problem persists: many resource-rich countries continue to suffer from underdevelopment, despite the potential of their resource riches. This can be partly explained with reference to governments' failure to adopt the necessary policies. Another piece of the puzzle is connected to the political mechanisms of the resource curse: in contexts suffering from inefficient redistribution of resources and patronage politics specific actors are benefitting from the status quo and are unlikely to introduce policies that would disrupt this status quo of affairs. Against this background, I have argued the need to consider the potential of transnational transparency-focused instruments in preventing the resource curse. Considering four such initiatives - the KP certification scheme, the PWYP campaign, the NRC, and the EITI - I traced the channels of impact that these initiatives have. My analysis shows that despite their common focus on transparency, they are concerned with different stages of the resource management cycle and operate through influencing different actors. Thus, they target different mechanisms of the resource curse as well as different actors involved. Among the above-discussed instruments, only the EITI gives countries both the option of extending its implementation beyond the minimum guidelines and the requirement of including actors other than just the government leading the implementation nationally. These two aspects of the instrument motivate this $\mathrm{PhD}$ project's empirical focus on the EITI. The EITI is the most elaborate initiative in existence and is the one that qua institutional design shows the biggest potential to make a difference in domestic settings that are at risk of suffering from the political resource curse.

Institutionalized participation of stakeholders other than the government is designed to work as a watchdog mechanism, pushing the extension of transparency requirements forward. The design of the instrument allowing various voluntary extensions to the implementation activities is supposed to drive transparency forward throughout all stages of natural resource management, thus aiming at eliminating the fluctuating locus of opportunities for corruption. Nonetheless, the 
voluntary nature of the EITI, in terms of both its adoption and the shape its implementation takes at the domestic level, is a potential impediment for effective natural resource governance. Against this background, research on the EITI, and in particular on conditions that facilitate its adoption and extensive implementation, may give us a better understanding of the potential of voluntary transnational instruments in addressing the resource curse. It is to these concerns that the next chapters of this thesis will turn. 


\section{Chapter 2: Theoretical Framework}

Summary: The purpose of this chapter is to elaborate on the theoretical choices guiding this $\mathrm{PhD}$ project. Starting with a review of existing studies on the EITI, themes common to the literature and specific research needs are identified. In particular, previous research has failed to convincingly address the following questions: 1) under what conditions the EITI is adopted, 2) how and why the implementation activities differ between the implementing countries, and 3) how stakeholder constituencies impact the implementation. The chapter then introduces conceptualizations of the dependent variables for each empirical chapter of the dissertation and explains why a rational actor framework is appropriate for each of the questions posed. The differences between the application of the rational actor model in each of the empirical chapters are specified.

\subsection{Introduction}

As argued in Chapter 1, the resource curse is hardly inevitable; instead, with the right mix of policies in the resource management, resource-abundant countries can overcome, or prevent, the symptoms of the resource curse. Still, there are difficulties, particularly regarding overcoming political mechanisms that contribute to the resource curse. In the contexts where the resource curse is brought about via political mechanisms, the will of the government which is needed to adopt and implement the necessary policies may simply be absent because the status quo is convenient for the ruling elites. It is because of this problem that increasing attention is directed at global governance initiatives, which can provide templates for sound policy in the sensitive area of transparency in natural resource management, and can increase the external pressure on countries to comply with certain standards of natural resource management. The best known initiatives in the field were discussed in the previous chapter. It was shown that in contrast to the other regulatory instruments considered, the EITI targets multiple actors involved and covers most of the resource management phases; hence, it was argued that comparatively the EITI has a larger potential to battle the resource curse. This $\mathrm{PhD}$ project therefore focuses on the potential of the EITI instrument as a global 
governance arrangement in increasing transparency of natural resource management and preventing, or mitigating, the symptoms of the resource curse.

Because adoption of the EITI is voluntary and implementation may occur in a variety of pathways, a key question is which conditions increase the likelihood of governments adopting the EITI and implementing it in a way conducive to its success. By focusing on this topic, this project contributes to two literatures: the literature on the effectiveness of global governance mechanisms and the literature on institutions necessary for prevention of the resource curse. This chapter serves as a theoretical guide for the study. In section 2.2, the literature on the EITI is reviewed, with a particular focus on the absence of studies considering the functioning of the EITI as a regulatory instrument. Conceptualizations of the dependent variables relevant for the questions posed by this study are explained in section 2.3. I then argue in section 2.4 that this study's specific questions are more productively addressed by the rational actor model, rather than the constructivist account, while also the differences between the application of the rational actor model in each of the empirical chapters are explained. A summary of the focus for the empirical chapters that follow is presented in section 2.5.

\subsection{Review of the Literature on the EITI: Motivating This Project's Research Puzzles}

With the increasing role of non-state actors in the global arena at the end of the $20^{\text {th }}$ century (Abbott \& Snidal, 2010), state-centered realist and liberal-institutionalist theories of international relations seemed to be unable to capture the ongoing transformation of the international system (Dingwerth \& Pattberg, 2006; Rosenau, 1988; Weiss, 2000). The global governance perspective aimed to fill this gap both by acknowledging the changing role of the nation-state in international relations and by studying the complexity of the relationships between states, intergovernmental organizations, and other non-state groups, such as NGOs, multi- 
national companies, and transnational activist networks. As Doris Fuchs has summarized, "the core of the global governance argument concerns the acquisition of authoritative decision-making capacity by non-state and supra-state actors" (2002, p.11). The EITI is an example of this in that we can observe specific decision-making capacities of non-state actors (company and civil society representatives) formally participating in the national level MSGs of the EITI and at the international level in the EITI Board. The EITI Board, besides managing decisions on the governance of the EITI standard globally, also has the final say in granting the status of "compliant" or "non-compliant" to the EITI participating countries. In this sense, a supra-state body also plays a key role in the EITI.

Another key aspect of the EITI that is also highlighted in the global governance literature concerns the soft law nature of the instrument (Shelton, 2009). This means that nation-states voluntarily adopt the initiative and are left a certain leeway in how they implement the initiative domestically. One of the critical and interesting features of the EITI is its focus on transnational actors. The three groups of stakeholders (government, companies, and civil society) design the particularities of the national implementation process, thus creating differences across countries in the implementation activities. So far, current scholarship has contributed little in particular to our understanding of why some national EITI programs are more ambitious than others.

Such questions relating to the concrete functioning of global governance arrangements in different national settings tie in with a "second generation" scholarship on global governance (Pollack, 2008). Originally, the key research agenda of "first generation" global governance scholars focused largely on understanding the emergence of global governance schemes. Examples include a discussion of the role of different actors in global governance (e.g. transnational companies in Scherer, Palazzo, \& Baumann, 2006, rebels in Vandeginste \& Sriram, 2011), and determinants and/or constraints for norm development (Grillot, 2011; Hafner-Burton \& Pollack, 2002). Dingwerth and Pattberg (2006) posit that the 
point of departure for global governance perspective is not the actors involved, but rather "the norms, rules, and standards that constrain social activity" (p.199). The scholars of the second generation, in contrast, aim to understand under what conditions new regulation instruments falling within the scope of global governance arrangements are applied in the first place, and under what conditions they are effective. Linked to this are proposals for the development of new and better governance schemes, based on certain normative approaches such as equality (for example Rixen, 2011). The present study aligns itself with the "second generation" scholarship on global governance, by posing questions about the functioning of the EITI and critically discussing proposals for its further development. 


\section{Box 2.1 EITI Technical Terms ${ }^{1}$}

The permanent global institutional bodies of the EITI are the EITI Members' Meeting, which is held every two years ${ }^{2}$ in connection with the EITI bi-annual ${ }^{3}$ conference, the EITI Board led by the EITI Chair, and the EITI International Secretariat. The EITI International Secretariat is responsible for the daily running of the initiative under the direction of the EITI Board. The Board is the executive body of the EITI that oversees the work plans, the budget, and the activity reports. The Board representatives are elected at the EITI Members' meeting by members of the EITI Association. At the global level, governments (both implementing and supporting); mining, and oil and gas companies (plus investors ${ }^{4}$ ); and civil society groups represent three constituencies of the EITI Association. At the country level, the EITI is overseen by the tri-partite Multi-Stakeholder Group (MSG), representing government, company, and civil society constituencies.

EITI Candidate status is given to a country which has fulfilled four sign-up criteria of the EITI Standard. According to the initial 2009 EITI rules, the EITI candidates were given two years to complete EITI validation, an external independent evaluation process ${ }^{5}$ which assesses the extent to which the country has fulfilled the EITI requirements. Later this deadline was extended, and the countries are now given 18 months to produce their first EITI report and two and a half years to submit a final validation report. ${ }^{6}$ If the country meets all the EITI requirements, the Board grants it the EITI Compliant status. Candidate and compliant countries are required to publish annual EITI reports. If the deadline requirements on publishing reports or completing validation are unmet, the country may request an extension. If the extension deadline is unmet, the EITI candidate/compliant status may be suspended, with eventual possibility of the country being de-listed from the EITI. ${ }^{7}$

\footnotetext{
${ }^{1}$ The summary is based on the following documents: EITI Rules (EITI International Secretariat, 2009), EITI Rules (EITI International Secretariat, 2011) outlining the revisions to 2009 rules, and EITI Standard (EITI International Secretariat, 2013) outlining the rules governing the EITI post-May 2013. The analysis in this dissertation assumes the pre-May 2013 EITI rules, with the exception of Chapter 6 where the new EITI Standard is discussed.

${ }^{2}$ In line with the new EITI standard (EITI International Secretariat, 2013), EITI Members' Meeting is to be held every three years.

${ }^{3}$ The EITI conference is to be held every three years, in line with the new EITI standard (EITI International Secretariat, 2013).

${ }^{4}$ These include asset management companies and pension funds.

${ }^{5}$ In line with the revisions in the EITI Standard (EITI International Secretariat, 2013), validation is now to be managed by the EITI International Secretariat rather than by the implementing countries.

${ }^{6}$ These are among changes specified in the EITI Rules (EITI International Secretariat, 2011).

${ }^{7}$ For more information on this rule, consult EITI Rules (EITI International Secretariat, 2011) and EITI Standard (EITI International Secretariat, 2013).
} 
Since the EITI is a relatively recent initiative, there has been little effort to look into the decision-making processes within the EITI itself, the conditions increasing the likelihood of country adoption ${ }^{14}$ and reasons for subsequent different implementation ${ }^{15}$ models. This section of the chapter concerns the state of the art in the scholarship on the EITI. While the initiative is young, several academic studies and reports by policymakers have meanwhile appeared. What are the insights on the EITI in this body of literature?

Zooming in on studies dealing with the EITI, some belong to the first generation of global governance literature. They discuss the development of transparency norms at the global level over time, and address the question of how and why the EITI came into existence (Gillies, 2010; Haufler, 2010a). There are also quite a few comprehensive studies aiming to make preliminary assessments of the standard's impact (Darby \& Lempa, n.d; Kolstad \& Wiig, 2008; Ölcer, 2009). Others, based on qualitative evidence, have stressed that for the EITI to be effective countries need institutional reforms, without which the EITI on its own is incapable of bringing large-scale change (Frynas, 2010; Hilson \& Maconachie, 2008, 2009). A number of studies have argued that the civil society of EITIimplementing countries is unable to hold the government accountable on the data provided through EITI reporting, either due to low capacity of civil society (Carbonnier, Brugger, \& Krause, 2011; Hilson \& Maconachie, 2009; Maconachie, 2009) or because the information provided in the reports remains opaque (Ölcer, 2009). Another argument on why the EITI is not maximally effective is linked to the fact that many of the resource abundant top producers still have not adopted the

\footnotetext{
${ }^{14}$ When I use the term "EITI adoption," I refer to the status of EITI Candidate. In cases of initiating the EITI prior to 2009 (when candidate status did not yet exist), the candidacy years are approximated based on a number of sources. Details on this information are available in Annex III.

${ }^{15}$ When the term "EITI implementation" is used, I refer to the process starting from EITI candidacy up to EITI compliance. "Extensive EITI implementation" refers to voluntary inclusion of additional EITI practices. Note that since the time period covered by this study some of these voluntary practices have become mandatory, as outlined in the new EITI Standard launched in May 2013.
} 
EITI, thus undermining the appeal of the initiative as a global standard (Ölcer, 2009).

The voluntary component of the EITI, which only allows, but does not require extensive reporting practices beyond the stage of revenue collection, has been argued to be insufficient for prevention or reversal of resource curse symptoms. It has been pointed out that transparency by itself is not a sufficient condition for positive change, and more stages of the resource management cycle need to be addressed in order to make a difference in the effective management of resources (Frynas, 2010; Kolstad \& Wiig, 2008). This argument is in line with the conceptual exercise conducted in the first chapter of this study where the channels of possible EITI impact are traced: indeed, it was shown that the EITI is able to address more mechanisms via which resource curse operates when more extensive practices are adopted. Voluntary inclusion of additional extensive reporting practices or practices further targeting other phases of resource management is not only advised, but also in practice occurring, documented by a number of policy reports (Darby, 2008; Darby \& the World Bank, 2008, pp. 23-38; Rosenblum \& Maples, 2009). Yet, the question of the conditions under which these extensive practices are adopted remains unaddressed in the current literature. Likewise, the question of what socio-economic and political factors influence the adoption of the EITI is largely absent from current scholarship (but see Pitlik, Frank, \& Firchow, 2010, for an exception).

As the literature review suggests, so far researchers have focused on three distinct themes. The first addresses the question of how and why the EITI has emerged as a global governance initiative (Gillies, 2010; Haufler, 2010a). Second, there is literature evaluating the EITI effectiveness (discussed on pp.35-36). Common to these studies is the claim that there has been a lack of EITI measurable impact so far, due to the initiative's modest minimum requirements, or structural conditions of contexts where the EITI operates. Finally, there is one study 
addressing the socio-economic and political factors increasing the likelihood of EITI adoption (Pitlik et al., 2010).

This research project undoubtedly belongs to the second generation of global governance literature, concerned with the functioning of the EITI as a regulation instrument. The empirical chapters focus on the following questions: 1) under what conditions the EITI is adopted in the first place (Chapter 3$),{ }^{16}$ ) how the implementation activities differ between countries, and why such differences occur (Chapter 4), 3) how stakeholder constituencies impact the implementation activities in the critical case countries (Chapter 5). The study thus does not focus on the conditions enabling new forms of governance in the extractive industries in general, but rather zooms in on one particular instrument in the sector (the EITI), which, as argued in Chapter 1, has the biggest potential among the existing global and transnational instruments to prevent or mitigate the resource curse.

Second, my study does not focus on the question of the EITI's impact on the ground. As this is a variable which might be intuitively appealing to consider, I outline a number of reasons for not following this route. First, studies of the EITI's impact may lead to premature conclusions. For one thing, the initiative is very young, and little time has passed since its establishment. Not every EITIimplementing country adopted the standard in 2003, when the initiative was launched. Furthermore, new countries continue to join the EITI, which makes it difficult to make cross-country comparisons for all EITI members. ${ }^{17}$ Obviously, the date of adoption is important: it is likely to be more productive to look at the initial impacts of the EITI in countries that have been implementing the standard for a considerable time period.

\footnotetext{
${ }^{16}$ In contrast to Pitlik et al. (2010), who focus on socio-economic and political factors, I consider country internal characteristics and external influence factors.

${ }^{17}$ In 2006, only seven countries had the EITI candidate status; in 2007, six new countries were granted the candidate status in the EITI club, followed by fifteen new members in 2008. By 2011 thirty-eight countries are participating in the initiative, out of which eleven have the status of compliant.
} 
Secondly, there is an even more compelling reason why EITI impact studies may be premature: one should really be looking at the outcome after a country has achieved compliant status, rather than candidate status. Sometimes countries indeed start implementing the standard right after, or in rare cases even before, achieving the status of candidacy. More often, though, candidate countries stall, postpone, or even suspend the implementation process. As one of the EITI officials referred to the phenomenon, there is a "hammock effect" in which we see much activity at the time of the candidacy, a long dip of low efforts after, and renewed progress right before the validation deadline (interview, March 4, 2010). The real impact of the EITI, then, would become manifest after the country has achieved compliant status and was able to carry out the EITI process in a meaningful way.

Thirdly, there is the issue of differences in implementation activities that countries undertake (see Chapter 4). While these differences are quite drastic between some (candidate) countries, the differences in implementation persist even in compliant countries, which makes it problematic to do cross-country comparisons of EITI impact. The effectiveness of the EITI in reaching its goal of increased transparency will vary from one country to the next, not only depending on the pre-conditions of the country contexts but also on the type of EITI implementation activities designed by the national policymakers. For a meaningful investigation of the EITI impact on the ground, then, we would first have to take into account the type of EITI implementation activities, reflected in the EITI process within each country over time.

Lastly, it is not much use to compare outcome measures in EITI countries vis-à-vis cases with no EITI. Ölcer (2009, p.12), for example, has descriptively compared corruption ratings between resource-rich countries that do and that do not implement the EITI. The scores on control of corruption for resource-rich nonimplementers turned out to be better than for the EITI countries, thus creating possible interpretations of these figures as evidence against EITI effectiveness. It 
would be erroneous, however, to make such inference arguing that resource-rich countries are better off without the EITI because it does not seem to have an impact. If non-EITI resource-rich countries are doing better than resource-rich EITI countries, it does not mean the EITI is not doing well. For one thing, the impact may not be visible due to the reasons outlined above. Also, it would be fundamentally wrong to assume that higher corruption scores in EITI countries visà-vis non-EITI countries have anything to do with the EITI's effectiveness. Most resource-rich countries that currently implement the EITI are at an extremely low starting point, and it is partly due to this reason that they may be motivated to implement it. These are countries that have had a long track of resource curse symptoms, have had high corruption ratings, and have suffered from rent-seeking politics, or they have recently come out of a conflict. Even before the EITI, they have been doing worse than the group of resource-rich countries that do not implement the initiative. In such case, high corruption ratings are not an effect of EITI implementation, but rather a potential cause of it.

Given the reasons outlined above, it might be too early to say anything definitive about the EITI's impact across countries. In contrast, my project aims to explain the mechanisms of the EITI's functioning, in order to understand in which country contexts, whether, and how, the EITI is able to achieve its goal of increased transparency in the governance of natural resources.

\subsection{Conceptualizing the Dependent Variables}

The questions of why new policies are adopted, why policy change occurs, or why the status quo prevails, and why policies differ between countries with similar structural pre-conditions have puzzled political scientists for decades, and they are far from being resolved. The transnational element of policies, given its rather recent rise as a phenomenon in international relations, has understandably been lacking from the original developments of theories on policy processes. Therefore, second-generation global governance scholars should now take on the task of 
incorporating existing theories on the role of different actors in policy processes from different sub-disciplines in the study of global governance arrangements. This $\mathrm{PhD}$ project, focusing on the new empirical terrain, needs to adapt existing theories in other fields to the study of questions on the functioning of the EITI as an instrument falling within the scope of global governance arrangements. This section of the chapter discusses the conceptualization of the dependent variables and the way they are used in each of the empirical chapters.

The literature on implementation processes, dealing with questions of implementation directly or indirectly, is vast and has existed since the 1950s. It is now a common understanding that the first generations of implementation research were lacking, both in theory and formulation of testable hypotheses that could be applied across different contexts and countries (DeLeon, 2005; DeLeon \& DeLeon, 2002). Since then, implementation research has moved into various theoretical approaches which are suitable for different questions under the broad umbrella of implementation (Lester \& Goggin, 1998; O’Toole, 2000; Sabatier \& JenkinsSmith, 1993). One reason for the variety of frameworks and theorizing is that researchers focused on different stages of the policy process, such as issue emergence, agenda-setting, alternative policy selection, enactment, implementation, and evaluation (Birkland, 2005, p.26). Understandably then, the literature on mechanisms for policy adoption, change, and implementation is extremely rich, and a multiplicity of different theoretical frameworks and methodological approaches exists. In the fifty years of scholarship development in studies of policy process, it has thus become apparent that there is no one common framework for studying policy adoption and implementation. Given the state of the art, the most appropriate strategy seems to avoid conceptualizations which cannot fully capture the dependent variables of this study. Rather, I want to outline the dependent variables as they will be used in each chapter and be explicit as to how they are conceptualized. 
The dependent variable in the third chapter is the decision whether to adopt the EITI. The puzzle I am concerned with in the third chapter is what mix of internal (domestic) country characteristics and external influence factors increases the likelihood of policy adoption, understood as the decision whether to adopt the EITI. This decision is operationalized as a binary choice - the presence (or lack thereof) of the EITI candidacy status. The focus of inquiry in this chapter is the factors increasing the likelihood of policy adoption in the EITI candidate countries vis-à-vis countries which have chosen not to adopt the EITI. The primary objective of the chapter is to explore whether certain external and internal factors are indeed more conducive to the country decision of initiating the EITI process, i.e. the decision of initiating transparency reforms in the extractive sectors.

Once the implementation starts, the voluntary nature of the instrument gives rise to different ways in which countries carry out their EITI implementation activities. The level of transparency achieved differs between the implementing countries - in this way, the EITI objective of increased transparency is realized differently depending on the implementation choices of the participating countries. To investigate these important differences and explore potential reasons for their existence, I will probe implementation activities among all EITI participants in Chapter 4. The focus is on the empirics of differences in the implementation, the types of differences, and exploration of the reasons why the differences in one of the implementation dimensions (extensive disaggregation of reporting) exist. Accordingly, the dependent variable of Chapter 4 is the extensiveness of implementation activities, which is broken down by dimensions along which implementation activities occur in all EITI candidate countries and the scope of activities within each of the dimensions. The aim is to break up the black-box of EITI implementation activities, thus assessing how the voluntary component of the EITI standard translates into the differences in EITI implementation across countries. Implementation activities here by no means automatically constitute effectiveness, and they do not necessarily lead to compliance status according to 
the EITI requirements. This means that a country may fulfill some, but not all, of the EITI required procedures and/or suggested voluntary practices.

In the fifth chapter the implementation activities in the selected cases (Azerbaijan and Kazakhstan) are addressed. The patterns found in Chapter 4 inform the selection of critical cases for further process tracing. Based on the findings of Chapter 4, countries authoritarian in regime and implementing the EITI in the oil and gas sector have not adopted the extensive disaggregation requirement, argued to be a very important dimension of EITI implementation. Undertaking the process tracing of EITI implementation over time, Chapter 5 explores two questions - 1) whether the expectation of less extensive implementation is indeed true for all dimensions of the implementation activities, and 2) how the positions of the stakeholders involved impact the implementation activities. The dependent variable thus is implementation activities in the selected case countries. In particular, Chapter 5 investigates whether and how configuration of national stakeholder positions impacts the implementation activities in the selected critical case countries.

If all of these questions are relevant for a type of policy process - policy adoption in the third chapter and policy implementation activities in chapters 4 and 5 - the focus of inquiry differs. First of all, the difference in the questions concerns the nature of the process under investigation. Whereas in Chapter 3 I look into the process of policy adoption, chapters 4 and 5 address implementation, i.e. the processes starting after adoption of the policy. As O'Toole (2000, p. 266) has defined it, "policy implementation is what develops between the establishment of an apparent intention on the part of government to do something, or to stop doing something, and the ultimate impact in the world of action." The intention in our case is the adoption of the EITI by a government; and the implementation starts once a government has initiated the set-up for governing the EITI. Secondly, there is a difference in analytical focus. The primary interest in Chapter 3 pertains to the explanatory factors - the conditions for policy adoption. The fourth chapter is 
concerned specifically with the dependent variable - differences in the implementation activities, treated in static terms, at one point in time. In Chapter 5, the first question focuses on the dependent variable-differences in the implementation activities over time, whereas the second question zooms in on the explanatory factors - the configuration of the stakeholder positions impacting implementation activities. By constructing the research design in this way, I aim to explore the mechanisms of the EITI's functioning, starting with the broader dynamics occurring at the state level of analysis, and progressively zooming in on research puzzles emerging at the group-level of analysis (MSGs of the selected cases).

\subsection{Rational Actor Framework Applied to the Empirical Questions of the PhD Project}

Methodological choices and specific theoretical frameworks put aside, when the analytical lens of theory-building is considered, there are at least two distinct lines of reasoning which have been employed by researchers to explain why policy changes. One of the traditional approaches to studying policy change is a rational actor model, the central assumption of which is the idea that governments (or other actors the analysis focuses on) make cost-benefit calculations prior to adoption of policies. This model assumes the actors involved in the decision-making to be strategic utility-maximizers operating in an environment with its constraints and incentives. The current practices in natural resource management can be viewed as a status quo, the "domestic equilibrium," which reflects the distribution of preferences and bargaining power in a society. With the appearance of the EITI as a voluntary standard, this domestic balance is presented with additional constraints and incentives, which may disrupt the status quo and lead to the adoption of the new policy. These additional external incentives may be of various nature. For instance, scholars focusing on coercion mechanisms would be interested in the 
involvement of other bilateral or international partners who have the power to threaten use of sanctions or promise aid for implementation. Scholars investigating economic competition would be more likely to emphasize such external incentives as the attraction of investment or lowering cost of doing business (Dobbin, Simmons, \& Garrett, 2007). The main hypothesis following from the rational actor model is grounded in the logic of cost-benefit analysis: a state adopts a policy if the benefits of policy rewards exceed domestic implementation costs. It thus attributes most importance to preferences and configurations of involved interests, which determine the outcome in line with the cost-benefit reasoning of rational actor models.

The constructivist school of thought focuses much more on the role of beliefs, identities, and social norms; hence, constructivists emphasize that governments are driven not only by strategic calculations. Rather, the starting point for constructivists is the focus on how interests are rooted both in specific constructed identities and beliefs about the state of the world and how social action may - under certain circumstances - follow a logic of appropriateness instead of strategic bargaining and utility maximization (Checkel, 2001; Dobbin et al., 2007). According to this logic, a government could adopt the EITI because of being persuaded about its merits. When considering the question of implementation, constructivists would argue that the discussion within the MSG is used as a socialization tool, through which a common consensus on the type of implementation is reached. Particularly important for constructivists is a focus on policy change as a result of being convinced that it is the right and appropriate thing to do in the given context. According to this approach, new policies are adopted or old policies are changed once the newly introduced ideas become internalized with already existent beliefs and values (for accounts of both rational and constructivist approaches, see Checkel, 2001; Dobbin et al., 2007; Jupille, Caporaso, \& Checkel, 2003; Schimmelfennig \& Sedelmeier, 2002; Walsh, 2000; 
for accounts of social learning - Hall, 1993; Johnston, 2008; Meijerink, 2005; for a debate between rationalists and constructivists, see Checkel \& Moravcsik, 2001).

Both rational actor and constructivist logic could be applied to make a possible case for why the EITI is adopted in the first place and why it is implemented differently. According to the basic argument of the rational actor model, governments would, first, adopt the policy based on strategic cost-benefit calculations, and second, once implementation starts, the outcome would differ based on the interests, positions, and strategies of the three stakeholder constituencies participating in the national stakeholder committees. In the reasoning of the constructivist account, the story would be different: governments would adopt the EITI, and MSGs would implement it extensively because they were socialized into believing in the appropriateness of transparent policies. In practice it is not so straightforward to determine whether a decision was motivated by rationally calculated cost-benefit considerations or whether it was an outcome of socialization processes. This ambiguity stems from the inherent methodological difficulty of distinguishing motivation types. Even if states (or MSGs in the case of subsequent implementation processes) act in line with normative arguments and logic of appropriateness, it does not necessarily mean that socialization explains the outcome. In other words, variation in the actor preferences, together with correlation to the norms (in our case, increased transparency) does not mean that the constructivist socialization account is causal for explaining the policy outcomes. Decisions to adopt and implement the standard can still be taken based on rational calculations, and the decision-making actors may choose to conform to the norms of appropriateness out of rational calculations of cost and benefit (Schimmelfennig, 2000). The preferences of the actors involved, thus, may change in favor of increased transparency independently of socialization processes (for instance, due to changed external factors impacting cost and benefit calculations).

The choice of the rationalist theoretical framework in this study is explained by the nature of the research questions posed and the data used. Chapters 
3 and 4, using a large-N design, are concerned with the variation at the country level. In Chapter 5, zooming in on two countries, I focus on the type of implementation activities over time, as well as the configuration of stakeholder positions at the MSG level, without disentangling the formation of preferences within each constituency. Thus, the research design needed in order to answer the posed questions makes it appropriate to treat preferences as fixed, in which case rational actor models are logical to start with. The remaining part of this chapter addresses the research questions posed and elaborates on the applications of the rationalist framework in each of the empirical chapters.

\subsubsection{Why countries adopt new policies}

The way the question in Chapter 3 is constructed - which internal and external characteristics increase the likelihood of EITI adoption - leaves room for explanatory variables considering country characteristics, as well as factors of external influence. The aim of the chapter is to identify the mix of characteristics increasing the likelihood of the adoption vis-à-vis non-adopters. This concern drives the choice of methodology as a large-N quantitative analysis, which means that in Chapter 3 the country is treated as the unit of analysis, and non-adopters as well as adopters are considered. Theories on determinants of policy adoption are well-developed in the literature on innovation and policy adoptions by firms, as well as policy adoptions by regions, US states in particular (Miller, 2004, p. 37; Walker, 1969). Theorizing the adoption of regulatory instruments falling within the scope of global governance arrangements so far has been less developed.

Therefore, in construction of the appropriate model for Chapter 3, this study draws on a number of different theories. 


\subsubsection{How do implementation activities differ between the EITI-implementing countries, and why?}

When the comparative element is added to the study of policy implementation, the issues researchers focus on pertain to two major questions - how and why policies differ across institutional settings (Gupta, 2012). Both quantitative and qualitative comparative studies work with these questions, conceptualizing and operationalizing the variables of interest quite differently. For instance, in quantitative studies the dependent variable can be an interval-level measure of political output (expenditures being an oft-used measure), policy-specific index or policy indicator, or categorical variable on policy presence or change. Qualitative studies, on the other hand, focus on the specifics of policy content, which is also the focus of the question posed in Chapter 4. The "how different" question in this study is approached by constructing an index of implementation activities which differs across dimensions.

Disaggregation of reporting as a feature of extensive implementation is reasoned to be of critical importance among these dimensions. Investigating the differences in this particular dimension, I test theoretical explanations for extensive implementation empirically. From the literature attempting to explain crosscountry policy differences, it is seen that the type of explanations often differs, again depending on whether the research is designed as a large- $\mathrm{N}$ or small-N study and hence, whether it is a quantitative or qualitative study. The explanations on why there are differences in policy outputs and outcomes focus on socioeconomic and sociopolitical characteristics that impact processes within the political system (Miller, 2004; Brunetti, 2002; Easton, 1965). In Chapter 4, taking into account all EITI countries, I assess the influence of such conditions on the extent of implementation activities in disaggregation of reporting, one of the dimensions of the implementation activities. Similarly to Chapter 3, the unit of analysis continues to be country, though only EITI implementers are considered in this chapter. Additionally, the analysis helps the selection of most interesting country cases for 
Chapter 5 in order to study detailed processes within the black box of the political system.

\subsubsection{How does the configuration of stakeholder positions at the MSGs impact the implementation activities?}

When considering what happens after the policy is adopted, i.e. once implementation starts, one of the key questions in the literature undoubtedly remains to be the question of how positions of different actors involved in policy implementation impact policy outcomes. This question helps to uncover processes within the "black box" of the political system that are taken as given in quantitative studies. The case countries selected for Chapter 5 are Azerbaijan and Kazakhstan. Both countries belong to the group of critical case countries, as identified in Chapter 4 - authoritarian EITI countries, implementing the initiative in the oil and gas sector, which are less likely to implement the initiative with extensive practices of disaggregation. Asking the question on how the configuration of stakeholder positions in the MSGs impacts the implementation activities in the case countries, allows me to formulate and test specific hypotheses on the influence of actors within the political system.

A major difference between the research questions asked in chapters 3 and 4 in comparison to Chapter 5 is the relaxation of the unitary actor assumption, which is 'the country as a sole decision-maker' in chapters 3 and 4, but 'the MSG - the national stakeholder group as a decision-maker" in Chapter 5. According to the unitary actor assumption, the dependent variables of policy adoption (Chapter 3 ) and extensiveness of the implementation activities (Chapter 4) were constructed as outcomes of the national government's decision (Chapter 3) and of the MSG's decision (Chapter 4). In Chapter 5 this assumption is relaxed, making it possible to consider policy implementation as an outcome of intra-MSG negotiation between different groups of actors. When the state is thought of as a complex organization, where implementation processes depend on the interplays of different groups of 
actors involved, more attention needs to be paid to the particular positions of these actors which affect the national implementation process. In the case of the EITI, the actors are government, companies, and civil society, all of which participate as represented constituencies in the MSG, the national committee overseeing implementation of the EITI. It is logical to expect the EITI implementation process to be the outcome of negotiations between the stakeholders, all of which may have different preferences, beliefs, and agendas.

There is a general argument in the literature that in most cases drastic policy change is unlikely and it is the status quo that prevails, with only possible windows of opportunities for incremental changes (Lindblom, 1959). Practice shows that quite often policy changes suggested by certain groups of actors are blocked by veto players - "collective actors which need to agree for a change of the status quo" (Tsebelis, 2000). In the case of the EITI, these collective actors can be thought of as three different groups of stakeholders, which have a power to block the joint decision of the multi-stakeholder group. The number of veto players within the multi-stakeholder group is held constant as a feature of the EITI's institutional set-up. These stakeholders act on the behalf of a larger constituency which they represent (government, companies, or civil society). If any of the three parties disagrees on the change proposed by the other stakeholder constituencies, policy stability prevails, and the status quo is un-disrupted. Large ideological distance between positions of the government, companies and civil society thus leads to higher probability of policy stability, with only incremental changes possible. The link between large divergence in preferences and its negative impact on the likelihood of policy change has been studied in different contexts, but particularly prominent are studies on the legislative decision-making within the EU (Golub, 2007; König \& Pöter, 2001; Selck \& Steunenberg, 2004; Tsebelis \& Garett, 2000).

The set-up of the EITI - unchanging number of stakeholder constituencies during the implementation process - permits to focus on the configuration of 
stakeholder positions impacting the implementation activities. Thus, to investigate whether and how configuration of national stakeholder positions impacts the implementation activities in the selected critical case countries, the positions of the stakeholder constituencies can be theorized from the existing literature. Specific expectations on positions of governments, companies and civil society are constructed in Chapter 5. By providing a detailed process tracing-study of the two cases, I will go beyond considering the stakeholder positions taken at one point in time and will rather look at the configuration of constituency positions over time.

\subsection{Conclusion}

This chapter served as a theoretical guide for analyzing the questions posed in the project. In section 2.2, I have reviewed the existing studies on the EITI in the literature, outlining the type of questions which have been asked so far and making the case for further need to study the EITI's functioning, in line with the research agenda of second generation of global governance theorists. The considerations behind the choice not to focus on the impact variables were elaborated. Section 2.3 specified how the dependent variables of the research questions for each of the forthcoming empirical chapters are conceptualized. Two main lines of reasoning in the literature - the rationalist, and the constructivist approach - were discussed in section 2.4. Having made the choice of the rational actor framework in this $\mathrm{PhD}$ project explicit, I further addressed the differences in the application of the rationalist approach in each of the empirical chapters, though reserving more detailed theoretical discussions for the forthcoming chapters.

In particular, the first question posed - why countries adopt the EITI - puts the focus on the domestic country characteristics and external international factors that may motivate countries to adopt an initiative which limits some of their sovereign powers, as well as disrupts the status quo potentially quite convenient for certain elites (Chapter 3). This question is also relevant as it explores why some resource-abundant countries that could also profit from adoption of the EITI have 
so far not adopted the initiative. The second question - how and why EITI implementation activities differ across countries - focuses on the differences between countries in terms of the extensiveness of their implementation activities. Such differences are a corollary of the voluntary dimension of the EITI governance mechanism. A key interest is to find out what factors determine the likelihood of disaggregated reporting practices, a dimension of implementation that will be shown in Chapter 4 to be of preeminent importance for the EITI success. Thirdly, this study aims to examine the role of specific stakeholder constituencies at the domestic level in two countries that are identified as critical cases in Chapter 4. More specifically, I probe the question of how the configurations of stakeholder positions impact implementation activities in the critical case countries (Chapter 5). By exploring these questions on the role and influence of the stakeholders in the decision-making at the national level, I ultimately target the issue of how the global governance mechanism instilled by the EITI impacts decision-making in the natural resource management, which from the moment of EITI adoption is no longer the sole prerogative of state actors. 


\section{Chapter 3: Why Adopt? Determinants of Country Decisions to Initiate EITI Candidacy}

Summary: To study the determinants of policy adoption, some scholars focus on internal country characteristics, whereas others focus on the factors of external influence. This chapter, taking into account factors from both approaches, aims to answer what mix of factors influences a country's decision to adopt the EITI as a candidate. The data used is compiled from a variety of sources which, together, make a unique dataset. According to the findings, low income, resource abundance, ethnic fractionalization, and recent change of polity toward democratization increase the likelihood of EITI candidacy. For the EITI as a regulatory instrument this means that the countries with a long track of stable government, be it democratic or authoritarian, as well as high GDP levels, are less likely to adopt the standard, though they could potentially benefit from the initiative.

\subsection{Introduction}

When the EITI was launched at the First EITI Plenary Conference in London on June 17, 2003, the initiative was adopted by the first pilot participants. Today the EITI is a well-known and a well-established standard, with twenty-four candidate countries, eleven compliant countries, and three countries working toward candidacy (as of April 2011). ${ }^{18}$

This chapter focuses on the question of what internal (domestic) and external (international) factors influence the decision to adopt the EITI as a candidate country. On the one hand, this question is relevant for studies of policy adoption processes, and particularly the adoption of instruments falling within the

\footnotetext{
${ }^{18}$ EITI compliant countries are Azerbaijan, Central African Republic, Ghana, Kyrgyz Republic, Liberia, Mongolia, Niger, Nigeria, Norway, Timor-Leste, and Yemen. EITI candidate countries include Afghanistan, Albania, Burkina Faso, Cameroon, Chad, Côte d'Ivoire, Democratic Republic of Congo, Gabon, Guatemala, Guinea, Indonesia, Iraq, Kazakhstan, Madagascar, Mali, Mauritania, Mozambique, Peru, Republic of the Congo, Sierra Leone, Tanzania, Togo, Trinidad and Tobago, and Zambia. Ethiopia, Guyana and Ukraine have expressed an interest to adopt the standard, but have not achieved a candidate status yet. Equatorial Guinea and Sao Tome and Principe are de-listed from candidates as they have not met the validation deadline.
} 
scope of global governance arrangements. Unlike policy adoption by firms or by regions, adoption of global governance regulation by countries still needs to be theorized, given the recent development of such regulatory initiatives. On the other hand, knowledge of factors associated with the increased likelihood of EITI adoption reveals useful insights for the EITI as an instrument of global governance. By probing which type of countries are drawn to the EITI, the chapter aims to gain insights on whether the initiative's design indeed attracts the resource-rich countries for the benefit of which the EITI project was initially launched.

The chapter is organized as follows. In section 3.2, I discuss the diffusion of the EITI which has occurred since the initiative's establishment in 2003. Specifically, I address the progress of the EITI in attracting new countries to adopt the standard and the progress countries have shown in qualifying for compliance status. In section 3.3, I theorize the factors influencing the decision to adopt the EITI. Data, methodology and the model are discussed in section 3.4. The results are presented in section 3.5, and the discussion concludes the chapter.

\subsection{EITI Adoption across Countries}

When looking at the development of the EITI, it is clear that the initiative has managed to attract quite a large number of countries. Figure 3.1 illustrates the adoption of the EITI over time, with an accompanying list of countries participating ${ }^{19}$ in the EITI and the respective years of candidacies. It should be noted that for countries which have adopted the EITI in the years preceding the official establishment of rules guiding candidacy and compliance procedure, the candidacy dates are more of an approximation, constructed on the basis of varying

\footnotetext{
${ }^{19}$ The particular status of EITI-participating countries may differ (candidate, compliant, suspended, or de-listed), and the figure does not track the changing country status over time, noting only years of EITI adoption. For the details on the dates of initiating steps toward implementation (situation prior to 2009 when candidacy status did not yet exist as part of the EITI rules) and candidacy, as well as achievement of compliance, consult the codebook in Annex III (pp.2-9) which reports the data in the table format together with the sources from which the dates were obtained.
} 
national sources (for details on the sources of data for the years of adoption, consult Annex III, variable year).

\section{Figure 3.1 EITI Adoption over Time Mapped}

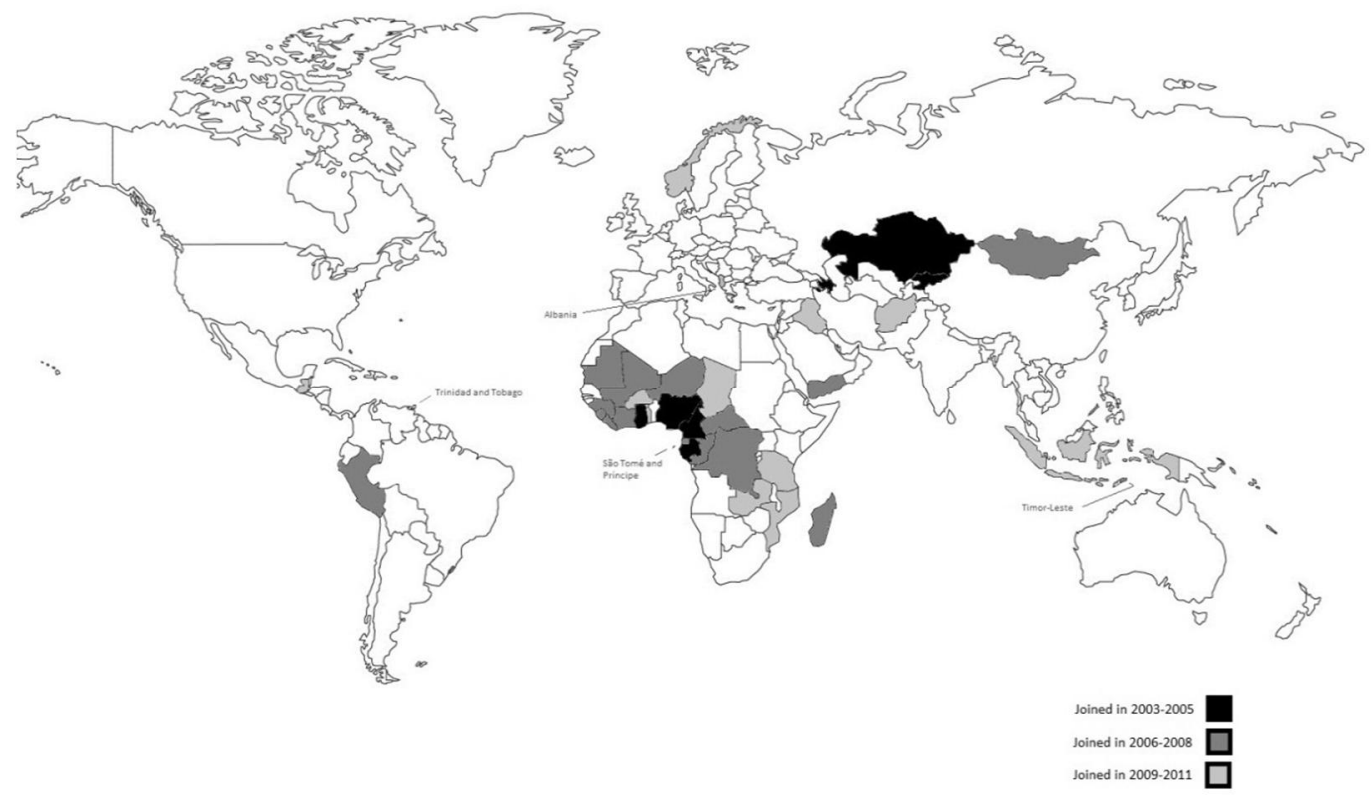

\begin{tabular}{|lllll|}
\hline Afghanistan & 2010 & Kyrgyzstan & 2004 & Zambia 2009 \\
Albania & 2009 & Liberia & 2007 & \\
Azerbaijan & 2003 & Madagascar & 2008 & \\
Burkina Faso & 2009 & Mali & 2007 & \\
Cameroon & 2005 & Mauritania & 2007 & \\
Central African Republic & 2008 & Mongolia & 2007 & \\
Chad & 2010 & Mozambique & 2009 & \\
Congo, Dem. Rep. & 2008 & Niger & 2007 & \\
Congo, Rep. & 2008 & Nigeria & 2003 & \\
Cote d'Ivoire & 2008 & Norway & 2009 & \\
Equatorial Guinea ${ }^{20}$ & 2007 & Peru & 2007 & \\
Gabon & 2005 & Sao Tome and Principe ${ }^{21}$ & 2008 & \\
Ghana & 2003 & Sierra Leone & 2008 & \\
Guatemala & 2011 & Tanzania & 2009 & \\
Guinea & 2007 & Timor-Leste & 2008 & \\
Indonesia & 2010 & Togo & 2010 & \\
Iraq & 2010 & Trinidad and Tobago & 2011 & \\
Kazakhstan & 2005 & Yemen, Rep. & 2007 & \\
\hline
\end{tabular}

Source: own compilation of EITI candidacies from country-by-country sources (Annex III).

${ }^{20}$ The country was later de-listed as a result of being unable to pass validation.

${ }^{21}$ The country was later de-listed as a result of being unable to pass validation. 
As seen in Figure 3.2, from 2003 until 2011 the EITI has steadily attracted new countries which adopted the standard. While between 2003 and 2005 there were only a few candidacies per year, in 2007-2008 an increase in the yearly number of candidate countries can be observed. In 2010 and 2011, the number of newly joined candidates has again decreased.

\section{Figure 3.2 EITI Participants over Time}

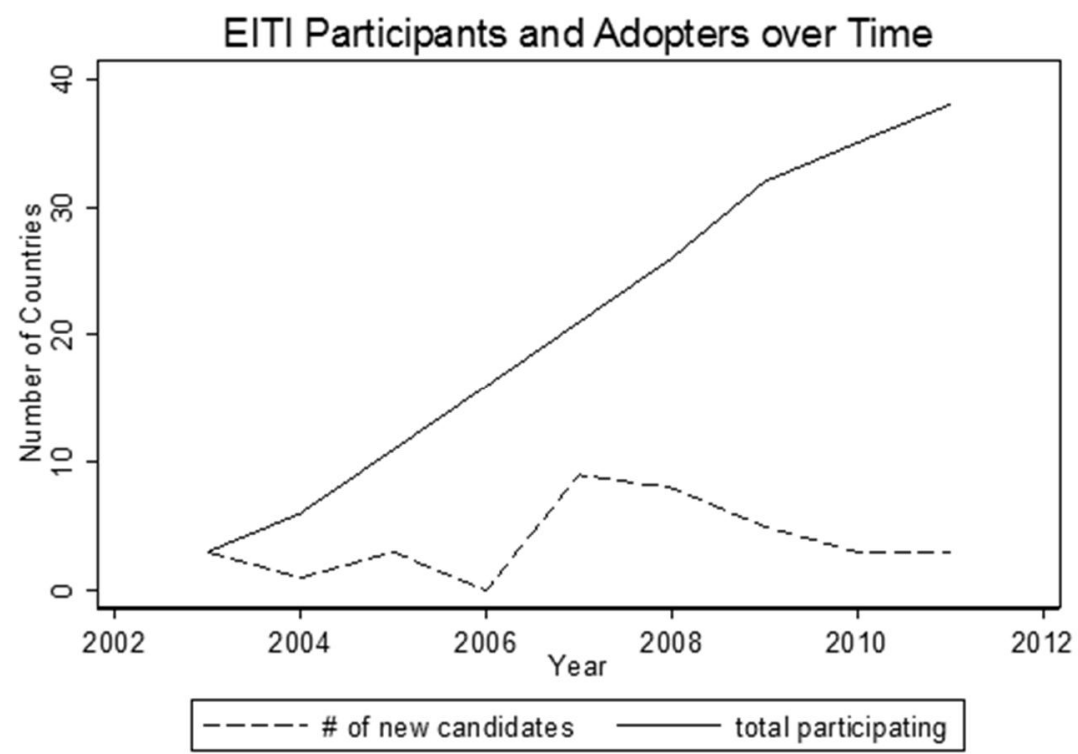

Source: own compilation from country-by-country sources on the year of EITI Candidacy, available in Annex III.

Though the number of new candidates per year has been decreasing, the EITI was able to make progress in the countries which already joined as candidates. From Table 3.1 it can be seen that among the candidate countries the progress in developing the EITI has been steady, resulting in qualification of compliance - a status granted by the EITI Board on the recommendation of the EITI International Secretariat after validation of a meaningful EITI process in the country involved. From 2009 onwards, countries start achieving the status of 
compliant with the EITI, and by 2011 ten countries have achieved the compliant status. As this table also shows, there was a peak of activity in preparation for candidacy in 2006 (steps toward implementation). This peak is consistent with the increase of candidacies in 2007 and 2008 which can be observed both in Table 3.1 and Figure 3.2.

Table 3.1 Implementation Progress

\begin{tabular}{|c|c|c|c|c|c|c|c|c|c|}
\hline Participation Status & 2003 & 2004 & 2005 & 2006 & 2007 & 2008 & 2009 & 2010 & 2011 \\
\hline \multicolumn{10}{|l|}{ Steps Toward } \\
\hline Implementation & 0 & 2 & 4 & 9 & 5 & 2 & 3 & 3 & 3 \\
\hline Candidate & 3 & 4 & 7 & 7 & 16 & 24 & 27 & 27 & 25 \\
\hline Compliant & 0 & 0 & 0 & 0 & 0 & 0 & 2 & 5 & 10 \\
\hline \multicolumn{10}{|l|}{ Total Participating } \\
\hline Countries & 3 & 6 & 11 & 16 & 21 & 26 & 32 & 35 & 38 \\
\hline \multicolumn{10}{|c|}{$\begin{array}{l}\text { Source: own compilation from country-by-country sources on the Year of EITI Candidacy, available } \\
\text { in Annex III. }\end{array}$} \\
\hline \multirow{2}{*}{\multicolumn{10}{|c|}{$\begin{array}{l}\text { Having shown the progress achieved by the EITI in attracting participating } \\
\text { countries, as well as bringing several participant countries from "candidate" to }\end{array}$}} \\
\hline & & & & & & & & & \\
\hline \multicolumn{10}{|c|}{ "compliant" status, the chapter continues to theorize the factors influencing the } \\
\hline
\end{tabular}

\subsection{Theorizing Determinants of EITI Adoption}

Large-N studies considering the question of why new policies are adopted differ with respect to the unit of analysis under examination - firms, cities, regions, or countries. Many studies considering discrete policy adoption are carried out at the firm level. At the regional level, much work has traditionally been done on policy adoption in the US states (Walker, 1969). Miller notes that most of the political science research on policy adoptions still focuses on the American states (2004, p.37), probably due to data availability. There are few studies, however, that focus on discrete policy adoptions at the country level, and there is practically a void of 
such literature considering voluntary transnational and global initiatives. Partly, this is due to the recent emergence of such regulatory instruments. In addition, there are issues of data availability: for anyone carrying out such a study, the data collection effort is challenging, since the new empirical terrain often requires building a unique dataset. Furthermore, there are no ready theoretical models that can be applied, and theorizing adoption of global regulatory instruments at the country level is currently in its infant stages of development. For the case of the EITI there is only one study which has looked into domestic political and socioeconomic factors that are contributing to the decision to adopt the EITI (Pitlik et al., 2010). Testing several specifications of the model, Pitlik et al. (2010) find differing results on the effects of the hypothesized relationships. Clear evidence is present for the effect of resource abundance and low income. Depending on the model specification, ethnic fractionalization, and OPEC membership have an effect. Depending on the variable operationalization and model specification, the level of democratic freedoms matters. In this chapter section, based on different literatures I develop theoretical arguments for the inclusion of factors in the model considered. In addition to the factors considered by Pitlik et al. (2010), I include variables on polity change and influence by external actors. Furthermore, the dataset used by Pitlik et al. (2010) did not contain information on post-2009 EITI candidacies, which are included in this study. ${ }^{22}$

\subsubsection{Domestic characteristics}

The cluster of domestic variables reflects country characteristics that may increase the likelihood of EITI adoption. The first factor to consider is resource abundance. As the detailed literature review in Chapter 1 disclosed, countries in which revenues from natural resources constitute a large share of the budget are at risk of suffering from the resource curse. They may be adopting the EITI as an instrument

\footnotetext{
22 The dataset used in this dissertation was updated in April 2011; post-March 2011 candidacies are not included.
} 
of battling the resource curse symptoms or improving their reputation - global and domestic - in the governance of the extractive sector. Regardless of these specific motivations, I hypothesize that

H1 Resource abundance is associated with the increased likelihood of EITI adoption.

The EITI also has a particular focus on transparency, which means that countries suffering from corruption would be most likely to benefit from the adoption of the initiative. At the same time though, corrupt countries may be caught in a resource trap, which in turn makes them less likely to initiate transparency-focused reforms in the extractive sectors. Because EITI candidacy by itself does not necessitate genuine reform and EITI implementation can take different forms (some more extensive than others), I hypothesize that countries with higher levels of corruption are more likely to adopt the EITI, be it from a desire for genuine reform in the sector, or for reasons of window-dressing and hopes of improving their perceived reputation.

H2 Higher levels of corruption are associated with the increased likelihood of EITI adoption.

If a country prior to the establishment of the EITI in 2003 had a track of low GDP per capita, it would also be more likely to adopt the EITI as a possible means to maximize revenue inflows and increase investments into the country. The key idea here is the notion that lower income countries have a higher return on their investment into the EITI commitment than countries that are already doing well in the areas that the EITI promises to contribute to. The adoption of the initiative can be viewed as a signaling mechanism to show that the country is serious about implementing reforms (Biglaiser \& Brown, 2005, p.675). Similar to the logic outlined above, two types of motivations may co-exist: countries may genuinely want to increase transparency of the process in order to attract companies, or simply improve their perceived reputation reflected in credit rankings. 
H3 Lower GDP per capita is associated with the increased likelihood of EITI adoption.

In the sphere of domestic political factors, I consider polity and change of polity prior to candidacy. Many have argued that institutional environments and preferences of groups in power influence decisions about policy adoptions (North, 1990), and that political leaders in authoritarian regimes have more incentives to block the introduction of innovation policies (Acemoglu \& Robinson, 2000, 2006; Biglaiser \& Danis, 2002; Milner, 2006). Leaders in authoritarian regimes have longer time horizons in terms of their political survival and may be less sensitive to potential economic problems, which would require adoption of new policies and interventions (Bueno de Mesquita \& Siverson, 1995; Milner, 2006). Authoritarian regimes may be less likely to adopt a new policy because they are less constrained by their respective electorates than democracies and can more easily ignore societal complaints on corruption practices. As a result, it may be harder for domestic interest groups concerned with the EITI adoption to pressure authoritarian governments to initiate policy change. This can be especially true for a sensitive sector such as natural resource management, where the welfare and power costs for stakeholders are especially high. Because EITI implementation can provide civil society with detailed information on revenue collection and potentially missing revenue streams in the budget, the EITI process may create grievances, which would be threatening to ruling groups in authoritarian regimes. Consequently, groups that are benefitting from the lack of transparency may resist introduction of the EITI reporting system as it would change the status quo practices. Thus, I hypothesize that a lower level of authoritarianism is associated with the increased likelihood of EITI candidacy.

H4 A lower level of authoritarianism is associated with the increased likelihood of EITI adoption.

At the same time there is a possibility that a major change in polity may catalyze reforms, particularly the decision to adopt the initiative. This logic is 
present in one of the hypotheses on policy change tested by Biglaiser and Brown (2005, p. 674), formulated by them in the following way: "structural reform occurs immediately after a change of government as political leaders have longer time horizons.” Baumgartner, Jones, \& Wilkerson (2011, p.948), as well as Zohlnhöfer (2009) also point out to the government change, which through shifting preferences after electoral replacement leads to policy change. Other literature on government change attempts to determine which particular pathways (age, generation effects, or period effects) lead to change in the preferences of policymakers (De Vries, 2005; de Vries, 1999; Inglehart, 1971; Riley, 1987). This scholarship starts from the same point of departure - the notion that as new people come into a policy field they may bring along different ideas, attitudes and hence, changes in policy. A change of polity potentially leading to EITI adoption is understood here as a change toward democratization, rather than toward authoritarianism; this decision is based on the literature linking authoritarianism with absence of policy change. H5 A lower number of years since the last change in polity toward democratization is associated with the increased likelihood of EITI adoption.

In several model specifications tested by Pitlik et al. (2010), ethnic fractionalization is found to increase the likelihood of EITI adoption. Ethnic heterogeneity has long been associated with political conflicts, as also discussed in section 1.2 (Collier, 2000c; Collier \& Hoeffler, 2005; Easterly, 2001; Hodler, 2006; Morrison, 2011). Thus, the EITI can be adopted by governments in highly fractionalized societies with a motivation to use it as an instrument of control over revenue distribution between different rent-seeking power groups. To test for this effect, also documented by Pitlik et al. (2010), I additionally include a variable on ethnic fractionalization in two of the model specifications.

H6 Higher score in the index on ethnic fractionalization is associated with the increased likelihood of EITI adoption. 


\subsubsection{External influence}

The variables dealing with external influences refer to the pressure or influence external actors have on the countries' decision to adopt the EITI. The link between the influence of international actors and policy adoption has been well studied. Such influences may not only stem from direct conditionality as a leverage mechanism of international institutions (Schimmelfennig \& Scholtz, 2008; Stallings, 1992). More subtle influence may be exerted via socialization strategies by external actors (Dobbin et al., 2007). Since becoming an EITI candidate is a voluntary decision of the country itself, and because the design of the EITI standard does not foresee any direct conditionality mechanisms used by the EITI International Secretariat, indirect mechanisms of influence seem to be more likely. For instance, countries which donate money to the EITI budget may be actively involved in promoting the EITI bilaterally. To test for such possible external influences on the decision to adopt the EITI, I consider 1) participation in projects related to extractive industries that are funded by EITI donor countries, ${ }^{23}$ and 2) former colonial links with the EITI donor countries.

H7 Participation in the extractive sector projects funded by EITI donor countries is associated with the increased likelihood of EITI adoption.

H8 Former colonial links with the EITI donor countries are associated with the increased likelihood of EITI adoption.

Aside from influence through bilateral links, participation in transnational (such as knowledge communities) or transgovernmental (such as linkages to governments in EITI donor countries) networks has been shown to be an influential determinant of policy adoptions (Bach \& Newman, 2010). Promotion of the policy may occur through social networks, via meetings and conferences where information and ideas are shared (Haufler, 2010a, p.57). Because such socialization influences cannot be measured directly, I use participation of a specific country in

\footnotetext{
${ }^{23}$ EITI donor countries are identified as the EITI member countries donating funds to the Multi-trust Donor Fund (MDTF), used for EITI implementation support.
} 
the first conference devoted to the EITI as a proxy for being involved in transnational networks and potentially coming under the influence of socializing forces.

H9 Participation in the first EITI conference is associated with the increased likelihood of EITI adoption.

\subsection{Research Model, Methodology, and Data}

The dependent variable used for this chapter is a binary variable "policy adoption" which shows whether a country has joined the EITI as a candidate during the eightyear period since the EITI's establishment (from June 17, 2003 until March 1, 2011). The decision to count "joined or not" once in an eight-year time period, rather than every year from 2003 until 2011, is driven by the nature of the question. ${ }^{24}$ Statistically, binary outcomes can be studied with nonlinear probability models (Aldrich \& Nelson, 1984; Cramer, 2002; Long \& Freese, 2006, pp.131181 ), and this chapter uses binary logistic regression. To conduct the analysis, a self-compiled cross-sectional dataset is used which uses a number of existing data sources. The sample is worldwide, but due to missing data on some of the variables it is reduced to 151 cross-country observations in the analysis. ${ }^{25}$ Descriptive statistics on the variables are presented in Table 3.2.

\footnotetext{
${ }^{24}$ Furthermore, the information on precise candidacy dates is sometimes difficult to obtain. Countries which adopted the standard in the first years of the process were not officially given the status of candidate because the EITI was a new initiative and extensive guidelines did not exist yet; therefore, their candidacy dates are somewhat vague. The dates used in section 3.2 for the overview of EITI diffusion process are approximated from a number of resources for illustrative purposes.

${ }^{25}$ Due to missing data, the following EITI countries have been excluded from the analysis: Afghanistan, Chad, Republic of Congo, Equatorial Guinea, Sao Tome and Principe, and Timor-Leste, thus reducing the sample of EITI countries in the analysis from 37 to 31.
} 
Table 3.2 Descriptive Statistics

\begin{tabular}{llllll}
\hline Variable & Obs & Mean & Std. Dev. & Min & Max \\
\hline & & & & & \\
country & 191 & 96 & 552.811 & 1 & 191 \\
eiticand & 191 & .1937173 & .3962486 & 0 & 1 \\
first_confer & 191 & .1623037 & .3696982 & 0 & 1 \\
VA & 191 & 4.870 .995 & 2.959 .254 & 0 & 100 \\
OECDEU & 191 & .2041885 & .4041668 & 0 & 1 \\
income & 188 & 2.260 .638 & 1.147 .489 & 1 & 4 \\
res_rich & 191 & .2774869 & .4489355 & 0 & 1 \\
polity & 161 & 3.149 .068 & 6.541 .417 & -10 & 10 \\
form_col & 191 & .6020942 & .4907522 & 0 & 1 \\
donor & 191 & .1570681 & .3648212 & 0 & 1 \\
polity_change & 161 & 1.435 .404 & 7.743 .069 & 1 & 23 \\
corr_wgi & 187 & -.0608556 & 100.409 & -1.75 & 2.46 \\
expdep & 174 & .2251103 & .2896594 & 0 & .9840927 \\
ethnicfrac & 186 & .4418876 & .256677 & 0 & .930175 \\
& & & & & \\
\hline
\end{tabular}

Source: data used in the analysis.

The explanatory variables include a set of variables measuring domestic country characteristics and external influence factors. The specified model makes it possible to explore the structural factors that differentiate the candidates from other countries, thus analyzing which mix of characteristics increases the likelihood of participation in the EITI in the first eight years of the EITI's existence as an initiative.

Table 3.3 and the subsequent discussion present a summary of the variables' construction and the sources from which they were obtained. More detailed information is available in the codebook (Annex III) and table 3.3. In line with the discussion above, the explanatory variables are separated into two categories, according to the theoretical model tested - the variables reflecting domestic characteristics of the participating countries, and variables of external influence. Self-constructed variables include candidacy, donor influence, change of polity toward democratization, dependence on the exports of natural resources, participation in the first EITI conference, and a dummy on colonial heritage. As 
most of the oil- and mineral-exporting countries are located in the non-Western

world, a dummy variable for $\mathrm{OECD/EU}$ membership is added as a control variable.

Table 3.3 Description of Variables

\begin{tabular}{|c|c|c|c|}
\hline Variable & Label & Units & Source \\
\hline EITI candidacy & Eiticand & $\begin{array}{l}\text { Binary: Did a country adopt the } \\
\text { EITI in the eight-year period from } \\
\text { June } 2003 \text { until March } 2011 ?\end{array}$ & Constructed \\
\hline \multicolumn{4}{|c|}{ Internal Characteristics } \\
\hline $\begin{array}{l}\text { Resource } \\
\text { abundance }\end{array}$ & $\begin{array}{l}\text { res_rich } \\
\text { (resource } \\
\text { abundance) }\end{array}$ & $\begin{array}{l}\text { Binary: Is a country considered } \\
\text { resource-rich? }\end{array}$ & $\begin{array}{l}\text { IMF (2002) and } \\
\text { update, available in } \\
\text { Annex II }\end{array}$ \\
\hline $\begin{array}{l}\text { Dependence on } \\
\text { the exports of } \\
\text { natural resources }\end{array}$ & $\begin{array}{l}\text { exp_dep } \\
\text { (resource } \\
\text { abundance) }\end{array}$ & $\begin{array}{l}\text { Exports of fuel and mining products } \\
\text { divided by total exports; for the year } \\
\text { of } 2002 \text { (in cases of missing data, } \\
\text { for the most recent available year) }\end{array}$ & Constructed \\
\hline $\begin{array}{l}\text { Control of } \\
\text { corruption }\end{array}$ & corr_wgi & Index; for the year of 2002 & $\begin{array}{l}\text { World Bank } \\
\text { Governance Indicators; } \\
\text { control of corruption }\end{array}$ \\
\hline Income level & Income & $\begin{array}{l}\text { Categorical: } 1=\text { low income, } 2=\text { lower } \\
\text { middle income, } 3=\text { upper middle } \\
\text { income, } 4=\text { high income; for the } \\
\text { year of } 2002\end{array}$ & $\begin{array}{l}\text { World Bank's country } \\
\text { income classifications }\end{array}$ \\
\hline Regime & $\begin{array}{l}\text { Regime } \\
\text { (polity) }\end{array}$ & Index; for the year of 2002 & $\begin{array}{l}\text { Polity2 figure from } \\
\text { POLITY IV }\end{array}$ \\
\hline $\begin{array}{l}\text { Voice and } \\
\text { Accountability }\end{array}$ & VA (polity) & Rank; for the year of 2002 & $\begin{array}{l}\text { World Bank } \\
\text { Governance Indicators; } \\
\text { voice and } \\
\text { accountability }\end{array}$ \\
\hline $\begin{array}{l}\text { Change of polity } \\
\text { toward } \\
\text { democratization }\end{array}$ & polity_change & $\begin{array}{l}\text { number of years since the last zero } \\
\text { in "durable" from Polity IV } \\
\text { corresponding to polity } 2 \text { positive } \\
\text { score change (counting starts at } \\
2002 \text { and goes backwards until } 1980 \\
\text { included) }\end{array}$ & $\begin{array}{l}\text { Constructed from } \\
\text { "durable" in POLITY } \\
\text { IV }\end{array}$ \\
\hline $\begin{array}{l}\text { Ethnic } \\
\text { fractionalization }\end{array}$ & Ethnicfrac & Index from 0 to 1 & Alesina et al. (2003) \\
\hline
\end{tabular}


Table 3.3 Description of Variables (Cont'd)

\begin{tabular}{|c|c|c|c|}
\hline Variable & Label & Units & Source \\
\hline \multicolumn{4}{|c|}{ External Influence } \\
\hline Donor influence & Donor & $\begin{array}{l}\text { Binary: Did a country have a project } \\
\text { in extractive industries funded by } \\
\text { one of the countries-donors to the } \\
\text { EITI Multi-Trust Donor Fund } \\
\text { (MDTF) prior to candidacy (in cases } \\
\text { of no candidacy, prior to 2011)? } \\
\text { (hydrocarbons, mineral, forestry } \\
\text { projects) }\end{array}$ & Constructed \\
\hline $\begin{array}{l}\text { Participation in } \\
\text { the first EITI } \\
\text { conference }\end{array}$ & first_conf & $\begin{array}{l}\text { Binary: Did a country participate in } \\
\text { the First EITI London Conference in } \\
2003 \text { ? }\end{array}$ & Constructed \\
\hline Colonial heritage & form_col & $\begin{array}{l}\text { Binary: Was a country non-settler } \\
\text { colony of one of the EITI donor } \\
\text { countries? (colonies of Portugal, } \\
\text { which is not a donor to the MTDF, } \\
\text { are excluded) }\end{array}$ & Constructed \\
\hline \multicolumn{4}{|l|}{ Controls } \\
\hline $\begin{array}{l}\text { OECD and/or EU } \\
\text { membership }\end{array}$ & OECDEU & $\begin{array}{l}\text { Binary: Is a country member of the } \\
\text { EU and/or OECD? }\end{array}$ & $\begin{array}{l}\text { OECD/EU } \\
\text { membership }\end{array}$ \\
\hline
\end{tabular}

Source: own data compilation, details available in Annex III.

Resource abundance is measured in two different ways to check for robustness - as a binary variable based on the IMF's classification and as a continuous export dependence variable. Corruption is measured by "control of corruption" from the Worldwide Governance Indicators (WGI). To measure the economic level of the countries, I use the World Bank's categorical classification of income. Level of democratic freedoms is measured by Polity index for 2002 and by "voice and accountability" from WGI as a check for robustness of the results. Ethnic fractionalization index comes from the dataset constructed by Alesina, Devleeschauwer, Easterly, Kurlat, \& Wacziarg (2003). To measure recent change in polity toward democratization, I construct a variable based on "polity2" and "durable" variables in Polity data. 
External influence via bilateral links is measured by involvement in the extractive projects led by bilateral partner countries, which are also donating money to the EITI Multi-donor Trust Fund (MDTF). The variable is selfconstructed on the basis of information provided in the websites of agencies which are donors to partner countries, as well as donors to the EITI's MDTF. A variable on participation in the first EITI conference is constructed on the basis of participation list provided by DFID sources. To control for possible influence through historical or economic linkages with the EITI donor countries, a variable on colonial heritage is included - whether a country has had colonial history with current EITI donor countries. Finally, OECD/EU membership is controlled for.

When not noted otherwise, the data for explanatory variables are for the year 2002, one year prior to the EITI's official launch. The focus on 2002, a oneyear observation, is a safe choice: the indicators chosen for measuring explanatory variables are not prone to large fluctuation from year to year. Polity change and donor influence are measured differently; details are specified in Table 3.3.

\subsection{Results}

The results of the binary logistic regression on the factors influencing the likelihood of countries joining as candidates are reported in Table 3.4 below. 
Table 3.4 Determinants of EITI Adoption

\begin{tabular}{|c|c|c|c|c|c|c|}
\hline VARIABLES & (1) & (2) & (3) & (4) & (5) & (6) \\
\hline res_rich & $\begin{array}{c}2.051 * * * \\
(0.000527)\end{array}$ & $\begin{array}{c}2.099 * * * \\
(0.000470)\end{array}$ & & & $\begin{array}{l}1.830 * * * \\
(0.00273)\end{array}$ & \\
\hline income & $\begin{array}{c}-1.001 * * \\
(0.0477)\end{array}$ & $\begin{array}{c}-1.049 * * \\
(0.0414)\end{array}$ & $\begin{array}{c}-1.098 * * \\
(0.0355)\end{array}$ & $\begin{array}{c}-1.025 * * \\
(0.0444)\end{array}$ & $\begin{array}{l}-0.912 * \\
(0.0695)\end{array}$ & $\begin{array}{c}-0.919 * \\
(0.0769)\end{array}$ \\
\hline donor & $\begin{array}{c}0.920 \\
(0.111)\end{array}$ & $\begin{array}{c}0.919 \\
(0.112)\end{array}$ & $\begin{array}{c}1.022 * \\
(0.0989)\end{array}$ & $\begin{array}{c}1.026^{*} \\
(0.0969)\end{array}$ & $\begin{array}{c}0.754 \\
(0.215)\end{array}$ & $\begin{array}{c}0.857 \\
(0.191)\end{array}$ \\
\hline first_confer & $\begin{array}{c}1.177 * \\
(0.0967)\end{array}$ & $\begin{array}{c}1.135 \\
(0.113)\end{array}$ & $\begin{array}{c}1.121 \\
(0.132)\end{array}$ & $\begin{array}{c}1.197 \\
(0.104)\end{array}$ & $\begin{array}{c}1.349 * \\
(0.0742)\end{array}$ & $\begin{array}{c}1.245 \\
(0.101)\end{array}$ \\
\hline regime & $\begin{array}{l}0.0135 \\
(0.785)\end{array}$ & & & $\begin{array}{l}0.0445 \\
(0.399)\end{array}$ & $\begin{array}{l}0.0155 \\
(0.754)\end{array}$ & $\begin{array}{l}0.0464 \\
(0.387)\end{array}$ \\
\hline corr_wgi & $\begin{array}{c}0.206 \\
(0.689)\end{array}$ & $\begin{array}{l}0.0731 \\
(0.898)\end{array}$ & $\begin{array}{c}0.405 \\
(0.465)\end{array}$ & $\begin{array}{c}0.579 \\
(0.274)\end{array}$ & $\begin{array}{c}0.121 \\
(0.818)\end{array}$ & $\begin{array}{c}0.467 \\
(0.395)\end{array}$ \\
\hline polity_change & $\begin{array}{c}-0.0997 * * \\
(0.0193)\end{array}$ & $\begin{array}{c}-0.0994 * * \\
(0.0157)\end{array}$ & $\begin{array}{c}-0.0990 * * \\
(0.0209)\end{array}$ & $\begin{array}{c}-0.0935 * * \\
(0.0340)\end{array}$ & $\begin{array}{c}-0.0753^{*} \\
(0.0929)\end{array}$ & $\begin{array}{c}-0.0771 * \\
(0.0979)\end{array}$ \\
\hline form_col & $\begin{array}{c}0.221 \\
(0.701)\end{array}$ & $\begin{array}{c}0.189 \\
(0.744)\end{array}$ & $\begin{array}{c}0.434 \\
(0.506)\end{array}$ & $\begin{array}{c}0.447 \\
(0.489)\end{array}$ & $\begin{array}{c}-0.0135 \\
(0.982)\end{array}$ & $\begin{array}{c}0.142 \\
(0.830)\end{array}$ \\
\hline OECDEU & $\begin{array}{l}-0.389 \\
(0.789)\end{array}$ & $\begin{array}{l}-0.479 \\
(0.743)\end{array}$ & $\begin{array}{l}-0.881 \\
(0.572)\end{array}$ & $\begin{array}{l}-0.733 \\
(0.638)\end{array}$ & $\begin{array}{c}0.127 \\
(0.930)\end{array}$ & $\begin{array}{l}-0.260 \\
(0.867)\end{array}$ \\
\hline VA & & $\begin{array}{l}0.0105 \\
(0.543)\end{array}$ & $\begin{array}{l}0.0197 \\
(0.275)\end{array}$ & & & \\
\hline expdep & & & $\begin{array}{l}3.280 * * * \\
(0.00364)\end{array}$ & $\begin{array}{l}3.133 * * * \\
(0.00428)\end{array}$ & & $\begin{array}{l}2.797 * * \\
(0.0157)\end{array}$ \\
\hline ethnicfrac & & & & & $\begin{array}{l}2.929 * * \\
(0.0294)\end{array}$ & $\begin{array}{l}2.758 * * \\
(0.0467)\end{array}$ \\
\hline Constant & $\begin{array}{c}0.336 \\
(0.751)\end{array}$ & $\begin{array}{l}0.0263 \\
(0.982)\end{array}$ & $\begin{array}{l}-0.410 \\
(0.743)\end{array}$ & $\begin{array}{l}0.0989 \\
(0.928)\end{array}$ & $\begin{array}{l}-1.558 \\
(0.244)\end{array}$ & $\begin{array}{l}-1.543 \\
(0.254)\end{array}$ \\
\hline Observations & 160 & 160 & 151 & 151 & 158 & 150 \\
\hline
\end{tabular}

Resource abundance matters in cases where it is measured by the IMF's classification (model 1) and by the dependence on mineral and fuel exports (model 4), thus making the results robust to different operationalizations of natural resource dependence. Being a resource-abundant country increases the likelihood of adopting the EITI as a candidate in both models: the result is statistically 
significant at a $1 \%$ level, thus confirming the main prediction on resource-abundant countries being more likely to adopt the EITI. This finding confirms that the intent of the EITI in targeting resource-rich countries indeed translates into the membership of countries with natural resource abundance. The hypothesis on the level of income is also supported: higher income decreases the likelihood of joining as a candidate, and this finding holds at a 5\% significance level. However, I do not find a relationship between the level of corruption and EITI adoption. These results are consistent with findings by Pitlik et al. (2010).

The policy variable measuring the level of democratic freedoms does not predict the likelihood of adoption, reflecting that this factor is not associated with the likelihood of EITI adoption. This result holds both when democratic freedoms are operationalized by the Polity IV indicator (models 1 and 4), and when voice and accountability from the World Governance Indicators is used (models 2 and 3). However, the larger the number of years since the change in polity toward democratization, the less likely adoption is to occur. This finding is consistent with the hypothesis posited: in countries where the change of political system toward democratization recently occurred, the EITI is more likely to be adopted. This finding is statistically significant at a $5 \%$ level, regardless of how resource abundance and level of democratic freedoms are operationalized.

The hypotheses on external influence do not find much support in the analysis. Colonial heritage turns out to have no statistically significant effect. Involvement in donor-led extractive projects shows up statistically significant only at a 10\% significance level and only in models 3 and 4 with resource dependence. Participation in the first conference on the EITI is statistically significant at a $10 \%$ level only in the first model. Ethnic fractionalization, in line with the theoretical prediction, increases the likelihood of EITI adoption and is statistically significant at a $5 \%$ level (models 5 and 6 ).

In a broader perspective, the above results mean that the EITI portrayal of itself as a standard for primarily resource-rich countries holds to its promise: 
countries abundant in natural resources are more likely to join the initiative than countries which are not resource-rich. According to the findings, high income decreases the likelihood of joining the initiative. This could be one explanation for the observation that not all resource-rich countries have joined the EITI. It is the resource-rich countries with low income that have been more likely to adopt the EITI. The larger the number of years since the last change in polity toward democratization, the less likely it is that the EITI would be adopted. Ethnically fractionalized societies are more likely to adopt the EITI. Finally, there is limited evidence that involvement in donor-led extractive projects prior to candidacy is associated with EITI adoption. When ethnic fractionalization is included in the models, this effect is no longer present.

\subsection{Discussion and Conclusion}

The results show that resource abundance, lower income, ethnic fractionalization, and low number of years since last polity change toward democratization are associated with the increased likelihood of EITI adoption. External influence variables seem to matter less. The findings on the importance of resource abundance, level of income and ethnic fractionalization are consistent with what Pitlik et al. (2010) have previously found out, whereas the effect of the recent change of polity toward democratization is a factor which has not been previously considered. The fact that I do not find strong evidence for the effect of external influence variables suggests, at least for the case of the EITI and given the operationalization of the variables, that domestic factors can explain the adoption decision better than external influence explanations. It must be acknowledged, however, that in part this result may be dependent on the difficulties associated with measuring external influence.

For the EITI as a regulatory instrument, the results reflect on the most difficult country cases for EITI adoption. So far the EITI has been unable to attract high-income resource-rich countries, which means that a large number of countries 
which are under the risk to experience the resource curse still have not adopted the initiative. Moreover, countries with a long track of stable regime are less likely to adopt the EITI. Stable resource-rich democracies may be of less interest to the EITI as countries where transparent practices are more likely to have been present for a long time, but the case of stable authoritarian regimes is curious: these resourcerich contexts are under particular risk to suffer from political mechanisms of the resource curse. The fact that they are not adopting the EITI means that they remain out of the initiative's scope, despite the attractive minimum rules, which in theory allow for usage of the EITI as a brand name (and, in extreme cases, even usage for window-dressing reasons), rather than targeted reform of the extractive sector.

Having determined what factors influence the initial decision to adopt the EITI and in which country contexts it seems to be more difficult to introduce the EITI, I proceed to the puzzle of differences in the way the EITI is variously implemented in the next chapters. The subsequent questions considered will move beyond the adoption processes and toward a focus on implementation. 


\section{Chapter 4: Opening up the Black Box of EITI Compliance: Cross-country Differences in the Implementation}

\section{Activities}

Summary: The design of the EITI standard allows for differences in the ways countries implement the initiative, even though the official compliance status granted by the EITI is a "pass or fail" outcome. This chapter first outlines conceptual differences between implementation, compliance and effectiveness, justifying the focus on implementation which is chosen here. Next, I develop an index of implementation activities along several EITI policy dimensions, and illustrate different implementation choices, using country examples. By focusing on one of the critical components of the EITI implementation activities - the extensiveness of disaggregation in reporting - my argument subsequently explores the reasons behind a country's decision whether or not to implement the EITI extensively in this dimension. I argue that the regime level and the nature of the reporting sector matter. Carrying out the EITI in the non-hydrocarbon mining sector only turns out to be a sufficient condition for extensive disaggregation. On the other hand, for countries including the oil and gas sector in their reporting, democracy is a necessary (but not sufficient) condition to introduce extensive disaggregation practices. The findings presented also influence the selection of cases for the country implementation studies in Chapter 5.

\subsection{Introduction}

The aim of this chapter is to take a closer look at what happens once EITI candidate countries start the implementation process and progress beyond candidacy status toward the status of compliance with the EITI. The EITI was designed in a way to allow members a range of choices in setting up their implementation process, which is why it comes as no surprise that differences in implementation activities occur across countries. As a result, "compliance" may mean different things in different countries and the compliant status granted by the EITI global authorities does not imply a uniform process of EITI implementation. Differences in the type of implementation exist not only between candidate countries working toward compliance, but continue to persist in countries that have 
qualified for the compliant status granted by the EITI authorities. This is acknowledged by the staff of the EITI International Secretariat and is argued to be a flexible advantage. Jonas Moberg, the Head of the EITI Secretariat, for instance, points out, "Every implementing country implements the EITI in different ways.

Some require total disaggregation of revenue information; some have set expansive standards for materiality; some include sectors beyond oil, gas and mining; some seek to include transparency of both contracts and operations; and some seek to include transparency of expenditures" (Moberg, 2008, p.6).

To develop this chapter's argument, section 4.2 not only introduces the conceptual differences between implementation, compliance, and effectiveness, but also accounts for the decision to focus on the implementation activities. In section 4.3, I perform an empirical exercise to investigate how EITI implementation activities differ across countries. The data for this section comes from the original EITI reports as well as secondary sources of information. The factors contributing to extensiveness in the implementation are theorized in section 4.4, where I devote particular attention to the question of why differences occur in one of the key components of the implementation activities - disaggregation by company and by revenue stream. I conclude with a summary of the main findings in section 4.5, also outlining the logic of the selection of cases for Chapter 5 .

\subsection{Conceptualizing Implementation, Compliance, and Effectiveness}

The design of the EITI leaves considerable space for specific country's decisions on the extensiveness of the implementation activities, which is likely to generate differences among countries in ways policies are carried out. This flexibility which is inherent to the EITI's design takes into account the different interests and priorities that countries may link with the adoption of the EITI. As Jacobson \& Weiss (1995, p.122) argue in their study of international legal instruments in 
environmental policy, "[w]hile countries may join only treaties that they regard as in their self-interest, there are a variety of reasons countries find them in their interest, and those reasons affect their willingness and ability to comply with them." It is only natural to expect that such different motivations for adopting the standard can contribute to subsequent differences in implementation of treaty obligations, in particular when such obligations are ambiguous or only couched in soft law terms, as in the case of the EITI. In respect to these questions, in Chapter 3 I only identified the structural determinants of the EITI adoption, without investigating how and to what extent such structural characteristics translated into specific countries' motives related to adopting and implementing the EITI. Nonetheless, the differences in the types and strategies of implementation by individual countries that are observed below indicate that such differences in motives do exist. These differences are reflected in the varying willingness countries exhibit in extending the EITI process beyond the minimum required for "pass/fail compliance." It seems a logical step, then, to move from considering the factors leading to EITI adoption vis-à-vis non-adoption toward studying the explanations for cross-country differences between EITI adopters that occur once policy implementation starts.

Studies focusing on the policy process "after" policy adoption often operate with the concepts of implementation, compliance, and effectiveness. In this section, I outline how these terms can be operationalized in the case of the EITI and motivate my decision to focus on the implementation activities, rather than on compliance or effectiveness.

A commonly used definition of compliance was put forward by Oran Young (1979, p.104), who claims that compliance occurs when "the actual behavior of a given subject conforms to prescribed behavior," while noncompliance happens when "the actual behavior departs significantly from prescribed behavior.” This definition is clear about separating compliance from implementation, the latter occurring from the moment a policy, a treaty, or an 
initiative is adopted. In the context of the EITI, this implies that implementation starts once a country achieves the candidate status. Compliance with the standard happens when the EITI candidates have completed a meaningful EITI reporting process, validated by an external agency and approved by the EITI International Secretariat, on the recommendation of which the EITI Board grants the compliant status to the country involved. In practice, because the EITI design leaves room for differences in how countries organize their implementation process, implementation activities differ among candidate countries and even compliant countries. Some choose to carry out the implementation activities according to the EITI minimum requirements, others extend the standard into aspects which are only recommended, or not even mentioned, by the EITI rules.

Beth Simmons (1998, p.78) draws attention to the fact that Young's definition also separates compliance and effectiveness: a country may be in compliance with an adopted agreement, yet not achieve the intended policy goal. Raustiala \& Slaughter (2002, p.539) also note that while effectiveness can be defined in different ways, ${ }^{26}$ compliance is neither a necessary condition for effectiveness, nor a sufficient one. There could be situations where the problem of concern is resolved even in the absence of the treaty or the standard: in this case compliance is not necessary for the problem to be effectively addressed.

Conversely, there may be cases where the country complies with the standard, yet is unable to solve the problem, either due to weak implementation of the policy, weak design of the policy, or domestic obstacles; in such case, compliance is not sufficient for the standard to be effective. The same issue is covered by Jacobson and Weiss (1995, p.124), who argue it is possible to have compliance with a policy without policy's objective being reached: "Compliance is related but not identical to effectiveness. Countries may be in compliance with a treaty, but the treaty may

\footnotetext{
${ }^{26}$ According to Raustiala and Slaughter (2002, p.539), effectiveness could be defined as "the degree to which a rule 1) induces changes in behavior that furthers the rule's goal, 2) improves the state of the underlying problem, 3) achieves the policy objective."
} 
nevertheless be ineffective in attaining its objectives. And even treaties that are effective in attaining their stated objectives may not be effective in addressing the problems they were intended to address." Even though the EITI is not a treaty, the logic of this argument is relevant. On the one hand, it is possible to conceive of a country undergoing the implementation process, qualifying as compliant, and yet being unable to improve the transparency of its natural resource management process fully. Because one needs to fulfill only the minimum requirements for compliant status with the EITI, it is possible that information on certain crucial aspects of the natural resource management cycle remains opaque. On the other hand, even if there were a hypothetical country that fully attained the objective of transparency of the natural resource management, such transparency by itself does not guarantee effectiveness in addressing the problems associated with the resource curse. The most obvious example would be ineffective fiscal management of the resource revenues coming into the budget, in which case the value of transparency would be negated.

As argued in the first chapter, transparency as intended in the EITI can increase the likelihood of resource curse prevention, when applied to the full natural resource management process, from the stage of contract signing, through resource reporting and up to revenue spending. Given the multiple causal mechanisms linked to the resource curse, transparency in different stages of resource management addresses different causal links, thus contributing to the overall effectiveness of the EITI in achieving both transparency intended by the standard, as well as addressing the resource curse-related problems. Therefore, countries that voluntarily increase the scope and depth of transparency by going for more extensive EITI implementation activities can target more possible sources of problems associated with the resource curse. Because of this implicit link between extensive implementation and the effectiveness of the EITI as a regulation instrument, it is crucial to study the implementation activities - and in particular 
the factors determining their extensiveness - in order to be able to make a meaningful assessment of the EITI.

\subsection{Cross-country Differences in the EITI Implementation}

Some authors have classified the different EITI practices as specific models of implementation ("basic", "extensive." and "beyond" in Darby, 2008; "core EITI" and "EITI plus" in Darby \& World Bank, 2008; "EITI+" and "EITI++" in World Bank, 2008). Such typologies, undoubtedly, are useful for understanding that countries vary greatly when it comes to the scope and depth of their EITI implementation. Because underneath these labels further meaningful variation in implementation may exist, this study refrains from classifying each country regarding the overall implementation model and rather focuses on assessing implementation activities dimension by dimension.

As argued in Chapter 1, the EITI, while not guaranteeing transparency of the full resource management process, undoubtedly has a lot of potential to remove most of the political mechanisms contributing to the resource curse, if it is implemented with the features of extensive implementation, beyond the minimum required. First and foremost, at the minimum level a well-implemented EITI increases transparency of revenues, tracked from companies to governments, thus ensuring that all revenues become part of the budget. Publication of revenue streams makes illegal activity more difficult, decreasing possibilities for rentseeking and patronage politics. This in turn battles corruption. Secondly, the EITI gives citizens of the implementing countries free access to information on the size of revenues from the extractive industries. On the one hand, this helps to avoid grievances based on incorrect perceptions of how much revenue is actually there, while, on the other hand, it allows citizens to raise questions on government spending of this revenue, thus indirectly stimulating democratic processes in the countries. Finally, the voluntary component of the EITI that may give rise to differing extensiveness of implementation - the focus of this chapter - also leaves 
room for the inclusion of all natural resource management phases, and as such it potentially targets most of the causal mechanisms contributing to the resource curse. If countries voluntarily include additional transparency practices in their EITI implementation, in addition to the minimum required targeting of revenue collection/reporting, other stages of resource management, such as contract transparency, revenue distribution, and revenue spending, become affected. These practices contribute to battling some of the economic mechanisms via which resource curse operates, as well as better targeting of the political mechanisms. Finally, the EITI can be a powerful signaling mechanism that improves countries' perception-based ratings and attracts new investments or capital from donor institutions, thus enabling possibilities to break out of the underdevelopment trap through indirect channels.

So far, my discussion of how the EITI can target multiple causes of the resource curse has been conceptual. But, I would argue, it is equally important to consider how these voluntary extensions of the EITI process function in actual practices in the implementing countries, and, more specifically, in what dimensions and to what extent differences occur across countries. In the section below, I aim to assess possible extensions beyond the minimum required in each dimension of the EITI implementation activities. To explore the variations in implementation, I adopted an inductive approach, analyzing the EITI annual reports and validation reports - of both compliant countries and countries working toward compliance as primary evidence of different implementation practices. In addition, I looked at secondary sources in the form of expert reports (published prior to June 2011). As I use examples of countries merely for illustrative purposes, I do not intend to classify each implementing country along every implementation dimension. Based on the analysis, the section below identifies eight major dimensions along which differences occur. These are 1) sector coverage, 2) definition of materiality, 3) type of audit/reconciliation, 4) extent of disaggregation, 5) inclusion of sub-national reporting, 6) inclusion of social payments, 7) inclusion of practices in additional 
phases of the resource management process (beyond focus on the upstream payments in the revenue collection), and 8) establishment of the multi-stakeholder group (MSG) prior to official EITI requirements. The EITI rules listed in the table do not reflect the changes in the EITI standard launched in May 2013, which are not addressed in this chapter.

Table 4.1 Conceptualizing EITI Implementation Activities

\begin{tabular}{|c|c|c|}
\hline & Advised by the EITI rules & Known Alternatives \\
\hline $\begin{array}{l}\text { 1. Which sectors are } \\
\text { covered? }\end{array}$ & oil and mineral sectors & $\begin{array}{l}\text { - oil sector only } \\
\text { - mineral sector only } \\
\text { - additional extractive sectors included }\end{array}$ \\
\hline $\begin{array}{l}\text { 2. How is "materiality" } \\
\text { of revenue streams } \\
\text { defined? }\end{array}$ & $\begin{array}{l}-98-99 \% \text { of revenues in the } \\
\text { oil sector } \\
-80 \% \text { of revenues in the } \\
\text { mining sector }\end{array}$ & $\begin{array}{l}\text { - mandatory reporting for all companies } \\
\text { - voluntary reporting for all companies } \\
\text { (could exist in the early EITI adopters - } \\
\text { pilot countries) } \\
\text { - selection of different companies every } \\
\text { reporting cycle }\end{array}$ \\
\hline $\begin{array}{l}3 \text {. How is data checked } \\
\text { for validity? }\end{array}$ & $\begin{array}{l}\text { - reconciliation by } \\
\text { independent administrator } \\
\text { - reporting entities should } \\
\text { be audited according to } \\
\text { international standards }\end{array}$ & $\begin{array}{l}\text { - reconciliation by independent } \\
\text { administrator } \\
\text { - reconciliation by independent } \\
\text { administrator with attached audit reports } \\
\text { by companies } \\
\text { - additional audit as part of EITI process } \\
\text { (physical audit, selective audit of } \\
\text { companies, process audit) }\end{array}$ \\
\hline $\begin{array}{l}\text { 4. What is the extent of } \\
\text { disaggregation? }\end{array}$ & $\begin{array}{l}\text { disaggregation is not a } \\
\text { requirement; however, } \\
\text { more disaggregation leads } \\
\text { to a more informative } \\
\text { report }\end{array}$ & $\begin{array}{l}\text { - report published in an aggregated format } \\
\text { - report, disaggregated by revenue streams } \\
\text { - report, disaggregated by companies } \\
\text { - report, disaggregated by companies and } \\
\text { revenue streams } \\
\text { - report, disaggregated by revenue streams } \\
\text { and some companies (which agreed to } \\
\text { publish figures in a disaggregated format) }\end{array}$ \\
\hline $\begin{array}{l}\text { 5. Is there sub-national } \\
\text { reporting? }\end{array}$ & not required & $\begin{array}{l}\text { - mandatory sub-national payments } \\
\text { included } \\
\text { - voluntary sub-national payments included } \\
\text { (see criteria below) }\end{array}$ \\
\hline
\end{tabular}


Table 4.1 Conceptualizing EITI Implementation Activities (Cont'd)

\begin{tabular}{|c|c|c|}
\hline & Advised by the EITI rules & Known Alternatives \\
\hline $\begin{array}{l}\text { 6. Are social payments } \\
\text { included? }\end{array}$ & not required & $\begin{array}{l}\text { - social payments to national government } \\
\text { included } \\
\text { - social payments to sub-national } \\
\text { governments included }\end{array}$ \\
\hline $\begin{array}{l}\text { 7. Are additional phases } \\
\text { of resource management } \\
\text { cycle included? }\end{array}$ & $\begin{array}{l}\text { not required; the focus is on } \\
\text { upstream }\end{array}$ & $\begin{array}{l}\text { - contract disclosure } \\
\text { - midstream payments } \\
\text { - downstream payments } \\
\text { - revenue spending }\end{array}$ \\
\hline $\begin{array}{l}\text { 8. In the years prior to } \\
\text { official EITI guidelines, } \\
\text { was there a multi- } \\
\text { stakeholder group } \\
\text { established? }\end{array}$ & $\begin{array}{l}\text { details of EITI design were } \\
\text { not finalized and, hence, } \\
\text { MSG representing the } \\
\text { constituencies (government, } \\
\text { companies, civil society) } \\
\text { was not required }\end{array}$ & $\begin{array}{l}\text { - MSG-like Council installed } \\
\text { - other forms of institutional arrangement } \\
\text { where some of the stakeholders are } \\
\text { consulted, but not formally included in the } \\
\text { MSG-like body }\end{array}$ \\
\hline
\end{tabular}

Source: Analysis based on review of the reports and the secondary literature below.

\subsubsection{Which sectors are covered?}

EITI implementation may differ with respect to the extractive sectors which are included in the implementation activities. The EITI as an initiative was brought about by issues tied to the resource curse, which is traditionally associated with dependence on hydrocarbons and minerals. Even in his speech, announcing the launch of the EITI in 2003, Tony Blair, then prime minister of the UK, discusses challenges of managing oil, gas, and mineral sectors only (Blair, 2003). It is also the case that in the description of the EITI standard, the EITI Secretariat focuses on oil, gas, and mining (EITI Secretariat, n.d-d). In practice, however, some countries have extended the standard to other extractive sectors, such as agriculture and forestry. While these sectors are not traditionally associated with the danger of the resource curse, they may certainly benefit from the increase in transparency practices and battling corruption. One example of a country extending the standard to these sectors is Liberia, which implements the EITI in agriculture and forestry, as well as in the mining and oil and gas sectors (LEITI Secretariat, 2010; Oxford Policy Management, 2009). 
Among the countries carrying out the EITI in the hydrocarbon and mineral sectors, not all countries choose to focus on both hydrocarbons and minerals in their EITI implementation. Some countries implement the EITI in the oil and gas sector only, e.g., in the case of Norway (Oxford Policy Management, 2010), Nigeria (Hart Nurse Ltd., 2011b), Timor-Leste ${ }^{27}$ (Timor-Leste EITI, 2009), or only in the mining sector as in the cases of Burkina Faso ${ }^{28}$ (KPMG, 2011) or Ghana ${ }^{29}$ (Ghana EITI Secretariat, 2010, p.25). Examples of countries which from the beginning of the implementation process cover both oil and gas, as well as nonhydrocarbon minerals, are Mongolia (Crane White \& Associates, n.d; Hart Nurse Ltd., 2011a, 2012), and Peru (Ernst \& Young, 2009, 2011). There have also been countries which have started out on their EITI activities in only one of the sectors mentioned above, and which later on extended the reporting into other sectors. Azerbaijan, for instance, initially started EITI implementation in the oil and gas sector only, but later added information on gold and silver payments (SOFAZ, 2010a, 2010b; Coffey International Development, 2009). Another example is Kyrgyzstan, which initially carried out reporting in the mining sector only, but later on extended its EITI activities to its oil and gas sector (KEITI, 2009, p.4).

\subsubsection{How is materiality of revenue streams defined?}

Besides differences in the type of sectors which may be covered by the EITI, there can be variations in the extensiveness of company and revenue coverage. The EITI as a standard specifies that countries need to define the "materiality" of revenue streams - i.e., a threshold regarding the size of payments above which payments have to be included in the reporting and/or the size of company operations determining whether companies are required to report. The purpose behind this is to include only the companies and revenue streams that make significant

\footnotetext{
${ }^{27}$ Reporting includes condensate, LPG, and gas only; oil is not included due to the fact that oil exploration activities have recently started.

${ }^{28}$ Reporting includes only gold.

${ }^{29}$ Reporting includes only gold, bauxite, and manganese.
} 
contributions to the economy, while keeping the reporting exercise manageable in terms of administration. Usually, it is advised that the EITI report should cover 98$99 \%$ of revenues in the oil sector and at least $80 \%$ of revenues in the mining sector (Darby, 2008, p.14). However, it is up to each participating country to define its own criteria of "materiality," which allows countries to set their own standards as to what constitutes materiality of revenue streams. In practice, the implementation activities in various countries have shown that the approaches to defining materiality have differed among countries, and, furthermore, that they were not always clearly specified in the public reports. According to the Revenue Watch Institute analysis (n.d) of the reports published up to September 2011, the reports of only twelve EITI-implementing countries are clear about the materiality thresholds, whereas the remaining sixteen countries have produced reports which do not clearly outline the country criteria of materiality thresholds.

For instance, in the first EITI report produced by Kazakhstan, as Darby points out in his report for the Revenue Watch Institute (2008, pp.14-16), the revenue streams were broken down by detailed categories - ranging from corporate income tax and revenues from profit oil to land taxes, bonuses, royalties and so on - but the reporting was voluntary for companies ${ }^{30}$ and therefore some major companies were excluded from the EITI process. Over the years of implementation in Kazakhstan, many companies have joined the EITI process voluntarily, causing an increase in the number of participating companies from the original 35 to over 100 (Deloitte, 2007; UHY Sapa-Consulting, 2009). What is more, the government of Kazakhstan introduced legislation making participation mandatory for companies entering the market from 2008 (Hart Nurse Ltd., 2010, p.34). It defined materiality of revenue streams as 1) "all types of payments made to the national budget based on the Tax Code and other legislation, regardless of how small the payment" and 2) "the percentage of payments/revenue between the extractive

\footnotetext{
${ }^{30}$ This is actually against the minimum required EITI rules, which require mandatory company reporting, based on the decided materiality criteria.
} 
industry and the government" (Hart Nurse Ltd., 2010, p.39). However, according to the EITI Validation Report of 2010 (Hart Nurse Ltd., 2010) and the EITI International Secretariat's Review of 2010 (p.4), the exclusion of some revenue streams in Kazakhstan appears to persist to this day, despite the fact that since the beginning of the implementation many more companies have voluntarily joined the implementation. Approximately $90 \%$ of the revenues in the oil and gas sector and about $60 \%$ of the revenues in the mining sector are covered in the recent EITI reports of Kazakhstan (Hart Nurse Ltd., 2010, p.39).

Another example of how materiality works in practice is the 2004 report by Ghana which covers only eight mines run by five companies, but these five companies constitute $99 \%$ of all minerals royalties. Ghana's report included information on the royalties which contributed $89 \%$ of the revenues received from these companies, plus information on the remaining $11 \%$ coming from license payments, corporate tax, property and ground rents, and dividends (Darby, 2008, p.16). Ghana's report for the years 2004 to 2008 covers eleven companies, contributing around 99\% of mineral revenues (Ghana EITI Secretariat, 2010). Another approach is used in Nigeria, where the government passed legislation to require all oil companies to report their revenues in the EITI process (NEITI Act, 2007).

\subsubsection{How is data checked for validity?}

According to the EITI guidelines, the information provided by the reporting entities - company, as well as government - should be reconciled by an independent administrator, with participating companies and governmental bodies fulfilling the international audit standards. This requirement still leaves room for each country to determine its method of reconciliation: if in some cases an independent administrator will simply reconcile existing data, in other cases companies are required to attach reports of their audits alongside submitted data, and in a few cases a physical audit or selective audit occurs. 
Ghana, for instance, required companies to submit audited financial statements to the reconciler, whereas government accounts were audited according to international standards; in addition, a process audit of mining and production, transportation, and sales and accounting processes was carried out (Ghana EITI Secretariat, 2010). In Kyrgyzstan's 2009 report, companies submitted audited financial statements to the reconciler, but, to the concern of the validator, a number of smaller companies were unable to provide audited accounts (Coffey International Development, 2010a; KEITI, 2009). A similar situation with smaller companies occurred in Liberia, where in order to compensate for the lack of audited accounts companies provided supporting receipts to the reconciler (LEITI Secretariat, 2010; Oxford Policy Management, 2009). Liberia has also agreed to carry out independent audits in the future reporting cycles and initiated the Public Management Act to audit government accounts in line with international standards, whereas before the government agencies were audited by the general Auditing Commission of Liberia (LEITI Secretariat, 2010; Oxford Policy Management, 2009). An example of an elaborate audit process for the EITI can be seen in the case of Nigeria, which performed fiscal, physical, and process audits for the years of 1999-2004 (Shaxson, 2009, pp.5-6).

\subsubsection{What is the extent of disaggregation?}

Disclosure of information can be aggregated or disaggregated by companies, so that the EITI report may or may not identify contributions made by individual companies, and by revenue streams, such as taxes of various sort, bonuses, royalties, and so on. It is important to point out that the issue of aggregation/disaggregation applies to published versions of the EITI reports, not to the actual disclosure of information to the independent administrator who reconciles the data. The disclosure of information always occurs in disaggregated form to allow the reconciler to trace discrepancies. However, the reports are sometimes published in aggregate form based on the argument of company 
confidentiality protection. In practice, all countries produce reports which at least to some extent disaggregate by revenue streams, but aggregation or disaggregation by company varies. For instance, in Ghana (Synergy Global Consulting Ltd., 2010), Liberia (Oxford Policy Management, 2009), Nigeria (Hart Nurse Ltd., 2011b), Mongolia (Coffey International Development, 2010b), Norway (Oxford Policy Management, 2010), and Timor-Leste (Coffey International Development, 2010c) the information is published disaggregated by company. In Azerbaijan (Coffey International Development, 2009), Cameroon (Republic of Cameroon Ministry of Finance, 2010), Kazakhstan (Hart Nurse Ltd., 2010), the Kyrgyz Republic (Coffey International Development, 2010a), and Mauritania (Islamic Republic of Mauritania National Committee for the EITI, 2010, pp.39-40) reports are aggregated by companies. In Peru, for example, a compromise was reached as a result of negotiations and part of the report is published disaggregated by company while part is aggregated (Ernst \& Young, 2009, 2011) due to the fact that a set of companies refused to disclose their figures in the published report.

It is also worthy to note that some companies lean toward publishing disaggregated figures and may do so even in the absence of government pressure. For instance, Statoil-Hydro and Talisman Energy disclose total payments (not disaggregated by revenue streams) to all governments of countries in which they operate. BP has disclosed disaggregated figures in Azerbaijan, even though Azerbaijan does not require disaggregation as part of their EITI process. An example of the opposite behavior would be ExxonMobil, which is in favor of aggregated reports (Darby, 2009, p.12).

\subsubsection{Is there sub-national reporting?}

Sub-national payments by the extractive companies are currently not required by the EITI rules, but some countries have chosen to require disclosure of these figures in their EITI process. Payments to sub-national governments could be reported by different entities (Darby \& the World Bank, 2008, p.34). On the one 
hand, some payments by companies and/or national governments are mandatory and are written out in laws or specific contract arrangements in the case of companies. On the other hand, some payments are discretionary and are voluntarily spent on local social or infrastructure projects by companies, or, if carried out by governments, are done on an ad hoc schedule. While now only a few countries have included sub-national reporting, many are considering the option. These developments are also entering the agenda of the EITI authorities globally. For instance, at the Global EITI Conference in Paris, Edward Bickham, a member of EITI Board, discussed the possibility of EITI Secretariat's phased-in EITI requirement of sub-national reporting (Bickham, 2011).

So far Mongolia, for one, took a step to include such data, which in its report was covered by voluntary company contributions to sub-national governments, as well as non-governmental agencies (Hart Nurse Ltd., 2011a). Ghana serves as another example of a country that has engaged in reporting on payments to sub-national governments (Synergy Global Consulting Ltd., 2010). In mining countries sub-national reporting is particularly important, as mines usually have a significant impact on local communities. It is also important for countries with a high level of fiscal decentralization, for which sub-national reporting may be more of an issue than for countries where all revenues are collected centrally. When discussing the issue of sub-national reporting, David Goldwyn cites Peru as a case where $50 \%$ of the mining tax goes to sub-national entities. Out of this tax going to sub-national entities, $40 \%$ is allocated to districts and provinces of the regions, $25 \%$ to provincial municipality of mine-producing areas, $25 \%$ to regional governments, and $10 \%$ to district administrations of mine-producing areas (Goldwyn, 2008, pp. 129-130). In such fiscal arrangements, sub-national reporting becomes a more critical issue for the EITI implementation in countries where substantial amounts of revenues are distributed to sub-national entities. 


\subsubsection{Are social payments included?}

While the EITI formally requires reporting of revenues from direct production only, some countries have gone beyond this to include indirect payments which are known as "social/community payments," or corporate responsibility payments. These are usually made "in kind," i.e. a company is providing goods or services rather than a financial payment. Such services are often, but not always, provided to sub-national governments. Sometimes they are required by national law and at other times they are done on a discretionary basis. Social payments are important not only because they can be quite substantial, but also because they are a venue for possible corruption. Darby (2008, p.26) notes that for example the Democratic Republic of Congo has requested the reporting companies to provide information on non-production related payments as well. Goldwyn (2008, p.154) points out another example of Ghana, where EITI templates for reporting corporate social payments was introduced at both national and sub-national levels.

\subsubsection{Are additional phases of the resource management cycle included?}

The EITI focuses on disclosing payments related to upstream activities, that is, activities of exploration, development, and production of mineral assets up to the point where the minerals extracted are in a marketable state without further processing activities involved. However, the cycle of natural resource management includes other phases as well, such that include payments on midstream ${ }^{31}$ and downstream $^{32}$ activities if we are discussing reporting of revenue collection, contract disclosure when the phase of setting up the fiscal regime and contracts is considered, or disclosure of spending in the revenue spending phase.

\footnotetext{
${ }^{31}$ Activities related to transportation, storage, and marketing of the extracted resources.

${ }^{32}$ Activities related to refining, processing, marketing, and distribution of the products in the oil and gas sector.
} 
Some of these extensive practices are gradually starting to be implemented in some countries as part of the EITI process. According to Rosenblum \& Maples (2009), the practices of contract transparency are currently increasing. For instance, some of the EITI participants who share their oil and gas contracts publicly include Timor-Leste and Peru; Liberia, through its 2009 EITI law, required public disclosure of all contracts; Ghana, DRC, and Iraq have also provided many of their petroleum agreements. Quite a number of countries (Niger, Sierra Leone, Sao Tome and Principe, and Guinea) have included provisions on contract transparency in their oil sector-related legislation (Revenue Watch Institute, 2012, April-b). As to other phases of the resource management, there have been initiatives to include revenue spending, and information on midstream/transit and downstream payments as part of the EITI disclosure requirements. These include a joint proposal by NGOs from Kazakhstan, Azerbaijan, Georgia, and Ukraine to expand the EITI to include payments on transportation of hydrocarbon resources (Radon, 2009), and reporting of downstream activities as part of the EITI, such as export sales in Iraq.

\subsubsection{In the years prior to official EITI guidelines, was there a multi-stakeholder group established?}

Once the EITI is adopted by the government, the national implementation of the initiative is overseen by the MSG, consisting of government, companies, and civil society constituencies. As explained in the first chapter, this institutional set-up clearly distinguishes the EITI from other transparency-focused regulatory initiatives in the sector. In particular, the inclusion of the civil society constituency in the MSG is crucial to increasing the likelihood of extensiveness of implementation. In the first years of the EITI's existence, there were no official guidelines on the minimum requirements of EITI implementation, which particularly had an impact on the EITI pilot implementers. Correspondingly, there was no requirement for the first adopting countries to establish an official MSG overseeing and deciding on the implementation issues. After the guidelines were 
established, every EITI country was required to institutionalize such a decisionmaking body, but for the initial pilot countries this was a matter of discretion, resulting in the differences of the organizational set-up for the EITI process. The lack of an MSG in the beginning of the domestic EITI implementation process could create an imbalance between the stakeholder constituencies, resulting in limitations to the inclusion of extensive EITI practices.

Having conceptualized the different dimensions along which EITI implementation activities may differ across countries, I will further probe one of these dimensions in the section below in order to examine whether there are factors at the country level determining the outcome of the implementation choice in this particular dimension. I choose to focus on company-by-company disaggregation, the dimension which I argue to be one of the most critical for extensive implementation and the effectiveness of the standard in reaching its transparency objective.

\subsection{Who Does More and Why? Disaggregation Practices among the EITI Participants}

An obvious question triggered by the differences in the EITI implementation activities is the following: why do some countries do more than the minimum required to comply? This question can be explored by studying the processes within the MSGs of implementing countries, via which the three stakeholder constituencies decide on the particular types of implementation activities. Yet it would not be possible to carry out a detailed investigation of processes within the MSGs of all EITI-implementing countries. Moreover, important explanations may be overlooked when employing such an inductive strategy. Therefore, before zooming in on detailed case studies of particular countries (Chapter 5), I consider structural explanations at the country level for one of the dimensions of extensive implementation - extensive reporting disaggregation. 
The previous section of the chapter has outlined variations in the scope and depth of the implementation activities across countries. What has become apparent is that some extensions to the EITI process may be relatively more costly to implement for one or more of the stakeholder constituencies in the respective MSGs. For example, current implementation practice shows that all EITIimplementing countries disaggregate their information by revenue streams (with varying level of extensiveness), whereas disaggregation company-by-company is more rare (Revenue Watch Institute, n.d). I argue below that extensive disaggregation of the reporting is a critical dimension, which is particularly difficult to introduce in the implementation activities and therefore important to investigate.

From the experiences of implementing countries it has turned out that the decision on the method of aggregation/disaggregation of the information in the agreed reporting standards is one of the most contested issues in the initiative's implementation (Darby, 2009; Iwerks, 2009; Ölcer, 2009; Revenue Watch Institute, 2012, April-a). Crucially, disaggregation of figures both company-bycompany and by revenue stream will produce the most detailed overview of different types of payments received by the government, as well as detailed figures on how much each company has paid in these payment categories.

While company-by-company disaggregation has so far not been a requirement to gain compliance status within the EITI, in practice its presence or absence is a critical factor influencing the extent to which the transparency target of the initiative can be reached, and, ultimately, how effective the EITI is in reaching its primary objective. The most extensive reporting is disaggregated both by company and by revenue stream, with a detailed break-down of revenue streams contributed by each company. A less extensive form of reporting includes disaggregation by companies, with a limited break-down of revenue streams contributed by each company. In the absence of disaggregation company-bycompany, the report is always disaggregated by revenue streams (with varying 
extensiveness of such disaggregation by revenue streams). When the EITI reports are published in a format which is not disaggregated by company, it is impossible to track the flow of payments from each participating company and, as a result, it is impossible to achieve transparency of payments made by each individual company. Of course, the aggregated form of the report will still provide a degree of transparency, giving information on total revenues collected by the government. Moreover, depending on the level of disaggregation by revenue stream, the report to a larger or lesser extent provides information on the revenues received by type. Yet it is obvious that extensiveness in the disaggregation of reporting provides a higher degree of transparency in the revenue flows into the budget.

Table 4.1 below illustrates the variance across countries that implement the EITI. Apart from the number and year coverage of the reports published up to June 2011, the focus is on the presence or absence of disaggregation at the company level. Out of the 37 implementing countries, only 28 EITI-participating countries are shown in the table. The remaining 9 countries $^{33}$ were excluded because as recent adopters they had not published an official report yet. As Table 4.2 illustrates, 17 out of 28 countries carried out reporting disaggregated by company, ${ }^{34}$ and 11 countries did not carry out such extensive disaggregation. It should also be noted that among the countries disaggregating company-by-company there is still variation in the extent to which company-by-company information is further disaggregated by revenue streams (this difference is not considered in the analysis).

\footnotetext{
${ }^{33}$ Countries with missing information that were excluded from the analysis are Afghanistan, Chad, Guatemala, Indonesia, Iraq, Madagascar, Sao Tome and Principe, Togo, and Trinidad and Tobago.

${ }^{34}$ Peru has provided partially disaggregated data by company, applying this only to companies that have agreed to disclose their disaggregated figures.
} 
Table 4.2 Type of Reporting in the EITI Implementers over Time: Reports

Published from the Beginning of Implementation until June $2011^{35}$

\begin{tabular}{|c|c|c|c|}
\hline Country & $\begin{array}{l}\text { Number of } \\
\text { reports } \\
\text { published }\end{array}$ & Years covered & Disaggregated by companies? \\
\hline Albania & 1 & 2009 & no \\
\hline Azerbaijan & 8 & $2003-2010$ & no \\
\hline Burkina Faso & 1 & 2008-2009 & yes \\
\hline Cameroon & 3 & $2001-2008$ & no \\
\hline $\begin{array}{l}\text { Central African } \\
\text { Republic }\end{array}$ & 2 & 2006-2009 & $\begin{array}{l}\text { no }\left(1^{\text {st }} \text { report published Feb. }\right. \\
2009) \text {, yes }(2 \mathrm{~d} \text { report published } \\
\text { July } 2010)\end{array}$ \\
\hline $\begin{array}{l}\text { Congo, Democratic } \\
\text { Republic }\end{array}$ & 1 & 2007 & yes \\
\hline Congo, Republic & 2 & 2004-2009 & no \\
\hline Cote d'Ivoire & 1 & 2006-2007 & no \\
\hline Equatorial Guinea & 2 & $2007-2008$ & no \\
\hline Gabon & 3 & 2004-2006 & no \\
\hline Ghana & 5 & 2004-2008 & yes \\
\hline Guinea & 2 & 2005-2006 & yes \\
\hline Kazakhstan & 5 & $2005-2009$ & no \\
\hline Kyrgyzstan & 1 & 2004-2008 & no \\
\hline Liberia & 3 & $2008-2010$ & yes \\
\hline Mali & 2 & $2006-2008$ & yes \\
\hline Mauritania & 2 & $2005-2006$ & no \\
\hline Mongolia & 4 & 2006-2009 & yes \\
\hline Mozambique & 1 & 2008 & yes \\
\hline Niger & 2 & 2005-2009 & yes \\
\hline Nigeria & 3 & 1999-2008 & yes \\
\hline Norway & 2 & $2008-2009$ & yes \\
\hline Peru & 1 & $2004-2007$ & yes \\
\hline Sierra Leone & 1 & 2006-2007 & yes \\
\hline Tanzania & 1 & 2008-2009 & yes \\
\hline Timor-Leste & 2 & 2008-2009 & yes \\
\hline Yemen & 1 & $2005-2007$ & no \\
\hline Zambia & 1 & 2008 & yes \\
\hline
\end{tabular}

Source: Analysis based on the EITI reports and Revenue Watch Institute (n.d).

When considering disaggregation by company over time, we can look at 17 countries which have published at least two reports by the time of the analysis (see Table 4.2). With the exception of Central African Republic, there have been no cases of switches from the aggregated by company form of reporting to

\footnotetext{
${ }^{35}$ Reports published in June 2011 were included if they were available.
} 
disaggregating by company, or vice versa. The pattern of the implementation activities in the first eight years of EITI's existence has been largely the following: once the initial decision on whether to report company by company is taken, countries stick to this form of implementation.

The next step of my analysis will focus on the dimension of disaggregation by company and will look for explanations of the presence or absence of disaggregation by company. The choice to focus on this dimension is motivated both by the empirical evidence illustrating difficulties in introducing extensive disaggregation and by the theoretical argument regarding the importance of extensive disaggregation for achieving the EITI's transparency objective. In addition, the demonstrated persistence of country choices regarding aggregation/disaggregation by company over time allows treating this factor in static terms - as a yes or no decision during the time period from the EITI's establishment until June 2011. ${ }^{36}$ This operationalization allows a cross-country comparison at one point in time, aimed at focusing on the structural differences between countries as explanatory factors. As regards explanations for the observed pattern of disaggregation, I test several theoretically derived explanations. As discussed above, I want to test for the possible influence of country-specific factors on the extensiveness of EITI implementation.

The existing literature offers a number of explanations for extensive implementation, which can be grouped into four main categories -1) characteristics of the standard, 2) characteristics of the activity, 3) country characteristics, and 4) influence of international actors (Jacobson \& Weiss, 1995, p.124-127; similar classification in Raustiala \& Slaughter $^{37}$, 2002, 545-548). These explanatory approaches are discussed below in more detail.

\footnotetext{
${ }^{36}$ The case of Central African Republic (the only country where there was a change from aggregation to disaggregation by company during the time period covered by the analysis) is treated as disaggregating.

${ }^{37}$ In addition to the four listed categories, they include additional categories of perceived legitimacy of the process and socialization into norms.
} 
When the characteristics of the standard are considered, these factors are constant across the implementing countries; in other words, I do not pursue comparison across different standards, but among various countries.

Taking the characteristics of the activity, we know that the EITI targets the extractive sector in all implementing countries. Yet, there may be an important difference: not all countries focus on their oil and gas, as well as non-hydrocarbon mining sectors. Consequently, the differences between these two sectors may have an effect on the extensiveness of implementation. Historically, the oil and gas sector has been more sensitive and more centrally controlled than the nonhydrocarbon mining sector. ${ }^{38}$ The sensitivity occurs for a number of reasons. First, economic rents from oil are higher than from non-hydrocarbon minerals, and oil projects are usually larger than mining projects; hence, the sector is a major source of revenues for the government. As a result, the oil sector is often viewed as a matter of national security by the government. Incidentally, one of the studies reviewed in section 1.2 finds a relationship between oil wealth (but not nonhydrocarbon mineral wealth) and the likelihood of civil war onset (de Soysa \& Neumayer, 2007). This finding further highlights sensitivity of the oil and gas sector, given the presence of particular risks associated with hydrocarbons, but not necessarily with other minerals. For reasons connected with security, the involvement of the state in the fiscal regime governing the extractive sectors is higher for the oil and gas sector than for mining, while oil production sharing agreements between the state and companies are much more common (Sunley \& Baunsgaard, 2001). Secondly, state-owned enterprises, often associated with centralized control, are much more common in the oil sector than in the mining sector, probably also for reasons of national security and also because of the capital intensiveness of the oil and gas sector. Thirdly, the oil and gas sector typically

\footnotetext{
${ }^{38}$ In the 1960s-1970s there was a massive push to nationalize industries, which within a decade was reversed as regards the mining sector, but not for the petroleum sector (World Bank, 2011).
} 
involves a lower number of companies competing, which limits the number of actors involved, thus further making the sector more sensitive to intrusions. According to Weiss and Jacobson (1995), the nature of the activity and, particularly, the costs and benefits of regulating the economic activity of concern, are important factors to consider. For the case of the EITI this means that it may be more difficult to introduce extensive disaggregation practices in the traditionally centralized oil and gas sector. This argument suggests the following hypothesis:

Hypothesis 1: Reporting in the oil and gas sector is associated with the absence of extensive disaggregation (disaggregation by companies).

The third category of explanations for extensive implementation practices is that of country characteristics. One variable frequently mentioned in the literature is the level of democratic freedoms. Many scholars argue that the mechanisms of public pressure and the better access to information that are characteristic for democratic regimes increase the capacities of implementation and the extensiveness of implementation. For this reason, the type of polity democratic or not - is a critical factor to consider (Weiss \& Johnson, 1995; Raustiala \& Slaughter, 2002). The regime type variable also turned out as an important explanation for policy adoption in the literature review in Chapter 3. While according to the findings of this chapter, the type of regime showed no observable effect on the decision to adopt the EITI, ${ }^{39}$ change of polity did matter, reflecting that systemic changes toward democratization can catalyze the adoption of the standard. Because of this, there is a particular interest to understand whether or not the type of regime has an impact on the post-adoption process of implementation. I therefore test the influence of the regime type on the

\footnotetext{
${ }^{39}$ It was argued that finding no relationship between the level of democratic freedoms and EITI adoption could be explained by the fact that democracies may already be doing well in the transparency of resource management and therefore do not see the benefits of adopting the standard. Additionally, authoritarian countries may be adopting the EITI as a brand name with the intention to improve their reputation, together with focusing only on the minimum required practices, without extending the scope and depth of the implementation process.
} 
extensiveness of disaggregation practices. Based on the polity-focused explanations, it is possible to formulate the following hypothesis:

Hypothesis 2: Democratic regime is associated with the presence of extensive disaggregation (disaggregation by companies).

The fourth cluster of variables considered in the literature on extensiveness of implementation refers to the influence of international actors. In the case of the EITI these are the EITI International Secretariat, the World Bank, and the NGOs, such as the Revenue Watch Institute, or Soros Foundation: they have the capacity to provide technical and in some case financial assistance to all implementing countries. Yet the extent of their assistance and influence may vary from country to country. Additionally, there may be the influence of bilateral country partners. Given this chapter's focus on the explanations at the country level, testing for the influence by these external agents is postponed until the detailed case study of the processes within the MSGs. At this stage, I focus on testing the effects of plausible structural constraints at the country level, such as polity and sector of implementation.

Data on aggregation/disaggregation practices and the reporting sector are self-compiled from the Revenue Watch Institute's data on EITI reports (Revenue Watch Institute, n.d) and the EITI reports. The most recent reports available at the time of analysis were published in June of 2011. Disaggregation is coded as 1 if done by company and as 0 if otherwise, and based on the last available report at the time period of analysis, as shown in Table 4.2. The data on the polity type comes from Polity IV database on regime levels. I take the polity score one year before the first report was published (regime level takes the values from -10 to 10). The reporting sector - oil and gas, and/or non-hydrocarbon mining - is coded based on the EITI reports and Revenue Watch Institute (n.d). The data is presented descriptively in Table 4.3 . 
Table 4.3 Overview: Regime Type, Reporting Sector and Disaggregation

Company-by-Company

\begin{tabular}{llll}
\hline Country & $\begin{array}{l}\text { Polity score one } \\
\text { year before the first } \\
\text { published report }\end{array}$ & Reporting Sector & $\begin{array}{l}\text { Disaggregation } \\
\text { by companies }\end{array}$ \\
\hline
\end{tabular}

Democracies

$\begin{array}{llll}\text { Albania } & 9 & \text { hydrocarbons } / \text { minerals } & \text { No } \\ \text { Ghana } & 6 & \text { minerals } & \text { Yes } \\ \text { Liberia } & 6 & \text { hydrocarbons } / \text { minerals } / \text { other } & \text { Yes } \\ \text { Mali } & 7 & \text { minerals } & \text { Yes } \\ \text { Mongolia } & 10 & \text { hydrocarbons } / \text { minerals } & \text { Yes } \\ \text { Niger } & 6 & \text { hydrocarbons } / \text { minerals } & \text { Yes } \\ \text { Norway } & 10 & \text { hydrocarbons } & \text { Yes } \\ \text { Peru } & 9 & \text { hydrocarbons } / \text { minerals } & \text { Yes (but partial) } \\ \text { Sierra Leone } & 7 & \text { minerals } & \text { Yes } \\ \text { Timor-Leste } & 7 & \text { hydrocarbons } & \text { Yes } \\ \text { Zambia } & 7 & \text { minerals } & \text { Yes }\end{array}$

Anocracies

Burkina Faso

Cameroon -4

Central African Republic ${ }^{41} \quad-1$

Congo, Dem. Rep. 5

Congo, Rep -4

Equatorial Guinea $\quad-5$

Gabon $\quad-4$

Guinea -1

Ivory Coast 0

Kyrgyzstan -3

Mauritania -3

Mozambique 5

Nigeria 4

Tanzania

Yemen -2

minerals Yes

hydrocarbons/minerals No

minerals Yes

hydrocarbons/minerals Yes

hydrocarbons No

hydrocarbons No

hydrocarbons/minerals No

minerals Yes

hydrocarbons No

hydrocarbons/minerals No

hydrocarbons/minerals No

minerals/gas Yes

hydrocarbons $\quad$ Yes

minerals/gas Yes

hydrocarbons No

Autocracies

$\begin{array}{llll}\text { Azerbaijan } & -7 & \text { hydrocarbons/minerals } & \text { No }\end{array}$

$\begin{array}{llll}\text { Kazakhstan } & -6 & \text { hydrocarbons/minerals } & \text { No }\end{array}$

Source: own analysis.

${ }^{40}$ The reports published in 2007 and 2009 included only minerals, whereas the reports in 2010 and 2011 covered hydrocarbons as well.

${ }^{41}$ Central African Republic as an exceptional case where there was a change toward disaggregation during the time period of the analysis cannot be explained by the change in regime type (as measured by Polity IV). The score of -1 in 2008 , before the first report, was also -1 in 2009 , before the second report. 
As Table 4.3 illustrates, there is a strong association between a positive regime score and disaggregation by companies. In fact, apart from the outlier case of Albania and the case of Peru with partial disaggregation, all democracies and all anocracies with a polity score above 0 carry out reporting disaggregated by company. Therefore, a positive polity score is not a sufficient condition for disaggregation by companies.

Despite a demonstrated strong association between a positive regime score and disaggregation by companies, a positive polity regime score is not a necessary condition for disaggregation by companies either. The rejection of necessity is demonstrated by tables 4.4 and 4.5. When considering the sample of countries which have carried out disaggregation by company (selection on the dependent variable, Table 4.4), we see that a positive regime score is not a necessary precondition because a sub-sample of anocracies with a polity score of 0 or -1 also carried out extensive disaggregation. An alternative way to demonstrate the same finding is to consider the EITI countries with a polity score equal to or below zero (selection on the x-variable, Table 4.5): among the countries in this sample, some carry out extensive disaggregation, which also proves that a polity score above zero is not a necessary precondition for disaggregation by companies. 
Table 4.4 Considering Only the Cases with Disaggregation by Companies

\begin{tabular}{lll}
\hline Country & Type of regime & $\begin{array}{l}\text { Disaggregation by } \\
\text { companies }\end{array}$ \\
\hline Burkina Faso & 0 & Yes \\
Central African Republic & -1 & Yes \\
Congo, Dem. Rep. & 5 & Yes \\
Ghana & 6 & Yes \\
Guinea & -1 & Yes \\
Liberia & 6 & Yes \\
Mali & 7 & Yes \\
Mongolia & 10 & Yes \\
Mozambique & 5 & Yes \\
Niger & 6 & Yes \\
Nigeria & 4 & Yes \\
Norway & 10 & Yes \\
Peru & 9 & Yes (but partial) \\
Sierra Leone & 7 & Yes \\
Tanzania & -1 & Yes \\
Timor-Leste & 7 & Yes \\
Zambia & 7 & Yes \\
& & \\
\hline
\end{tabular}

Table 4.5 Considering Only the Cases of EITI Countries with a Polity Score Equal to or Below Zero

\begin{tabular}{lll}
\hline Country & Type of regime & $\begin{array}{l}\text { Disaggregation by } \\
\text { companies }\end{array}$ \\
\hline Azerbaijan & -7 & No \\
Burkina Faso & 0 & Yes \\
Cameroon & -4 & No \\
Central African Republic & -1 & Yes \\
Congo, Rep & -4 & No \\
Equatorial Guinea & -5 & No \\
Gabon & -4 & No \\
Guinea & -1 & Yes \\
Ivory Coast & 0 & No \\
Kazakhstan & -6 & No \\
Kyrgyzstan & -3 & No \\
Mauritania & -3 & No \\
Tanzania & -1 & Yes \\
Yemen & -2 & No \\
& & \\
\hline
\end{tabular}

Source: own analysis.

When the nature of the sector (hydrocarbons, or mining) is considered, there is empirical support for the argument that reporting in the oil and gas sector 
(hydrocarbons) is a necessary (but not sufficient ${ }^{42}$ ) condition for the absence of disaggregation by companies. The fulfillment of criteria for necessity is shown in tables 4.6 and 4.7. EITI countries with no disaggregation by companies (selection on the y-variable, Table 4.6), are all countries implementing the EITI in the oil and gas sector (hydrocarbons). An alternative way to prove the same is to look at the sample of the EITI countries implementing the standard in the non-oil sector (selection on the $\mathrm{x}$ variable, Table 4.7): we see that all non-oil mineral reporters have disaggregated their reporting by companies. Moreover, since all EITI non-oil mineral reporters have done extensive disaggregation company-by-company, reporting in the non-hydrocarbon mining sector turns out to be a sufficient condition for disaggregation by companies.

Table 4.6 Considering Only the Cases with Absence of Disaggregation by Companies

\begin{tabular}{lll}
\hline Country & Type of reporting & $\begin{array}{l}\text { Disaggregation by } \\
\text { companies }\end{array}$ \\
\hline Albania & Hydrocarbons/minerals & No \\
Azerbaijan & Hydrocarbons/minerals & No \\
Cameroon & Hydrocarbons/minerals & No \\
Congo, Rep & Hydrocarbons & No \\
Equatorial Guinea & Hydrocarbons & No \\
Gabon & Hydrocarbons/minerals & No \\
Ivory Coast & Hydrocarbons & No \\
Kazakhstan & Hydrocarbons/minerals & No \\
Kyrgyzstan & Hydrocarbons/minerals & No \\
Mauritania & Hydrocarbons/minerals & No \\
Yemen & Hydrocarbons & \\
\hline
\end{tabular}

\footnotetext{
${ }^{42}$ It is not a sufficient condition because we observe democratic EITI countries reporting in
} the oil and gas sector and doing disaggregation by companies (see Table 4.3). 
Table 4.7 Considering Only the Cases of EITI Countries Carrying out Reporting in the Non-oil Mining Sector

\begin{tabular}{lll}
\hline Country & Type of reporting & $\begin{array}{l}\text { Disaggregation by } \\
\text { companies }\end{array}$ \\
\hline & & \\
Burkina Faso & Minerals & Yes \\
Central African Republic & Minerals & Yes \\
Ghana & Minerals & Yes \\
Guinea & Minerals & Yes \\
Mali & Minerals & Yes \\
Mozambique & Minerals/gas & Yes \\
Sierra- Leone & Minerals & Yes \\
Tanzania & Minerals/gas & Yes \\
Zambia & Minerals & Yes \\
& & \\
\hline
\end{tabular}

Source: own analysis.

The empirical evidence strongly supports the claim that for the processes of implementation the regime type and the type of sector both play a prominent role in determining the extent of implementation activities in the dimension of disaggregation. According to the data, it turns out that implementing the EITI only in the non-hydrocarbon mining sector has so far been a sufficient condition for the inclusion of the disaggregation requirement by company. When looking at the impact of regime type, non-democracies with an established oil sector do not disaggregate the data by company. The EITI participants in the oil and gas sector have disaggregated company by company only in democratic settings (and even then, democratic regime was not a sufficient condition for company by company disaggregation, as the case of Albania has shown).

These findings have implications for the strategy of case selection for further investigation of the stakeholder processes within the EITI countries. The way in which the EITI can achieve the highest transparency (and thus likely the highest impact) would be through the adoption of additional features of extensive implementation (of which disaggregation is an important one, but not the only one). A key challenge for the EITI, therefore, is constituted by countries that are not voluntarily adopting transparency policies beneficial to the improvement of 
resource revenue management. As this chapter has shown, such countries are with some likelihood countries with a negative polity score rich in oil and natural gas. It therefore seems promising to take a closer look at these countries, in order to identify the bottlenecks for more extensive implementation. At the same time, such an enquiry may lead to the identification of mechanisms that possibly enable policy change within the countries that are experiencing deadlocks in furthering the scope of their implementation. The logical strategy to achieve such a deeper understanding is to study in detail the way in which implementation is done in those countries. Of particular importance in this respect is the structure of domestic arrangements and the stakeholder negotiations leading to specific implementation outcomes. Against this background, Chapter 5 will study the impact of stakeholder positions on the implementation activities in two EITI countries characterized by an authoritarian political system and EITI implementation in the oil and mineral sectors.

\subsection{Conclusion}

As argued above, country choices on the specifics of EITI implementation affect not only the implementation processes, but ultimately have an impact on the effectiveness of the policy. This chapter first conceptualized the difference between implementation, compliance, and effectiveness, explaining the necessity to focus on the implementation activities in more detail. Next, I constructed an index of various dimensions of implementation along which cross-country differences occur. Eight major dimensions along which countries can vary in their EITI implementation are 1) which sectors they cover in the EITI process, 2) how they define materiality of revenue streams to be reported, 3) how audit or reconciliation is carried out, 4) the extent to which disaggregation occurs, 5) whether sub-national reporting is done, 6) whether social payments are reported, 7) whether phases other than upstream activities are included, and 8) how the EITI is organized formally at the domestic level, i.e. what the shape of the multi-stakeholder group is. The first 
dimension reflects which sectors the country chose to cover under the EITI - both the non-hydrocarbon sector (most importantly minerals, but also other raw materials), and the hydrocarbon sector (oil and gas), or only one of the above. Dimensions 2 through 6 concern the level of payments' transparency, while dimension 7 relates to possible extensions to other natural resource management phases, prior or post payment collection. Finally, dimension 8 reflects on the institutional set-up and has implications on decision-making structures, more or less conducive to promoting extensive transparency practices.

In the fourth section of the chapter, I took up one of the critical dimensions of the implementation - the level of disaggregation in the reporting - and explored whether the prominent theoretical explanations for the extensiveness of implementation activities can explain the decision to disaggregate company by company. Based on the literature review, polity type and sector were identified as important predictors. My analysis showed that implementing the EITI in the nonhydrocarbon mining sector so far has been a sufficient condition for extensive disaggregation. On the other hand, implementing the EITI in the oil and gas sector was a necessary condition for the absence of disaggregation by companies (not a sufficient condition because most EITI democracies reporting payments in the oil and gas sector did carry out disaggregation by companies).

It was also shown that extensive disaggregation in countries with a positive polity score occurred in all cases, except Albania (a democracy not carrying out extensive disaggregation). Democracy by itself was neither a necessary nor a sufficient condition for extensive disaggregation (due to the outlier case of Albania), though it was strongly associated with the likelihood of extensive disaggregation: of the 14 countries with a positive regime score, 13 carried out extensive disaggregated reporting.

The implication of these findings is that besides the influence of MSG stakeholders at the national level, larger overarching factors can explain certain implementation outcomes at the country level. Yet the findings also matter for the 
case selection strategy in Chapter 5. Based on the results of this chapter's analysis, it was argued that countries with authoritarian regimes carrying out the EITI in the oil and gas sector are most likely to profit from extensive EITI implementation, and at the same time the least likely to carry out this model. I therefore selected countries from this category for within-country investigation in Chapter 5. 


\section{Chapter 5: The Influence of Stakeholder Arrangements on the EITI Implementation in Azerbaijan and} Kazakhstan

Summary: Having shown how the EITI implementation activities differ across various policy dimensions, the previous chapter has concluded by introducing the case for further investigating the implementation processes in "critical case" countries - authoritarian in regime and carrying out the EITI in the oil and gas sector. This chapter undertakes a detailed study of the EITI domestic implementation processes in such critical case environments. Using the cases of Azerbaijan and Kazakhstan, I look into whether and how the configuration of stakeholder positions impacted the implementation activities in the two countries during the time period of 2003-2011.

\subsection{Introduction}

The findings of Chapter 3 revealed that resource abundance, low income, ethnic fractionalization, and polity change toward democratization increase the likelihood of country participation in the EITI. In Chapter 4 it was shown that once the EITI is adopted (i.e. a country achieves EITI candidacy status) and countries start implementation of the EITI, the content of the implementation activities varies greatly across countries. Even countries which have already achieved the status of compliance with the EITI can differ significantly in the ways they implement the initiative. Moreover, it was argued that authoritarian countries implementing the EITI in the oil and gas sector are likely to be more difficult in the sense of not voluntarily adopting extensive implementation practices. Taking the analysis of the various conditions of adoption and implementation one step further again, this chapter concentrates on the more detailed processes occurring within countries. Specifically, I explore the question of how the configuration of stakeholder ${ }^{43}$

\footnotetext{
${ }^{43}$ The stakeholders, in line with the EITI design, are the representatives of government, companies and civil society.
} 
positions influences the extensiveness of the EITI implementation activities in the critical case countries.

Azerbaijan and Kazakhstan were chosen for closer investigation through detailed country case studies. They are both authoritarian, oil-rich countries, which given their economic situation are expected to benefit from the EITI. As Chapter 4 has shown empirically, these countries, given their political climate and focus on the EITI in the oil and gas sector, are expected to encounter most difficulties when it comes to implementing the EITI beyond the required minimum as regards disaggregation as a dimension. Both countries joined the EITI as candidates as part of the first wave of participants ${ }^{44}$; both were present at the first 2003 EITI conference; and both are rich in oil and natural gas and have similar figures on relevant economic variables. Moreover, Azerbaijan and Kazakhstan both are autocracies with a low Polity score, causing them to have the lowest ranking on democratic freedoms among the sample of authoritarian countries that implement the EITI.

The methodological approach used in this chapter combines process tracing, analysis of primary documents in the form of EITI reports and official EITI-related documents, and semi-structured interviews with stakeholders and experts (the list of conducted interviews is available in Annex IV). Findings are discussed against expectations, which can be derived from the literature on the particular motivations of government, companies, and civil society constituencies for the extensiveness of the EITI implementation.

\footnotetext{
${ }^{44}$ Azerbaijan announced its decision to start implementation at the very first EITI Conference in London in 2003, followed by the establishment of the NGO Coalition created in 2004. Kazakhstan's timeline was different: first, on the basis of recommendations at the Public Policy Forum (held in 2003), an NGO Coalition was established in 2004. The EITI was officially endorsed in 2005. Official EITI candidacy, however, was granted to both countries at the same time on 27 September 2007. This happened on the same date (even though Azerbaijan has declared implementation earlier) due to the fact that the EITI guidelines and rules on candidacy were established only in 2007. At that time, a number of countries were pioneering in the implementation of the initiative already.
} 
The time period covered by my analysis comprises the years from 2003 until the end of 2011. During this period, Azerbaijan's published reports address the years 2003-2010, while Kazakhstan's published reports disclose figures on the years 2005-2009.

The case study was conducted in three phases. In the first phase, broad structured interviews were conducted with the officials at the EITI Secretariat. The purpose of these exploratory interviews in the early stages of the project was to formulate expectations about the motivations of countries ${ }^{45}$ to adopt the EITI and implement it extensively. Prior to the interviews, potential motivations were derived from the theoretical literature, and the aim of the interviews was to explore whether there may be other factors, besides the ones identified in the literature. More specifically, in inquiring about potential motivations to adopt the standard and implement it extensively, I probed for possible effects of lower economic development, desire to attract FDI, regime type and political leadership, reputational motivations, external influence factors, and recent discovery of extractive resources. Based on the evidence from the interviews and the results of chapter 4 , the selection of case studies was completed, and I have formulated two objectives for the comparative analysis of the EITI process in Azerbaijan and Kazakhstan - first, tracing whether the expectation for these countries as critical cases (where extensive implementation is not likely) indeed holds true for all dimensions of EITI implementation; second, how the configuration of stakeholder positions has impacted the EITI process in the two countries over time. In the second phase of the case study, I have analyzed primary sources (EITI reports), as well as secondary sources (documents by the MSGs, the civil society constituencies, validator companies and EITI Secretariat reports), thus conducting a process tracing of the implementation activities in the two countries over time.

\footnotetext{
${ }^{45}$ I inquired about motivations of all possible EITI implementing countries (not focusing specifically on Azerbaijan or Kazakhstan), as the interviews had been conducted before the selection of cases for chapter 5 was finalized (also before the model in chapter 3 was developed).
} 
Finally, the third phase of the case study relied on the interviews conducted in Baku and Almaty, which were used to cross-check the analysis conducted and to clarify questions or issues, for which I needed further evidence. In preparing and designing the fieldwork, I have contacted members from all constituencies of the respective MSGs, but most of the interviews were conducted only with the members of the civil society constituencies, reflecting absence of response from the constituencies of government and companies. This limitation of the study means that my findings can only identify the official stakeholder positions in the MSG negotiations, but not the preferences of the stakeholder members within each constituency (with the exception of the constituency of civil society, for which I was able to acquire evidence on within-the-constituency preferences ${ }^{46}$ ). The interviews lasted approximately for an hour and were conducted in Russian or, when preferred by the respondents, in Azerbaijani (with the help of a certified interpreter) or in English. All interviews were recorded, transcribed, and archived both as audio files and transcribed documents.

The chapter is organized as follows. The socio-economic similarities between Azerbaijan and Kazakhstan are outlined in greater detail in section 3.2, setting up the argument for their comparability as countries with similar structures. Next, I proceed to theory building and the formulation of concrete expectations regarding the positions of stakeholders with respect to extensive or less extensive EITI implementation. Section 5.4 traces the implementation activities in Azerbaijan and Kazakhstan over time, identifying the outcome of MSG negotiations on each of the dimensions of implementation. In section 5.5, I analyze the configuration of the stakeholder positions in the domestic negotiations of the

\footnotetext{
${ }^{46}$ Some evidence on differences in preferences within the constituencies of companies and government was available, and I include these findings in the analysis (section 5.5). However, I explicitly state that the primary focus of this chapter is on the official stakeholder positions in the MSG (not on the stakeholder preferences), as I have not been able to confirm the evidence on the differences within the constituencies of government and companies through the extensive interviews with the respondents from the respective constituencies.
} 
two countries in order to find out whether the positions observed empirically agree with the theoretical expectations. Finally, the conclusion of this chapter will follow in section 5.6.

\subsection{Similarities in Socio-economic Structures of Azerbaijan and Kazakhstan}

If Azerbaijan's first commercial production of oil started in 1873, Kazakhstan's oil drilling took off almost forty years later, in 1911 (World Energy Council, 2010). Kazakhstan is in fact the most oil-abundant country among the former Soviet republics (not counting Russia). For instance, in 1998 Azerbaijan was estimated to possess 1.2 thousand million barrels of oil and 0.8 trillion cubic meters of natural gas, whereas Kazakhstan was estimated to control 5.4 thousand million barrels of oil and 1.8 trillion cubic meters of natural gas. With further oil discoveries, these estimates were updated to present estimates of 7 thousand million barrels in Azerbaijan and 30 thousand million barrels of oil in Kazakhstan. These reserves constitute $0.4 \%$ and $1.8 \%$, respectively, of the global reserves in 2011 . For natural gas, the difference between the two countries is smaller, with estimates for Kazakhstan being 1.9 trillion cubic meters, or $0.9 \%$ of the world's reserves in 2011, and for Azerbaijan 1.3 trillion cubic meters, or $0.6 \%$ of the world's reserves (Table 5.1 based on BP, 2012). 
Table 5.1 Oil and Natural Gas Reserves in Azerbaijan and Kazakhstan

\begin{tabular}{|c|c|c|c|c|c|c|c|c|}
\hline & 1997 & 1998 & $\begin{array}{l}1999- \\
2001\end{array}$ & 2002 & $\begin{array}{l}2003- \\
2006 \\
\end{array}$ & 2007 & $\begin{array}{l}2008- \\
2011 \\
\end{array}$ & $\begin{array}{l}2011 \\
\text { share of } \\
\text { world } \\
\text { reserves }\end{array}$ \\
\hline \multicolumn{9}{|l|}{$\begin{array}{l}\text { Oil Reserves (thousand } \\
\text { million barrels) }\end{array}$} \\
\hline Azerbaijan & $\mathrm{n} / \mathrm{a}$ & 1.2 & 1.2 & 7.0 & 7.0 & 7.0 & 7.0 & $0.4 \%$ \\
\hline Kazakhstan & \multirow{2}{*}{$\mathrm{n} / \mathrm{a}$} & \multirow{2}{*}{5.4} & \multirow[t]{2}{*}{5.4} & \multirow[t]{2}{*}{5.4} & \multirow[t]{2}{*}{9.0} & \multirow[t]{2}{*}{30.0} & \multirow[t]{2}{*}{30.0} & \multirow[t]{2}{*}{$1.8 \%$} \\
\hline $\begin{array}{l}\text { Natural Gas Reserves } \\
\text { (trillion cubic meters) }\end{array}$ & & & & & & & & \\
\hline Azerbaijan & 0.8 & 0.8 & 1.2 & 1.2 & 1.2 & 1.2 & 1.3 & $0.6 \%$ \\
\hline Kazakhstan & 1.8 & 1.8 & 1.8 & 1.8 & 1.8 & 1.9 & 1.9 & $0.9 \%$ \\
\hline
\end{tabular}

Source: BP Statistical Review of World Energy (2012).

When considering which of the two sectors - mining or hydrocarbons accounts for the larger share of exports, it can be observed that for both countries the oil and gas sector is more prominent. Figure 5.1 shows the trend of fuel and mining product exports for Azerbaijan and Kazakhstan. When the exports of nonfuel mining products are excluded (Figure 5.2), the overall export value decreases only slightly, thus showing that it is fuels that comprise most of the exports from the resource-intensive sector for both countries. 
Figure 5.1 Exports of Fuels and Mining Products by Azerbaijan and Kazakhstan

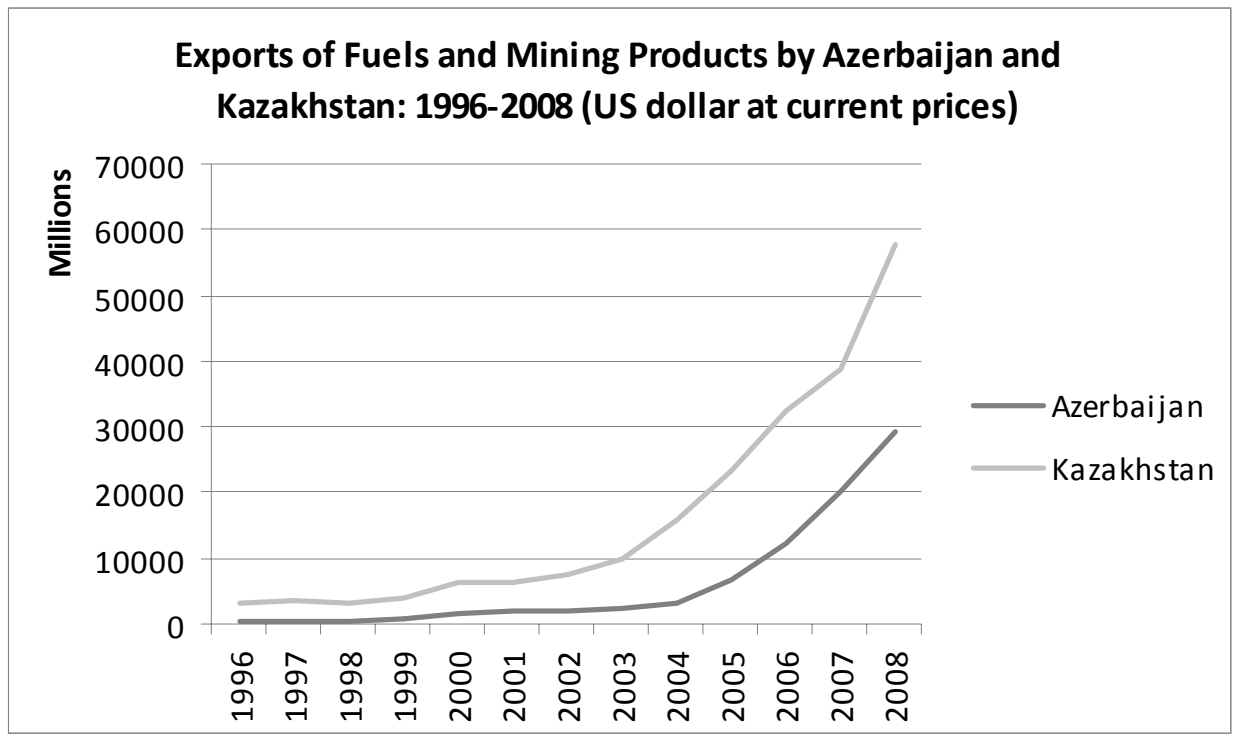

Source: WTO Trade Profiles (2012).

Figure 5.2 Exports of Fuels by Azerbaijan and Kazakhstan

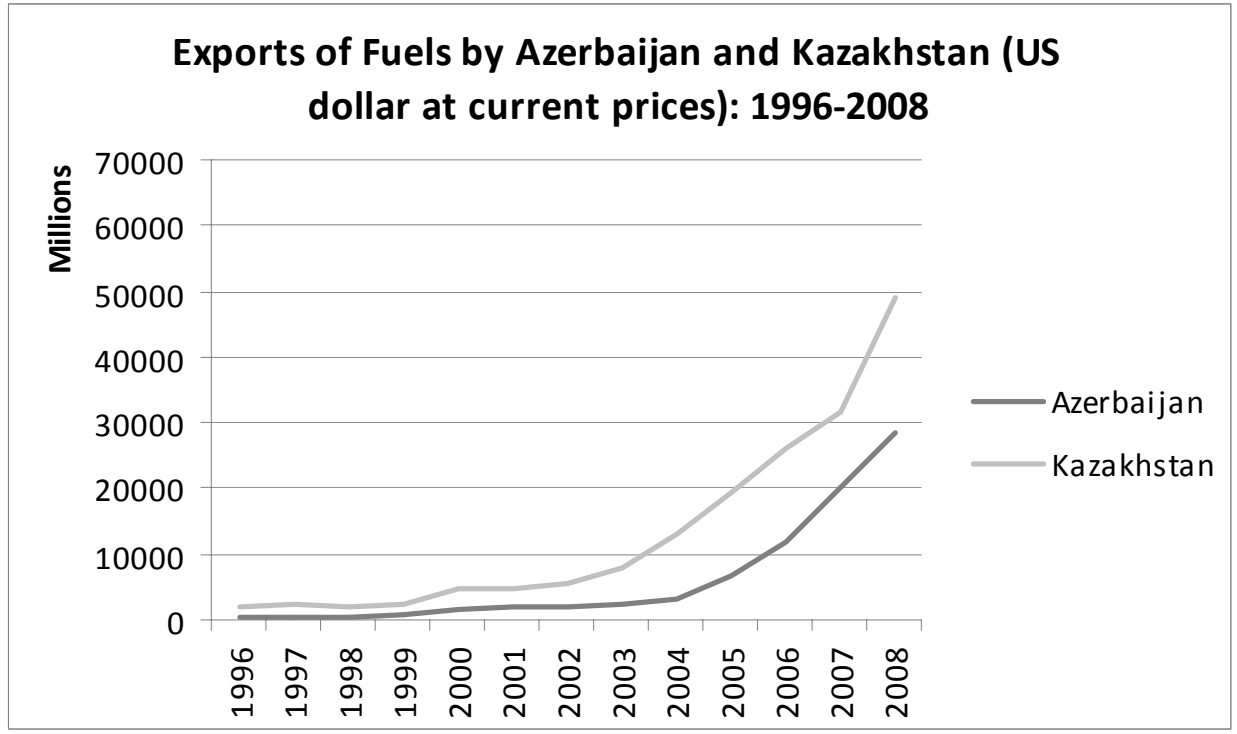

Source: WTO Trade Profiles (2012). 
Furthermore, Figure 5.2 shows an upward trend for fuel exports in both countries, as well as the different size of their fuel exports. Figure 5.3 on oil production supports the impression of the two trends shown above: a rising production of oil in both countries and differences in the annual amount produced by each country (which is to be expected, given their variously sized reserves).

\section{Figure 5.3 Oil Production in Azerbaijan and Kazakhstan}

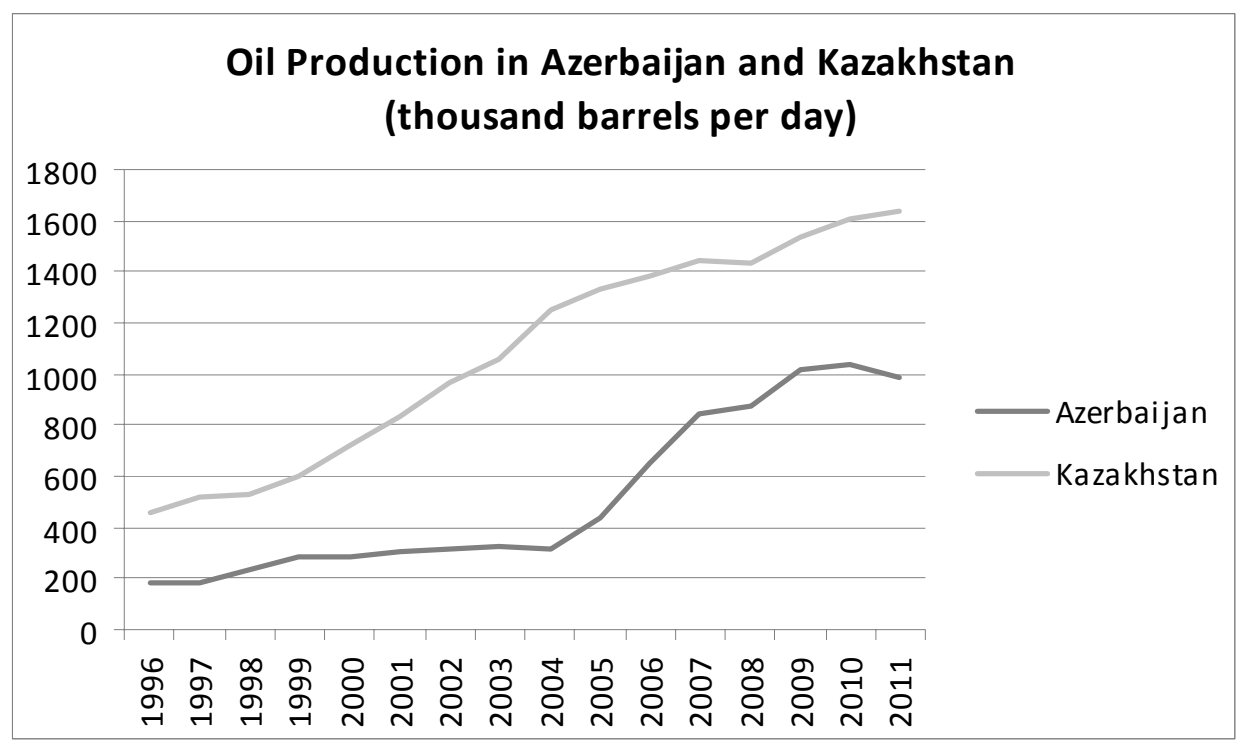

Source: U.S. Energy Information Administration (2012).

In addition, it is important to assess the level of economy's dependence on the oil exports. As one might expect, both Azerbaijan and Kazakhstan are highly dependent on their extractive industries: the breakdown in the economy's total exports by commodity (between the sectors of manufacturing, agriculture, and fuel and mining products) reveals that for 2010, 95.7\% of Azerbaijan's exports and $82.9 \%$ of Kazakhstan's exports comprise fuels and mining products (WTO, 2012). Although the two countries produce and export different volumes of mineral products, we can reasonably consider them to have a similar economic structure. Both specialize in the oil and gas sector, marked by a high level of oil production 
in particular, while their economies are highly dependent on the revenues from the extractive sector.

Regarding their political systems, both countries were former republics of the Soviet Union; therefore, in the early 1990s they faced challenges common to all Newly Independent States. According to Polity IV regime trends (Polity IV, 2010), both Azerbaijan and Kazakhstan have gradually become more authoritarian since the break-up of the Soviet Union. The most recent data (Figure 5.4) classify them as autocracies (Polity score of -6 or below). The Corruption Perception Index of Transparency International for 2011 (Transparency International, 2011) gives a 2.4 score to Azerbaijan and a 2.7 score to Kazakhstan, with 0 meaning "highly corrupt" and 10 meaning "very clean." It is therefore reasonable to consider the countries as critical cases - authoritarian in regime, with relatively high corruption scores, and rich in oil and gas. These characteristics were shown in Chapter 4 to be associated with the absence of extensive disaggregation transparency practices. 
Figure 5.4 Polity Trends in Kazakhstan and Azerbaijan: 1991-2010 Authority Trends, 1991-2010: Kazakhstan

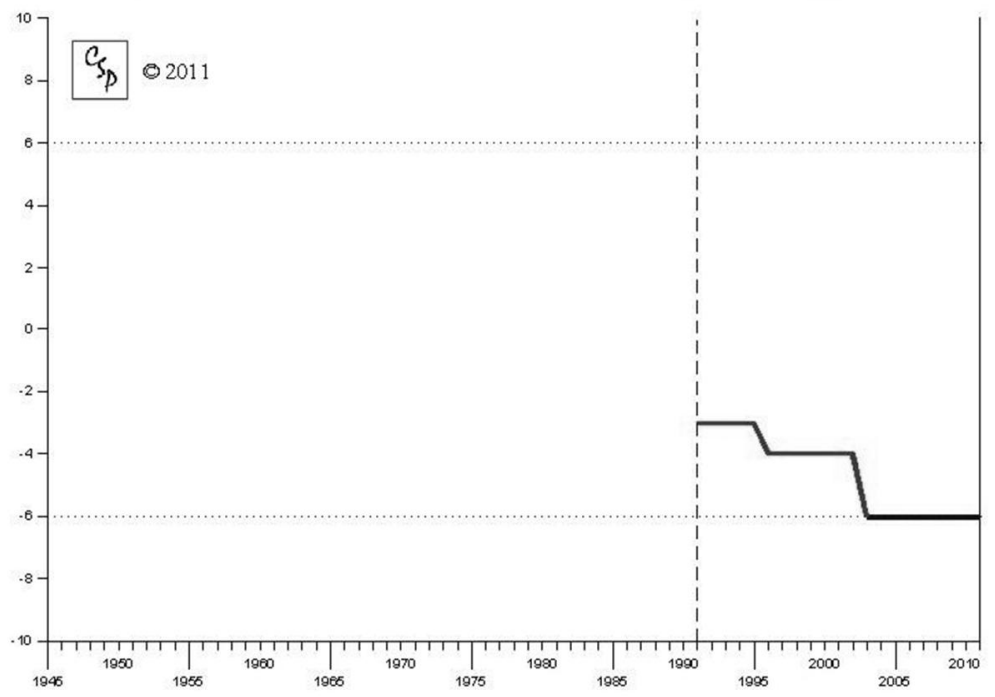

Authority Trends, 1991-2010: Azerbaijan

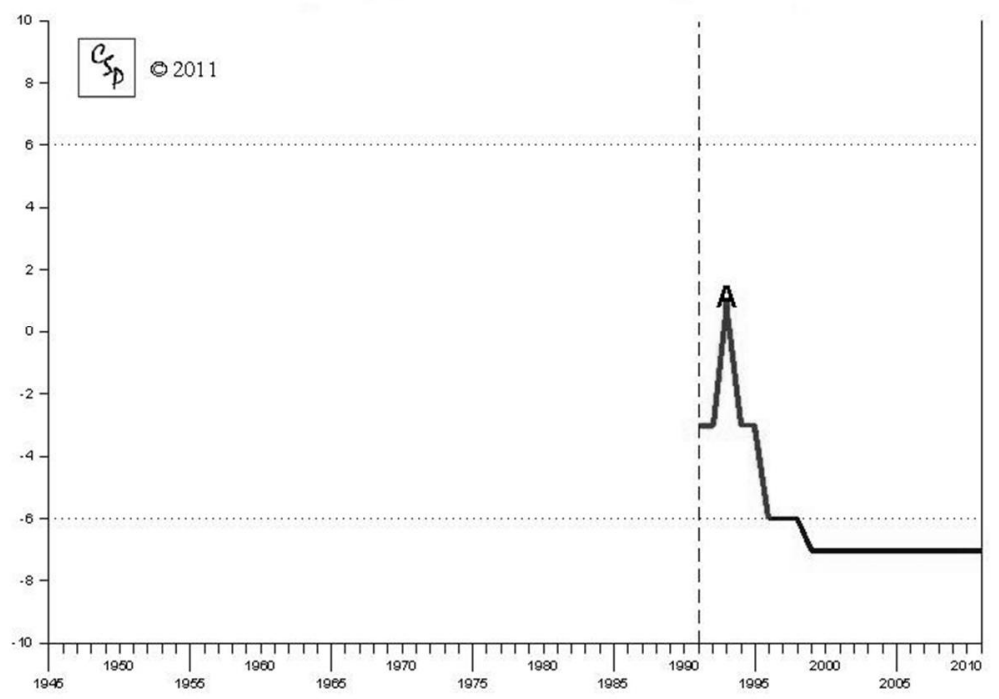

Source: Polity IV Individual Country Polity Trends (2010). 


\subsection{MSG Stakeholder Positions: Expectations from the}

\section{Literature}

Based on the general hypothesis addressing the question of the stakeholder committee impact on the implementation activities (see 2.4.3 above), it is possible to formulate the following more specific hypothesis: large ideological distance between stakeholders leads to policy stability, or, in other words, blocked change in a country's implementation activities over time.

A subsequent relevant step is to derive expectations about the stakeholder positions regarding the extensiveness of the EITI implementation activities. Using existing theoretical literature, specific predictions on the positions of each stakeholder constituency are formulated, with the aim of checking these against a country's realities. I first derive particular expectations on the stakeholder positions from existing theories of government, company and civil society motivations, after which I analyze whether the empirically observed positions in the case study countries correspond with the theoretically derived expectations. A crucial point to note is that I focus on the joint position of each stakeholder constituency in the MSG, meaning that internal differences within a constituency are not a primary concern here. I theorize differing preferences within each constituency to some extent in order to determine the expectations on the joint position of each constituency. In fact, the interviews I held with stakeholders provided some information on such differences within constituencies. Where relevant, I discuss these findings, yet I stress that the focus remains on the official position of each constituency in the MSG (and not on the within-the-constituency preferences). A study of internal group differences would require a different methodology, one more in line with constructivist approaches, which are beyond the scope of my project.

Regarding the position of the government, it is plausible to expect that a non-democratic government is likely to negotiate for less extensive EITI 
requirements. The theoretical justification and empirical evidence in support of such expectation, particularly for the critical contexts regarding the EITI in the oil and gas sector, were presented already in my analysis of disaggregation practices (see 4.4). While Chapter 4 dealt with disaggregation as a particularly difficult dimension to be introduced, the same theoretical reasons for expecting less extensive practices can be applied to other dimensions of implementation. One possible reason for the authoritarian government not to introduce any radical change in favor of the extensive practices is the lack of opposition parties, which in democratic societies often exert pressure on the government by pointing out the failures and thus forcing the government to take action. If there is little party-based competition within a country's political structure, little pressure for change will be exerted on that country's government (Zohlnhöfer, 2003, p.127). Such a government, in other words, does not feel much external pressure to do more than the minimum agreed, which encourages policy stability, or only incremental policy change. Moreover, non-democratic countries are more likely to suffer from corruption (Zhang, Cao, \& Vaughn, 2009). This implies that actors within the government who profit from negotiating specific contracts and deals can highly benefit from the status quo (Collier \& Hoeffler, 2005; Robinson et al., 2006). Introduction of an extensive transparency mechanism would significantly limit opportunities for personal gain in such situations, which means that politicians in power wishing to introduce reforms may face serious counteraction from those standing to lose. Thus, the joint government position is driven toward less extensive implementation. It should be noted that less extensive implementation is still beneficial for the government constituency, which continues to benefit from improved internal reporting and tracking of revenues, as well as from an improved international reputation.

As to the position of companies in the MSGs, studies identified a number of reasons that may motivate companies to implement extensive practices. Many studies have shown the importance of public pressure in explaining the outcome of 
high or low corporate social disclosure (Patten, 1991; Trotman \& Bradley, 1981). Public pressure variables are usually measured as proxies and, as a result, may vary from one study to the next; especially common proxies in the literature are company size and industry. Other oft-considered explanatory variables are profitability, country of company ownership, country in which reporting occurs, and ownership identity (state or private). In addition, some literature looks into capital intensity, senior executive attitudes, company age and the existence of CSR committees (detailed reviews in Cowen, Ferreri, \& Parker, 1987; Hackston \& Milne, 1996; Tagesson, Blank, Broberg, \& Collin, 2009). The causal explanation for corporate social disclosure is usually the following: transnationalization of company operations which has occurred throughout the $20^{\text {th }}$ century (Reed, 2002), together with parallel growing recognition that governments alone cannot solve societal problems (Smith, 2003), led to the situation where MNCs have become globally visible and are facing more external pressures to be involved in CSR practices (Cowen et al., 1987; Hackston \& Milne, 1996; Jenkins, 2004; Tagesson et al., 2009). It is plausible, therefore, to expect that the pressures for large transnational companies to disclose extensive corporate information are also high in the case of the EITI standard.

First, the global visibility of large companies increases their reputational risks primarily in consumer markets, but also in labor and equity markets. In consumer markets such risks are related to profitability and, even more so, possible losses from civil activists' pressure, such as boycotts. In labor markets the risks are related to the loss of high-skilled employees who are concerned with ethical issues and prefer to work for socially responsible companies. Smaller size companies, on the other hand, are less visible and therefore face less risk to their brand image or reputation. These companies usually focus on CSR in local programs (Jenkins, 2004); due to the lower number of shareholders, they may even report such CSR involvement via informal channels rather than official reporting (Cowen et al., 1987). Furthermore, MNCs have a larger global societal impact and therefore face 
more pressure from media and the public (Smith, 2003; Tagesson et al., 2009). Another reason for the expectation that companies of smaller size will lean toward less extensive EITI practices is linked to the minimal pressures, if any, on these companies from the EITI global governance structures. Most transnational companies have officially articulated their support for the EITI standard, as stakeholder of the EITI as a global initiative. Because they are represented on the EITI Board, they may be more familiar with the potential benefits of the extensive EITI and are more likely to be socialized into extensive EITI practices than small local companies which do not participate in the EITI globally. Virginia Haufler argues that one of the very important reasons for company involvement in CSR is learning from business communities (Haufler, 2001, p. 20). In the case of the EITI, such learning is less relevant for small companies than for the MNCs. Whereas transnationals often represent the constituency of companies at the EITI global structures, most companies of smaller size are not involved with the EITI at the international level, nor do they have access to all the EITI Board debates on the nature of EITI reporting. Thus, small companies have less information on the EITI and may be more likely to resist extensive requirements, which are new to them both in practice and discourse. Given the same logic of different pressures exerted on companies, it is important to consider company ownership. It is reasonable to expect local companies to be significantly more under the influence of the national government in cases where companies are state-owned (or operators of state-owned companies) rather than privately owned. In such cases, the government may have more influence on the company position as regards the form of EITI implementation.

Azerbaijan and Kazakhstan both have oil and gas companies, as well as mining companies, which are either privately-owned or state-owned while their size varies. According to the above-discussed literature, such differences in company characteristics imply likely differences in the preferences and positions of different companies, reflected in the presence or absence of a willingness to adopt 
additional transparency requirements. My expectation on the joint company position is the least common denominator, resulting in minimal addition of extensive voluntary practices.

I expect the stakeholder side representing civil society to negotiate for extensive implementation and inclusion of additional requirements in the implementation activities. One of the main goals of civil society organizations is the improvement of accountability mechanisms, through which regulatory instruments can be subject to public scrutiny. The first objective in reaching this goal is an increase in transparency of the regulatory mechanism, resulting in a greater public disclosure of activities in respect to which the actors involved (the government and the companies for the EITI case) are to be held accountable. The subsequent objective is monitoring and evaluation of the policies (Scholte, 2004). To achieve both of these objectives, the stakeholder constituency representing civil society has a direct interest in the inclusion of the extensive reporting templates to realize optimally transparent management of the natural resources. As a stakeholder constituency, then, this actor is expected to be the one most interested in the extensive practices of the EITI.

The composition of the constituency representing civil society can be quite diverse. According to the policy networks perspective, groups of actors or professional associations influence particular issues at stake (Capano, 2009; Cope, 2001), which means that the civil society organizations within the constituency may have a specific interest in different issues. For example, some civil society organizations could focus on the human rights of workers in the industries involved, others could push the agenda of transparent budget practices, while still others may be primarily interested in broader anti-corruption efforts. As demands of various civil society groups may differ depending on their issue focus, I expect their joint constituency position to be in favor of extensive transparency requirements across all dimensions. 
Finally, I consider the possibility of external influence by the international actors on the likelihood of more extensive EITI requirements. The analysis of Chapter 3 found little support for the hypothesis on external influence as being associated with the likelihood of EITI adoption. Nonetheless, external influence mechanisms may play a larger role in the processes subsequent to adoption of the initiative. External influence actors - such as the World Bank, bilateral partners, the EITI International Secretariat, donor agencies, and transnational NGOs potentially alter incentives for one or more of the stakeholder constituencies, thus influencing the formation of their positions on the extensiveness of EITI implementation.

In summary, I expect a wide gap between the government's positions and those of civil society, while companies are likely to side with the government, which results in the status quo of less extensive EITI practices and no radical policy changes. According to the predictions derived from the existing literature, the constituency of companies in both Kazakhstan and Azerbaijan are expected to be quite diverse in terms of within-the-constituency preferences: the interests of the small (usually local) companies may contradict those of the transnational companies, and state-owned companies may have interests different from privately-owned companies. Government and civil society, on the other hand, are expected to be more coherent internally as constituencies, yet they presumably hold opposing views as regards the extensiveness of implementation.

Given my research focus, this chapter concentrates mainly on the theorized joint constituency positions, reflected in the outcomes of the negotiations between the stakeholders in the MSGs. To test the main hypothesis - that the ideological distance between the stakeholder constituencies explains the lack of extensive implementation activities in both Azerbaijan and Kazakhstan - I empirically explore the nature of the implementation activities in the case countries. To test whether the predictions about the positions of the stakeholder constituencies are 
confirmed, I analyze data collected from the primary documents, the historical process tracing, and the interviews with the stakeholders.

\subsection{EITI Implementation Activities in Azerbaijan and Kazakhstan}

Having established in Chapter 4 the dimensions along which differences in EITI implementation activities can occur, I assess the type of implementation in each one of the dimensions for Azerbaijan and Kazakhstan. In contrast to the particular focus on disaggregation as a dependent variable (see 4.4), the qualitative nature of the case study allows one to consider all dimensions of the implementation activities. While theories on the stakeholder positions outlined in the previous section lead me to expect policy stability and absence of extensive implementation in both countries, this expectation needs to be assessed empirically. Given that decisions on each of the dimensions could change throughout the course of implementation, I moreover trace each of the dimensions over time. By doing so, I aim to conduct a process tracing of EITI implementation activities in the two case countries and thus assess the differences and similarities in this dependent variable. After providing a summary of the implementation history in the two countries, I will assess the various separate dimensions of their implementation activities.

\subsubsection{Summary of Implementation History in Azerbaijan and Kazakhstan}

Azerbaijan was one of the first EITI countries, as it became involved in the implementation shortly after the EITI was announced by the British Prime Minister Tony Blair in 2002. At the First EITI Global Conference in London in 2003, the delegation of Azerbaijan officially announced the government's decision to adopt the initiative (SOFAZ, n.d-a). It was Ilham Aliyev, at the time a first vice president of the State Oil Company of Azerbaijan Republic (SOCAR), who served as 
spokesperson on behalf of the government at the first EITI Conference (Aliyev, 2003). In the same year he became vice president of Azerbaijan, and, a few months later, its president.

The first EITI reports, which disclosed figures for 2003 and the first 6 months of 2004, were published on March 15, 2005 (SOFAZ, n.d-c). By the beginning of 2007 Azerbaijan had already published five EITI reports (SOFAZ, n.d-e). Such progress was recognized by the UN, and Azerbaijan became a winner of the 2007 UN Public Service Award in the category "Improving transparency, accountability and responsiveness in the public service" (SOFAZ, n.d-e). Azerbaijan gained the status of EITI compliance on February 16, 2009. By the end of 2011, the country had published eight annual reports.

According to the EITI Secretariat (EITI International Secretariat, n.d-c), Kazakhstan's endorsement of the EITI occurred in 2005, when President Nazarbayev announced his government's decision to adopt the initiative. The process leading up to this event had started much earlier, however. As Aitenova et al. (2007, p.7) point out, the British DFID initiated negotiations with the government of Kazakhstan about EITI participation soon after the establishment of the initiative. The first information on prospects of the EITI in Kazakhstan appeared in the report Caspian Oil Windfalls: Who Will Benefit (Tsalik, Ebel, \& Caspian Revenue Watch, 2003), produced by the Open Society Institute (OSI) with participation by experts from Kazakhstan, among others. The report was presented in June 2003 in Almaty at a roundtable organized by the Public Policy Research Centre (PPRC) with financial support from the OSI and the Soros FoundationKazakhstan (Aitenova et al., 2007, p.7). As a result of increasing public knowledge about the EITI, in the summer of 2004 sixteen Kazakhstani non-governmental organizations created a coalition representing civil society, which was named Oil Revenues - under Public Oversight! Shortly after the first press conference given by the Coalition, the number of NGO participants had increased to 43 (Aitenova et al., 2007, p.7). Aitenova et al. (2007, p.8) explain that the Coalition initiated a 
campaign to attract public and government attention to the issues of transparency in natural resource management. In February 2005, a letter outlining the benefits of the EITI was sent to all members of the Kazakh Parliament. Two members of its Lower House - Mr. Itegulov and Mr. Ibrahimov - formally requested a government position on the EITI by sending an inquiry to the country's then prime minister, Danial Akhmetov. As a result of these activities, in April 2005 a governmental inter-departmental working group was established to examine the details of the EITI process with the aim of defining a formal government position on the initiative (Aitenova et al., 2007, p.8). On June 14, 2005 President Nazarbayev announced his support of the EITI at the opening of the International Business Conference in Almaty (Nazarbayev, 2005).

The first reporting exercise was conducted in 2006, but the report from that year was unavailable to the public due to the kind of audit standard selected. This was corrected, and the subsequent reports are open to public access. The first report was published in 2007 (with figures for 2005). The second EITI Report was published in 2008, and the third and fourth reports, covering the years 2007 and 2008 , appeared in 2009 . The last available report on the period under scrutiny was published in 2011 and covered payments for 2009. Despite progress in EITI implementation, the validation report - endorsed by the National Stakeholder Council of Kazakhstan in August 2010 - did not convince the EITI Board that it should grant the status of compliant member to the country. After the evaluation, the EITI Board granted Kazakhstan additional six months (until June 12, 2011) to complete the necessary actions to achieve compliance with the EITI standard (EITI International Secretariat, n.d-c), but the initial validation deadline was not met. Since then and until the end of 2011, Kazakhstan has not been able to achieve compliance status; it only produced another report in 2011 (covering figures for 2009). 


\subsubsection{Which sectors are covered?}

In Azerbaijan the reporting templates in the beginning of the EITI process included figures on oil and gas, which resulted in six annual reports covering the years from 2003 until 2008. Starting in 2010 and until, most recently, 2012 (when the reports covering 2009, 2010 and 2011 were published) information on gold and silver was included in addition to payments in the oil and gas sector. In Kazakhstan the first report published in 2007 covered figures for 2005 and reported payments in the oil and gas sector only. Starting from the second report published in 2008 up to the most recent, fifth report published in 2011, payments in the mining sector were added for the reports covering the years from 2006 up to 2009. Both countries, therefore, have expanded the sectoral scope of their EITI implementation activities over time, but they continued to concentrate on the traditional hydrocarbon and mining sectors, rather than including forestry or agriculture, as some of the other innovating countries have done.

\subsubsection{How is "materiality" of revenue streams defined?}

Companies that are members to the Memorandum of Understanding $(\mathrm{MoU})^{47}$ in Azerbaijan are obliged to disclose their payments. In the report covering 2005, 21 companies had submitted the information on their payments. The number of companies that are party to the $\mathrm{MoU}$ and participating increased to 31 by 2011 . As one of the interviewees noted, with the recent increase in company participation, all companies with material revenues in the oil and gas sector are now involved in Azerbaijan's EITI (interview, April 13, 2010).

In Kazakhstan company participation in the EITI process was voluntary in the first years of implementation. For example, the first report covering figures for 2005 included information submitted by 35 companies, whereas the Memorandum

\footnotetext{
47 The MoU was signed in November 2004 by the constituencies of the government, companies and civil society as the document governing EITI implementation in Azerbaijan. The governing structures are discussed in more detail in 5.4.9.
} 
of Understanding had been signed by 42 companies. The civil society coalition called attention to this underrepresentation, declaring that only a small number of extractive companies had joined the implementation process and that mining companies were underrepresented (Aitenova et al., 2007, p.14). The situation has improved since then: the second report with figures for 2006 covered payments by 102 companies, the third and fourth reports (2007-2008 figures) covered 108 and 109 companies, respectively, and the last available report (2009 figures) covered payments by 123 companies. Furthermore, a new law was adopted which introduced mandatory subscription to the EITI process for all companies bidding for future contracts on subsoil usage.

From the discussion above it becomes apparent that decisions on materiality criteria - the threshold determining the size of payments and/or the size of company operations to be reported - can indeed vary, as illustrated by the implementation activities in Azerbaijan and Kazakhstan. The oil and gas sector in Azerbaijan involves a lower number of companies than in Kazakhstan, which explains the differing number of companies participating in the EITI in the two countries. In the beginning of EITI implementation, Kazakhstan did not specify a materiality criterion, which led to a situation of voluntary joining by companies (reflected in the report for 2005). The minimum required EITI was not achieved due to the exclusion of significant revenue volumes. When the MSG in Kazakhstan later corrected this issue, the definition of materiality in Kazakhstan covered all companies in the sector, which meant that over 100 companies reported. Despite the progress on this issue, the EITI Board has requested additional information on the methodology for setting a materiality criterion before the status of compliance could be granted to Kazakhstan (EITI International Secretariat, 2012, 14-15 February, pp. 6-7). 


\subsubsection{How is data checked for validity?}

In both countries, every report was checked for its validity by an audit company through a reconciliation exercise, which analyzed the reports of payments, provided by the government and companies. Information on discrepancies was included. In the case of differences between the payments reported, where possible it was explained how they occurred and/or were resolved.

\subsubsection{What is the extent of disaggregation?}

In both countries, during the period of scrutiny, the reports did not disclose any information on payments at the company level (though in Azerbaijan payments by local and foreign companies were separated). There was, however, disaggregation by revenue streams. In Azerbaijan the first reports provided figures on oil and gas production in volume only, and for minerals in value only, which became one of the points the civil society coalition addressed. For example, suggestions by the coalition after examining the reports for the January-June 2005 period included provision of revenue figures in value terms, as well as in-kind terms (The Coalition of Azerbaijan Non-Governmental Organizations, 2006). This suggestion was adopted and already in the 2007 report on 2006 oil was reported in value, as well as volume; in the 2008 report (on 2007) figures on gas in value were added. Further revenue streams were added in subsequent years: in 2009 (the report on 2008) gas in volume was divided into streams for natural gas and associated gas; in 2010 (report on 2009) the figures on volume of silver and gold were added, and the information on price change ${ }^{48}$ was included. While disaggregation by revenue streams has been increasing over time, disaggregated reporting by companies was not adopted (interview, April 13, 2010; interview, November 22, 2011; interviewa, November 23, 2011; interview-c, November 23, 2011; interview, November 24, 2011; interview, November 25, 2011).

\footnotetext{
${ }^{48}$ This stream refers to the revenues from the price difference between the budgeted price and the world market price of exported oil.
} 
Not all companies in Kazakhstan operate under production-sharing agreements (PSAs) and, as a result of Subsoil Use Law adopted in 2010, Kazakhstan will no longer sign contracts structured as PSAs. This means that the difference between Azerbaijan and Kazakhstan regarding the type of reported revenue streams is partly due to the difference in the fiscal regimes governing their oil and gas sector, with Kazakhstan not including information on production volumes. Still, the breakdown by taxes is very extensive in Kazakhstan. As the respondents noted, one of the accomplishments was to include even the tax payments that are non-existent in the current law framework, yet are continuing to be paid as part of the signed PSAs (interview, December 1, 2011). In the first report covering payments for 2005 , disaggregation by revenue streams was done with a detailed breakdown by categories of taxes, ${ }^{49}$ special payments of subsurface users, ${ }^{50}$ other mandatory fees,${ }^{51}$ customs payments, ${ }^{52}$ payments to the state, ${ }^{53}$ fines and penalties paid to the state. ${ }^{54}$ Subsequent reports for the years 2006, 2007, and 2008 excluded the categories of payments to the state and fines and penalties, keeping the remainder of revenue stream categorization intact. The last available report published in 2011 and covering 2009 included an additional category of dividends. ${ }^{55}$ It should be noted that the issue of company by company disaggregation has been on the agenda of MSG discussions since the very beginning of the EITI process in Kazakhstan, similar to the situation in Azerbaijan

\footnotetext{
${ }^{49}$ Corporate income tax, excise tax, social tax, land tax, personal income tax withheld at the source of payment, vehicle tax, and property tax.

${ }^{50}$ Excess profit tax, bonuses, royalty, rent tax, share of Kazakhstan in profit oil, additional payment under production sharing agreement.

${ }^{51}$ Fees for land use, environmental protection, water use, forest use, radio spectrum, miscellaneous duties, and other budgetary duties.

${ }^{52}$ Customs fees, custom duties.

${ }^{53}$ Payments to the road fund, the obligatory medical insurance fund, the state social insurance fund, as well as other payments.

${ }^{54}$ Administrative fines and penalties imposed by the central state authorities and their territorial subdivisions, administrative fines and penalties imposed by the local state authorities, and other fines and penalties imposed by the state bodies financed by the state budget.

${ }^{55}$ For nationally and regionally owned state shares.
} 
(interview, November 13, 2011; interview, December 1, 2011; interview, December 15, 2011).

\subsubsection{Is there sub-national reporting?}

In the reports up to present (for Kazakhstan last report covering 2009 and for Azerbaijan last report covering 2010) reporting templates did not include subnational payments.

\subsubsection{Are social payments included?}

In the case of Kazakhstan, the first report covering 2005 had included mandatory monetary social payments by type and value; however, this stream was excluded from the reports covering subsequent years. During the period covered by my analysis, both countries have engaged in discussions on the inclusion of social payments in the reporting schemes, and they have reached a provisional agreement on the inclusion of this revenue stream in the new templates for forthcoming reports (interview-a, November 22, 2011; interview, November 25, 2011; interview, December 1, 2011; interview, December 14, 2011).

\subsubsection{Are additional phases of resource management cycle included?}

Neither of the countries has included information on the additional phases of the resource management cycle associated with their EITI process. However, some information is available through other venues. For example, Azerbaijan has made some of the PSAs public (interview-c, November 23, 2011; interview, April 13, 2010). In contrast, the PSAs signed by Kazakhstan are not publicly available (interview, April 13, 2010; interview, December 1, 2011). An important extensive feature in Kazakhstan is availability of company-by-company disaggregated information through the sources of the state ministry (2011, interview, December 
$15,2011)$. In both cases this information has not been officially linked to or included in the EITI reports.

\subsubsection{In the years prior to official EITI guidelines, was there a MSG established?}

When Azerbaijan joined the EITI as a pilot country in 2003, the EITI did not yet have guidelines about the creation of a domestic multi-stakeholder group, which today is a requirement before candidacy status is granted to a country. Therefore, initially Azerbaijan did not have a tri-partite MSG consisting of companies, government, and civil society; rather, the government created a different structure overseeing the implementation. By ordinance No. 224, dated November 13, 2003 the Cabinet of Ministers of Azerbaijan established the National Committee on the EITI. The Committee was chaired by the Executive Director of the State Oil Fund of Azerbaijan (SOFAZ) and included Azerbaijan's ambassador to the UK, members of the state oil company (SOCAR), and representatives from different state ministries. $^{56}$

Key to establishing the Committee and initiating implementation was the current President of Azerbaijan, Ilham Aliyev (SOFAZ, n.d-a) who at the time of EITI initiation was the first vice president of SOCAR. The National Committee on the EITI held its first meeting on December 22, 2003 (SOFAZ, n.d-b); and in November 2004 a Memorandum of Understanding between the National Committee, extractive oil and gas companies, and the NGO Coalition was signed (SOFAZ, n.d-d). An important point in this regard is that the structure of the National Committee on the EITI in Azerbaijan did not involve civil society members at the time. The NGO Coalition was a party to the Memorandum of Understanding and therefore could exercise its right to ask for additional meetings

\footnotetext{
${ }^{56}$ Ministry of Foreign Affairs, Ministry of Economic Development, Ministry of Industry and Energy, Ministry of Finance, Ministry of Tax, Ministry of Ecology and Natural Resources, and Ministry of Statistics.
} 
if the need arose, but no regular meetings were scheduled. In practice this set-up made it much more difficult to have negotiations between the stakeholder constituencies in the way it was envisioned by the EITI (interview-a, November 22, 2011). In addition to the National Committee, two other committees played a role: the Audit Selection Committee, composed of two representatives from each of the constituencies of the stakeholders, and the Validation Steering Committee, composed of three representatives from each of the stakeholder sides. Furthermore, ad hoc "EITI Committee" meetings have been held twice a year since 2003, chaired by the executive director of SOFAZ and composed of government representatives and SOCAR representatives (Coffey International Development Ltd., 2009, pp.6-9).

Even though establishment of a permanent MSG was advocated by the NGO coalition, the government took action on this point only after the validation exercise. At the third International EITI Board meeting held on September 27, 2007, a validation procedure was created by the EITI Board, and Azerbaijan initiated its validation process in 2008 (SOFAZ, n.d-f). Following validation and recommendations of the EITI Board, Azerbaijan established an MSG, including members from government, companies and civil society, and created a work plan (EITI International Secretariat, n.d-a). It comprised steps that were not carried out in the early years of implementation because the guidelines at the time did not demand such steps. In January 2009 the EITI Secretariat in Azerbaijan officially proposed creation of the MSG, which was subsequently established (Coffey International Development Ltd, 2009, pp.6-9), thus resolving the concern about the deficit of NGO formal participation. The EITI Board designated Azerbaijan as Compliant on February 16, 2009 (EITI Secretariat, n.d-a), when Azerbaijan became the first EITI compliant country (SOFAZ, n.d-g).

The announcement of EITI adoption in Kazakhstan was followed up by drafting the Memorandum of implementation, which outlined the details of how the implementation process would be organized. The Memorandum's first draft was 
done by the Ministry of Energy and Mineral Resources. Members of Oil Revenues - under Public Oversight!, the NGO coalition of civil society groups, agreed upon a number of propositions to the Memorandum, among which were disaggregation of data on payments at company level and by types of payment, and company disclosure of information on social investments and payments to the local budgets (Aitenova et al., 2007, p.9). However, at the next meeting the new version of the Memorandum produced by the Kazakhstan Petroleum Association was much more protective of the extractive industries' interests. According to Aitenova et al. (2007, p.10), the date for signing the Memorandum was so close that the disagreements on the Memorandum's content were not resolved, and there was no consensus on the final document when the Memorandum was presented for signing on October 5, 2005. As a result, it was signed by the representative of the government working group, by a group of parliamentarians, and by 26 oil companies, but not by the civil society coalition. A number of other NGOs were then invited to join as signatories on the behalf of civil society, which made the Memorandum legitimate. Aitenova et al. $(2007$, p.10) state that isolating the coalition from the EITI process concerned some parliamentarians and representatives of extractive companies. Eventually a consensus was reached that established a National Stakeholders Council (NSC), a body overseeing EITI implementation, which formally institutionalized the stakeholders in the process - government, companies, parliamentarians, and civil society - in line with the earlier proposal of the coalition. Kazakhstan's NSC, to a great extent, resembled what would be later designed as the MSG by the EITI guidelines. Oil Revenues - under Public Oversight! then signed the Memorandum on December 9, 2005.

\subsubsection{Comparative summary of implementation activities in Azerbaijan and Kazakhstan}

For the time period addressed by my analysis, the key dimension identified in Chapter 4 - disaggregation - was realized in both countries by means of revenue 
streams. In the case of Kazakhstan the revenue streams covered by the first report were already quite extensive; later reports excluded the category of payments to the state and the category of fines and penalties; the last report covering 2009 included an additional category of dividends. The number of participating companies grew from the initial 35 to 123. In Azerbaijan the reporting templates gradually introduced additional revenue streams over the years, starting from reporting oil and gas in value besides volume. Later on, gas was divided into an associated gas stream and a natural gas stream, while also streams on gold and silver volume were added, as well as price changes in local companies. The number of companies increased from the initial 21 to 31 . Another difference concerned the status of the MSG: whereas in Azerbaijan it was officially established only in recent years, the civil society coalition in Kazakhstan refused to sign the Memorandum until the MSG was created, even though it was not an official EITI requirement at the time.

Despite these differences, it can be said that the patterns of implementation activities over time were quite similar in the two countries. As it turned out, in both countries the process of change was incremental, with minor additions or changes in the revenue streams of reporting templates during the period of 2003 to 2011. This finding highlights that even in the authoritarian countries implementing the EITI in the oil and gas sector (argued to be difficult cases) extensions of the EITI process have been introduced over time. During the period under scrutiny (20032011) both Azerbaijan and Kazakhstan have gradually introduced incremental changes in most dimensions of implementation. Extensive disaggregation by revenue stream and by company was not introduced in those years, even though it was adopted in Kazakhstan's later reports. ${ }^{57}$

\footnotetext{
${ }^{57}$ This issue is further discussed below, in 5.5.
} 


\subsection{Analyzing the Influence of Stakeholders on the Implementation Activities}

The interviews conducted for this project only in part confirmed the theoretically derived expectations on the positions of the stakeholders during MSG negotiations. To discuss the positions in detail, I outline the findings in this section for each of the stakeholder constituencies.

The expectations on the position of civil society were largely confirmed. In both Azerbaijan and Kazakhstan, the civil society members have been advocating the most extensive EITI possible. In both countries the interviewees confirmed that the civil society constituency strongly insisted on disaggregation by companies and by revenue streams from the very beginning of the EITI implementation.

Moreover, further practices for a more extensive EITI were advanced by the civil society coalition, some of which were later adopted and implemented.

In Azerbaijan, for example, the information on production figures was incomplete initially (figures were published only in volume for oil and gas, and only in monetary value for minerals). In later reports this was changed on the recommendations of civil society actors (interview, November 22, 2011; interviewc, November 23, 2011; interview, November 24, 2011; interview, November 25, 2011), and the report for 2006 included figures on values as well as volume of oil. The report for 2007 had additional figures on gas in value, and in the report for 2009 , figures on volume of silver and gold were added; "other payments" in the report were broken down by tax categories. The changes in the type of reporting in Azerbaijan were introduced slowly over the years. The respondents noted that pressure from civil society also led to the inclusion of company social payments that would be introduced in the next report of Azerbaijan for the first time. This is a proposal which was put forward by the civil society coalition from the very beginning of the EITI process (interview, November 22, 2011; interview-c, November 23, 2011). Furthermore, one of the respondents (interview-c, November 
$23,2011)$ noted that disclosure of all contracts is being discussed within the MSG and most likely will eventually become available. ${ }^{58}$

In Kazakhstan, the situation was the same in the sense that demands made by the civil society constituency were similar and that progress in the reporting was due to civil society influence. As seen from the history of the NSC's establishment, civil society was instrumental in organizing the EITI process in the country. Moreover, from the outset Kazakhstan's reporting was disaggregated by type of payments with a very detailed breakdown by sub-categories of taxes and fees. In the report covering 2009 dividends were added and the last accomplishment was the expected addition of social payments in the upcoming report (interview, November 30, 2011; interview, December 1, 2011). Some respondents noted that an important move was the inclusion of all taxes, currently existing and already non-existing in the law, but continuing to be paid by the companies (interview, December 1, 2011). Furthermore, the next planned report will comprise a planned pilot inclusion of sub-national reporting (interview, November 30, 2011).

Beyond the confirmation of the broad expectation about extensive implementation demands by the constituency representing civil society, some interesting additional differentiations surfaced. I expected civil society to be united in demanding extensive EITI practices. In practice, though, coherence in the coalition was hardly a straightforward matter. For instance, in Azerbaijan the civil society coalition included NGOs which focused on ecology and human rights issues besides organizations mainly promoting transparency in natural resource management (the core focus of the EITI). Some wanted to focus more on the spending side of the revenues, and others wanted to battle specific corruption cases (interview, November 22, 2011; interview-a, November 23, 2011; interview-b, November 23, 2011). The demands of these organizations exceeded the core of the EITI as it is defined internationally, which made it extremely difficult for the civil

\footnotetext{
${ }^{58}$ Currently only two contracts are publicly disclosed.
} 
society coalition to keep its strategies primarily focused on the main requirements: the disclosure of revenue figures.

While the members of the civil society constituency in Azerbaijan were united in their desire of extensive implementation, there were differences within the constituency over tactics of negotiation in the MSG. These mainly concerned differences on how radical the demands of the civil society constituency should be. Some of the respondents in Azerbaijan were discontent with incremental changes. Dissatisfaction with the audit procedure, lack of contract transparency, and limited report dissemination were raised as issues (interview-a, November 23, 2011; interview-b, November 23, 2011; interview, November 25, 2011), while skepticism was voiced on whether the EITI had any potential to be a real mechanism of transparency (interview-a, November 23, 2011; interview-b, November 23, 2011). At the same time, others disagreed and advocated the EITI should move step-by step with incremental changes; accordingly, the civil society coalition should press for small changes rather than radically demand the inclusion of all possible extensive features of the implementation at once (interview, November 22, 2011; interview-c, November 23, 2011). One respondent in Azerbaijan (interview-a, November 23, 2011), for instance, stated that one of the tactics suggested by the civil society members in the beginning of the implementation process was to include only one and the most important proposal - extensive disaggregation company-by-company - for the Memorandum of Understanding when it was being drafted. This suggestion, however, was not adopted, and a list of proposals to amending the Memorandum was added, out of which, according to the respondent, the most important demand of disaggregation by companies was predictably excluded by other stakeholders from the later negotiations. Another respondent in Azerbaijan disagreed with the strategy of requesting transnational companies to participate in the EITI, which according to the respondent was unacceptable, and civil society should have had the right to demand rather than request provision of transparent information (interview-b, November 23, 2011). 
In Kazakhstan similar differences on the civil society tactics occurred. Originally there was only one civil society coalition in Kazakhstan (Oil Revenues Under Public Oversight!), but over time two additional coalitions within the stakeholder constituency of civil society developed. During late 2011, when the interviews were conducted, Grazhdanskiy Alyans and Azamattyk Kuryltay were active as well, while two more coalitions ${ }^{59}$ were in the process of formation (interview, November 30, 2011; interview, December 14, 2011; interview, December 15, 2011). The breakdown of Kazakhstan's civil society coalition into three factions occurred in 2008 (interview, November 30, 2011), and many disagreements among them were over tactical issues. Whereas Oil Revenues Under Public Oversight! and Grazhdanskiy Alyans believed that the progress in Kazakhstan's EITI was sufficient to qualify for compliance, Azamattyk Kuryltay interpreted certain EITI indicators of compliance as not fulfilled, thereby advocating that given the current state of affairs Kazakhstan could not qualify for compliance (interview, November 30, 2011; interview, December 1, 2011; interview, December 15, 2011). One of the issues brought up by some respondents was the unfair representation of coalitions in the civil society constituency at the MSG. They maintained that the pro-government coalition Grazhdanskiy Alyans, while formally being part of the EITI process, did not participate de facto, and many members of Oil Revenues - Under Public Oversight! were simultaneously members of Grazhdanskiy Alyans, which resulted in blocked proposals of the underrepresented Azamattyk Kuryltay within the civil society constituency (interview, December 14, 2011; interview, December 15, 2011). This situation led to questions regarding the parity of sides representing the civil society constituency in Kazakhstan. Incidentally, similar sentiments regarding pro-government civil society representatives within the constituency of the civil society were also voiced by some respondents in Azerbaijan (interview-a, November 23, 2011; interview-b,

\footnotetext{
${ }^{59}$ One of these two new formations were to be titled "EITI +"; the name of the other one was still unknown.
} 
November 23, 2011). In Kazakhstan, however, the situation got more complicated when Azamattyk Kuryltay wrote to the EITI Secretariat expressing arguments why Kazakhstan should not be granted the status of being compliant with the initiative. The other coalitions from civil society disagreed, considering the former letter a radical move and rather advocating Kazakhstan to be worthy of the compliance status based on the progress in implementation it had achieved.

Finally, the issue of incentives for civil society was brought up by some of the respondents. Some considered the financial support of the civil society coalition (for instance, by SOROS, DFID) to have a negative impact on the role of civil society in its functioning as a stakeholder constituency because civil society ended up fighting over who would receive the grants rather than focus on the real issues improving the implementation of the EITI (interview-a, November 23, 2011; interview-b, November 23, 2011). In Kazakhstan some of the respondents (interview, November 30, 2011; interview, December 1, 2011) brought up the issue of disagreements between civil society coalitions over who would represent the civil society stakeholder constituency during the multi-stakeholder negotiations (3 representatives and 3 substitutes for each stakeholder constituency), as well as issues over financial incentives (interview, December 1, 2011).

Regarding the position of companies, the expectation that there would be a common joint company position against extensive implementation practices was confirmed in both countries under scrutiny. At the same time, there was some evidence on differences in the positions of transnational companies and local companies, in line with the theoretical expectations. In Azerbaijan, the official position of the company constituency during MSG negotiations was against disaggregation; in line with the reasoning that disaggregation might reveal confidential information. However, several interviewees observed a difference between the positions of some MNCs and local companies (interview, April 13, 2010; interview, November 22, 2011; interview, November 24, 2011; interview, November 25, 2011). To be sure, there were also differences among the MNCs: 
whereas BP and Statoil voluntarily provided their disaggregated information (interview-c, November 23, 2011; interview, November 24, 2011), American companies, together with local operators, were against company-by-company disaggregation (interview, April 13, 2010; interview, November 25, 2011). SOCAR's position was to provide disaggregated information only in the case of all companies agreeing to do so (interview, November 22, 2011). Even though BP and Statoil individually provided disaggregated information, one of the respondents (interview-a, November 23, 2011) pointed out that in several recent court cases, both BP and Statoil were reluctant to reveal certain information, for instance, on their local contracting organizations. This, according to the respondent, showed that even transnational companies may have to operate within the opaque mechanisms still prevalent in the local contexts. Another issue involving lack of transparency by individual companies was raised regarding SOCAR, and the respondent gave examples of how figures on oil production from SOCAR were inconsistent across different sources of information. When the respondent requested such type of information via letters to SOCAR, letters were ignored, and when SOCAR was contacted by phone regarding the issue, it was asked to pose the questions in writing (interview-a, November 23, 2011). Thus the reluctance of all companies to provide disaggregated data was viewed by some respondents as an indirect confirmation of company involvement in secret deals and corrupt agreements (interview-a, November 23, 2011; interview-b, November 23, 2011). At the same time, several respondents stated there were reasons to expect that disaggregation by companies would eventually occur in Azerbaijan. For instance, according to one of the respondents, the representative of the company constituency had recently stated in the MSG meeting that all companies but one agreed to provide disaggregated information (interview-c, November 23, 2011). Due to the lack of consensus on the side of companies, in the period under scrutiny only few companies provided their disaggregated reporting voluntarily. With the Dodd-Frank Act (requiring all registered with the US Securities and Exchange 
Commission (SEC) companies to provide their disaggregated reporting) and a similar EU proposal soon to go into force, ${ }^{60}$ an increasing number of transnational companies was expected to start disclosure of disaggregated reporting (interview, April 13, 2010; interview, November 23, 2011). For instance, Exxon Mobil and Chevron would be affected by this law, and these companies, as several interviewees explicitly noted, so far had refused to provide disaggregated data for publication (interview, April 13, 2010; 2011, interview, November 25, 2011).

In the case of Kazakhstan, respondents also confirmed that companies differed in their positions, but similar to the situation in Azerbaijan a joint lowest common denominator position on the level of extensiveness seemed to prevail during the negotiations (interview, December 14, 2011; interview, December 15, 2011). Exxon Mobil was given as an example of a company reluctant to provide disaggregated information to the public (interview, November 30, 2011; interview, December 14, 2011), just as it was the case for this company in Azerbaijan. One respondent (interview, December 15, 2011) noted that there was not much active participation by local companies in the MSG negotiations, so that the company stakeholder constituency was represented by one of the major transnational companies (Exxon Mobil, and later Statoil). Another respondent stated that the contribution of companies in introducing extensive implementation features was absent, or even negative (interview, December 14, 2011). Some of the other respondents noted cases where the companies concurred with the position of the civil society coalition on certain issues. For instance, in the very beginning of the EITI set-up, when the civil society coalition refused to sign the Memorandum unless there would be a National Stakeholder Council (MSG-like body), it was the side of companies that demanded the civil society coalition to be included in the process, on the grounds that it would participate in drafting the Memorandum of Understanding. Another example was the support which some companies gave to

\footnotetext{
${ }^{60}$ The discussion on Dodd-Frank's Section 1504 and the EU Regulation on Transparency is taken up in Chapter 6 (see 6.3.3).
} 
civil society's critical stance on a government proposal to include KazEnergy, the national state company, in the MSG on the side of company representatives (interview, November 30, 2011; interview, December 14, 2011).

Regarding the position of the government on the type of reporting, in both countries the government representatives did not put forward strict requirements on company-by-company disaggregation, though over time they were willing to extend the implementation activities in other dimensions. In Azerbaijan some respondents were skeptical on the role of the government and claimed that the EITI was a project for the government and companies to figure out who cheated each other by how much. The motivation to have a better overview of the revenue flows was therefore the initial interest of the government in adopting the EITI, and subsequent disinterest in further disaggregation of information in the reporting for the public (interview-a, November 23, 2011; interview-b, November 23, 2011). According to another respondent, however, the government in Azerbaijan was interested in introducing further requirements to the implementation activities and thus supported the position of the civil society coalition in the disaggregation of reporting. This was based on the grounds of preserving Azerbaijan's international reputation as a champion of the EITI, a country which became one of the first EITI pilots and was the first one to achieve the status of compliant (interview, November $22,2011)$. Another respondent pointed out that the position of the government on disaggregation changed from the initial "not against" to "we support, but we cannot force the companies because the EITI principles do not have such requirements" (interview-c, November 23, 2011).

In Kazakhstan, all of the respondents noted that the government constituency had over time been represented by different ministries. This reshuffling of governmental responsibility over the EITI had a negative impact on the flow of procedural organization, stalling the negotiation within the MSG. Initially, the government constituency in the MSG was represented by the Ministry of Energy and Mineral Resources. This was later changed to the Ministry of Oil and 
Gas, and again later the representational role was afforded to the Ministry of Industry and New Technologies (interview, November 30, 2011). Another story particular to Kazakhstan's EITI had to do with the involvement of parliamentarians in the set-up of the initiative, who were initially contacted by the civil society representatives and helped to pressure government to adopt the EITI. While formally they serve as a fourth stakeholder constituency in Kazakhstan's MSG, their role in the EITI implementation activities was mostly visible in the initial support of the civil society's position when establishing the initiative (interview, December 1, 2011).

Several respondents noted that the question of whether or not there would be disaggregation largely hinged on the government because companies had always shown a variety of opinions on the matter. But without the government's official support of disaggregation, companies could not do anything due to confidentiality agreement restrictions (interview, December 1, 2011). The respondents also noted that there was some change in the government's position to perhaps even recommending disaggregation, though these discussions had not yet moved to the official positions (interview, December 1, 2011). According to one of the respondents, there was a short-lived breakthrough in the negotiations with the government (under the Ministry of Industries and New Technologies), when the technical template for the report was agreed to include the requirement of company-by-company disaggregation, social payments, and the inclusion of all companies to the EITI. However, within a month there were staffing changes in the representatives of the Ministry of Industries and New Technologies responsible for the EITI, the leadership of the EITI secretariat in Kazakhstan was replaced and all agreements on the technical template up to that point were overruled (interview, December 14, 2011). Furthermore, the new government representatives brought up the question of the legal status of the National Stakeholder Council: it turned out that the constituency of the civil society in the NSC is technically not supposed to participate in the audit company selection due to legal restrictions outlined in the 
national law. Until this was raised as an issue, the question never came up because civil society never had a problem with the audit selection procedure. The need to formalize the status of the NSC and the apparent miscommunications in how this need was explained to the civil society members (interview, December 15, 2011) led to the suspension of the issue for an extended period of time. The breakdown of all EITI implementation activities in Kazakhstan, perhaps exacerbated by the civil society divisions over assessments of the situation and subsequent strategies of action, caused the delay with the decision on whether Kazakhstan was to be granted the compliance status, despite the country's clear progress since the beginning of its implementation process. The clarifying questions that the EITI Board posed to the MSG of Kazakhstan after the validation procedure were not addressed because of the temporary collapse in the EITI implementation activities. While the implementation has since resumed, the decision on the compliance status is not to be taken by the EITI Board until the end of 2013 because Kazakhstan's extension of the candidate status runs out on August 15, 2013 (pp. 6-7, EITI International Secretariat, 2012, 14-15 February). It should be noted that by the end of 2012 Kazakhstan published new reports which included disaggregation by companies. This development serves as indirect evidence on how one of the crucial issues in the MSG negotiations ${ }^{61}$ - extensiveness of disaggregation - was eventually resolved in Kazakhstan.

External influence in both countries has been mostly visible in the initial stages of the EITI process, when the implementation of the initiative was set up. The respondents seemed to agree that once the implementation activities started, the particularities of the EITI process were negotiated domestically without the involvement of external actors. In Azerbaijan, interviewees pointed to support from the Open Society Institute (OSI), the Revenue Watch Institute, and the government of Norway (interview, April 13, 2010) in setting up the EITI. In this respect,

\footnotetext{
${ }^{61}$ The issue of extensive disaggregation had, however, no bearing on the criteria needed to comply with the EITI standard at the time.
} 
respondents in Kazakhstan mentioned efforts by Publish What You Pay (PWYP), Soros Kazakhstan, Kazakhstan's branch of the Revenue Watch, and the British DFID (interview, December 1, 2011; interview, December 14, 2011).

\subsection{Conclusion}

The detailed process tracing, together with the interviews I conducted, has revealed the complexity and changes over time of the implementation activities in both countries. Both countries carried out the EITI with incremental changes in the reporting templates over time, and rejected company-by-company disaggregation. Azerbaijan initially chose basic implementation without formal participation of civil society. The status of the civil society stakeholder constituency was only formalized later, and the changes in the reporting content were incremental, with gradual inclusion of more requirements moving the process toward more extensive implementation. In Kazakhstan, on the other hand, the implementation process started already with quite extensive disaggregation by the revenue streams, yet the status of participating companies was questionable. Kazakhstan's EITI experienced more commotions and changes, resulting from the fact that representation in the MSG passed from ministry to ministry. Frequent changes in the staffing of those responsible for the EITI on the side of government caused delays in the implementation, and, to a large extent, explained Kazakhstan's non-compliance with the standard.

As to the question of the influence of stakeholder positions' configuration on the implementation activities, the predictions on the nature of government, company and civil society positions in the negotiations were confirmed when considering the dimension of extensive disaggregation: in both countries civil society wanted the most extensive EITI possible, while the government did not push for the extensive implementation and companies chose the lowest common denominator siding with the government, even though there was evidence that 
certain companies were more willing to include extensive requirements than others. This explains why the nature of the stakeholder positions in both Azerbaijan and Kazakhstan was largely similar.

The influence of the external actors was minimal, and mostly visible during the time preceding the initial adoption of the initiative. Moreover, there was some limited evidence of indirect influence of external actors, largely through the provision of funds for the organization of civil society constituencies. However, once the implementation had started, the decisions taken were the outcome of the MSG's activities, without involvement by external actors.

Regarding the hypothesis on the ideological distance between stakeholders impacting policy stability, the empirical evidence showed that in both countries the government and the companies showed support for a less extensive form of implementation than what civil society had called for, thus predicting a status quo, or incremental changes over time, according to the formulated hypothesis. The initial large difference in the implementation activities - the formalized role of civil society in the Kazakhstan's MSG and the informal role of civil society consultation in Azerbaijan's MSG - can be explained by the agent of EITI initiation (the government in the case of Azerbaijan and the civil society in the case of Kazakhstan). In the case of Azerbaijan, the government as initiating actor established the formal EITI institutional set-up, whereas in the case of Kazakhstan the civil society coalition acted as initiator, which by ultimatum tactics managed to formalize its institutional involvement in the EITI from the very beginning of the EITI process. The formal participation of Kazakhstan's civil society coalition in the stakeholder group gave civil society additional leverage in the negotiation process within the Stakeholder Council, whose decisions had to be consensus-based.

Authoritarian countries are particularly prone to the risk of suffering from political symptoms of the resource curse, and therefore they would benefit from extensive EITI implementation. However, as my study of the implementation in the two case countries has revealed, authoritarian governments also seem to be less 
interested in fulfilling the extensive disaggregation requirements that would go beyond the required minimum standard stipulated in the EITI guidelines. Given that in our two cases the company constituency as a joint stakeholder settled on the common lowest denominator, the situation created an unfavorable balance for civil society to achieve its main demand of extensive disaggregation. However, as the process tracing has revealed, extensions to other dimensions of implementation did occur over time. The changes in the reporting templates that occurred in both Azerbaijan and Kazakhstan were of an incremental nature, targeting particular streams of revenues. The issue of company-by-company disaggregation, which has been contentious from the beginning of the EITI process in both countries and is the most critical demand of the civil society coalition, has not been adopted by the respective MSGs into the reporting standards during the time under scrutiny. Recent developments, however, show progress on the issue, with Kazakhstan publishing first disaggregated reports in December 2012. This, however, does not detract from the findings of this chapter, which show that this eventual change has taken years to accomplish and was blocked for a considerable period of time in the past.

Besides the insights on the particularities of the implementation process in the case countries, the findings have implications for the EITI as a global standard. According to the analysis, the participation of the civil society coalition turns out to be crucial in increasing the effectiveness of the process, since (at least in the critical country cases that were investigated in this chapter) civil society is the only stakeholder that shows a consistent position in favor of extensive features of EITI implementation beyond the minimum required. At the same time increasing demand from the side of civil society for inclusion of extra extensive requirements does not guarantee a successful EITI and may work against the coherence of civil society, as both country cases have shown. It turned out that the constituency of civil society can be quite divided over strategies and tactics of negotiation. In the studied cases, the civil society stakeholder constituency in both Azerbaijan and 
Kazakhstan experienced within-the-group disagreements on how to reach the objective of extensive implementation - via proposals of incremental or radical change. 


\section{Chapter 6: Lessons from Implementation: Reforming the EITI?}

Summary: Based on the findings of the dissertation, this chapter assesses the potential of the EITI in achieving its main objective of increasing transparency in the natural resource management, as well as its broader targets as a transnational regulatory instrument for preventing the resource curse. The chapter first introduces the two main challenges the EITI is currently facing: the issue of nonadoption by the countries who would benefit from the initiative and the lack of extensive practices which are needed in order to achieve the most from the EITI. Having discussed these challenges in the context of the dissertation's findings, the chapter proceeds to introduce three EITI reform scenarios. I assess the implications of these reforms for different types of contexts relevant to the EITI: non-EITI countries, extensive EITI implementers, and less ambitious EITI implementers.

\subsection{Introduction}

By examining various aspects of the EITI in depth, this study has sought to elucidate why countries adopt the initiative, how its implementation differs from one country to the next, why in fact such differences in the implementation activities occur, and how stakeholder constituencies impact the implementation activities in critical case countries. Close analysis of this array of concerns has generated a better understanding of the conditions for the EITI's effectiveness in achieving its main goal of increased transparency in natural resource governance. The purpose of this chapter is to synthesize these findings by outlining current limitations of the EITI and assessing the various strategies to overcome them that are currently being promoted by the EITI bodies or in domestic and supranational law. The chapter is structured as follows: the challenges in the adoption and implementation phases of the EITI process are summarized in section 6.2. Next, against the backdrop of the findings, I continue with a discussion of three potential or existing policy options for reforming the EITI: 1) mandatory extensive EITI requirements, 2) voluntary extensive EITI requirements, together with a changed scoring of compliance, and 3) US and EU laws making it mandatory for companies 
to disclose the extensive information on the payments in the sector. Particular attention is devoted to the question of how such changes to the EITI would have an impact on extensive EITI implementers, less ambitious EITI implementers, and non-EITI countries. Finally, in section 6.4, I summarize how each of the suggested policy options impacts the relevant country contexts and I assess the potential of the EITI in overcoming the resource curse.

\subsection{Challenges of Non-adoption and Absence of Extensive}

\section{Implementation}

It was shown in Chapter 3 that certain factors increase the likelihood of EITI adoption, and that not all countries who are within the scope of the EITI's targets are adopting the standard. I also argued, in chapters 1 and 4 , that in order to carry out a meaningful EITI program, a country will achieve increased transparency only if it introduces additional extensive implementation practices that are currently not required for compliance with the EITI standard. These two issues present two main challenges in advancing the transparency goal of the EITI: first, not all countries that could benefit from the initiative actually adopt it; and, secondly, not all adopters initiate the voluntary extensive practices of implementation, which are needed in order to achieve a meaningful transparency process. Based on the research carried out, my subsequent argument will center on two main themes: 1) the type of country contexts in which each of these challenges is most relevant, and 2) the conditions under which adoption and extensive implementation are more likely to occur. The discussion below is organized by the two challenges: first, the challenge of non-adoption, and second, the lack of extensive implementation.

\subsubsection{Obstacles to adoption}

As it was shown in the literature review in Chapter 1, the countries which are likely to suffer from the symptoms of the resource curse are those where resources are not 
effectively managed. In line with the mechanisms behind the resource curse, particularly at risk are non-democratic settings, characterized by opacity in the channels via which resource revenues are collected and lack of civil society pressure on the government for accountability. As also argued in Chapter 1, any country receiving a significant share of its budget in the form of resource revenues would benefit from increased transparency in its resource management process. Transparency in the stage of contract signing helps to achieve better terms and fairer deals for the country. Tracking transparency in the phase of revenue collection ensures that the money due is not lost along the way. Transparency in the revenue spending phase encourages prudent use and well-planned investments, while also bolstering the government's accountability to the public. However, as demonstrated in Chapter 3, not all resource-rich countries that could benefit from the EITI are also adopting the initiative. Factors that proved to be statistically significant in explaining the likelihood of EITI adoption were resource abundance, lower income levels, ethnic fractionalization, and recent polity change toward democratization. On the other hand, high-income authoritarian settings with a long history of a stable regime are unlikely to adopt the EITI. Resource-rich and highincome democracies not joining the EITI also belong to the group of non-adopters. One may argue that the latter are less likely to suffer from the resource curse, and therefore, not as critical. Yet according to the EITI logic, they would still benefit from the increased transparency; and if comparable standards of transparency already exist, it seems nonetheless fair to implement the standard which many of these democracies have been supporting at the global level. For the EITI as a transnational instrument this means that a significant number of countries which could potentially benefit from transparency in natural resource governance are not subscribing to the EITI process in the first place. 


\subsubsection{Obstacles to extensive implementation}

A second challenge occurs once the implementation of the initiative starts. It was argued in Chapter 1 that the full cycle of natural resource management needs to be addressed in order to achieve meaningful transparency; otherwise, there is a danger of merely moving the locus of corruption from one phase of the resource management to another. Yet as shown in chapters 4 and 5, the design of the EITI encourages extensive implementation practices but does not require many of them. Such voluntary extensions are reporting templates disaggregated by companies and by revenue streams, audit of the EITI process rather than reconciliation only, a materiality criterion which includes all payments, and the inclusion of additional requirements (contract transparency, information on company social transfers, subnational payments, or information on revenue spending). The design of the EITI, then, does leave room for countries to determine their own scope of implementation, but leads to a situation of varying degrees of transparency achieved by different implementers. It is obvious that extensive implementation, including features beyond the minimum required for compliance with the standard, is needed for the transparency intended by the EITI. In practice, however, it is observed that many countries are reluctant to include such extensive practices, and, as a result, are unable to achieve full transparency of the resource management cycle. The outcome is uneven progress in achieving transparency in natural resource governance and, therefore, potentially uneven benefits from the EITI for different countries. For example, as argued in Chapter 4, disaggregation of reporting by companies, though not part of the required core implementation, is of critical importance in raising the level of transparency the EITI aims to achieve. As revealed in that chapter, however, not all EITI-implementing countries are willing to make the move toward including this requirement. In particular, nondemocracies carrying out the EITI in the oil and gas sector are less likely to adopt extensive disaggregation practices. If these are also the countries where the MSG is unable to resolve disagreements and move beyond a basic implementation, the 
potential of the initiative to improve the situation in the countries that are most in need of increased transparency in resource governance is significantly limited.

Under what conditions does voluntary inclusion of the extensive implementation features occur? First and foremost, as highlighted in Chapter 4, democratic countries are prone to include company-by-company disaggregation in their implementation templates, a critical feature strongly desired for the most transparent EITI possible at present. All EITI-implementing democracies with a polity score above five (except Albania and a case of Peru's partial disaggregation $)^{62}$, as well as anocracies with a polity score above zero ${ }^{63}$ have produced reports with extensively disaggregated figures. Intuitively, one should not be surprised about this finding: there are many variations on the argument that in various respects democracies do better than authoritarian governments due to the more extensive system of checks and balances at work in democracies. The findings of Chapter 4 become more puzzling, however, when seeking to account for the differences within the group of autocracies and anocracies with a lower polity score. It turns out that all EITI countries with a polity score of zero or below and which included only non-oil minerals in their reporting templates carried out extensive disaggregation of figures. On the other hand, all their counterparts which included hydrocarbons in their reporting templates carried out aggregated disclosure.

Carrying out the EITI only in the non-hydrocarbon mining sector proves to be a sufficient condition for company-by-company disaggregation. In these settings, a lower polity score did not lead to the absence of extensive disaggregation. On the other hand, in countries that carry out reporting for hydrocarbons, democracy greatly increases the likelihood of company-by-company disaggregation (but is not a sufficient condition, as the cases of Albania and Peru

\footnotetext{
${ }^{62}$ These EITI countries are Ghana, Liberia, Mali, Mongolia, Niger, Norway, Sierra Leone, Timor-Leste, and Zambia.

${ }^{63}$ These EITI countries are Congo DRC, Mozambique, and Nigeria.
} 
show). For the EITI as a transnational regulatory instrument, this finding has crucial implications, as it shows that voluntary extensive disaggregation is easier to be introduced in democracies and non-oil mining countries regardless of their regime type.

In Chapter 5 I looked into the specifics of the stakeholder positions' configurations in authoritarian oil-rich settings. The analysis of the stakeholder positions revealed that conflicts about the extensiveness of disaggregation - one of the most critical features for increasing transparency achieved through implementation - do indeed occur between civil society stakeholders and the other two stakeholder constituencies and are difficult to resolve. Some other extensive features of implementation were added to the reporting templates in both countries in an incremental manner, while the battle over disaggregation has been continuing unabatedly in both countries. In both countries the issue was not resolved in favor of the inclusion of extensive disaggregation during the time period of the analysis, but the last reports of Kazakhstan published in December 2012 show that in its case company-by-company disaggregation was finally adopted. This recent development however does not take away from the fact that there were long struggles over this issue in the MSG.

In Chapter 5, for both case countries it was observed that the stakeholder constituency most willing to introduce extensive implementation was the civil society coalition, which has been pushing for an increasing number of additional details in the reporting. However, the argument in Chapter 5 also demonstrated that the civil society position in favor of the extensive EITI implementation is not enough to carry out such implementation when the government and the companies in a country are against the proposed extensive practices. In Kazakhstan, an important extensive feature of the stakeholder committee composition (the existence of a tripartite MSG-like body despite the lack of official guidelines at the time) was adopted in the initial stages of the implementation. While this occurred not without commotion, it underscores the importance of the agenda-setting phase 
in the implementation process, which largely impacts subsequent path dependency of policy development. Yet even if the civil society group is quite strong and formally involved in the MSG from the beginning of the implementation process (as in the case of Kazakhstan), this does not guarantee adoption of extensive practices. The divisions which have occurred in the civil society stakeholder constituency in Kazakhstan, together with changes in the governmental authorities responsible for EITI implementation, unwillingly contributed to lagging the implementation process in the country despite the seeming initial progress. Moreover, the civil society stakeholder constituency in both countries has experienced divisions over tactics, thus highlighting the difficulties of negotiations that can occur within the constituencies.

The reluctance to include extensive practices of disaggregation was observed in the critical country cases selected where the divisions between the positions of the civil society stakeholder constituency and the other two stakeholder sides became apparent. One of the assumptions of the current EITI design is that national multi-stakeholder groups consisting of the representatives from government, companies, and civil society should be able to achieve consensual outcomes through a process of negotiation between the stakeholders. However, as became apparent in Chapter 5, the positions of the stakeholders can be irreconcilable, with the position of the civil society constituency being opposed to the government and company preferences. The presence of supporters for extensive EITI implementation practices turns out to be an insufficient condition for EITI advancement at the national level if these supporters have comparatively weaker power positions. The experiences of Azerbaijan and Kazakhstan have clearly revealed this problem and also serve as a reminder that EITI candidacy is by no means equivalent to the intent of carrying out the broadest possible EITI as regards the extensiveness of transparency practices. The difficult nature of negotiations at the MSG level and the divergent preferences bring up the issue of motivations and/or incentives that actors have to press for, or agree to, in their negotiations of 
the EITI implementation activities. Aside from the objective to increase transparency, additional motivations such as improving one's reputation, benefits for government from improving the tracking of revenues received, or concerns over adverse publicity in the case of increased transparency play an important role in defining the positions of the stakeholders involved. One important reason why such additional motivations are playing a big role in the concrete implementation of the EITI is the lack of stricter EITI rules and the absence of a binding legal framework in the area of resource governance.

Against these backgrounds, and given the difficulties related to adoption and the subsequent introduction of extensive implementation practices the question on what the EITI as a global standard can do to address these challenges remains an urgent one. After outlining three currently emerging reform options in the EITI standard or the area of natural resource governance more broadly, the next section will discuss how they address each of the challenges introduced. Three types of country contexts - extensive EITI implementers, less ambitious EITI implementers, and non-EITI countries - are discussed to show how each of these reform options would change the incentive structure for these different types of countries.

\subsection{New Instruments Improving Transparency in Natural Resource Management Practices}

The discussion above introduced the details behind two main challenges preventing the EITI to be effective in reaching its main objective of increased transparency. As indicated by my analysis, these challenges - non-adoption and lack of extensive implementation - apply differently to various countries, and it is possible to speak of at least three clear groups of contexts. I will refer to the first as non-EITI countries: countries that are resource-rich and are therefore targeted by the EITI, but that do not adopt the EITI. As the analysis in Chapter 3 suggests, this pertains 
in particular to resource-abundant, high-income countries with a history of a stable regime.

The EITI's goal of increased transparency in reporting practices of resource-rich countries is realized differently by the various implementing countries, and the scope of transparency achieved varies as well. A major deadlock, which prevents extensive implementation practices and, in particular, disaggregation by companies, occurs within the MSG, when stakeholders disagree on how to implement the EITI. This second challenge pertains to the different levels of implementation and this gives rise to the group of extensive EITI implementers, countries that do more than the necessary minimum required to comply, and the group of less ambitious EITI implementers, countries that, while possibly including some extensive practices, have not moved toward disaggregation both by companies and revenue streams. Extensive EITI implementers are countries that advance the EITI process beyond the initially designed minimum practices; they find themselves in the vanguard of EITI implementers, and are able to gain more transparency in the sector through the implementation of the initiative. As revealed in Chapter 4, this group mostly consists of democratic countries and countries focusing only on non-oil minerals. Conversely, the less ambitious EITI implementers comprise non-democratic contexts implementing the EITI in the oil and gas sector. For this group of countries, the lack of extensive implementation is most relevant as a challenge.

A number of reforms aimed at improving the transparency of natural resource management have been suggested, some of which have taken shape beyond the mere level of discussion. This section of the chapter, while introducing such initiatives aiming to increase transparency in the natural resource management, mainly aims to assess how these policy options would alter the situation in three types of countries - non-EITI, extensive EITI implementers, and less ambitious EITI implementers. I take these contexts into account separately 
because the various reform options present different challenges to these groups of countries.

One of the most intuitive ways to stimulate a greater adoption of extensive transparency requirements is to reform the initiative's design. Two options easily come to mind, both of which have also been contemplated by the EITI Board (EITI International Secretariat, 2012, June 8, October 25-26). The first reform would phase in additional requirements as mandatory for achieving the compliance status. The second option, in line with the current spirit of the voluntary approach, would introduce a scored compliance grading based on progress in different dimensions of the implementation activities instead of interpreting compliance as a dichotomous (yes or no) criterion. Other solutions could be directed at laws on company disclosure, targeting one of the stakeholder constituencies involved in the EITI process. Below these three options are discussed in detail, by pointing out the rationale of these suggested changes, and their implications for the three categories identified: extensive implementers, less ambitious implementers, and nonmembers.

\subsubsection{Mandatory EITI extensive requirements}

The most straightforward option to increase adoption of the extensive EITI requirements would be the introduction of mandatory extensive practices in the EITI, such as disaggregation, inclusion of social payments or sub-national payments, and so on. Such a reform would require participating countries to do more than the minimum the EITI prescribes. If one looks at the original discussions on the design of the EITI held prior to the initiative's establishment, it becomes clear that such proposals were considered in the early days of the EITI's development. For instance, the EITI discussion paper for the meeting with the international stakeholders (EITI, 2003, Annex B under the heading "Detailed Issues"), already mentioned payments to sub-national governments, transfers to national state-owned companies, inclusion of downstream payments, and a strict 
definition of materiality in its discussion of disclosure guidelines. However, by May 2003 the guidelines were revised, with the exclusion of payments to subnational governments or any downstream payments, as well as leaving materiality undefined, even though some options for how it may be defined were suggested (EITI, 2003, May 23). Disaggregation company by company was also discussed frequently, at times as a possible feature of implementation (EITI, 2003, February 11-12, p.3, p.8; EITI International Secretariat, 2008, October, pp.8-9). While stakeholders considered extensive features as part of the mandatory requirements at the time of the EITI's establishment, due to mutual disagreements they were put aside for a considerable time after the formal launch of the initiative. The compliance and validation rules, as well as the governance rules of the EITI management itself, were officially put forward only in the EITI rules established later on. Achieving compliance in the participating candidate countries dominated the concerns of the Board in the initial years of the EITI's existence. After the assessment of the standard's effectiveness commissioned by the Board in 2011 (EITI International Secretariat, n.d-b), public consultation on policy reform proposals was initiated.

The progress made toward modifying the current EITI requirements is reflected in the consideration of extending the standard to make certain implementation practices mandatory, as becomes evident from the recent proposals on the EITI future (EITI International Secretariat, 2011, October 25-26, 2012, February 14-15, June 27-28, October 25-26). In the EITI Board's meeting of October 2011, discussion on the EITI strategy included proposals to increase the mandate of the initiative beyond transparency in payments to the other stages of resource revenue management, such as contract management and revenue spending. During the $20^{\text {th }}$ Board Meeting held on 27-28 June, 2012, and in the follow-up policy proposal of the Strategy Working Group, the following mandatory EITI requirements were proposed: disaggregation company by company and by revenue stream, disclosure of payments and receipts from state 
oil and gas export sales, material revenues received by state-owned companies and material transfers made by state-owned companies to government entities, and sub-national payments (EITI International Secretariat, 2012, June 27-28, July 24).

Other proposed extensive requirements, such as the inclusion of midstream payments, disclosure of licenses and contracts, and project by project reporting, did not reach a consensus at the time. The proposed changes (EITI International Secretariat, 2012, October 25-26) were finalized and adopted during the 2013 global EITI conference and were formally launched on May 22, 2013.

In summary, the new EITI requirements oblige implementing countries to practice much more detailed reporting. In the contextual information provided in the public report, countries are now required to include a summary of the legal framework and fiscal regime, an overview of the extractive industries, the extractive industries' contribution to the economy, ${ }^{64}$ production data, ${ }^{65}$ state participation in the extractive industries, where it is material, ${ }^{66}$ revenue allocations, ${ }^{67}$ and a public license register, including specification of criteria for license allocations (EITI International Secretariat, 2013, pp. 21-24). The disclosure

\footnotetext{
${ }^{64}$ This information has to include "a) size of the extractive industries in absolute terms and as a percentage of GDP, including an estimate of informal sector activity, b) total government revenues generated by the extractive industries (including taxes, royalties, bonuses, fees, and other payments) in absolute terms and as a percentage of total government revenues, c) exports from the extractive industries in absolute terms and as a percentage of total exports, d) employment in the extractive industries in absolute terms and as a percentage of the total employment, e) key regions/areas where production is concentrated" (EITI International Secretariat, 2013, pp.21-22).

${ }^{65}$ Production data must include "a) total production volumes and the value of production by commodity, and when relevant, by state/region, b) total export volumes and the value of exports by commodity, and, when relevant, by state/region of origin" (EITI International Secretariat, 2013, p. 22).

${ }^{66}$ To fulfill this requirement, the report must explain the rules governing the relationship between the government and the state-owned companies, disclose quasi-fiscal expenditures of the state-owned companies (i.e. payments for social service, infrastructure, subsidies, etc.), and disclose beneficial ownership of companies (EITI International Secretariat, 2013, p. 22).

${ }^{67}$ This item concerns explanations on how the revenues are distributed. For instance, are they allocated to the national budget, or special funds, or sub-national government entities, etc.? (EITI International Secretariat, 2013, pp. 22-23).
} 
of beneficial ownership for all companies ${ }^{68}$ is recommended, and disclosure of contracts is encouraged (EITI International Secretariat, 2013, pp. 23-35).

Furthermore, the number of revenue streams to be disclosed in the report has been extended to require social payments if they are mandatory by national law, payment flows to and from state-owned companies, direct payments to subnational government entities where these payments are material, and subnational transfers where they are mandated by a revenue-sharing mechanism specified in law (EITI International Secretariat, 2013, p. 27-29). The revenue streams for which disclosure is encouraged but not required include transportation and infrastructure payments (EITI International Secretariat, 2013, pp. 27-28). Finally, a requirement on disaggregation of information by individual company, government entity, and revenue stream was adopted. Where consistent with the US SEC rules and the forthcoming EU laws (discussed below in 6.3.3), this disaggregation requirement is also obligatory at the project level (EITI International Secretariat, 2013, p.31).

The revisions to the EITI standard are very recent and therefore it is not possible to assess how they will be reflected in the reporting carried out by countries, yet it is worthwhile to consider the implications of these changes. While over the years of implementation all countries proved willing to gradually extend the standard to include new revenue streams in the reporting, the issue of disaggregating the reports both by revenue streams and companies has always been more challenging. What is more, some of the other new requirements have so far been absent from the implementation activities of the participating countries. What do these substantial changes in the extensiveness of reporting mean for the three groups of countries outlined above?

\section{Extensive EITI implementers}

For the countries already implementing the EITI with additional voluntary extensive practices, the proposed mandatory changes will mainly confirm the

\footnotetext{
${ }^{68}$ Mandatory only for state-owned companies (EITI International Secretariat, 2013, p. 24).
} 
current state of affairs: they have already put many of the proposed practices in place, such as disaggregation by company and by revenue stream, reporting by state-owned companies, and including sub-national payments. Reporting templates will largely remain unchanged, since the MSG has already moved toward implementing these extra implementation features. The direction toward including further extensive practices will be encouraged.

\section{Less ambitious EITI implementers}

In countries which implemented the EITI according to the minimum level of required practices, the change in the EITI mandatory requirements will imply a significant development that may lead to two possible outcomes: either a strengthening of the reporting scope in line with the mandatory changes or the possibility of being de-listed or dropping out of the standard. It is clear that for civil society stakeholder constituencies in many countries the proposed changes to mandatory requirements will be a breakthrough in a long-standing debate on the issue of contestation in the MSGs regarding disclosure of disaggregated payments not only by revenue stream, but also by company. For the companies, the mandatory requirements will alleviate some of the concerns on competitiveness since participating companies in all EITI countries will be required to disclose the information. Yet potential complaints over the issues of disadvantage regarding companies in non-EITI countries (which do not have to reveal their disaggregated information but will have access to the information of companies in EITIparticipating countries) will linger. Whether the governments of less ambitious EITI-implementing countries are ready to include the new practices or will drop out remains to be seen. This means that the outcomes of the reform and the extent to which challenges to the EITI implementation will be overcome are uncertain: the countries will either adopt the required mandatory practices, thus overcoming the challenge of non-extensive implementation, or will drop out of the standard, thus increasing the problem of non-adopters. 


\section{Non-EITI countries}

The new requirements will increase the requirements directed at non-members considering adoption of the EITI. Whereas under the current state of affairs there was an option to carry out the minimum guidelines required with the aggregated final reporting, this option will disappear in the future, significantly increasing the level of mandatory transparency in the disclosure of information. This change will likely discourage countries that consider the EITI as a window-dressing option from adopting it; and one will be more certain to say that the implementation of the EITI is equivalent to a visible reform in the management of the sector indeed. Such strengthened meaning of the EITI would increase the level of mandatory transparency in the standard. For the countries that have not yet adopted the EITI, no immediate changes are expected, since the reformed EITI does not seem to offer additional benefits compared to the ones already existing.

\subsubsection{Compliance as a scaled index}

Beyond extending the scope of mandatory EITI requirements, one can think of strengthening the voluntary nature of the EITI by introducing a different conceptualization of compliance, based on a scaled index rather than the currently used pass/fail distinction. Such a graduated system would leave the option of an EITI with the minimum required, while at the same time recognizing the progress in the countries that have included extensive voluntary practices. A reform along these lines would serve as a voluntary peer pressure mechanism, potentially increasing the scope of the EITI standard in the long run. A scoring system could include indicators on natural resource management in the phases currently beyond the focus of the EITI on upstream payments.

The EITI Board has considered this possibility of rating compliance in terms of a score denoting achievements (EITI International Secretariat, 2011, October 25-26, pp.12-15, 2012, February 14-15), and it has proposed to introduce a validation system beyond pass/fail compliance, though focused only on the current 
scope of the EITI in the upstream payments disclosure. The proposal (EITI International Secretariat, 2012, June 8) intended to recognize countries that go beyond the mandatory practices by changing the interpretation of compliance from pass/fail to a numerical scoring from 0 to 3 on each current EITI requirement. This score would reflect whether the country has made no progress $(0)$, some minimal progress (1), met the requirement (2), or went beyond the requirement (3) on each specific indicator. A final compliance score for the country would be an average of scores on the requirements; if one of the requirements received a score of zero, the final numerical score could be no higher than 1 . Also, an alphabetical scoring was suggested, the intent of which was to be non-comparable between countries, but rather be a reflection of within-country progress based on MSG decisions. To date, however, these proposals were not adopted. According to the revised EITI standard (EITI International Secretariat, 2013, p. 39), the validator, when ranking whether the requirements have been fulfilled, has to assess each requirement as "met" or "unmet." ${ }^{69}$ Numerical or alphabetical scoring was not adopted, and compliance is continuing to be assessed as a pass/fail outcome. If the modification toward interpretation of compliance as a scaled index were to be adopted in the future, what would it mean for the three groups of different implementers?

\section{Extensive EITI implementers}

The change in the interpretation of EITI compliance and the subsequent change in validation scoring would be a reward to countries already doing more than required by the standard. The system would also simplify the public's understanding as well as the knowledge of investors regarding the countries at the top of best practices, thus bringing reputational rewards for the EITI-extensive implementers.

\footnotetext{
${ }^{69}$ Unmet can be "with meaningful progress," or "limited progress."
} 


\section{Less ambitious EITI implementers}

To understand the scope of country implementation, one has to go through the reports, which for an untrained reviewer are quite complicated and perhaps hard to comprehend. With the introduction of compliance as an index, it would become much easier to understand who is doing more and who is doing less, and on which particular indicators. The change might work as a peer pressure mechanism and might in the long run encourage less ambitious implementers to increase the scope of their reporting practices, thus contributing to the solution of the second challenge, related to the lack of extensive implementation. Furthermore, it would be easy to expose potential window-dressers, even if they are not necessarily excluded from the initiative.

\section{Non-EITI countries}

The reform of compliance scoring does not directly present new incentives for the current non-adopters, so there will be probably no changes in the short run for this group of countries. In the long term, there is potentially an effect via increase in the extensiveness of the reporting practices, through which transparency in the extractive sectors would gradually become less and less of a breakthrough innovation and more and more of a commonly accepted norm. As a result, the peer pressure would apply not only to less ambitious EITI implementers as introduced above, but also to non-EITI countries. The effect could be seen in the increased activities of the civil society stakeholder groups in the non-EITI countries, thus potentially encouraging adoption of the standard in these countries.

\subsubsection{Mandatory company reporting: US and EU law developments}

Besides changes to the EITI itself, developments in laws related to the management of natural resources may have an impact on the incentives for actors to adopt the EITI or to implement it in a more extensive way. One such development is 
legislation which requires companies registered in the US Stock Exchange and the regulated markets in the EU to report all their payments in all countries of operation. Such legislation was recently adopted in the US and is currently under revision in the EU. While this legislation is not directly part of the EITI process, it has direct implications on the EITI implementation and alters processes relevant for the MSGs of EITI-implementing countries, as well as the contexts of non-EITI countries.

While the legislation has passed in the US already (Section 13 (q) of Section 1504 of the 2010 Dodd-Frank Wall Street Reform and Consumer Protection Act - H.R. 4173, 111th Cong., 2010, with the Securities and Exchange Commission's (SEC) final rule passed in November 2012 - Disclosure of Payments by Resource Extraction Issuers, 2012), the respective discussion in the EU is still underway. The proposed EU legislation refers to the Directive of the European Parliament and of the Council amending Directive 2004/109/EC on the harmonization of transparency requirements in relation to information about issuers whose securities are admitted to trading on a regulated market and to the Commission Directive 2007/14/EC (COM, 2011, pp. 8-9). Since the proposed EU legislation has not been adopted yet, the discussion below focuses on the US Section 1504 of the Dodd-Frank Act and only briefly refers to the EU legislation where it is known to differ from the Dodd-Frank Act.

Section 1504 is based on the bill entitled Energy Security through Transparency Act of 2009. The section is titled "Disclosure of payments by resource extraction issuers" and was introduced to the Dodd-Frank Wall Street Reform and Consumer Protection Act of 2010 (from hereafter "Section 13(q)" or "Section 1504 of the Dodd-Frank Act") by senators Cardin and Lugar. It requires extractive companies registered with the SEC to submit detailed reports of their payments to the US government and foreign governments of operation. While Section 13(q) was to a large degree inspired by the EITI approach, it intends reporting beyond the minimum standards of the EITI, according to Senator 
Benjamin Cardin (2010), one of the introducers of the Sect. 1504 amendment. In comparison to the EITI there are substantial differences, as has become apparent after the SEC decision on the statute interpretation.

The companies which fall under the category of "resource extraction issuers" are required to file an annual report with the SEC; both U.S. and foreign companies engaged "in the commercial development of oil, natural gas or minerals" fall under this category. No exemptions have been given, and in practice it means that companies of all size - small and large issuers, as well as national state-owned companies - are required to report. In addition, the SEC did not accept proposals for exemptions in the cases of host country laws, participation in the EITI, confidential clauses in the contracts, commercially sensitive information, or issues of safety and security of operations, and these do not qualify for the exemptions from reporting. According to the SEC final rule, the expected number of issuers falling under the statute is $1,101 .^{70}$

Section 1504 defines "commercial development of oil, natural gas, or minerals" to include upstream and downstream activities and thus goes beyond the current scope of the EITI, which focuses on upstream activities only. Specifically, the activities covered by Section 1504 are exploration, extraction, processing, export, and acquisition of license for any such activity. Not required to be reported are preparatory activities, such as manufacture of a product used in the above-listed activities, or transportation activities for purpose other than export. "Payment" is defined as "not de minimis," focusing on the lower threshold standards, which is different from the EITI materiality standard. "Not de minimis" is defined as "any payment, whether made as a single payment or series of related payments, that equals or exceeds $\$ 100,000$ during the most recent fiscal year." The streams

\footnotetext{
${ }^{70}$ There is a difference in the EU-proposed legislation: issuers in the natural resource sector, as well as issuers in the logging of primary forests, are included. Additionally, besides listed in the regulated markets companies, the EU proposal includes large non-listed companies. As noted in footnote 570 of the SEC final rule, together with the EU $90 \%$ of companies in the oil/gas and mineral industries will be covered.
} 
covered are taxes, royalties, fees (license, entry, rental, concession), production entitlements, bonuses (signature, discovery, production), dividends, and payments for infrastructure improvements. Many of these streams required by Section 1504 have been part of the voluntary extensive features in the pre-May 2013 EITI reporting templates. Community/social payments, which are included by some EITI-participation countries, are not required by Section 1504. Additionally, payments are required to be filed project by project. "By project" is currently left undefined, but specified not to mean "material," "country" (country allowed only if corporate income tax is levied with respect to all projects), "at the reporting unit level (which in practice is often country)," or "geologic basin." Furthermore, it is also required to report payments to subsidiaries or entities under the control of foreign government (such as national state-owned companies).

Foreign government is defined as "foreign national government as well as a foreign sub-national government, such as the government of a state, province, county district, municipality, or territory under a foreign national government." US government is meant as the federal government, and sub-national entities are not included.

The disclosure practices involve an annual report to be publicly disclosed 150 days after the end of the fiscal year. The report is to be disclosed via the EDGAR archive in the interactive data format for public analyses. Confidential reporting with a public compilation of limited information, as suggested by some commentators, has been rejected by the SEC in the final rule (Disclosure of Payments by Resource Extraction Issuers, 2012). For reasons of comparability, the report is to be in either US\$ or issuer's reporting currency. The reports are to be filed (rather than furnished), which means liability for the reporting entities.

The rule is effective for fiscal years ending after September 30, 2013 which means that the company is required to file a report "for the period beginning October 1, 2013 through the end of its fiscal year." If the issuer's fiscal year begins before September 30, 2013, a partial report is allowed for the first reporting cycle 
(a SEC-given example is an issuer for whom the fiscal year ends on December 31, 2013: the first report of this issuer would cover the period from October 1, 2013 until December 31, 2013). In practice the effective date means that the first reports will become available in 2014 at the earliest. What will the changes mean for the positions and incentives of the countries relevant to the EITI?

\section{Extensive EITI implementers}

In countries which have already started including extensive EITI practices, the newly available additional data from companies may facilitate inclusion of further voluntary additional implementation requirements, introduced by Section 1504. If as a result of the new laws companies are required to provide extensive reporting information anyway, they may also be more willing to share this data in the EITI process. Notably, these can include disclosure of exports, project by project disclosure, sub-national payments, and transfers to subsidiaries. Largely, the provisions of Section 1504 are complementary to the practices of the countries which have already required extensive disclosure practices in their national EITI contexts. Thus, Section 1504 and the related EU reforms are expected to contribute to the increase in the scope of extensive practices.

\section{Less ambitious EITI implementers}

In countries which so far have been reluctant to include additional extensive practices, Section 1504 will reveal many payments which have not been available so far, thus indirectly revealing information on some of the extensive implementation practices. First, the payments of participating companies which were out of the EITI's scope will become available. Secondly, payments of companies which were excluded from reporting based on the materiality criteria will be possibly disclosed. Thirdly, all company payments will be available on the disaggregated basis by revenue streams and by project. Fourthly, payments and transfers of national state-owned companies may become transparent. As a result, 
the arguments in favor of confidentiality used by companies and government against introduction of extensive practices into the EITI disappear: the companies are required by law to disclose this information in any case. Theoretically, it could be the case that companies choose to de-register from the US market or are excluded from future projects in the countries of operation, in the extreme cases having to close down operations in countries which prohibit disclosure. However, if the laws of the US and the EU together cover $90 \%$ of companies in the sector, as the SEC final rule suggests, such scenarios, perhaps, may be less likely.

\section{Non-EITI Countries}

Perhaps, the highest impact in terms of difference with respect to the current state of affairs will occur in countries not implementing the EITI. By law, companies operating in these countries will be required to disclose their information. Company disclosures, which used to be available only in the EITI countries, will become public in the case of companies operating in non-EITI countries as well. As a result, discussions over the revenue flows received and revenues spent domestically that the EITI intends to encourage will start, even if the EITI has not been adopted in those countries. This may lead to eventual adoption of the standard; in cases where the standard is not adopted, information on many extensive practices will nonetheless be open to public.

\subsection{Conclusion}

As seen from the reforms at the global level, the EITI is entering a new phase of improved governance of the initiative itself. Additional requirements not originally included in the EITI are gaining more emphasis and are aiming to increase the extensiveness of transparency possible to achieve through the EITI. This development is seen in the long-debated new mandatory criteria to the EITI guidelines, finally launched in May 2013. One of the other options that would encourage extensive voluntary practices is a numerical rating of EITI compliance - 
which to date is still in a proposal stage. Moreover, the initiatives taken by the US in the form of the Section 1504 of the Dodd-Frank Act, and the EU, in the form of the proposed Directive of the European Parliament and of the Council amending Directive 2004/109/EC and Commission Directive 2007/14/EC, aim to increase the transparency of natural resources by targeting companies. These laws have a direct impact on all countries - even those countries whose governments have not taken any initiative to increase transparency in resource governance thus far, and that are not participants to the EITI. In addition, if according to the new US and EU laws, companies will be required to report their figures in the countries where the EITI is operational, the company positions within the MSG may change as more and more companies will anyway be required to disaggregate their information by country or even by project. Thus, the laws introduced by the EU and the US are likely to change the options available for companies at the MSG, bringing them closer in line with the demands of civil society: if the company falls under the discussed legislation, it will have to start disaggregation. All three policy reforms discussed mark a trend toward changes in the sense of transparency in the natural resource governance being accepted as a global norm rather than an initiative by the select few.

The implications of the proposed or already occurring reforms for the three types of countries discussed above differ. For the countries which have already moved toward the inclusion of extensive reporting practices, the changes are consistent with their current focus, perhaps only encouraging further expansion to other phases of revenue management beyond the EITI upstream activities. For those EITI implementers which have been reluctant to implement the extensive practices, the difficulties lie in overcoming the MSG deadlocks and increasing the scope of the initiative - the second challenge introduced in the previous sections. The first two policy options related to the EITI reform will likely either bring them up to the current best practices in the sector, or reveal them as the laggards. The laggard outcome in the mandatory extensive practices scenario would mean 
exclusion from the EITI after failure to comply and thus implies joining the group of non-adopting countries. In the compliance ranking policy scenario, the laggards would lose reputational benefits from the EITI implementation and thus would be encouraged to join the group of extensive implementers. With the strengthened content component of the EITI, implementation for window-dressing reasons will be practically impossible. This may lead to a higher likelihood of extensive implementation, which may happen, however, at the expense of losing some EITI members if they refuse to increase their implementation standards. The US and EU reforms on company payments disclosure, the third policy development theorized here, will most likely have an indirect effect of strengthening the EITI in the nonextensive implementing countries by making it mandatory for companies to disclose their information in a detailed and disaggregated form - the battle for which civil society has been fighting in the MSG negotiations.

Finally, for non-EITI countries the effect of recent and possible future EITI reforms on natural resource management is minimal; in the short term it may even further discourage them from considering adoption. If any, the impact of the EITI reforms would seem to become visible only in a long-term perspective, assuming that transparency in the extractive sectors eventually becomes a widely accepted global norm. For this group of countries, however, the company disclosure required by the US and the EU laws is of tremendous impact. For the democracies among the non-EITI countries, the adoption of the US and EU laws signal an increased acceptance of transparency in the extractive sectors as a global norm. For the authoritarian resource-rich non-EITI countries, these laws will forcefully speed up the process of transparent practices in natural resource management, regardless of whether or not the EITI is adopted. The information companies will start providing on their activities in these countries may catalyze the activities of the interested civil society groups and, perhaps, create pressure to adopt the EITI. Thus, the first challenge currently faced by the EITI - non-adoption of the standard by some 
countries - may be indirectly resolved via the processes initiated by mandatory company law.

Considering the debate on the mechanisms that can prevent the symptoms of the resource curse, all three policy options contribute to increasing the transparency in the governance of the sector. The first EITI reform policy mandatory extensive practices - will strengthen the standard both by increasing transparency in the upstream activities (the current focus of the EITI) and by encouraging transparency in the other stages of the resource management. The second option (the reform in the interpretation of compliance and scaled index of implementation) - if ever adopted - would facilitate a clearer understanding on who are the leaders and laggards among the implementing countries. Finally, the mandatory law for company reporting will also target transparency processes in the non-EITI countries, which currently lie outside the initiative's scope. Interestingly, while the mandatory law targeting companies indirectly strengthens the EITIrelated processes without being part of the initiative itself, the bill introducing Section 1504 and the strict SEC interpretation of the final rule would not have originated without the existing EITI norm and the activities of the EITI supporters. This can be vividly seen in the amount of letters from the EITI activist groups written to the SEC with opinions on the scope of the rule interpretation (SEC, 2012). As noted in Section 1504 (see footnotes 14 and 15 in Disclosure of Payments by Resource Extraction Issuers, 2012), the bill's intent also originated in the EITI mission. The EITI, as a soft governance initiative, started out as a voluntary instrument, with much flexibility given to the implementing countries on how to carry out their implementation process. Over time, though, the initiative has evolved; years of implementation experience and the debate within the EITI Board have led to the reform extending the scope and the depth of the standard. At the same time, the norm has evolved into hard laws, complementary to the EITI and impacting companies as one of the stakeholders to the EITI process. 


\section{Conclusion}

In this dissertation, I analyzed the conditions under which countries adopt the EITI and implement it differently. Using mixed methods, including binary logistic regression, analysis of primary documents, process tracing, a comparative case study and semi-structured interviews with the EITI stakeholders in Azerbaijan and Kazakhstan, I argue that the potential of the EITI in reaching its objective of transparency is dependent on the extensiveness of the implementation activities undertaken. However, despite the inclusion of transnational actors in the EITI process, the effectiveness of the instrument continues to be conditioned on the decision-making of politicians in power.

This research fits within the second generation of global governance studies, which disentangle the functioning of specific regulatory instruments. The results showed that for both the questions of adoption and implementation some of the hypotheses developed in the rationalist framework were supported by empirical evidence. In the study of structural factors motivating countries to adopt the initiative, the factors that increased the likelihood of adoption were resource abundance, low income, ethnic fractionalization, and recent trend toward democratization. Chapter 4 has shown that differences in the implementation activities can be accounted for by rationalist explanations at the country level, namely the nature of the regime and the type of extractive sector - oil and gas, or non-hydrocarbon. The findings of Chapter 5, through the analysis of the stakeholder positions during the implementation process in Azerbaijan and Kazakhstan, supported the rationalist hypothesis on predicted policy stability in the critical oil-rich authoritarian settings. The difficulties in achieving a consensus between the stakeholders at the MSG level were observed in both Azerbaijan and Kazakhstan, and in both countries the process of change has been incremental.

Finally, Chapter 6 discussed the main challenges the EITI is facing in achieving its target of increased transparency -1) the issue of non-adoption by the countries which are expected to benefit from the standard, and 2) non-ambitious 
implementation practices. The three reforms discussed have different effects on the three groups of contexts: the non-EITI countries, the less ambitious EITI implementers, and extensive EITI implementers. Accordingly, their potential to increase the transparency of natural resource management varies between these groups of country contexts.

While this $\mathrm{PhD}$ project showed that the EITI adoption and implementation outcomes can be explained by rational actor models, I do not disregard the potential usefulness of the socialization and constructivist explanations. The importance of these approaches focusing on the ideas, beliefs, and norms is obvious in the light of increasing global efforts in supporting transparency-focused regulation in natural resource governance. Other than done in the present large- $\mathrm{N}$ study, constructivist approaches would have to focus on the socialization and persuasion processes in individual domestic administrations which ultimately may or may not result in the adoption of the EITI. Moreover, an interesting research topic to consider further would be the potential influence of socialization within the MSGs at the domestic level. To convincingly show constructivist socialization occurring within the MSGs, it would be critical to consider the cases of countries switching from aggregation of the reporting by companies to company-bycompany and by revenue stream extensive disaggregation. During the time span covered by this study, there have been no such switches: the countries doing extensive disaggregation have started these practices early on in their implementation processes. However, such cases of policy change, if observed, could lend powerful support to constructivist explanations if one can convincingly show socialization processes occurring at the level of the MSG. Yet even for such cases of changing to extensive requirements along the way, the rationalist explanations for the stakeholder position change and subsequent policy change at the MSG level might offer convincing explanations. Two such main explanations could be the change in the stakeholder constituency's composition (resulting in a position change) and the position change due to external conditions (such as 
democratization of the country, Dodd-Frank, or EITI reforms). This difficulty of disentangling socialization explanations from cost-benefit arguments would have to be taken seriously in designing methodology of studies focusing on this question.

This possible venue for further research is not just an abstract question, since some such changes toward more ambitious implementation practices have occurred recently. In the last two years, a period not covered by the research presented in Chapter 4, there have been seven cases that present a puzzle in terms of their decision to move from aggregated reporting toward company-by-company disaggregation. These seven are among the 32 countries that currently implement the EITI (and that have published at least two reports up to and including July 2013). The countries involved - Cameroon, Chad, Republic of Congo, Kazakhstan, Kyrgyzstan, Madagascar, and Mauritania - all have switched to disclosure disaggregated by individual company and revenue stream. With the exception of the Republic of Congo and Madagascar, which both had introduced the change prior to November 2012 when the SEC final rule on Section 1504 was passed, the other five countries have introduced extensive disaggregation practices only after November 2012. This strongly suggests potential effects of the US and EU laws on the changes in the type of reporting, though in some cases the change in the reporting by EITI-implementing countries can be explained by the change in the regime type. In seeking explanations for why the change occurred in these countries, research will need to take into account potential effects of the laws introduced on the positions of the stakeholders in the MSGs of the respective countries.

Returning to the discussion on the EITI's potential to overcome the resource curse, and given the current state of affairs, the EITI cannot guarantee the establishment or improvement of extensive transparency practices in all country contexts it targets. First, not all countries under risk of suffering from the symptoms of the resource curse are adopting the initiative. Second, the design of the instrument still leaves space for differences in the implementation activities 
among those that do adopt it; as a result, transparency in the extractive sector is being achieved with varying degrees of extensiveness. Being a voluntary instrument, the EITI is dependent on cooperation of domestic actors. Especially in corrupt contexts these actors stand to lose from the very extensive forms of implementation that the EITI promotes. In this sense, it is difficult to expect from this instrument a fundamental change in overcoming the political resource curse, especially in countries which from the beginning of the implementation process are reluctant toward adopting extensive practices. Moreover, even in cases where the EITI is implemented in a more stringent manner, we cannot discard the possibility that existing corruption may simply move into the stages of resource management not included in the EITI practices of a particular implementing country.

A tempting solution to the outlined above problem of corruption moving throughout the full cycle of natural resource management may be complete transparency in the form of full disclosure in all dimensions of EITI implementation activities. Yet I argue that such a solution is not as clear-cut as it may seem, and can be outright quite costly, given certain negative effects of transparency. Even when transparency requirements to disclosure are applied to all phases of natural resource management, this would not necessarily lead to perfect information about the behavior of agents involved. As a result, space for corruption remains even in the presence of openness throughout the full resource management cycle.

To give an example, let's consider a case of mandatory contract disclosure. Full disclosure of contracts between companies and the government may help decreasing corruption in the phases between revenues due and revenues collected into the budget, but it does not solve the problem of revenues leaking in the interaction between the company and the government official prior to signing of the contract. Even opening up the bidding process does not guarantee absence of corruption, as bribes from companies to government officials may still occur behind the scenes. To take an example from another phase of resource 
management, let's consider revenue collection. Even if all the revenue streams collected in the budget are received, corruption can occur via misappropriation of resource streams in unregistered volume. Without physical audits, this form of corruption would not be accounted for. Finally, let's take an example from the phase of revenue spending. Even under the conditions of full disclosure of revenues spent, corruption can remain in the form of revenue transfers that benefit rent-seeking officials (for instance, to organizations owned by the persons affiliated to the official). What emerges out of this discussion is a curious implication: to effectively stop corruption in the sector, increase in transparency throughout the full cycle of natural resource management is simply not enough. Even in systems where accountability mechanisms are present, corruption opportunities will still exist even if full disclosure of practices in the sector is carried out. Given that transparency is not equal to perfect information, corruption possibilities may continue to exist even in highly transparent systems.

Despite the inclusion of transnational actors in the decision-making process (companies and civil society), the EITI thus continues to be dependent on the constituency representing the government. The effectiveness of the instrument in overcoming the resource curse is largely conditioned by the decision-making of politicians in power. This is not necessarily a negative outcome. In contexts where the politicians in power are reform-oriented, the EITI can improve internal reporting and tracking of the received revenues. In these cases, the EITI may help overcome some of the political resource curse symptoms even in the absence of extensive transparency practices, such as extensive disaggregation available for the public. In this sense, the inclusion of all extensive transparency practices is not a necessary condition for the EITI to be effective. Moreover, before the introduction of extensions to the EITI process, the impacts of increased transparency in each dimension of EITI implementation should be carefully assessed. In some cases, transparency in revenue allocation to regional entities may lead to sub-optimal economic decisions. Disclosure of detailed information on resource location and 
volumes may cause breaches to security, or concerns of industry competitiveness in the global markets. More research on these possible effects is needed, and further studies on EITI and other transparency-focused regulatory instruments could specify the conditions under which transparency is beneficial, and the thresholds beyond which transparency may have negative effects.

It must be acknowledged that the new mandatory requirements adopted in May 2013 have significantly changed the EITI by extending the depth and the scope of required minimum transparency practices. However, we do not yet know whether these changes will lead to the extensions of the mandatory practices in the implementing countries, or rather to their unwillingness to comply with the new requirements, in which case the current implementing countries may eventually be de-listed. These new developments are another possible venue for future research.

Despite the challenges the EITI is facing in achieving its objective of increased transparency in the extractive sectors, it is impossible to disregard the influence this soft regulation instrument has had on the evolvement of the global transparency norm in natural resource management. By establishing the idea of transparency in natural resource management as a value toward which we should strive, the EITI (together with other transparency-focused initiatives in the sector) operated as an instrument of norm formation. This development is another promising field for constructivist approaches, which are well-equipped with the tools to explore whether and how transparency-focused regulatory instruments have changed the very nature of the discourse around the issues connected to the management of the extractive sector. 


\section{Annex I. The EITI Principles and Criteria.}

\section{The EITI Principles}

1. We share a belief that the prudent use of natural resource wealth should be an important engine for sustainable economic growth that contributes to sustainable development and poverty reduction, but if not managed properly, can create negative economic and social impacts.

2. We affirm that management of natural resource wealth for the benefit of a country's citizens is in the domain of sovereign governments to be exercised in the interests of their national development.

3. We recognise that the benefits of resource extraction occur as revenue streams over many years and can be highly price dependent.

4. We recognise that a public understanding of government revenues and expenditure over time could help public debate and inform choice of appropriate and realistic options for sustainable development.

5. We underline the importance of transparency by governments and companies in the extractive industries and the need to enhance public financial management and accountability.

6. We recognise that achievement of greater transparency must be set in the context of respect for contracts and laws.

7. We recognise the enhanced environment for domestic and foreign direct investment that financial transparency may bring.

8. We believe in the principle and practice of accountability by government to all citizens for the stewardship of revenue streams and public expenditure.

9. We are committed to encouraging high standards of transparency and accountability in public life, government operations and in business,

10. We believe that a broadly consistent and workable approach to the disclosure of payments and revenues is required, which is simple to undertake and to use. 
11. We believe that payments' disclosure in a given country should involve all extractive industry companies operating in that country.

12. In seeking solutions, we believe that all stakeholders have important and relevant contributions to make - including governments and their agencies, extractive industry companies, service companies, multilateral organisations, financial organisations, investors, and non-governmental organisations.

\section{The EITI Criteria}

1. Regular publication of all material oil, gas and mining payments by companies to governments ("payments") and all material revenues received by governments from oil, gas and mining companies ("revenues") to a wide audience in a publicly accessible, comprehensive and comprehensible manner.

2. Where such audits do not already exist, payments and revenues are the subject of a credible, independent audit, applying international auditing standards.

3. Payments and revenues are reconciled by a credible, independent administrator, applying international auditing standards and with publication of the administrator's opinion regarding that reconciliation including discrepancies, should any be identified.

4. This approach is extended to all companies including state-owned enterprises.

5. Civil society is actively engaged as a participant in the design, monitoring and evaluation of this process and contributes toward public debate.

6. A public, financially sustainable work plan for all the above is developed by the host government, with assistance from the international financial institutions where required, including measurable targets, a timetable for implementation, and an assessment of potential capacity constraints. 
Annex II. Resource-Rich Countries and EITI Implementation Status.

\begin{tabular}{|c|c|c|}
\hline Country & Status of Implementation & Type of Resource \\
\hline Algeria & none & Hydrocarbons \\
\hline Angola & none & Hydrocarbons \\
\hline Azerbaijan & Compliant & Hydrocarbons \\
\hline Bahrain & none & Hydrocarbons \\
\hline Bolivia & none & Hydrocarbons \\
\hline Botswana & none & Minerals \\
\hline Brunei Darussalam & none & Hydrocarbons \\
\hline Cameroon & Candidate & Hydrocarbons \\
\hline Chad & Candidate & Hydrocarbons \\
\hline Chile & none & Minerals \\
\hline Colombia & none & Hydrocarbons \\
\hline Congo, Dem. Rep. & Candidate & Minerals \\
\hline Congo, Rep. & Candidate & Hydrocarbons \\
\hline Ecuador & none & Hydrocarbons \\
\hline Equatorial Guinea & De-listed from candidates & Hydrocarbons \\
\hline Gabon & Candidate & Hydrocarbons \\
\hline Ghana & Compliant & Minerals \\
\hline Guinea & Candidate & Minerals \\
\hline Indonesia & Candidate & Both \\
\hline Iran & none & Hydrocarbons \\
\hline Iraq & Candidate & Hydrocarbons \\
\hline Jordan & none & Minerals \\
\hline Kazakhstan & Candidate & Hydrocarbons \\
\hline Kuwait & none & Hydrocarbons \\
\hline Kyrgyz Republic & Compliant & Minerals \\
\hline Liberia & Compliant & Minerals \\
\hline Libya & none & Hydrocarbons \\
\hline Mauritania & Candidate & Both \\
\hline
\end{tabular}


Mexico

Mongolia

Namibia

Nigeria

Norway

Oman

Papua New Guinea

Peru

Qatar

Russia

Sao Tome and Principe

Saudi Arabia

Sierra Leone

South Africa

Sudan

Syria

Tanzania

Timor-Leste

Trinidad and Tobago

Turkmenistan

United Arab Emirates

Uzbekistan

Venezuela

Vietnam

Yemen, Rep.

Zambia none

Compliant

none

Compliant

Compliant

none

none

Candidate

none

none

De-listed from candidates

none

Candidate

none

none

none

Candidate

Compliant

Candidate

none

none

none

none

none

Suspended from Compliant

countries

Candidate
Hydrocarbons

Minerals

Minerals

Hydrocarbons

Hydrocarbons

Hydrocarbons

Minerals

Minerals

Hydrocarbons

Hydrocarbons

Hydrocarbons

Hydrocarbons

Minerals

Minerals

Hydrocarbons

Hydrocarbons

Minerals

Hydrocarbons

Hydrocarbons

Hydrocarbons

Hydrocarbons

Both

Hydrocarbons

Hydrocarbons

Hydrocarbons

Minerals

NOT CLASSIFIED AS RESOURCE-RICH EITI Countries
Afghanistan
Candidate
Albania
Candidate 
Burkina Faso

Central African Republic

Cote d'Ivoire

Guatemala

Guyana

Ethiopia

Madagascar

Mali

Mozambique

Niger

Togo

Ukraine
Candidate

Compliant

Candidate

Candidate

Candidate

Steps toward Implementation, but no Candidacy yet

Candidate

Compliant

Candidate

Compliant

Candidate

Steps toward Implementation, but no Candidacy yet

Based on the IMF (2002) and data from the EITI Secretariat and country EITI sources (Annex III, October 2011). 
Annex III. EITI Dataset Codebook.

\section{TABLE OF CONTENTS}

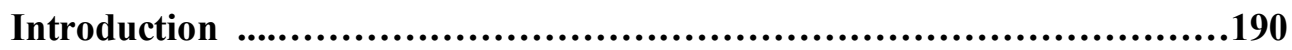

Country and Time Coverage ............................................190

Country Identifier Codes...................................................190

ccode Country Code Numeric.....................................190

ccodealp 3-letter Country Code ......................................190

cname Country Name ..........................................191

Variables...............................................................194

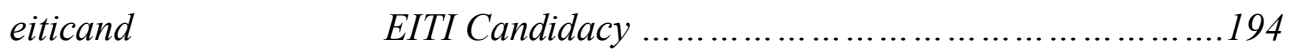

year $\quad$ Year of EITI Candidacy .................................. 194

res_rich Resource Abundance …................................201

min $\quad$ Minerals Abundance....................................201

hydroc Hydrocarbons Abundance …...........................202

fuel_min_exp Exports of Fuel and Mining Products... ..................202

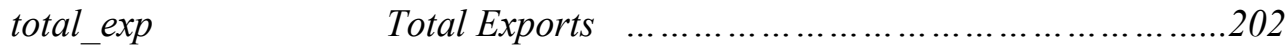

exp_dep Dependence on Natural Resources Exports _..............203

corr_ti Corruption Perception Index ...........................203

corr_wgi Control of Corruption …................................203

income $\quad$ Income Level ...........................................204

fdi_gdp FDI Inflows as Percentage of GDP ....................204

regime Revised Combined Polity Score ...........................204

polity_change Change of Polity toward Democratization ..................205

donor Donor Influence .......................................205

first_conf Participation in the First EITI Conference (2003).......209

form-col Colonial Heritage .........................................209 


\section{Introduction}

This codebook compiles the information on the variables used in chapter 3, exploring the factors increasing the likelihood of countries adopting the EITI (Extractive Industries Transparency Initiative). For this chapter, a cross-sectional dataset with global coverage has been compiled. The sources draw on a number of freely available data and a number of self-compiled data.

\section{Country and Time Coverage}

I include all countries in the world recognized by the United Nations as of 2002 for the total of 191 countries observed. The year 2002 is chosen because most of the data for the independent variables come for the year of 2002, prior to the establishment of the EITI in 2003.

\section{Country Identifier Codes}

ccode Country Code Numeric

http://www.qog.pol.gu.se/data/QoG_Codebook_v6Apr11.pdf

Numeric country codes are taken from "Quality of Government" dataset (April 2011 version). These are based on codes of International Organization for Standardization (ISO-3166-1 numeric).

\section{ccodealp 3-letter Country Code}

http://www.qog.pol.gu.se/data/QoG_Codebook_v6Apr11.pdf

3-letter country codes are taken from "Quality of Government" dataset (April 2011 version). These are based on codes of International Organization for Standardization (ISO-3166-1 alpha3). 


\section{cname}

\section{Country Name}

ccode ccodealp cname

\begin{tabular}{|c|c|c|c|c|c|}
\hline 4 & AFG & Afghanistan & 140 & CAF & Central African Rep. \\
\hline 8 & ALB & Albania & 148 & TCD & Chad \\
\hline 12 & DZA & Algeria & 152 & CHL & Chile \\
\hline 20 & AND & Andorra & 156 & $\mathrm{CHN}$ & China \\
\hline 24 & $\mathrm{AGO}$ & Angola & 170 & $\mathrm{COL}$ & Colombia \\
\hline 28 & ATG & Antigua and Barbuda & 174 & $\mathrm{COM}$ & Comoros \\
\hline 32 & ARG & Argentina & 178 & $\mathrm{COG}$ & Congo \\
\hline 51 & ARM & Armenia & 180 & COD & Congo, Dem. Rep. \\
\hline 36 & AUS & Australia & 188 & CRI & Costa Rica \\
\hline 40 & AUT & Austria & 384 & CIV & Cote d'Ivoire \\
\hline 31 & AZE & Azerbaijan & 191 & HRV & Croatia \\
\hline 44 & BHS & Bahamas & 192 & CUB & Cuba \\
\hline 48 & BHR & Bahrain & 196 & CYP & Cyprus \\
\hline 50 & BGD & Bangladesh & 203 & $\mathrm{CZE}$ & Czech Republic \\
\hline 52 & $\mathrm{BRB}$ & Barbados & 208 & DNK & Denmark \\
\hline 112 & BLR & Belarus & 262 & DJI & Djibouti \\
\hline 56 & BEL & Belgium & 212 & DMA & Dominica \\
\hline 84 & BLZ & Belize & 214 & $\mathrm{DOM}$ & Dominican Republic \\
\hline 204 & BEN & Benin & 218 & $\mathrm{ECU}$ & Ecuador \\
\hline 64 & BTN & Bhutan & 818 & EGY & Egypt \\
\hline 68 & BOL & Bolivia & 222 & SLV & El Salvador \\
\hline 70 & $\mathrm{BIH}$ & Bosnia and Herzegovina & 226 & GNQ & Equatorial Guinea \\
\hline 72 & BWA & Botswana & 232 & ERI & Eritrea \\
\hline 76 & BRA & Brazil & 233 & EST & Estonia \\
\hline 96 & BRN & Brunei & 231 & ETH & Ethiopia (1993-) \\
\hline 100 & BGR & Bulgaria & 242 & FJI & Fiji \\
\hline 854 & BFA & Burkina Faso & 246 & FIN & Finland \\
\hline 108 & BDI & Burundi & 250 & FRA & France \\
\hline 116 & KHM & Cambodia & 266 & GAB & Gabon \\
\hline 120 & CMR & Cameroon & 270 & GMB & Gambia \\
\hline 124 & CAN & Canada & 268 & GEO & Georgia \\
\hline 132 & CPV & Cape Verde & 276 & DEU & Germany \\
\hline
\end{tabular}




\begin{tabular}{|c|c|c|}
\hline 288 & GHA & Ghana \\
\hline 300 & GRC & Greece \\
\hline 308 & GRD & Grenada \\
\hline 320 & GTM & Guatemala \\
\hline 324 & GIN & Guinea \\
\hline 624 & GNB & Guinea-Bissau \\
\hline 328 & GUY & Guyana \\
\hline 332 & HTI & Haiti \\
\hline 340 & HND & Honduras \\
\hline 348 & HUN & Hungary \\
\hline 352 & ISL & Iceland \\
\hline 356 & IND & India \\
\hline 360 & IDN & Indonesia \\
\hline 364 & IRN & Iran \\
\hline 368 & IRQ & Iraq \\
\hline 372 & IRL & Ireland \\
\hline 376 & ISR & Israel \\
\hline 380 & ITA & Italy \\
\hline 388 & JAM & Jamaica \\
\hline 392 & JPN & Japan \\
\hline 400 & JOR & Jordan \\
\hline 398 & KAZ & Kazakhstan \\
\hline 404 & KEN & Kenya \\
\hline 296 & KIR & Kiribati \\
\hline 408 & PRK & Korea, North \\
\hline 410 & KOR & Korea, South \\
\hline 414 & KWT & Kuwait \\
\hline 417 & KGZ & Kyrgyzstan \\
\hline 418 & LAO & Laos \\
\hline 428 & LVA & Latvia \\
\hline 422 & LBN & Lebanon \\
\hline 426 & LSO & Lesotho \\
\hline 430 & LBR & Liberia \\
\hline 434 & LBY & Libya \\
\hline
\end{tabular}

\begin{tabular}{|c|c|c|}
\hline 438 & LIE & Liechtenstein \\
\hline 440 & LTU & Lithuania \\
\hline 442 & LUX & Luxembourg \\
\hline 807 & MKD & Macedonia \\
\hline 450 & MDG & Madagascar \\
\hline 454 & MWI & Malawi \\
\hline 458 & MYS & Malaysia \\
\hline 462 & MDV & Maldives \\
\hline 466 & MLI & Mali \\
\hline 470 & MLT & Malta \\
\hline 584 & MHL & Marshall Islands \\
\hline 478 & MRT & Mauritania \\
\hline 480 & MUS & Mauritius \\
\hline 484 & MEX & Mexico \\
\hline 583 & FSM & Micronesia \\
\hline 498 & MDA & Moldova \\
\hline 492 & $\mathrm{MCO}$ & Monaco \\
\hline 496 & MNG & Mongolia \\
\hline 504 & MAR & Morocco \\
\hline 508 & $\mathrm{MOZ}$ & Mozambique \\
\hline 104 & MMR & Myanmar \\
\hline 516 & NAM & Namibia \\
\hline 520 & NRU & Nauru \\
\hline 524 & NPL & Nepal \\
\hline 528 & NLD & Netherlands \\
\hline 554 & NZL & New Zealand \\
\hline 558 & NIC & Nicaragua \\
\hline 562 & NER & Niger \\
\hline 566 & NGA & Nigeria \\
\hline 578 & NOR & Norway \\
\hline 512 & $\mathrm{OMN}$ & Oman \\
\hline 586 & PAK & Pakistan (1972-) \\
\hline 585 & PLW & Palau \\
\hline 591 & PAN & Panama \\
\hline
\end{tabular}




\begin{tabular}{|c|c|c|c|c|c|}
\hline 598 & PNG & Papua New Guinea & 756 & $\mathrm{CHE}$ & Switzerland \\
\hline 600 & PRY & Paraguay & 760 & SYR & Syria \\
\hline 604 & PER & Peru & 762 & TJK & Tajikistan \\
\hline 608 & PHL & Philippines & 834 & TZA & Tanzania \\
\hline 616 & POL & Poland & 764 & THA & Thailand \\
\hline 620 & PRT & Portugal & 626 & TLS & Timor-Leste \\
\hline 634 & QAT & Qatar & 768 & TGO & Togo \\
\hline 642 & ROU & Romania & 776 & TON & Tonga \\
\hline 643 & RUS & Russia & 780 & TTO & Trinidad and Tobago \\
\hline 646 & RWA & Rwanda & 788 & TUN & Tunisia \\
\hline 882 & WSM & Samoa & 792 & TUR & Turkey \\
\hline 674 & SMR & San Marino & 795 & TKM & Turkmenistan \\
\hline 678 & STP & Sao Tome and Principe & 798 & TUV & Tuvalu \\
\hline 682 & SAU & Saudi Arabia & 800 & UGA & Uganda \\
\hline 686 & SEN & Senegal & 804 & UKR & Ukraine \\
\hline 891 & SCG & Serbia and Montenegro & 784 & ARE & United Arab Emirates \\
\hline 690 & SYC & Seychelles & 826 & GBR & United Kingdom \\
\hline 694 & SLE & Sierra Leone & 840 & USA & United States \\
\hline 702 & SGP & Singapore & 858 & URY & Uruguay \\
\hline 703 & SVK & Slovakia & 860 & UZB & Uzbekistan \\
\hline 705 & SVN & Slovenia & 548 & VUT & Vanuatu \\
\hline 90 & SLB & Solomon Islands & 862 & VEN & Venezuela \\
\hline 706 & $\mathrm{SOM}$ & Somalia & 704 & VNM & Vietnam \\
\hline 710 & $\mathrm{ZAF}$ & South Africa & 887 & YEM & Yemen \\
\hline 724 & ESP & Spain & 894 & ZMB & Zambia \\
\hline 144 & LKA & Sri Lanka & 716 & ZWE & Zimbabwe \\
\hline 659 & KNA & St Kitts and Nevis & & & \\
\hline 662 & LCA & St Lucia & & & \\
\hline 670 & $\begin{array}{l}\text { VCT } \\
\text { Grenadin }\end{array}$ & $\begin{array}{l}\text { St Vincent and the } \\
\text { hes }\end{array}$ & & & \\
\hline 736 & SDN & Sudan & & & \\
\hline 740 & SUR & Suriname & & & \\
\hline 748 & SWZ & Swaziland & & & \\
\hline 752 & SWE & Sweden & & & \\
\hline
\end{tabular}




\section{Variables}

eiticand

EITI Candidacy

This is a constructed variable which identifies whether the country of observation has adopted the EITI in the time period from June 2003 when the EITI was established until March 2011. The variable equals 1 if a country has adopted the EITI as candidate country in the eight years since the EITI's establishment as an initiative. The variable equals 0 otherwise. Data is obtained from the EITI Secretariat http://eiti.org/implementingcountries. Candidacy is a status acquired by countries intending to implement the EITI after they have achieved four sign-up criteria required by the EITI. These include a government announcement of implementation, commitment to work with the stakeholders, appointment of an implementation leader, and a composition of a fully costed work plan.

year

\section{Year of EITI Candidacy}

The variable identifies a year in which a country has adopted the EITI as candidate. The data is obtained from the EITI Secretariat's country web pages and country national web pages in cases where the EITI Secretariat's data was missing. The candidacies are coded from the establishment of the EITI in 2003 until 1 March 2011. Years of candidacy for countries which have adopted the EITI in the early years of the EITI's establishment (before such guidelines as "EITI candidate" have been established) are coded on the basis of information provided by the EITI Secretariat, consultations with people who were involved with the EITI from its establishment and information on dates of national implementation committees' establishments. Detailed notes on country status changes and sources are provided in the table below. 





2007 Candidate

2008 Candidate

2009 Candidate

$2010 \quad$ Candidate

\begin{tabular}{|c|c|c|}
\hline \multirow{5}{*}{$\begin{array}{l}\text { Central } \\
\text { African } \\
\text { Republic }\end{array}$} & 2007 & $\begin{array}{l}\text { Steps toward } \\
\text { Implementation }\end{array}$ \\
\hline & 2008 & Candidate \\
\hline & 2009 & Candidate \\
\hline & 2010 & Candidate \\
\hline & 2011 & Compliant \\
\hline Chad & 2010 & Candidate \\
\hline \multirow[t]{3}{*}{$\begin{array}{l}\text { Congo, } \\
\text { Dem. Rep. }\end{array}$} & 2005 & $\begin{array}{l}\text { Steps toward } \\
\text { Implementation }\end{array}$ \\
\hline & 2006 & $\begin{array}{l}\text { Steps toward } \\
\text { Implementation }\end{array}$ \\
\hline & 2007 & $\begin{array}{l}\text { Steps toward } \\
\text { Implementation }\end{array}$ \\
\hline
\end{tabular}

2008 Candidate

2009 Candidate

2010 Candidate

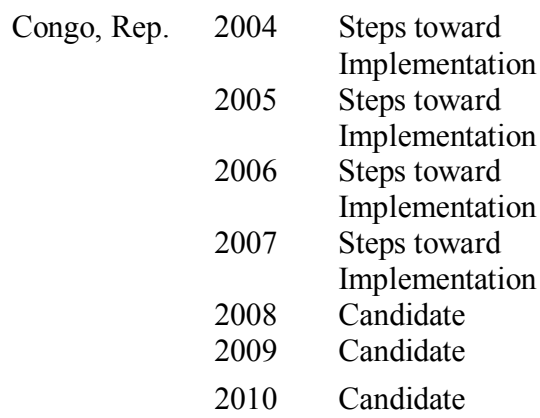

for reconciliation of figures and volumes for the years 2001 to 2004, and 2005

December 2006: Publication of the first report for the period 2001-2004

Sep-07

Statement of commitment

21-Nov-08

1-Mar-11

Source: minutes from the 12th EITI Board meeting held on 15-16 April 2010

Official endorsement of the EITI principles, EITI London Conference, 17 March 2005

3 September 2007: presidential ordinance $N^{\circ} 07 / 065$ creates the National EITI Committee 12 October 2007: nomination of members of the multi stakeholder political and technical committee by ministerial decree $\mathrm{N}^{\circ}$ 24-26 CAB/MIN. PL/2007

10 December 2007: election and subsequent nomination of the members of the permanent secretariat by Ministerial decree $\mathrm{N}^{\circ} 27 \mathrm{CAB} / \mathrm{MIN}$. $\mathrm{PL} / 2007$

12 December 2007: budgeted work plan published 22-Feb-08

June 2004: intention to adopt announced

28 December 2007: work plan finalized

$2 / 22 / 2008$ 


\begin{tabular}{|c|c|c|c|}
\hline \multirow[t]{5}{*}{ Cote d'Ivoire } & 2006 & $\begin{array}{l}\text { Steps toward } \\
\text { Implementation }\end{array}$ & endorsement of the EITI principles, 15 May 2006 \\
\hline & 2007 & $\begin{array}{l}\text { Steps toward } \\
\text { Implementation }\end{array}$ & \\
\hline & 2008 & Candidate & $\begin{array}{l}12 \text { May 2008: Candidate status; /4 February 2008: } \\
\text { EITI National Committee launched } \\
1 \text { April 2008: budgeted work plan/ }\end{array}$ \\
\hline & 2009 & Candidate & \\
\hline & 2010 & Candidate & \\
\hline \multirow[t]{2}{*}{ Ethiopia } & 2009 & $\begin{array}{l}\text { Steps toward } \\
\text { implementation }\end{array}$ & $\begin{array}{l}\text { Source: minutes from the } 10 \text { th EITI Board Meeting } \\
\text { held on } 14-15 \text { October } 2009\end{array}$ \\
\hline & 2010 & $\begin{array}{l}\text { Steps toward } \\
\text { implementation }\end{array}$ & \\
\hline \multirow{4}{*}{$\begin{array}{l}\text { Equatorial } \\
\text { Guinea }\end{array}$} & 2007 & Candidate & 27-Sep-07 \\
\hline & 2008 & Candidate & \\
\hline & 2009 & Candidate & \\
\hline & 2010 & $\begin{array}{l}\text { Extension not granted; } \\
\text { de-listed }\end{array}$ & $\begin{array}{l}\text { Source: minutes from the 12th EITI Board meeting } \\
\text { held on } 15-16 \text { April } 2010\end{array}$ \\
\hline \multirow[t]{5}{*}{ Gabon } & 2004 & $\begin{array}{l}\text { Steps toward } \\
\text { Implementation }\end{array}$ & $\begin{array}{l}28 \text { July 2004, Paul Toungui, Minister of Economy, } \\
\text { Finance, and Budget of Gabon informed the World } \\
\text { Bank of his country's commitment to adhere to the } \\
\text { EITI, and requested technical assistance for its } \\
\text { implementation. }\end{array}$ \\
\hline & 2005 & Candidate & $\begin{array}{l}\text { Candidate based on pilot status (source: interview) } \\
24 \text { February 2005: the EITI Work Group created by } \\
\text { Ministerial decree } \\
\text { March 2005: letter of intent to implement EITI to } \\
\text { IMF; December 2005: first report }\end{array}$ \\
\hline & 2006 & Candidate & \\
\hline & $\begin{array}{l}2007 \\
2008\end{array}$ & $\begin{array}{l}\text { Candidate } \\
\text { Candidate }\end{array}$ & \\
\hline & 2009 & Candidate & \\
\hline \multirow[t]{5}{*}{ Ghana } & 2003 & Candidate & $\begin{array}{l}\text { Candidate based on pilot status (source: } 2 \text { interviews) } \\
\text { June 2003: intention to implement the EITI } \\
\text { announced; Sept. 2003: first release of revenue } \\
\text { figures by the Minerals Commission }\end{array}$ \\
\hline & 2004 & Candidate & \\
\hline & 2005 & Candidate & $\begin{array}{l}\text { Feb. 2005: National Steering Committee established } \\
\text { by the ministerial decree to oversee the } \\
\text { implementation of the EITI }\end{array}$ \\
\hline & 2006 & Candidate & \\
\hline & 2007 & Candidate & 27-Sep-07 \\
\hline
\end{tabular}


2008 Candidate

2009 Candidate

2010 Compliant

$\begin{array}{lll}\text { Guatemala } & 2011 & \text { Candidate } \\ \text { Guinea } & 2007 & \begin{array}{l}\text { Candidate } \\ \text { Candidate }\end{array} \\ & 2008 & \begin{array}{l}\text { Suspended } \\ 2009\end{array} \\ & 2010 & \begin{array}{l}\text { Suspended } \\ \text { Candidate }\end{array} \\ & 2011 & \\ \text { Guyana } & 2010 & \begin{array}{l}\text { Steps toward } \\ \text { Implementation }\end{array}\end{array}$

Indonesia $2009 \quad$ Steps toward Implementation

2010 Candidate

Iraq

Kazakhstan

2005 Candidate

2006 Candidate

2007 Candidate

2008 Candidate

2009 Candidate

2010 Candidate

$\begin{array}{llll}\text { Kyrgyz } & 2004 & \text { Candidate } & \text { pilot country (source: 2 interviews) } \\ \text { Republic } & 2005 & \text { Candidate } & \\ & 2006 & \text { Candidate } & \\ 2007 & \text { Candidate } & \\ 2008 & \text { Candidate } & \\ & 2009 & \text { Candidate } & \\ & 2010 & \text { Candidate } & \text { 1-Mar-11 } \\ & 2011 & \text { Compliant } & \\ & & \text { Commitment announced } \\ \text { Liberia } & 2006 & \text { Steps toward } & \text { Implementation } \\ & 2007 & \text { Candidate } & \text { 27 September 2007 (source: letter from Peter Eigen, }\end{array}$

Source: minutes from the 13th EITI Board meeting held on 19-20 October 2010

1-March-2011

27-Sep-07

12/19/2009: voluntary suspension approved

1-Mar-11

Guyana's Prime Minister, Samuel A. Hinds, expressed his Government's commitment to implement the EITI standard, 4 May 2010

Announced intent to implement

Source: minutes from the 13th EITI Board meeting held on 19-20 October 2010

minutes from the 11th Board meeting held on 9-10 Feb 2010 (special case of reporting)

Based on documents at Kazakhstan's national website and 2 interviews 
2008 Candidate

2009 Compliant

\begin{tabular}{|c|c|c|}
\hline \multirow[t]{2}{*}{ Madagascar } & $\begin{array}{l}2008 \\
2009\end{array}$ & $\begin{array}{l}\text { Candidate } \\
\text { Candidate }\end{array}$ \\
\hline & 2010 & Candidate \\
\hline \multirow[t]{2}{*}{ Mali } & $\begin{array}{l}2007 \\
2008\end{array}$ & $\begin{array}{l}\text { Candidate } \\
\text { Candidate }\end{array}$ \\
\hline & 2009 & Candidate \\
\hline \multirow[t]{5}{*}{ Mauritania } & 2005 & $\begin{array}{l}\text { Steps toward } \\
\text { Implementation }\end{array}$ \\
\hline & 2006 & $\begin{array}{l}\text { Steps toward } \\
\text { Implementation }\end{array}$ \\
\hline & 2007 & Candidate \\
\hline & 2008 & Candidate \\
\hline & 2009 & Candidate \\
\hline \multirow[t]{6}{*}{ Mongolia } & 2005 & $\begin{array}{l}\text { Steps toward } \\
\text { Implementation }\end{array}$ \\
\hline & 2006 & $\begin{array}{l}\text { Steps toward } \\
\text { Implementation }\end{array}$ \\
\hline & 2007 & Candidate \\
\hline & 2008 & Candidate \\
\hline & 2009 & Candidate \\
\hline & 2010 & Compliant \\
\hline
\end{tabular}

$\begin{array}{lll}\text { Mozambique } & 2009 & \begin{array}{l}\text { Candidate } \\ \text { Niger }\end{array} \\ & 2010 & \text { Candidate } \\ & 2006 & \begin{array}{l}\text { Steps toward } \\ \text { Implementation }\end{array} \\ & 2007 & \begin{array}{l}\text { Candidate } \\ \text { Candidate } \\ \text { Candidate }\end{array} \\ & 2008 & \text { Candidate } \\ & 2010 & \text { Compliant } \\ & 2011 & \\ & 2003 & \text { Candidate } \\ \text { Nigeria } & 2004 & \text { Candidate }\end{array}$

"key documents" on LEITI website)

Source: minutes from the 10th EITI Board Meeting held on 14-15 October 2009

22-Feb-08

9/27/2007 (source: Mali's EITI website)

(Source: Mauritania's EITI website)

27-Sep-07

27-Sep-07

Source: minutes from the 13th EITI Board meeting held on 19-20 October 2010

Source: minutes from the 9th EITI Board meeting held on 14-15 May 2009

27-Sep-07

1-Mar-11

Candidate based on pilot status (source: interview); statement of commitment February 2004: NEITI launched under Former President Olusegun Obasanjo 


\begin{tabular}{|c|c|c|c|}
\hline & & & Assembly \\
\hline & 2005 & Candidate & \\
\hline & 2006 & Candidate & $\begin{array}{l}\text { 2006: results of the first financial, physical and } \\
\text { process audit for 1999-2004 published }\end{array}$ \\
\hline & 2007 & Candidate & 9/27/2007 official candidacy \\
\hline & 2008 & Candidate & \\
\hline & 2009 & Candidate & \\
\hline & 2010 & Candidate & \\
\hline & 2011 & Compliant & 1-Mar-11 \\
\hline Norway & 2009 & Candidate & 11-Feb-09 \\
\hline & 2010 & Candidate & \\
\hline & 2011 & Compliant & 1-Mar-11 \\
\hline Peru & 2006 & $\begin{array}{l}\text { Steps toward } \\
\text { implementation }\end{array}$ & $\begin{array}{l}12 \text { May 2006: the Government of Peru published an } \\
\text { Executive Decree that approves the EITI Action Plan } \\
\text { and creates an EITI Working Group }\end{array}$ \\
\hline & 2007 & Candidate & Sep-07 \\
\hline & 2008 & Candidate & \\
\hline & 2009 & Candidate & \\
\hline $\begin{array}{l}\text { Sao Tome } \\
\text { and Principe }\end{array}$ & 2008 & Candidate & $\begin{array}{l}\text { 2008; based on Peter Eigen's } 2010 \text { letter of extension } \\
\text { refusal: extension can be asked at the end of two year } \\
\text { time period of implementation (letter available at the } \\
\text { EITI Secretariat's website) }\end{array}$ \\
\hline & 2009 & Candidate & \\
\hline & 2010 & $\begin{array}{l}\text { No suspension } \\
\text { granted; de-listed }\end{array}$ & $\begin{array}{l}\text { Source: minutes from the 12th EITI Board Meeting } \\
\text { held on 15-16th April } 2010\end{array}$ \\
\hline Sierra Leone & 2006 & $\begin{array}{l}\text { Steps toward } \\
\text { Implementation }\end{array}$ & June 2006: intention announced \\
\hline & 2007 & $\begin{array}{l}\text { Steps toward } \\
\text { Implementation }\end{array}$ & June 2007: official launch of Sierra Leone EITI \\
\hline & 2008 & Candidate & 22-Feb-08 \\
\hline & 2009 & Candidate & \\
\hline & 2010 & Candidate & \\
\hline Tanzania & 2009 & Candidate & $\begin{array}{l}\text { Source: minutes from the } 7 \text { th board meeting held on } \\
16 \text { Feb. } 2009\end{array}$ \\
\hline & 2010 & Candidate & \\
\hline Timor-Leste & 2008 & Candidate & 2/22/2008 (source: Timor-Leste Validation report) \\
\hline & 2009 & Candidate & \\
\hline & 2010 & Compliant & 1-Jul-10 \\
\hline Togo & 2010 & Candidate & Source: minutes from the 13th EITI Board meeting \\
\hline & & & 200 \\
\hline
\end{tabular}

December 2004: legal bill introduced to the National Assembly

2006: results of the first financial, physical and process audit for 1999-2004 published 9/27/2007 official candidacy Executive Decree that approves the EITI Action Plan and creates an EITI Working Group Sep-07 refusal: extension can be asked at the end of two year time period of implementation (letter available at the EITI Secretariat's website)

Source: minutes from the 12th EITI Board Meeting teld on 15-16th April 2010

June 2006: intention announced

June 2007: official launch of Sierra Leone EITI

Source: minutes from the 7th board meeting held on 16Feb. 2009

2/22/2008 (source: Timor-Leste Validation report)

1-Jul-10

Source: minutes from the 13th EITI Board meeting 


$\begin{array}{lcll}\begin{array}{l}\text { Trinidad and } \\ \text { Tobago }\end{array} & 2011 & \text { Candidate } & \text { 1-March-2011 } \\ \text { Ukraine } & 2010 & \begin{array}{l}\text { Steps toward } \\ \text { Implementation }\end{array} & \\ \text { Yemen, Rep. } & 2007 & \begin{array}{l}\text { Candidate } \\ \text { Candidate }\end{array} & \text { 27-Sep-07 } \\ & 2008 & \\ & 2009 & \text { Candidate } & \\ & 2010 & \text { Candidate } & \text { 1-Mar-11 } \\ & 2011 & \text { Compliant } & \text { Source: minutes from the 9th EITI Board meeting } \\ \text { Zambia } & 2009 & \text { Candidate } & \text { held on 14-15 May 2009 } \\ & 2010 & \text { Candidate } & \end{array}$

res_rich

Resource Abundance

This variable identifies countries which are classified as hydrocarbon and mineral resource-rich by the International Monetary Fund (IMF) during the time period from 2000 until 2005. The variable equals 1 if the country is classified as resourcerich and 0 otherwise. The IMF criterion for resource abundance is as follows: (i) an average share of hydrocarbon and/or mineral fiscal revenues in total fiscal revenue is at least 25 percent during the period 2000-2005, or (ii) an average share of hydrocarbon and/or mineral export proceeds in total export proceeds is at least 25 percent during the period 2000-2005. http://www.imf.org/external/np/pp/2007/eng/051507g.pdf

$\min$ Minerals Abundance

This variable is constructed on the basis of res_rich to identify countries rich in mineral resources. It equals 1 if the country is classified as mineral resource-rich and 0 otherwise. 


\section{hydroc Hydrocarbons Abundance}

This variable is constructed on the basis of res_rich to identify countries rich in hydrocarbons. It equals 1 if the country is classified as hydrocarbons resource-rich and 0 otherwise.

\section{Fuel_min_exp Exports of Fuel and Mining Products}

(N: 175)

This variable measures exports of fuel and mining products per country for the year of 2002 (in cases of missing data - for the most recent to 2002 available year). The unit of measurement is US dollars at current prices. The data is obtained from the World Trade Organization (WTO) data on merchandise trade by commodity, which is collected from UNSD Comtrade and Eurostat. Fuels and mining products include i) ores and other minerals: crude fertilizers (other than those classified in chemicals) and crude minerals; metalliferous ores and metal scrap (SITC divisions 27, 28); ii) fuels: (SITC section 3), and iii) non-ferrous metals: (SITC division 68). http://stat.wto.org/StatisticalProgram/WSDBStatProgramSeries.aspx?Language=E

\section{total_exp Total Exports}

(N: 175)

This variable measures total merchandise trade per country for the year corresponding to the year for which fuel_min_exp were obtained; the unit of measurement is US dollars at current prices. The data comes from the WTO. Total merchandise trade is defined according to the general trade definition and includes all types of inward and outward movement of goods through a country or territory including movements through customs warehouses and free zones. Goods include all merchandise that either add to or reduce the stock of material resources of a country by entering (imports) or leaving (exports) the country's economic territory. For further explanations on specifics for the particular countries, see WTO technical notes at 
http://stat.wto.org/StatisticalProgram/WSDBStatProgramTechNotes.aspx?Languag e=E\#Def_Meth_TMV http://stat.wto.org/StatisticalProgram/WSDBStatProgramSeries.aspx?Language=E

\section{exp_dep Dependence on Natural Resources Exports}

This variable measures country dependence on resource exports and is constructed in the following manner: fuel_min_exp divided by total_exp.

corr_ti

Corruption Perception Index

(N: 100)

This variable measures corruption for the year of 2002 and is obtained from Transparency International's Corruption Perception Index. The variable ranges from 0 (highly corrupt) to 10 (very clean). CPI defines corruption as abuse of entrusted power for personal gain and is an aggregate indicator which combines different sources of information about corruption. http://www.transparency.org/policy_research/surveys_indices/cpi/2002\#cpi

corr_wgi Control of Corruption

(N: 187)

This variable measures corruption for the year of 2002 and is obtained from Worldwide Governance Indicators. Corruption is defined as public power exercised for private gain, including both petty and grand forms of corruption, as well as "capture" of the state by elites and private interests. "Control of corruption" is an aggregate indicator, based on several sources. The variable ranges from -2.5 (most corrupt) to 2.5 (least corrupt).

http://info.worldbank.org/governance/wgi/resources.htm 


\section{income Income Level}

(N: 188)

This variable classifies countries by their income level for the year of 2002 according to the World Bank's country income classifications of four categories. The variable equals 1 if the country has a low income classification, 2 if the country has a lower middle income classification, 3 if the country is classified as upper middle income class, and 4 if the classification is high income.

\section{fdi_gdp FDI Inflows as Percentage of GDP}

(N: 187)

This variable measures foreign direct investment (FDI) into the country of observation as percentage of gross domestic product (GDP) for the year of 2002 . The data is obtained from UNCTAD. FDI is defined as an investment involving a long-term relationship and reflecting a lasting interest in and control by a resident entity in one economy (foreign direct investor or parent enterprise) of an enterprise resident in a different economy (FDI enterprise or affiliate enterprise or foreign affiliate).

http://unctadstat.unctad.org/ReportFolders/reportFolders.aspx?sCS_referer=andsC S_ChosenLang=en

\section{regime}

\section{Revised Combined Polity Score}

(N: 161)

This variable is obtained from POLITY IV database for the year of 2002. The variable modifies the combined annual polity score (which ranges from +10 strongly democratic to -10 strongly autocratic) by applying a simple treatment to convert instances of "standardized authority scores" (i.e., -66, -77, and -88) to conventional polity scores (i.e., within the range, -10 to +10 ). The values have been converted according to the following rule set: 
(-66) Cases of foreign "interruption" are treated in Polity IV as "system missing," but treated in this dataset as zeros.

(-77) Cases of "interregnum," or anarchy, are converted to a "neutral" Polity score of " $0 . "$

(-88) Cases of "transition" are prorated across the span of the transition. http://www.systemicpeace.org/polity/polity4.htm

\section{polity_change Change of Polity toward Democratization}

(N: 161)

This variable is constructed on the basis of variables "durable" and "polity2" in Polity IV. "Durable" is a Polity IV variable measuring regime durability, which is defined as the number of years since the most recent regime change (the regime change is a three-point change in the POLITY score over a time period of three years or less) or the end of transition period. The variable "polity_change" is defined as the number of years since the last zero in "durable" from Polity IV corresponding to "polity2" positive score change toward democratization. Counting starts at 2002 and goes backwards until 1980 included. If no positive change in "polity2" during this time period occurred, number of years is coded as "23 years or more" since last change toward democratization.

\section{donor Donor Influence}

(N: 191)

This variable identifies whether a country has had at least one project in extractive industries prior to candidacy (in cases of no candidacy - prior to 2011) funded by donor, which also makes financial contributions to the EITI's Multi-Trust Donor Fund. Cases where projects with countries were mentioned, but did not contain dates, were not included. The variable equals 1 if a project occurred and 0 otherwise. Extractive industries include oil, minerals and forestry; forestry is included because several EITI countries have carried out the EITI in the forestry 
sector, besides the oil and mineral sectors. Countries and their respective agenciesdonors to EITI's MDTF were obtained from the EITI website. These include Australia (AUSAID), Belgium (DGDC), Canada (CIDA), Finland (MFA), France (MEFI), Germany (MBZ), the Netherlands (MDC), Norway (MFA), Spain (MFA), Switzerland (FDEA), UK (DFID), the US (USAID). Projects conducted by these countries in countries of observation were obtained from coding available information on the project portals of the respective donor agencies. Detailed information on projects that were coded is included below:

\section{Australia, The Australian's Government Overseas Aid Program (AusAID) \\ Iraq, June 2009 (Memorandum of Understanding on Resources and Energy) \\ Sri Lanka, new program for 2010-2015 (Community Forestry Program to improve management of natural resources; built on the previous 6 year Sri Lanka Australia Natural Resource Management Project) \\ China, 2002-2008 (Completed Qinghai Forestry Resources Management Project)}

\section{Belgium, Directorate-General for Development Cooperation (DGDC)}

None identified. The few mentions of natural resources found were related to environmental projects.

\section{Canada, Canadian International Development Agency (CIDA)}

Peru, 2002-2011 (Peru-Canada Mineral Resources Reform Project (Percan), technical assistance for regulatory reform)

2003-2009 (Peru Hydrocarbon Assistance Project (PHAP) for new institutional and regulatory frameworks)

Bolivia, 2003-2012 (Hydrocarbon Regulation)

Indonesia, 2009-2012 (Papua: Land of Peace - Civil Society Leadership in Conflict Transformation, for civil society)

Honduras, 2009-2010 (Conference: Rethinking Extractive Industry: Regulation, Dispossession, and Emerging Claims) 
Tanzania, 2008-2011 (Strengthening Policy Forum for NGOs, for increasing non-state actors' knowledge about different policy issues, among which are extractive industries and transparency)

\section{Finland, Ministry of Foreign Affairs (MFA)}

Nepal, 2009-2014 (Forest Resources Assessment)

Zambia, 2008-2012 (Development of Environmental and Natural Resources Management, Zambia) 2000-2008 (Forestry Sector Support Programme II)

Vietnam, 2004-2011 (Forestry Trust Fund)

\section{France, Ministry of Economy, Finance and Industry (MEFI)}

Cameroon, "over the years" n.d. available (natural resource management priority, forest industry)

\section{Germany, Federal Ministry for Economic Cooperation and Development (BMZ)}

No project was included. Project with Yemen was considered, but had no date attached.

\section{The Netherlands, Ministry of Foreign Affairs, Development Cooperation (MDC)}

None reported

\section{Norway, Ministry of Foreign Affairs (MFA)}

Oil for Development (OfD) countries:

- Afghanistan, 2007-2010

- $\quad$ Angola, 2008-2010 (cooperation since 1987)

- $\quad$ Bangladesh, 2006-2011

- $\quad$ Bolivia, 2008-2012 (cooperation since 2006)

- $\quad$ Cambodia, 2006-2008, 2009-2010

- $\quad$ Ecuador, 2007-2010

- Iraq, September 2005-November 2009, new programme: 2010-2013 (cooperation since 2004)

- $\quad$ Ivory Coast, $2008-2010$ (cooperation since 2006) 
- $\quad$ Lebanon, 2007-2011

- $\quad$ Madagascar, 2007-2011 (Frozen in 2009 due to the political situation)

(cooperation since 2005)

- $\quad$ Mozambique, 2006-2010 (cooperation since 1983)

- $\quad$ Nicaragua, 2008-2009 (cooperation since 1990s)

- $\quad$ São Tomé and Principe, April 2008 - December 2009 (cooperation since 2005)

- $\quad$ Sudan, 2006 onwards

- $\quad$ Tanzania, 2005 - 2009 (cooperation since 1985)

- $\quad$ Uganda, 2009-2014

- $\quad$ Vietnam, 2008-2011 (cooperation since 2002)

\section{Spain, Ministry of Foreign Affairs (MFA)}

None reported

\section{Switzerland, Federal Department of Economic Affairs (FDEA)}

None reported

\section{United Kingdom, Department for International Development (DFID)}

DRC, 2007-2015 (revenue transparency in the mineral sector), 2006-2009 (forestry)

China, 2010 (conference on mining policy)

Sierra Leone, 2006-2009 (mineral sector)

Malawi, 2007-2009 (mineral promotion package, not for profit org)

Uganda, 2009-2012 (strategic financial and technical support to oil and diversity task teams to facilitate their influencing agenda)

Mozambique, 2008-2011 (mining policy)

Cambodia, 2005-2010 (forestry)

Cameroon, 2004-2009 (forestry)

Burkina Faso, 2007-2012 (forestry)

Bangladesh, 2009-2011 (forestry) 


\section{United States, US Agency for International Development (USAID)}

No projects included. Several projects in question (with Ghana, Liberia, Nigeria) had no date, therefore were not included.

\section{first_conf Participation in the First EITI Conference (2003)}

(N: 191)

The variable identifies whether a country has participated in the first EITI

Conference which took place in London on 17 June 2003. The variable equals 1 if the invited country has participated in the conference and equals 0 otherwise. The data is obtained from the list of conference participants available in the "final attendance list" at http://collections.europarchive.org/tna/20070701080507/http:/www.dfid.gov.uk/ne ws/files/eitireportconference17june03.asp

\section{form_col Colonial Heritage}

This variable identifies if the country has colonial heritage with one, or more, of the EITI donor countries. Protectorates, as well as colonies are included (former colonies of Portugal are not included, since Portugal is not among the EITI donor countries). 


\section{Annex IV. List of the Conducted Interviews.}

Interview \#1 with Respondent 1 and Respondent 2, members of the EITI governing structures, Oslo, 24 February 2010.

Interview \#2 with Respondent 3, member of the EITI governing structures, Oslo, 4 March 2010.

Interview \#3 with Respondent 4, member of the EITI governing structures, Oslo, 4 March 2010.

Interview \#4 with Respondent 5, member of the EITI governing structures, Berlin, 13 April 2010.

Interview \#5 with Respondent 6, member of the EITI governing structures, conducted via Skype, 5 May 2010.

Interview \#6 with Respondent 7, member of the EITI civil society stakeholder coalition in Azerbaijan, Baku, 22 November 2011.

Interview \#7 with Respondent 8, member of the EITI civil society stakeholder coalition in Azerbaijan, Baku, 23 November 2011 [conducted in Russian].

Interview \#8 with Respondent 9, former member of the EITI civil society stakeholder coalition in Azerbaijan, Baku, 23 November 2011 [conducted in Russian].

Interview \#9 with Respondent 10, member of the EITI civil society stakeholder coalition in Azerbaijan, Baku, 23 November 2011 [conducted in Russian].

Interview \#10 with Respondent 11, member of the EITI governmental structures in Azerbaijan, Baku, 24 November 2011 [conducted in Russian].

Interview \#11 with Respondent 12, member of the EITI civil society stakeholder coalition in Azerbaijan, Baku, 25 November 2011 [conducted in Azerbaijani, with help of a certified Russian-Azerbaijani interpreter]. 
Interview \#12 with Respondent 13 and Respondent 14, members of the EITI civil society stakeholder coalition in Kazakhstan, Almaty, 30 November 2011 [conducted in Russian].

Interview \#13 with Respondent 15, Respondent 16, and Respondent 17, members of an NGO dealing with transparency issues in Kazakhstan, Almaty, 1 December 2011 [conducted in Russian].

Interview \#14 with Respondent 18, member of the EITI civil society stakeholder coalition in Kazakhstan, conducted via Skype, 14 December 2011 [conducted in Russian].

Interview \#15 with Respondent 19, member of the EITI civil society stakeholder coalition in Kazakhstan, conducted via Skype, 15 December 2011 [conducted in Russian]. 


\section{References}

Abbott, K. W., \& Snidal, D. (2010). International regulation without international government: Improving IO performance through orchestration. The Review of International Organizations, 5(3), 315-344.

Acemoglu, D., \& Robinson, J. (2000). Political losers as a barrier to economic development. The American Economic Review, 90(2), 126-130.

Acemoglu, D., \& Robinson, J. (2006). Economic backwardness in political perspective. American Political Science Review, 100(1), 115-131.

Acosta, A. M. (2013). The impact and effectiveness of accountability and transparency initiatives: The governance of natural resources. Development Policy Review 31 (S1), S89-S105.

Ahmad, E., \& Mottu, E. (2002). Oil revenue assignments: Country experiences and issues (Working paper No. WP/02/203). IMF.

Aitenova, S., Artemyev, A., Issabekov, M., Krivodanov, Y., Lobachyov, P., \& Yantsen, N. (2007). 2005-2007: Two years of implementation of Extractive Industries Transparency Initiative (EITI) in Kazakhstan: Conclusions and recommendations. Almaty. Retrieved April 6, 2011, from

http://www.publicoversight.kz/files/coalition_report_on_eiti_in_rk_eng.pdf

Aldrich, J. H., \& Nelson, F. D. (1984). Linear probability, logit, and probit models. Beverly Hills: Sage Publications.

Alesina, A., Devleeschauwer A., Easterly W., Kurlat S., \& Wacziarg R. (2003). Fractionalization. Journal of Economic Growth, 8 (June), 155-194.

Aliyev, I. (2003). Speech at the London EITI conference. Retrieved May 1, 2011, from http://www.eiti-az.org/ts_gen/eng/eiti/eiti7_IAliyev_statement.htm

Auty, R. (1993). Sustaining development in mineral economies: The resource curse thesis. London: Routledge.

Bach, D., \& Newman, A. L. (2010). Transgovernmental networks and domestic policy convergence: Evidence from insider trading regulation. International Organization, 64(03), 505-528.

Ballentine, K., \& Sherman, J. (2003). The political economy of armed conflict: Beyond greed and grievance. Boulder, CO: Lynne Rienner. 
Baumgartner, F. R., Jones, B. D., \& Wilkerson, J. (2011). Comparative studies of policy dynamics. Comparative Political Studies, 44(8), 947-972.

Berdal, M., \& Malone, D. M., eds. (2000). Greed and grievance: Economic agendas in civil wars. Boulder, CO: Lynne Rienner.

Bhattacharyya, S., \& Hodler, R. (2010). Natural resources, democracy and corruption. European Economic Review, 54(4), 608-621.

Bickham, E. (2011). Using EITI reports: What numbers say." Speech on a panel. Paris, 3 March 2011.

Biglaiser, G., \& Danis, M. A. (2002). Privatization and democracy: The effects of regime type in the developing world. Comparative Political Studies, 35(1), 83-102.

Birkland, T. A. (2005). An introduction to the policy process : Theories, concepts, and models of public policy making. Armonk, N.Y.: M.E. Sharpe.

Blair, T. (2003). Extractive Industries Transparency Initiative. Speech at the 17 June 2003 London Conference.

Blomström, M., \& Kokko, A. (2007). From natural resources to high-tech production: the evolution of industrial competitiveness in Sweden and Finland. In D. Lederman, \& W.F. Maloney (Eds.), Natural resources: Neither curse nor destiny (pp. 71-99). Washington, DC: Stanford University Press and the World Bank.

BP. (2012). Statistical Review of World Energy.

Braumoeller, B. F., \& Goertz, G. (2000). The methodology of necessary conditions. American Journal of Political Science, 44(4), 844-858.

Brunetti, A. (2002). Political variables in cross-country growth analysis. Journal of Economic Surveys, 11(2), 163-190.

Bueno de Mesquita, B., \& Siverson, R. (1995). War and the survival of political leaders: Comparative study on regime types and political accountability. The American Political Science Review, 89(4), 841-855.

Capano, G. (2009). Understanding policy change as an epistemological and theoretical problem. Journal of Comparative Policy Analysis: Research and Practice, 11(1), 7-31. 
Carbonnier, G., Brugger, F., \& Krause, J. (2011). Global and local policy responses to the resource trap. Global Governance, 17, 247-264.

Cardin, B. (2010, December 1). Letter to the Honorable Mary L. Schapiro, chairman of the U.S. Securities and Exchange Commission. Retrieved from http://www.sec.gov/comments/df-title-xv/specializeddisclosures/specializeddisclosures-94.pdf

Cavalcanti, T. V. de V., Mohaddes, K., \& Raissi, M. (2011). Growth, development and natural resources: New evidence using a heterogeneous panel analysis. The Quarterly Review of Economics and Finance, 51(4), 305-318.

Checkel, J. (2001). Why comply? Social learning and European identity change. International Organization, 55, 553-588.

Checkel, J. T., \& Moravcsik, A. (2001). A constructivist research program in EU studies? European Union Politics, 2(2), 219-249.

The Coalition of Azerbaijan Non-Governmental Organizations. (2006). Press Release. Retrieved May 1, 2011, from http://www.eitiaz.org/ts_gen/eng/feal/index_f10.php

Coffey International Development. (2009). Validation of the EITI in the Republic of Azerbaijan. Retrieved from http://www.oilfund.az/pub/uploads/AzerbaijanEITIValidationFinalReport.pdf

Coffey International Development. (2010a). Validation of the Kyrgyzstan Extractive Industries Transparency Initiative (KEITI). Retrieved from http://eiti.org/files/Kyrgyz_Republic_final_validation.pdf

Coffey International Development. (2010b). Validation of the EITI in Mongolia. http://eiti.org/files/Mongolia\%20Final\%20Validation\%20Report.pdf

Coffey International Development. (2010c). Validation of the EITI in Timor-Leste. Retrieved from http://eiti.org/files/Timor\%20Leste\%20Final\%20Validation\%20Report.pdf

Collier, P. (2000a). Doing well out of war. In M. Berdal \& D. Malone (Eds). Greed and grievance: Economic agendas in civil wars. Boulder, CO: Lynne Rienner.

Collier, P. (2000b). Rebellion as a quasi-criminal activity. Journal of Conflict Resolution, 44, 839-853. 
Collier, P. (2000c). Ethnicity, politics and economic performance. Economic and Politics, 12, 225-245.

Collier, P., Elliot L., Hegre H., Hoeffler A., Reynal-Querol M., \& Sambanis N. (2003). Breaking the conflict trap: Civil war and development policy. Oxford: Oxford University Press.

Collier, P., \& Hoeffler, A. (2004). Greed and grievance in civil war. Oxford Economic Papers, 56, 563-595.

Collier, P. \& Hoeffler, A. (2005). Resource rents, governance, and conflict. Journal of Conflict Resolution, 49, 625-633.

COM. (2011). 683 final. Proposal for a Directive of the European Parliament and of the Council amending Directive 2004/109/EC on the harmonisation of transparency requirements in relation to information about issuers whose securities are admitted to trading on a regulated market and Commission Directive 2007/14/EC.

Cope, M. (2001). Between welfare and work: the roles of social service organizations in the social regulation of labor markets and regulation of the poor. Urban Geography, 22(5), 391-406.

Corden, W. (1984). Booming sector and Dutch Disease economics: Survey and consolidation. Oxford Economic Papers, 36(3), 359-380.

Corden W., \& Neary J. (1982). Booming sector and de-industrialisation in a small open economy. The Economic Journal, 92, 825-848.

Cowen, S., Ferreri, L., \& Parker, L. (1987). The impact of corporate characteristics on social responsibility disclosure: a typology and frequency-based analysis. Accounting, Organizations and Society, 12(2), 111-122.

Cramer, J. S. (2002). The origins of logistic regression. SSRN eLibrary. Retrieved from http://papers.ssrn.com/sol3/papers.cfm?abstract_id $=360300$

Cramton, P. (2007). How best to auction oil rights. In M. Humphreys, J. Sachs, \& J. E. Stiglitz (Eds.), Escaping the resource curse. New York: Columbia University Press. 
Crane White \& Associates (n.d.). EITI: 2006 report on the first Mongolian reconciliation. Retrieved 14 December, 2012, from

http://resource3.sodonvision.com/eiti/file/2012/11/ck1p88f7qunu788txc4mxjc sl/MONGOLIA\%20FIRST\%20EITI\%20RECONCILIATION\%20REPORT\% 202006.pdf

Darby, S. (2008). EITI - beyond the basics. Revenue Watch Institute.

Darby, S. (2009). The case for company-by-company reporting of data in the EITI. Revenue Watch Institute.

Darby, S., \& Lempa, K. (n.d.). Advancing the EITI in the mining sector: Implementation issues. World Bank's Oil, Gas and Mining Policy Operations Unit (COCPO).

Darby, S., \& the World Bank. (2008). Implementing the Extractive Industries Transparency Initiative: Applying early lessons from the field. Washington, DC: World Bank.

De Ferranti, D., Perry, P., Lederman, D., \& Maloney, W. (2002). From natural resources to the knowledge economy trade and job quality. Washington, DC: World Bank.

DeLeon, P. (2005). The missing link revisited: contemporary implementation research. Review of Policy Research, 16(3-4), 311-338.

DeLeon, P., \& deLeon, L. (2002). What ever happened to policy implementation? An alternative approach. Journal of Public Administration Research and Theory, 12(4), $467-492$.

Deloitte (2007). The report on the Extractive Industries Transparency Initiative of the Republic of Kazakhstan. Retrieved 21 December, 2012, from http://eiti.org/files/Kazakhstan\%202005\%20EITI\%20Report.pdf

De Soysa, I., \& Neumayer, E. (2007). Resource wealth and the risk of civil war onset: Results from a new dataset of natural resource rents, 1970-1999. Conflict Management and Peace Science, 24: 201-218.

De Vries, M. S. (1999). Developments in Europe: The idea of policy generations. International Review of Administrative Sciences, 65(4), 491-510. 
De Vries, M. S. (2005). Changing policy views at the local level: The effect of age, generations and policy-periods in five European countries. European Journal of Political Research, 44(1), 1-15.

Dingwerth, K., \& Pattberg, P. (2006). Global governance as a perspective on world politics. Global Governance, 12, 185-203.

Disclosure of Payments by Resource Extraction Issuers, 17 C.F.R. pt. 240 \& 249. (2012).

Dobbin, F., Simmons, B., \& Garrett, G. (2007). The global diffusion of public policies: Social construction, coercion, competition, or learning? Annual Review of Sociology, 33(1), 449-472.

Easterly, W. (2001). Can institutions resolve ethnic conflict? Economic Development and Cultural Change, 49, 687-706.

Easton, D. (1965). A systems analysis of political life. New York: Wiley.

Extractive Industries Transparency Initiative (2003). Discussion paper for international stakeholders meeting. Retrieved 10 March, 2011, from http://collections.europarchive.org/tna/20070701080507/http://www.dfid.gov. uk/pubs/files/eitipaper.pdf

EITI. (2003, February 11-12). Report of the EITI workshop. Retrieved 10 March, 2011, from http://collections.europarchive.org/tna/20070701080507/http://www.dfid.gov. uk/pubs/files/eitiworkshopreportfeb03.pdf

EITI. (2003, May 23). Revised draft reporting guidelines. Retrieved 10 March, 2011, from

http://collections.europarchive.org/tna/20070701080507/http://www.dfid.gov. uk/pubs/files/eitidraftreportguidelines.pdf

EITI International Secretariat. (n.d.- a). Azerbaijan $\mid$ Extractive Industries Transparency Initiative. Retrieved April 6, 2011, from http://eiti.org/Azerbaijan

EITI International Secretariat. (n.d.-b). EITI strategy review. Retrieved October 8, 2012, from http://eiti.org/about/strategy-review 
EITI International Secretariat. (n.d.-c). Kazakhstan $\mid$ Extractive Industries Transparency Initiative. Retrieved April 6, 2011, from http://eiti.org/Kazakhstan

EITI International Secretariat. (n.d.-d). What is the EITI? Retrieved from http://eiti.org/eiti

EITI International Secretariat. (n.d.-e). EITI Reports. Retrieved 20-25 June, 2013, from http://eiti.org/countries/reports.

EITI International Secretariat. (2005). EITI Source book.

EITI International Secretariat. (2008, October 29-30). Minutes of the $6^{\text {th }}$ EITI Board meeting.

EITI International Secretariat. (2009). EITI rules.

EITI International Secretariat. (2009). EITI fact sheet. Retrieved June 29, 2009, from http://eitransparency.org/files/2009-05-

27\%20EITI\%20Fact\%20Sheet.pdf

EITI International Secretariat. (2010). Review: Kazakhstan. Retrieved 21 December, 2012, from http://eiti.org/files/Secretariat\%20Review\%20Kazakhstan.pdf

EITI International Secretariat. (2011). EITI rules. Retrieved from http://eiti.org/files/EITI_Rules_Validations_April2011.pdf

EITI International Secretariat. (2011, October 25-26). Minutes of the $18^{\text {th }}$ EITI Board meeting.

EITI International Secretariat. (2012, February 14-15). Minutes of the $19^{\text {th }}$ EITI Board meeting.

EITI International Secretariat. (2012, June 8). EITI strategic options: For discussion and decisions. Board paper 20-2 A.

EITI International Secretariat. (2012, June 27-28). Minutes of the $20^{\text {th }}$ EITI Board meeting.

EITI International Secretariat. (2012, July 24). Policy proposal: revision of the EITI. Strategy Working Group meeting. 
EITI International Secretariat. (2012, October 25-26). Minutes of the $21^{\text {st }}$ Board meeting.

EITI International Secretariat. (2013, May 22). The EITI Standard.

Ernst \& Young. (2009). Final report: Consulting service for preparation of the EITI - Peru national reconciliation study.

Ernst \& Young (2011). Final report: Second national reconciliation study of the Extractive Industries Transparency Initiative (EITI) in Peru (2008 - 2010).

Fearon, J. (2005). Primary commodities exports and civil war. Journal of Conflict Resolution, 49(4), 483-507.

Fearon, J., \& Laitin, D. (2003). Ethnicity, insurgency, and civil war. American Political Science Review, 97(1), 1-16.

Fishman, J. (2004-2005). Is diamond smuggling forever? The Kimberley Process Certification Scheme: The first step down the long road to solving the blood diamond trade problem. 13 U. Miami Bus. L. Rev., 217, 217-242.

Frynas, J. G. (2010). Corporate social responsibility and societal governance: Lessons from transparency in the oil and gas sector. Journal of Business Ethics, 93(S2), 163-179.

Fuchs, D. A. (2002). Globalization and global governance: discourses on political order at the turn of the century. In F. V. Kratochwil (Ed.), Transformative change and global order : reflections on theory and practice. Münster; Piscataway, NJ: Lit.

Gelb, A. (1988). Oil windfalls: Blessing or curse? New York: Oxford University Press.

Ghana EITI Secretariat. (2010). Report on the aggregation/reconciliation of mining sector payments and receipts: 2004-2008.

Gillies, A. (2010). Reputational concerns and the emergence of oil sector transparency as an international norm. International Studies Quarterly, 54(1), $103-126$.

Goertz, G., \& Starr, H. (Eds.). (2003). Necessary conditions: Theory, methodology and applications. Rowman \& Littlefield Pub Incorporated. 
Goldwyn, D., ed. (2008). Drilling down: The civil society guide to extractive industry revenues and the EITI.

Golub, J. (2007). Survival analysis and European Union decision-making. European Union Politics, 8(2), 155-179.

Grant, J. A., \& Taylor, I. (2004). Global governance and conflict diamonds: the Kimberley Process and the quest for clean gems. The Round Table: The Commonwealth Journal of International Affairs, 93(375), 385-401.

Grillot, S. (2011). Global gun control: examining the consequences of competing international norms. Global Governance, 17(4), 529-555.

Gupta, K. (2012). Comparative public policy: Using the comparative method to advance our understanding of the policy process. Policy Studies Journal, 40, $11-26$.

Gylfason, T. (2001). Natural resources, education, and economic development. European Economic Review, 45, 847-859.

Hackston, D., \& Milne, M. J. (1996). Some determinants of social and environmental disclosures in New Zealand companies. Accounting, Auditing and Accountability Journal, 9(1), 77-108.

Hafner-Burton, E., \& Pollack, M. A. (2002). Mainstreaming gender in global governance. European Journal of International Relations, 8(3), 339-373.

Hall, P. (1993). Policy paradigms, social learning, and the state: The case of economic policymaking in Britain. Comparative Politics, 25(3), 275-296.

Hart Nurse Ltd. (2010). Validation of the Extractive Industries Transparency Initiative in Kazakhstan: Final report to the National Stakeholder Council. Retrieved August 26, 2011, from http://eiti.org/files/Kazakhstan\%20\%28ENG\%29.pdf

Hart Nurse Ltd. (2011a). MEITI: Mongolia fourth EITI reconciliation report 2009. Retrieved from http://eitimongolia.mn/modules/download/files/Mongolia\%20EITI\%20Recon ciliation\%204th\%20report\%20for\%202009.pdf

Hart Nurse Ltd. (2011b). NEITI 2006-2008 reconciliation. Retrieved from http://www.neiti.org.ng/files-pdf/NEITI2006-2008ReconciliationFinalReport-010211.pdf 
Hart Nurse Ltd. (2012). MEITI: Mongolia fifth EITI reconciliation report 2010. Retrieved 14 December, 2012, from http://resource3.sodonvision.com/eiti/file/2012/11/7ev4ykxhjoh9nejkemqr4lz m5/MONGOLIA\%20FIFTH\%20EITI\%20RECONCILIATION\%20REPORT \%202010.pdf

Haufler, V. (2001). A public role for the private sector: industry self-regulation in a global economy. Washington, D.C: Carnegie Endowment for International Peace.

Haufler, V. (2010a). Disclosure as governance: the Extractive Industries Transparency Initiative and resource management in the developing world. Global Environmental Politics, 10(3), 53-73.

Haufler, V. (2010b). The Kimberley Process Certification Scheme: An innovation in global governance and conflict prevention. Journal of Business Ethics, 89(S4), 403-416.

Hausmann, R., \& Rigobón, R. (2003). An alternative interpretation of the 'resource curse': Theory and policy implications. In J. M. Davis, R. Ossowski, \& A. Fedelino (Eds.), Fiscal Policy Formulation and Implementation in Oilproducing Countries. Washington, D.C.: International Monetary Fund.

Herbst, J. (2000). Economic incentives, natural resources and conflict in Africa. Journal of African Economies, 9, 270-294.

Hilson, G., \& Maconachie, R. (2008). "Good governance" and the extractive industries in Sub-Saharan Africa. Mineral Processing and Extractive Metallurgy Review, 30(1), 52-100.

Hilson, G., \& Maconachie, R. (2009). The Extractive Industries Transparency Initiative: Panacea or white elephant for Sub-Saharan Africa? In J. Richards (Ed.), Mining, Society, and a Sustainable World (pp. 469-491). Berlin, Heidelberg: Springer Berlin Heidelberg.

Hodler, R. (2006). The curse of natural resources in fractionalized countries. European Economic Review, 50(6), 1367-1386.

H.R. 4173, 111th Cong. (2010). Dodd-Frank Wall Street reform and consumer protection act. Pub. L. No. 111-203. 1504 Stat.

Humphreys, N. (2003). Natural resources, conflict, and conflict resolution. Cambridge,MA: Harvard University. 
Humphreys, M., Sachs, J., \& Stiglitz, J. E. (2007). Escaping the resource curse. New York: Columbia University Press.

Humphreys, M., \& Sandbu, M. (2007). The political economy of natural resource funds. In M. Humphreys, J. Sachs, and J. E. Stiglitz (Eds.), Escaping the Resource Curse. New York: Columbia University Press.

Inglehart, R. (1971). The silent revolution in Europe: Intergenerational change in post-industrial societies. The American Political Science Review, 65(4), 9911017.

Innis, H. (1956). Essays in Canadian economic history. Toronto: University of Toronto.

International Monetary Fund. (2007). Guide on resource revenue transparency. Washington, D.C.

International Monetary Fund. (2008). World economic outlook: Housing and business cycle. Washington, D.C.

IMF. (n.d). Hydrocarbon rich and mineral rich countries. IMF estimates for 20002005.

Islamic Republic of Mauritania National Committee for the EITI. (2010).

Validation report. Retrieved 27 December, 2012, from

http://eiti.org/files/Final_Validation_Report_Mauritania_EN.pdf

Iwerks, R. (2009, May 18). World Bank EITI reporting meeting focuses on disaggregation. Retrieved October 15, 2012, from http://www.revenuewatch.org/news/world-bank-eiti-reporting-meetingfocuses-disaggregation

Jacobson, H. K., \& Weiss, E. B. (1995). Strengthening compliance with international environmental accords: Preliminary observations from collaborative project. Global Governance, 1, 119.

Jenkins, H. (2004). A critique of conventional CSR theory: An SME perspective. Journal of General Management, 29(4), 37-57.

Johnston, A. I. (2008). Socialization in international relations theory. In Social States: China in International Institutions, 1980-2000. Princeton, N.J.: Princeton University Press. 
Johnston, D. (2007). How to evaluate the fiscal terms of oil contracts. In M.

Humphreys, J. Sachs, and J. E. Stiglitz (Eds.), Escaping the Resource Curse.

New York: Columbia University Press.

Jupille, J., Caporaso, J. A., \& Checkel, J. T. (2003). Integrating institutions:

Rationalism, constructivism, and the study of the European Union.

Comparative Political Studies, 36(1-2), 7-40.

Kaplinsky, R. (2011). Commodities for industrial development: Making linkages work (No. Working paper 01/2011). United Nations Industrial Development Organization.

Karl, T. L. (1997). The Paradox of Plenty: Oil Booms and Petro-States. Berkeley: University of California Press.

KEITI. (2009). Information on the implementation of Extractive Industries Transparency Initiative (EITI) in Kyrgyzstan. Retrieved from http://eiti.org/files/Kyrgyzstan\%20EITI\%20Report\%20for\%202009\%20$\% 20$ for\%20publishing.pdf

Kimberley Process. (n.d.-a). Retrieved April 8, 2013, from http://www.kimberleyprocess.com/web/kimberley-process/kp-basics

Kimberley Process. (n.d.-b). Retrieved April 8, 2013, from http://www.kimberleyprocess.com/web/kimberley-process/faq

Klare, M. (2001). Resource wars: The new landscape of global conflict. New York: Henry Holt and Company; Metropolitan Books.

Kolstad, I., \& Wiig, A. (2008). Is transparency the key to reducing corruption in resource-rich countries? World Development, 37, 521-532.

Kolstad, I., Wiig, A., \& A. Williams. (2009). Mission improbable: Does petroleumrelated aid address the resource curse? Energy Policy, 37, 954-965.

König, T., \& Pöter, M. (2001). Examining the EU legislative process: The relative importance of agenda and veto power. European Union Politics, 2(3), 329351.

KPMG. (2011). Rapport sur les procédures convenues relatives aux recettes minières perçues par l'Etat pour les années 2008 et 2009. Retrieved June 12, 2013, from http://eiti.org/files/Burkina-Faso-2008-2009-EITI-Report.pdf 
Kurtz, M. J., \& Brooks, S. M. (2011). Conditioning the 'resource curse': Globalization, human capital, and growth in oil-rich nations. Comparative Political Studies, 44(6), 747-770.

Lederman, D., \& Maloney, W., eds. (2007). Natural resources: Neither curse nor destiny. Stanford, CA: Stanford University Press.

Lester, J. P., \& Goggin, M. L. (1998). Back to the future: The rediscovery of implementation studies. Policy Currents, 8(3), 1-9.

Liberia Extractive Industries Transparency Initiative (LEITI) Secretariat. (2010). Final report of the administrators of the second LEITI reconciliation. Retrieved from http://www.leiti.org.lr/doc/LEITI2ndReconciliationFinalReport.pdf

Lindblom, C. (1959). The science of 'muddling through'. Public Administration Review, 19(2), 79-88.

Long, J. S., \& Freese, J. (2006). Regression models for categorical dependent variables using Stata (2nd ed.). College Station, Tex: StataCorp LP.

Lujala, P., Rød, J., \& Thieme, N. (2007). Fighting over oil: Introducing a new dataset. Conflict Management and Peace Science, 24, 239-256.

Maconachie, R. (2009). Diamonds, governance and "local" development in postconflict Sierra Leone: Lessons for artisanal and small-scale mining in subSaharan Africa? Resources Policy, 34(1-2), 71-79.

Maloney, W. (2002). Missed opportunities: Innovation and resource-based growth in Latin America. Economia, 3, 111-167.

McFerson, H. M. (2009). Governance and hyper-corruption in resource-rich African countries. Third World Quarterly, 30(8), 1529-1547.

Mehlum, H., Moene, K., \& Torvik. R. (2006). Institutions and the resource curse. The Economic Journal, 116, 1-20.

Meijerink, S. (2005). Understanding policy stability and change. the interplay of advocacy coalitions and epistemic communities, windows of opportunity, and Dutch coastal flooding policy 1945-2003. Journal of European Public Policy, 12(6), 1060-1077. 
Miller, E. A. (2004). Advancing comparative state policy research: Toward conceptual integration and methodological expansion. State and Local Government Review, 36(1), 35-58.

Milner, H. V. (2006). The digital divide: The role of political institutions in technology diffusion. Comparative Political Studies, 39(2), 176-199.

Moberg, J. (2008). Foreword. In EITI - Beyond the Basics. Revenue Watch Institute Report.

Morrison, K. M. (2011). Nontax revenue, social cleavages, and authoritarian stability in Mexico and Kenya: 'Internationalization, institutions, and political change' revisited. Comparative Political Studies, 44(6), 719-746.

Natural Resource Charter. (n.d). Frequently asked questions. Retrieved April 3, 2013, from http://naturalresourcecharter.org/content/understanding/faq

Natural Resource Charter. (2010, November). Retrieved April 3, 2013, from http://naturalresourcecharter.org/sites/default/files/NRC\%20Eng_2011.pdf

Nazarbayev, N. (2005, June 14). Address by President of the Republic of Kazakhstan at the International Business Conference of the Asian Society. Retrieved April 11, from http://www.embkazjp.org/additionalpages/Businessconference14062005.htm

Nigeria Extractive Industries Transparency Initiative (NEITI) Act. (2007). Retrieved from http://www.neiti.org.ng/

North, D. C. (1990). Institutions, institutional change, and economic performance. Cambridge; New York: Cambridge University Press.

North, D., Wallis, J., Webb, S., \& B. Weingast. (2007). Limited access orders in the developing world: A new approach to the problems of development. Policy Research Working Paper Series 4359, The World Bank.

Ölcer, D. (2009). Extracting the maximum from the EITI (Working paper No. DEV/DOC(2009)1). OECD.

O'Toole, L. J. (2000). Research on policy implementation: Assessment and prospects. Journal of Public Administration Research and Theory, 10(2), 263 -288 . 
Oxford Policy Management. (2009). Validation of EITI in Liberia. Retrieved from http://eiti.org/files/Liberia\%20Final\%20Validation\%20Report.pdf

Oxford Policy Management. (2010). Validating the Norwegian EITI implementation. Retrieved from http://eiti.org/files/2010-1121_Final_Validation_Report_Norway_0.pdf

Patten, D. M. (1991). Exposure, legitimacy, and social disclosure. Journal of Accounting and Public Policy, 10(4), 297-308.

Pegg, S. (2006). Can policy intervention beat the resource curse? Evidence from the Chad-Cameroon pipeline project. African Affairs, 105/418, 1-25.

Pitlik, H., Frank, B., \& Firchow, M. (2010). The demand for transparency: An empirical note. The Review of International Organizations, 5(2), 177-195.

Polity IV individual country regime trends, 1946-2010. (2010). Retrieved May 1, 2013, from http://www.systemicpeace.org/polity/polity4.htm

Pollack, M. (2008). Discussion: The community method and new modes of governance. In B. Kohler-Koch and F. Larat (Eds.), Efficient and Democratic Governance in the European Union, CONNEX Report. Mannheim: CONNEX.

Prebisch, R. (1950). The economic development of Latin America and its principal problems. United Nations Dept. of Economic Affairs.

Radon, J. (2007). How to negotiate an oil agreement. In M. Humphreys, J. Sachs, and J. E. Stiglitz (Eds.), Escaping the Resource Curse. New York: Columbia University Press.

Radon, J., ed. (2009, January). Expanding the Extractive Industries Transparency Initiative (EITI) agenda to transportation of hydrocarbon resources. A joint proposal by non-governmental organizations from Kazakhstan, Azerbaijan, Georgia and Ukraine. Retrieved from http://eiti.org/files/A\%20joint\%20proposal\%20by\%20NGOs\%20from\%20Ka zakhstan\%20Azerbaijan,\%20Georgia\%20and\%20Ukraine.pdf

Raustiala, K., \& Slaughter, A.-M. (2002). International law, international relations and compliance. In W. Carlnaes, T. Risse, \& B. Simmons (Eds.), The Handbook of International Relations. Sage Publications, Ltd. 
Reed, D. (2002). Resource extraction industries in developing countries. Journal of Business Ethics, 39, 199-226.

Republic of Cameroon Ministry of Finance (2010). Comparison of figures and volumes within the framework of the Extractive Industries Transparency Initiative (EITI) in Cameroon for the 2006, 2007 and 2008 fiscal years. Retrieved 27 December, 2012, from http://eiti.org/files/Cameroon-2006-20072008-EITI-Report.pdf

Revenue Watch Institute. (n.d). EITI reports: Results and analysis. Retrieved June 23, 2012, from http://data.revenuewatch.org/eiti/

Revenue Watch Institute. (2012, April-a). Disaggregation by company.

Background paper for the EITI Strategy Working Group. Retrieved October 15,2012 , from

http://eiti.org/files/SWG/RWI_SWG_Paper_Disaggregation_by_company_A Apri_2012.pdf

Revenue Watch Institute. (2012, April-b). Contract disclosure through the EITI. Background paper for the EITI Strategy Working Group. Retrieved October 15,2012 , from http://eiti.org/files/SWG/RWI_SWG_Paper_Contract_Transparency_April_20 12.pdf

Riley, M. W. (1987). On the significance of age in sociology. American Sociological Review, 52(1), 1-14.

Rixen, T. (2011). Tax competition and inequality: The case for global tax governance. Global Governance, 17(4), 447-467.

Robinson, J., Torvik, R., \& Verdier. T. (2006). The political foundations of the resource curse. Journal of Development Economics, 79, 447-468.

Rosenau, J. (1988). Patterned chaos in global life: Structure and process in the two worlds of world politics. International Political Science Review, 9(4), 327364.

Rosenblum, P., \& Maples, S. (2009). Contracts confidential : Ending secret deals in the extractive industries. New York, NY: Revenue Watch Institute.

Ross, M. (1999). The political economy of the resource curse. World Politics, 51, 297-322. 
Ross, M. (2001). Does oil hinder democracy? World Politics, 53(3), 325-361.

Ross, M. (2003). Natural resources and civil conflict: Evidence from case studies. International Organization, 58, 35-67.

Ross, M. (2004). What do we know about natural resources and civil war? Journal of Peace Research, 41, 337-356.

Ross, M. (2007). How mineral-rich states can reduce inequality. In J. Sachs, J. E. Stiglitz, and M. Humphreys (Eds.), Escaping the Resource Curse. New York: Columbia University Press.

Ross, M., Lujala, P., \& Rustad, S. (2011). Horizontal inequality, decentralizing the distribution of natural resource revenues, and peace. In P. Lujala and S. Rustad (Eds.), High-Value Natural Resources and Post-conflict Peacebuilding. Routledge.

Rudra, N., \& Jensen, N. M. (2011). Globalization and the politics of natural resources. Comparative Political Studies, 44(6), 639-661.

Sabatier, P. A., \& Jenkins-Smith, H. C. (1993). Policy change and learning : An advocacy coalition approach. Boulder, Colo.: Westview Press.

Sachs, J., \& Warner, A. (1995). Natural resource abundance and economic growth (Working paper No. 5398). National Bureau of Economic Research.

Sachs, J., \& Warner, A. (2000). Natural resource abundance and economic growth." In Leading Issues in Economic Development. New York: Oxford University Press.

Sachs, J., \& Warner, A. (2001). Natural resources and economic development: The curse of natural resources. European Economic Review, 45, 827-838.

Sala-i-Martin, X., \& Subramanian, A. (2003). Addressing the natural resource curse: An illustration from Nigeria. NBER Working Paper 9804. Cambridge, MA.

Scherer, A. G., Palazzo, G., \& Baumann, D. (2006). Global rules and private actors: Toward a new role of the transnational corporation in global governance. Business Ethics Quarterly, 16(4), 505-532. 
Schimmelfennig, F. (2000). International socialization in the new Europe: Rational action in an institutional environment. European Journal of International Relations, 6(1), 109-139.

Schimmelfennig, F., \& Scholtz, H. (2008). EU democracy promotion in the European neighbourhood: Political conditionality, economic development and transnational exchange. European Union Politics, 9(2), 187-215.

Schimmelfennig, F., \& Sedelmeier, U. (2002). Theorizing EU enlargement: Research focus, hypotheses, and the state of research. Journal of European Public Policy, 9(4), 500-528.

Scholte, J. A. (2004). Civil society and democratically accountable global governance. Government and Opposition, 39(2), 211-233.

Securities and Exchange Commission. (2012, November 26). Comments on file no. s7-42-10. Retrieved May 11, 2013, from http://www.sec.gov/comments/s7-4210/s74210.shtml

Selck, T. J., \& Steunenberg, B. (2004). Between power and luck: The European Parliament in the EU legislative process. European Union Politics, 5(1), 2546.

Shaxson, N. (2009). Nigeria's Extractive Industries Transparency Initiative: Just a glorious audit? Chatham House.

Shelton, D. (2009). Soft law. In D. Armstrong (Ed.), Routledge Handbook of International Law. UK: Routledge.

Simmons, B. (1998). Compliance with international agreements. The Annual Review of Political Science, 1, 75-93.

Singer, H. (1950). The distribution of trade between investing and borrowing countries. American Economic Review, 40, 473-485.

Smith, C. N. (2003). Corporate social responsibility: Whether or how? California Management Review, 45, 52-76.

Snyder, R. (2002). Does lootable wealth breed civil war? Resource extraction and political order in comparative perspective. Boston: Paper presented at the American Political Science Association (APSA) annual meeting. 
Stallings, B. (1992). International influence on economic policy. In S. Haggard and R. Kaufman (Eds.), The Politics of Economic Adjustment. Princeton: Princeton.

State Oil Fund of the Republic of Azerbaijan (SOFAZ). (n.d.-a). Extractive Industries Transparency Initiative. Retrieved April 19, 2011, from http://www.oilfund.az/eiti/en/content/2/2/

State Oil Fund of the Republic of Azerbaijan (SOFAZ). (n.d.-b). Extractive Industries Transparency Initiative. Retrieved April 19, 2011, from http://www.oilfund.az/eiti/en/archive/2003

State Oil Fund of the Republic of Azerbaijan (SOFAZ). (n.d.-c). Extractive Industries Transparency Initiative. Retrieved April 19, 2011, from http://www.oilfund.az/eiti/en/archive/2005

State Oil Fund of the Republic of Azerbaijan (SOFAZ). (n.d.-d). Extractive Industries Transparency Initiative. Retrieved April 19, 2011, from http://www.oilfund.az/eiti/en/news/41

State Oil Fund of the Republic of Azerbaijan (SOFAZ). (n.d.-e). Extractive Industries Transparency Initiative. Retrieved April 19, 2011, from http://www.oilfund.az/eiti/en/archive/2007

State Oil Fund of the Republic of Azerbaijan (SOFAZ). (n.d.-f). Extractive Industries Transparency Initiative. Retrieved April 19, 2011, from http://www.oilfund.az/eiti/en/news/87

State Oil Fund of the Republic of Azerbaijan (SOFAZ). (n.d.-g). Extractive Industries Transparency Initiative. Retrieved May 1, 2011, from http://www.oilfund.az/eiti/en/news/94

State Oil Fund of the Republic of Azerbaijan (SOFAZ). (2010a). Report of the Government of the Republic of Azerbaijan (host government) about aggregated receipts from the extractive industries Reporting period JanuaryDecember 2010 (annual). Retrieved from http://www.oilfund.az/pub/uploads/E1kA4yY2.pdf

State Oil Fund of the Republic of Azerbaijan (SOFAZ). (2010b). The Committee on the Extractive Industries Transparency Initiative of the Republic of Azerbaijan (independent accountants report) for the 12 months ended 31 December 2010. Retrieved from http://www.oilfund.az/pub/uploads/iZWKoT3j.pdf 
Stevens, P., \& Dietsche, E. (2008). Resource curse: An analysis of causes, experiences and possible ways forward. Energy Policy, 36, 56-65.

Stijns, J.-P. C. (2005). Natural resource abundance and economic growth revisited. Resources Policy, 30(2), 107-130.

Sunley, E., \& Baunsgaard, T. (2001). The tax treatment of the mining sector: An $I M F$ perspective (Background paper for the World Bank workshop on the taxation of the mining sector).

Synergy Global Consulting Ltd. (2010). Validation of the Extractive Industries Transparency Initiative in Ghana.

Tagesson, T., Blank, V., Broberg, P., \& Collin, S.-O. (2009). What explains the extent and content of social and environmental disclosures on corporate websites: a study of social and environmental reporting in Swedish listed corporations. Corporate Social Responsibility and Environmental Management, 16(6), 352-364.

Timor-Leste EITI. (2009). 2009 Report. Retrieved from http://www.laohamutuk.org/Oil/OilIndex.html

Transparency International. (2011). Corruption perception index.

Trotman, K. T., \& Bradley, G. W. (1981). Associations between social responsibility disclosure and characteristics of companies. Accounting, Organizations and Society, 6(4), 355-362.

Tsalik, S., Ebel, R., \& Caspian Revenue Watch. (2003). Caspian oil windfalls: Who will benefit? Philadelphia Pa.: Open Society Institute Central Eurasia Project.

Tsebelis, G. (2000). Veto players and institutional analysis. Governance, 13(4), 441-474.

Tsebelis, G., \& Garrett, G. (2000). Legislative politics in the European Union. European Union Politics, 1(1), 9-36. 
UHY Sapa-Consulting. (2009). Report on reconciliation of data related to taxes and other obligatory payments to the budget, submitted by the extractive companies and Ministry of Finance of the Republic of Kazakhstan (authorized body) for 2008 within the frameworks of the national program «Extractive Industries Transparency Initiative implementation in the Republic of Kazakhstan.» Retrieved 21 December, 2012, from http://eiti.org/files/Kazakhstan\%202008\%20EITI\%20Report.pdf

U.S. Energy Information Administration. (2012). International energy statistics.

Vanderginste, S., \& Sriram, C. L. (2011). Power sharing and transitional justice: A clash of paradigms? Global Governance, 17, 489-505.

Van der Ploeg, F. (2011). Natural resources: Curse or blessing? Journal of Economic Literature, 49(2), 366-420.

Walker, J. (1969). The diffusion of innovations among the American states. The American Political Science Review, 63(3), 880-899.

Walsh, J. I. (2000). When do ideas matter? Explaining the successes and failures of Thatcherite ideas. Comparative Political Studies, 33(4), 483-516.

Watkins, M. (1963). A staple theory of economic growth. The Canadian Journal of Economics and Political Science, 29, 141-158.

Weinstein, J. (2005). Resources and the information problem in rebel recruitment. Journal of Conflict Resolution, 49, 598-624.

Weiss, T. G. (2000). Governance, good governance and global governance: Conceptual and actual challenges. Third World Quarterly, 21(5), 795-814.

Winters, M. \& Gould, J. (2011). Betting on oil: The World Bank's attempt to promote accountability in Chad. Global Governance, 17, 229-245.

World Energy Council. (2010). Survey of energy resources. London, UK.

Wright, C. (2004). Tackling conflict diamonds: The Kimberley process certification scheme. International Peacekeeping, 11(4), 697-708.

Wright, G., \& Czelusta, J. (2004). The myth of the resource curse. Challenge, $47(2), 6-38$. 
The World Bank. (2008). Fact sheet: Extractive Industries Transparency Initiative Plus Plus: EITI++. Retrieved September 4, 2011, from http://web.worldbank.org/WBSITE/EXTERNAL/NEWS/0,,contentMDK:217 27813 pagePK:64257043 piPK:437376 theSitePK:4607,00.html

The World Bank. (2011). Overview of state ownership in the global minerals industry. Retrieved 9 November, 2012, from http://siteresources. worldbank.org/INTOGMC/Resources/GlobalMiningIndust ry-Overview.pdf

World Trade Organization. (2012, April). Trade profiles.

Young, O. (1979). Compliance and public authority: A theory with international applications. Baltimore: publ. for Resources for the Future by the Johns Hopkins University Press.

Zhang, Y., Cao, L., \& Vaughn, M. S. (2009). Social support and corruption: Structural determinants of corruption in the world. Australian and New Zealand Journal of Criminology, 42(2), 204-217.

Zohlnhöfer, R. (2003). Partisan politics, party competition and veto players: German economic policy in the Kohl era. Journal of Public Policy, 23(02), $123-156$.

Zohlnhöfer, R. (2009). How politics matter when policies change: Understanding policy change as a political problem. Journal of Comparative Policy Analysis: Research and Practice, 11(1), 97-115. 


\section{Addendum on Valorization}

This thesis is of relevance to not only the research community and policymakers specializing in the field, but also to the general public with an interest in the problems of resource curse, transparency-focused regulation and global governance. When discussing possible applications of the research findings, the work is particularly relevant for policymakers and other parties involved in implementing the EITI or considering the possibility of setting up the EITI in their country.

More specifically, the first chapter outlines different mechanisms of the resource curse. For policymakers, these are important to distinguish, as different factors that are crucial in the emergence of the resource curse call for different policy strategies of overcoming or preventing the associated problems.

Transparency practices can target the economic or political factors that are important in the emergence of the resource curse. The economic factors are mostly related to a government's ineffectiveness in translating fiscal resource rents into development in other sectors. Political factors are connected to a government's inability or even disincentive to collect good fiscal rents for its national budget. Both aspects of the management cycle are crucial. To develop, one needs to know where to invest and how to spend the resource revenues well (issues tied to the economic mechanisms creating the resource curse). At the same time, it is crucial to ensure that the resource revenues end up in the budget, thus breaking the incentives or opportunities for looting and corruption of the politicians in power (problems that have been described as 'political mechanisms' above).

Analysis of the potential impact of the Kimberley Process (KP), the Publish What You Pay (PWYP) Campaign, the Natural Resource Charter (NRC), and the EITI reveals that these transparency-focused initiatives mostly address the political mechanisms (less so the economic ones) leading to the resource curse. 
Their limitations in addressing the economic mechanisms are very important to acknowledge for policymakers considering the implementation of such instruments. However, when focusing on the political mechanisms only, the design of the EITI holds promise in the sense that it involves multiple actors (companies, civil society, and government) in the decision-making by the multi-stakeholder group (MSG), thus aiming at increasing the mutual accountability of the stakeholders involved in the sector. Another important dimension of the EITI which increases its ability to target political mechanisms of the resource curse is that the EITI in principle allows the inclusion of all natural resource management stages in the reporting process through voluntary extensions to the implementation process. The key implication of Chapter 1 is to demonstrate that while the EITI design has more potential for achieving extensive transparency in the sector than the design of other voluntary regulation discussed, it is still strongest in targeting political mechanisms of the resource curse (less so the economic ones). This characteristic of the EITI needs to be reflected when discussing the significance of the EITI and when deriving policy implications from the present study.

The central concern of Chapter 3 is under what conditions governments choose to adopt the EITI, given that EITI membership may not only yield benefits, but also generate policy constraints and costs of implementation. This chapter is relevant for policymakers or civil society groups which may be interested in identifying the contexts where introducing the EITI so far has been easier. For the EITI as a regulation instrument, the findings show that the critical country cases those that can potentially benefit from the initiative, yet are not adopting it - are resource-rich high-income countries marked by a sustained history of stable regime, be it democratic or authoritarian regime type. At the same time, there are concerns that also remain for the group of adopting countries, as we do not know the precise motivations of each EITI candidate country - more specifically, whether they adopt the initiative with the intent to catalyze reforms in the sector, or whether the EITI is rather used as window-dressing. For the reform-oriented 
policymakers, the key lesson to take from this chapter is that adoption of the EITI by itself cannot tell us anything about the effectiveness of the instrument in mitigating the resource curse-related symptoms. For the group of non-adopters, there may be transparency-focused policies in the absence of the EITI that contribute toward the same goal of battling the resource curse. For the group of adopters, the EITI in its very minimum format can be used simply as a label to attract investments or improve reputation. Additionally, the findings of Chapter 3 can inform campaigning efforts of the EITI promoters, helping to identify the most likely countries for EITI adoption, as well as the most difficult cases where the EITI is less likely to be introduced, but where it could create benefits.

The central question discussed in Chapter 4 is how implementation activities differ in practice, and what determines the extensiveness of implementation in a given country. The chapter concludes that both the regime type and the sector in which EITI reporting is done are important for the extensiveness of implementation activities. Carrying out the EITI in the non-oil mining sector turns out to be a sufficient condition for extensive disaggregation of reporting. For the countries implementing the EITI in the oil and gas sector, a positive polity score is a necessary (but not sufficient) condition for the inclusion of extensive disaggregation. For the EITI as a global standard, these findings imply that authoritarian countries implementing the EITI in the oil and gas sector are the most difficult cases as regards disaggregated reporting. At the same time, these cases are critical for the success of the initiative. In terms of policy relevance, these findings point to the crucial differences between the sectors in which the EITI is implemented, highlighting that a more extensive form of the EITI may be significantly easier to achieve in the context of countries specializing in the non-oil mining sector. For civil society groups negotiating the extensive implementation activities in the MSGs, this finding means that one of the negotiations strategies they could use is to pressure for extensive requirements in the non-oil mining sector as a starting point. If this proves to be successful in the authoritarian 
countries specializing in hydrocarbons, the implementation practices established in the non-mining sector may be easier transferred to the oil sector later. Additionally, the constructed typology of implementation activities can serve as a guide on different extensions to the EITI process, particularly useful for building up the expertise of civil society actors. The chapter also identifies EITI countries ranking high on transparency in disaggregation of reporting - these findings can inform selection of country cases for future research exploring the impacts of such extensive disaggregation practices on the ground.

Against this background, Chapter 5 takes a closer look at the implementation of the EITI in two cases that are expected to be most difficult in terms of developing an extensive implementation of the EITI. Implementation activities in two authoritarian countries with similar socio-economic characteristics that are implementing the EITI in the oil and natural gas sector (Azerbaijan and Kazakhstan) were reconstructed, supported by interviews with key stakeholders. The findings reveal that the ideological distance between the stakeholders in the multi-stakeholder groups (MSGs) leads to policy deadlock and only to an incremental change in the implementation process. In terms of relevance to the policy community, the findings of Chapter 5 are of particular interest to the MSG actors of EITI-implementing countries and countries considering the implementation of the EITI. From the conducted process tracing, the civil society stakeholder coalitions can learn about the obstacles that the MSGs of the case countries have faced and about different strategies of overcoming the deadlocks in the MSGs (collaboration with company or parliamentary actors, tactics of radical versus incremental change, and formation of a united position of the civil society constituency in the MSG negotiations).

Finally, Chapter 6 provides an overview of new developments in transparency regulation on natural resource management. These policy reforms have implications not only for the policymaking communities, but also for investors, companies, and the general public. The reform scenarios pertain to three 
themes: the increase in EITI mandatory requirements, interpretation of compliance with the EITI as a scaled index rather than a binary pass/fail outcome, and mandatory extensive reporting for the extractive companies, as required by recent US and EU law making. The first EITI reform policy -mandatory extensive practices -strengthens the standard both by increasing transparency in the upstream activities (the current focus of the EITI) and by encouraging transparency in the other stages of the resource management. The second option (the reform in the interpretation of compliance and scaled index of implementation) - if ever adopted - would facilitate a clearer understanding on who are the leaders and laggards of extensive EITI implementation. Finally, the mandatory law for company reporting will also target transparency processes in the non-EITI countries, which currently lie outside the initiative's scope. These changes are remarkable in the sense that they address the important bottlenecks to extensive transparency identified in this thesis. However, it should be noted that the adopted instruments - mandatory extensive practices in the EITI and mandatory extensive company reporting operate as regulatory mechanisms targeting behavior of companies and government actors (more precisely, the extensiveness of reporting practices), but not the conscience of the involved actors. This characteristic of the newly adopted instruments means that even with the increase of transparency in the sector, the effectiveness of these regulatory instruments still will be conditioned on the political will of government actors to reform and the ability of civil society to hold these actors accountable.

Returning to the discussion on the EITI's potential to overcome the resource curse, and given the current state of affairs, the findings of the dissertation show that the EITI cannot guarantee the establishment or improvement of extensive transparency practices in all country contexts it targets. First, not all countries under risk of suffering from the symptoms of the resource curse are adopting the initiative. Second, the design of the instrument still leaves room for differences in the implementation activities among those that do adopt it; as a 
result, transparency in the extractive sector is being achieved with varying degrees of extensiveness. Being a voluntary instrument, the EITI is dependent on cooperation of domestic actors. Especially in corrupt contexts these actors stand to lose from the very extensive forms of implementation that the EITI promotes. In this sense, it is difficult to expect from this instrument a fundamental change in overcoming the political resource curse, especially in countries which from the beginning of the implementation process are reluctant toward adopting extensive practices. Moreover, even in cases where the EITI is implemented in a more stringent manner, we cannot discard the possibility that existing corruption may simply move into the stages of resource management not included in the EITI practices of a particular implementing country.

Despite the inclusion of transnational actors in the decision-making process (companies and civil society), the EITI continues to be dependent on the constituency representing the government. The effectiveness of the instrument in overcoming the resource curse is largely conditioned by the decision-making of politicians in power. This is not necessarily a negative outcome. In contexts where accountability mechanisms are absent, the impact of the EITI unfortunately would be limited. However, in contexts where the politicians in power are reformoriented, the EITI can improve internal reporting and tracking of the received revenues. In these cases, the EITI may help overcome some of the political resource curse symptoms even in the absence of extensive transparency practices, such as extensive disaggregation available for the public. In this sense, the inclusion of all extensive transparency practices is not a necessary condition for the EITI to be effective.

In terms of policy recommendations, the above discussion highlights two important aspects. First, increased transparency in the extractive sector can indeed help overcome many of the political mechanisms of the resource curse. As the findings of the thesis illustrate, the EITI has its limitations, but in presence of political actors who are reform-oriented, it can contribute to removing many 
symptoms of the political resource curse. Second, a key factor in the success of the EITI is the political will to overcome political mechanisms of the resource curse. This political will may be engendered through the presence of accountability mechanisms in the political system that may help in battling corruption in the sector. Thus, the enhancement of such accountability mechanisms would be necessary. Another promising strategy for action is to focus on changing the conscience of government actors who have direct control over the management of the extractive sector in the affected countries. Countries which are cautious to adopt the EITI may have reasonable concerns, given the absence of many EITI donor countries in the implementation of the initiative and given the presence of very extensive transparency requirements in the recently reformed EITI standard, which will make the information available not only to the public of the reporting country, but to all external parties, thus increasing the vulnerability of the reporting country. In this sense, the caution toward very extensive public disclosure that the government stakeholders often outline in MSG discussions may have legitimate grounds. The civil society should be aware of the continuing discussion on transparency effects, as arguments against full public disclosure may well be motivated by reasonable concerns and do not necessarily hint to corruption of the government actors cautious toward full public disclosure. In this respect, the discussions that take place via interactions between the government actors and the civil society experts in the MSG can hold promise in making the civil society experts aware of the concerns on the government side, while also making the relevant public officials aware of the problems that, otherwise, may not have come to their attention. Moreover, the presence of the negotiation context of an MSG implementing the EITI can be viewed as a socialization setting via which political actors may be persuaded to initiate the reforms in the management of the extractive sectors. 


\section{Samenvatting}

Het is een bekend verschijnsel dat landen die rijk zijn aan grondstoffen vaak niet in staat zijn om hun potentieel op dit gebied om te zetten in economische groei. Het beheer van de grondstoffen van een land heeft tot voor kort veel aandacht gekregen in studies over de governance van natuurlijke hulpbronnen. In deze studies is onderzocht welke specifieke beleidsmaatregelen van de overheid nodig zijn om het doelmatige beheer van die hulpbronnen te verzekeren.

Veel landen die rijk zijn aan grondstoffen blijven echter worstelen met problemen die verband houden met de zogeheten 'grondstoffenvloek', terwijl de bestaande best practices ten aanzien van het grondstoffenbeheer niet worden vertaald in gedegen beleid ter plaatse. De verklaring voor dit verschijnsel heeft deels te maken met het politiseerde karakter van de grondstoffenvloek. Hierdoor raken de betrokken instituties uitgehold en ontstaat gaandeweg een verstarde structuur, waarbij de politieke wil tot verwezenlijking van de noodzakelijke hervormingen ten enenmale ontbreekt. Het gevolg hiervan is dat landen waar de aanwezigheid van natuurlijke hulpbronnen tot de 'politieke grondstoffenvloek' heeft geleid, verstrikt zijn geraakt in een 'grondstoffenval': enerzijds worden hoge staatsinkomsten uit grondstoffen via corrupte kanalen misbruikt, en anderzijds zijn de door corruptie verzwakte instellingen niet (meer) in staat om inkomsten uit de grondstoffensector op een nuttige manier aan te wenden.

In reactie op deze paradox, en ondanks het conventionele perspectief op grondstoffenbeheer als een zaak van de nationale overheid, is er sinds tien jaar sprake van een toenemende transnationale regulering op vrijwillige basis, gericht op transparante governance van de grondstoffensector. Bij de meeste praktijken die zich in de afgelopen tien tot vijftien jaar hebben aangediend gaat het om nietbindende verplichtingen, maar recentelijk zijn er eveneens ontwikkelingen op het 
vlak van krachtige wetgeving, die van invloed is op de transparantie van de activiteiten van bedrijven die grondstoffen uit de bodem halen.

Tegen deze achtergrond beoogt dit proefschrift om te onderzoeken of transnationale regulering van de governance van grondstoffen op basis van vrijwillige en niet-bindende instrumenten kan bijdragen aan het oplossen van de grondstoffenvloek, met name in landen die kampen met zwakke instellingen en niet in staat zijn hun inkomsten uit grondstoffen doelmatig te beheren. In het bijzonder richt ik me op het zogenaamde 'initiatief voor transparantie van de grondstoffensector' (Extractive Industries Transparency Initiative, EITI), een vrijwillig regulatief instrument dat niet alleen grotere transparantie in het beheer van inkomsten uit grondstoffen nastreeft, maar ook de potentieel negatieve gevolgen van grondstoffenwinning wil afzwakken. Meer specifiek, en vooral vanwege het onverplichte karakter van dit instrument, kijk ik naar de voorwaarden waaronder afzonderlijke landen zich achter het EITI scharen en hoe zij er vervolgens een meer of minder ambitieuze of 'uitgebreide' invulling aan geven. Door nader onderzoek van de processen rond het aannemen en implementeren van het EITI ontstaat de mogelijkheid om de mechanismes voor het functioneren ervan te ontrafelen.

Dit proefschrift is als volgt opgebouwd. In het eerste hoofdstuk ga ik nader in op het verschijnsel van de grondstoffenvloek, onder meer door aandacht te schenken aan de bepaling van de mechanismes die eraan bijdragen en de evaluatie van hoe en met welke middelen diverse transnationale initiatieven voor meer transparantie zich op deze mechanismes richten. Analyse van de potentiële impact van het Kimberley Proces (KP), de Publish What You Pay (PWYP) Campagne, het Natural Resource Charter (NRC) en het EITI toont aan dat initiatieven tot transparantie veeleer de politieke in plaats van de economische mechanismes aan de orde stellen die tot de grondstoffenvloek hebben geleid. Onder de beoordeelde instrumenten is het EITI het enige initiatief waarin meerdere actoren een rol spelen (bedrijven, civil society, overheid) én in beginsel alle fasen van grondstoffenbeheer 
in de verslaglegging aan bod kunnen komen. Door deze twee intrinsieke eigenschappen van het EITI kan dit instrument zich richten op alle relevante betrokken actoren en op de meeste mechanismes die tot de grondstoffenvloek leiden. Ik concentreer me dan ook op het EITI als een van de potentieel interessante transnationale en mondiale initiatieven gewijd aan transparantie in het grondstoffenbeleid en -beheer.

$\mathrm{Na}$ in het eerste hoofdstuk het belang van bestudering van het EITI te hebben belicht, alsmede van de mechanismes waarmee het de governance van grondstoffen aan de orde kan stellen, behandelt hoofdstuk 2 de opbouw van het theoretische kader voor de specifieke vragen van het project. Tot dusver is de literatuur over mondiale governance grotendeels gewijd aan vraagstukken rond de opkomst van transnationale en mondiale kaders ervoor. Hoewel vragen over het functioneren van deze mechanismes in het verleden minder aan bod zijn gekomen, worden zij in hedendaags onderzoek in toenemende mate ter discussie gesteld. Binnen de politicologie als discipline is bijvoorbeeld al sprake van inzichtverschillen, en dit heeft ertoe geleid dat dezelfde vragen vanuit meerdere onderzoekslijnen worden bestudeerd. Hoofdstuk 2 ontleent inzichten van die diverse scholen en schetst de onderzoeksvragen voor elk van de empirische hoofdstukken. Vervolgens worden de afhankelijke belangenvariabelen gespecificeerd, terwijl bovendien uitleg wordt gegeven over de theoretische en conceptuele keuzes voor bestudering van de specifieke vragen die in dit proefschrift aan de orde komen.

Hoofdstuk 3 behandelt onder welke voorwaarden een regering besluit om zich achter het EITI te scharen; het EITI-lidmaatschap biedt mogelijk immers niet alleen voordelen, maar ook kan leiden tot beleidsmatige inperkingen en hoge implementatiekosten. Gezien de gevoeligheid van de governance rond natuurlijke hulpbronnen die samenhangt met de politieke mechanismes van de grondstoffenvloek, is deze kwestie hoogst relevant. Uit de literatuur over politieke obstakels voor effectief grondstoffenbeheer weten we dat verstoring van de status- 
quo door het introduceren van zelfopgelegde, transparantiegerichte regulering uiterst kostbaar kan zijn voor de elites die baat hebben (gehad) bij het niet-open karaker van het stelsel. Door te kijken naar de vraag waardoor de waarschijnlijkheid van adoptie van het EITI wordt bepaald, kunnen we de structurele voorwaarden - eigenschappen van landen en invloedsfactoren van buiten - vaststellen die impact hebben op het besluit om het EITI als standaard aan te nemen. Dat besluit wordt geoperationaliseerd als een binaire variabele (ja of nee), terwijl in dit hoofdstuk een binaire logistische regressie als statistisch instrument wordt gebruikt. De dataset voor de analyse werd samengesteld uit uiteenlopende bronnen. De resultaten laten zien dat de waarschijnlijkheid van aanneming van het EITI toeneemt naarmate landen rijk zijn aan grondstoffen. Ik heb eveneens bewijs gevonden voor hypotheses over het effect van lage inkomens en etnische verdeeldheid op deelname aan het initiatief. Al wijst de analyse niet naar een significant effect van het regimeniveau op adoptie van het EITI, landen met een staatsbestel dat recentelijk is opgeschoven in de richting van democratisering zijn meer geneigd zich achter het EITI te scharen. Afhankelijk van de modelspecificatie is er enig bewijs voor de relevantie van externe invloeden, zoals de aanwezigheid van internationale donoren. Voor het EITI als een regulatief instrument betekent het resultaat dat de 'kritische landen' als categorie - zij die potentieel van het initiatief kunnen profiteren, maar het niet aannemen - landen zijn met veel grondstoffen, een hoog inkomen en een langdurig stabiel bewind, hetzij democratisch of autoritair.

Naast vaststelling van de eigenschappen van landen die de waarschijnlijkheid van hun deelname aan het EITI vergroten, is het van belang te kijken naar factoren die betrekking hebben op de verschillen in EITIimplementatie. Analyse van het eerstgenoemde laat geen ruimte voor deducties over verdere fases van het beleidsproces, want het ontwerp van het EITI staat landen toe om zelf de bijzonderheden van hun implementatieproces in te vullen. $\mathrm{Er}$ is dan ook sprake van verschillende soorten invoeringsactiviteiten binnen de groep 
van landen die het initiatief hebben aangenomen. De centrale vraag in hoofdstuk 4 luidt als volgt: hoe verschillen invoeringsactiviteiten in de praktijk, en wat bepaalt de uitgebreidheid van het invoeren van het EITI in een gegeven land? Om hier inzicht in te verwerven biedt het betoog in dit hoofdstuk een typologie van invoeringsactiviteiten op grond van verschillende procedurele en inhoudsgerelateerde dimensies. Mogelijke redenen voor meer uitgebreide implementatiekeuzes worden getheoretiseerd, gevolgd door een vergelijking van de verschillen in de invoering van wat aantoonbaar een van de kritische dimensies uitgebreide ontbundelingspraktijk - onder de EITI-deelnemers is. Mijn conclusie luidt dat zowel het regimetype als de sector waarop EITI-verslaglegging betrekking heeft cruciaal is voor de uitgebreidheid van de invoeringsactiviteiten. Het implementeren van het EITI in de niet-oliewinning sector blijkt een voldoende voorwaarde voor uitgebreide ontbundeling (disaggregation) te zijn. Voor de landen die het EITI in de olie- en aardgassector implementeren, is positieve Polity score een noodzakelijke (doch niet een voldoende) voorwaarde voor opname van uitgebreide ontbundeling. Voor het EITI als een mondiale standaard impliceren deze bevindingen dat autoritaire landen die het EITI invoeren in de olie- en aardgassector de lastigste gevallen zijn als het gaat om ontbundelde verslaglegging. Tegelijkertijd zijn deze gevallen bepalend voor het succes van het initiatief.

Tegen deze achtergrond ga ik in hoofdstuk 5 nader in op de implementatie van het EITI in de 'kritische landen'-categorie door de uitwerking van een vergelijkende casestudy van twee autoritair geleide landen met vergelijkbare socioeconomische eigenschappen die werken aan invoering van het EITI in de olie- en aardgassector (Azerbeidzjan en Kazachstan). De vergelijkbaarheid van contextuele factoren biedt de kans om de invoeringsactiviteiten in deze kritische contexten gedetailleerd te onderzoeken. Met name ben ik geïnteresseerd in de invloed van de multi-stakeholder groepen (MSG's), waarbinnen de achterban van de drie stakeholders zoals vertegenwoordigd door overheid, bedrijven en civil society beslissingen neemt over het soort invoeringsactiviteiten met betrekking tot het 
EITI. Deze onderzoeksfocus wordt ingegeven door theoretische verwachtingen ontleend aan de literatuur over het vermoedelijke karakter van stakeholderposities. Uit analyse van het implementatieproces en interviews met de stakeholders blijkt dat de ideologische afstand tussen de stakeholders leidt tot beleidsstabiliteit en slechts marginale veranderingen in het invoeringsproces.

Tot slot biedt hoofdstuk 6 een synthese van de bevindingen. Ik richt me hier op de twee hoofdthema's van dit onderzoeksproject: wat zijn de voorwaarden voor het aannemen van het EITI en de uitgebreide implementatie ervan, en onder welke voorwaarden is er daarbij sprake van het ontstaan van problemen. Na het geven van een samenvatting van de empirische bevindingen in deze studie over de contexten waarin adoptie van het EITI en het vervolgens uitgebreid implementeren ervan uiterst lastig zijn, vervolg ik met een inschatting van de mate waarin verschillende, momenteel bediscussieerde hervormingsscenario's voor het EITI oplossingen zouden kunnen bieden. Deze hervormingsscenario's hebben betrekking op drie thema's: de toename van het aantal verplichte eisen van het EITI, de interpretatie van naleving als een scaled index in plaats van een binair resultaat (voldoende/onvoldoende), en verplichte uitgebreide verslaglegging voor de ontginningsbedrijven, zoals vereist door recente wetgeving in de VS en de EU.

In de conclusie van dit proefschrift ga ik nader in op twee meer abstracte discussies. De eerste hiervan is gewijd aan de implicaties van de resultaten voor de theorievorming over adoptie en implementatie van vrijwillige reguleringsinstrumenten op het gebied van mondiale governance. De tweede komt terug op de kwestie van de potentiële doelmatigheid van zulke instrumenten voor het vergroten van de transparantie van het grondstoffenbeheer en het bestrijden van de grondstoffenvloek. 


\section{Biography}

Oxana Slobozhan holds an MA degree in European Studies, with a specialization in International Politics (cum laude) from Maastricht University and a BA degree in International Studies (summa cum laude) from the University of South Carolina. In 2008, Oxana joined Maastricht Graduate School of Governance (MGSoG) as a research fellow in the PhD Program in Economics and Governance, with a specialization in Public Policy and Policy Analysis. At MGSoG, her research focused on the study of global soft regulation mechanisms in the extractive sectors. As part of the $\mathrm{PhD}$ research project, she has been a visiting researcher at the Peace Research Institute Oslo (PRIO), funded by the Yggdrasil program of the Research Council of Norway. Besides her research, Oxana has also been active in teaching at the Faculty of Arts and Social Sciences and University College Maastricht.

Currently, she is a lecturer at the Department of International and European Law at Maastricht University. 


\section{MGSoG Dissertation Series}

Luis Bernardo Mejia Guinand

The Changing Role of the Central Planning Offices in Latin America:

A Comparative Historical Analysis Perspective (1950-2013)

MGSoG Dissertation Series, nr 46 (2014)

Cheng Boon Ong

Ethnic Segregation in Housing, Schools and Neighbourhoods in the Netherlands

MGSoG Dissertation Series, nr 45 (2014)

Luciana V. Cingolani

Bureaucracies for Development: Oxymoron or Reality?

Studies on State Capacity in Challenging Governance Contexts

MGSoG Dissertation Series, nr 44 (2014)

Carlos Cadena Gaitán

Green Politics in Latin American Cities - Sustainable Transport Agendas

MGSoG Dissertation Series, nr 43 (2014)

Katie Kuschminder

Female Return Migration and Reintegration Strategies in Ethiopia

MGSoG Dissertation Series, nr 42 (2014)

Metka Hercog

Highly-Skilled Migration and New Destination Countries

MGSoG Dissertation Series, nr 41 (2014)

Margaret Agaba Rugadya

Can Remittances Influence the Tenure and Quality of Housing in Uganda?

MGSoG Dissertation Series, nr 40 (2014)

Ilire Agimi

New Governance Under Limited Statehood

The Case of Local Government Reform in Kosovo

MGSoG Dissertation Series, nr 39 (2014) 
Kristine Farla

Empirical Studies on Institutions, Policies and Economic Development

MGSoG Dissertation Series, nr 38 (2013)

Marina Petrovic

Social Assistance and Activation in the Pursuit of Happiness:

Shedding New Light on Old Policy Solutions to Social Exclusion

MGSoG Dissertation Series, nr 37 (2013)

Laura Torvinen

Assessing Governance Assessments; The Case of Mozambique

Governance Assessments in the Context of Aid Effectiveness Discourse

MGSoG Dissertation Series, nr 36 (2013)

Biniam Egu Bedasso

Institutional Change in the Long Shadow of Elites

Essays on Institutions, Human Capital and Ethnicity in Developing Countries

MGSoG Dissertation Series, nr 35 (2013)

Sepideh Yousefzadeh Faal Deghati

Childhoods Embargoed

Constructing and Reconstructing Multidimensional Child Poverty in Iran 1984-2009

MGSoG Dissertation Series, nr 34 (2013)

Robert Bauchmüller

Investing in Early Childhood Care and Education:

The Impact of Quality on Inequality

MGSoG Dissertation Series, nr 33 (2013)

Martin Rehm

Unified Yet Separated

Empirical Study on the Impact of Hierarchical Positions within Communities of Learning

MGSoG Dissertation Series, nr 32 (2013)

Dorcas Mbuvi

Utility Reforms and Performance of the Urban Water Sector in Africa

MGSoG Dissertation Series, nr 31 (2012) 
Lina Salanauskaite

Distributional Impacts of Public Policies:

Essays in Ex-Ante and Ex-Post Evaluation

MGSoG Dissertation Series, nr 30 (2012)

Esther Schüring

To Condition or not - is that the Question?

An Analysis of the Effectiveness of Ex-Ante and Ex-Post Conditionality in Social Cash Transfer Programs

MGSoG Dissertation Series, nr 29 (2012)

Joe Abah

Strong Organisations in Weak States

Atypical Public Sector Performance in Dysfunctional Environments

MGSoG Dissertation Series, nr 28 (2012)

Zina Samih Nimeh

Social Citizenship Rights: Inequality and Exclusion

MGSoG Dissertation Series, nr 27 (2012)

Lenka Eisenhamerová

Legitimacy of 'Humanitarian Military Intervention'

MGSoG Dissertation Series, nr 26 (2011)

Sonila Tomini

Informal Payments for Health Care Services in Albania

MGSoG Dissertation Series, nr 25 (2011)

Jinjing Li

Dynamic Microsimulation in Public Policy Evaluation

MGSoG Dissertation Series, nr 24 (2011)

Aziz Atamanov

Rural Nonfarm Employment and International Migration as Alternatives to Agricultural

Employment:

The Case of Kyrgyzstan

MGSoG Dissertation Series, nr 23 (2011)

Frieda Vandeninden

Poverty Alleviation: Aid and Social Pensions

MGSoG Dissertation Series, nr 22 (2011) 
Juliana Nyasha Tirivayi

The Welfare Effects of Integrating AIDS Treatment with Food Transfers:

Evidence from Zambia

MGSoG Dissertation Series, nr 21 (2011)

Agnieska Ewa Sowa

Who's Left Behind? Social Dimensions of Health Transition and Utilization of Medical Care in Poland

MGSoG Dissertation Series, nr 20 (2011)

Emmanaouil Sfakianakis

The Role of Private Actors in the Provision of Public Goods with Applications to Infrastructure and Financial Stability

MGSoG Dissertation Series, nr 19 (2011)

Siu Hing Lo

White Collars Green Sleeves

An Interorganizational Comparison of Determinants of Energy-Related Behaviors among Office Workers

MGSoG Dissertation Series, nr 18 (2011)

Treena $\mathrm{Wu}$

Constraints to Human Capital Investment in Developing Countries:

Using the Asian Financial Crisis in Indonesia as a Natural Experiment

MGSoG Dissertation Series, nr 17 (2011)

Henry Espinoza Peña

Impact Evaluation of a Job-Training Programme for Disadvantaged Youths:

The Case of Projoven

MGSoG Dissertation Series, nr 16 (2011)

Florian Tomini

Between Family and Friends

Understanding the Interdependency of Private Transfers

MGSoG Dissertation Series, nr 15 (2010)

Michał Polalowski

The Institutional Transformation of Social Policy in East Central Europe:

Poland and Hungary in comparative and historical perspective

MGSoG Dissertation Series, nr 14 (2010) 
Maha Ahmed

Defining, Measuring and Addressing Vulnerability:

The Case of Post Conflict Environments

MGSoG Dissertation Series, nr 13 (2010)

Pascal Beckers

Local Space and Economic Success

The role of spatial segregation of migrants in the Netherlands

MGSoG Dissertation Series, nr 12 (2010)

Victor Cebotari

Conflicting Demands in Ethnically Diverse Societies

Ethnopolitical Contention and Identity Values in Europe

MGSoG Dissertation Series, nr 11 (2010)

Dennis Gyllensporre

Competing and Complementary Perspectives on the EU as a Crisis Management Actor:

An Examination of the Common Security and Defence Policy through the Lenses of Idealism and Realism

MGSoG Dissertation Series, nr 10 (2010)

Judit Vall Castello

Business Cycle and Policy Effects on Labour Market Transitions of Older and Disabled

Workers in Spain

MGSoG Dissertation Series, nr. 9 (2010)

Keetie Roelen

False Positives or Hidden Dimensions: the definition and measurement of child poverty

MGSoG Dissertation Series, nr. 8 (2010)

Denisa Maria Sologon

Earning Dynamics in Europe

MGSoG Dissertation Series, nr. 7 (2010)

Melissa Siegel

Money and Mobility: Migration and Remittances

MGSoG Dissertation Series, nr. 6 (2010) 
Jessica S. Hagen-Zanker

Modest Expectations: Causes and effects of migration on migrant households in source countries

MGSoG Dissertation Series, nr. 5 (2010)

Mirtha R. Muniz Castillo

Human Development and Autonomy in Project Aid: Experiences from four bilateral projects in Nicaragua and El Salvador

MGSoG Dissertation Series, nr. 4 (2009)

Christiane Arndt

Governance Indicators

MGSoG Dissertation Series, nr. 3 (2009)

Britta Augsburg

Microfinance - Greater Good or Lesser Evil?

MGSoG Dissertation Series, nr. 2 (2009)

Geranda Notten

Measuring and Managing Poverty Risks

MGSoG Dissertation Series, nr. 1 (2008) 